\title{
THE COMMON SENSE OF THE MILK QUESTION
}

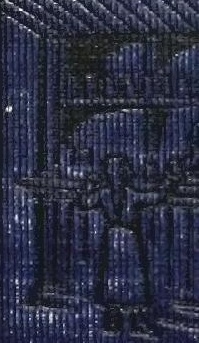




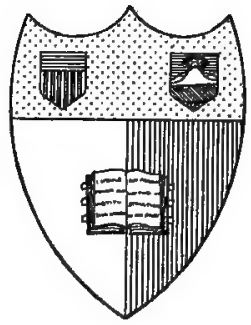

\section{Hew 县ack State College af Agriculture At Garnell Itniuergity 3 Ithaca, N. ‥}

\section{Titithary}




\section{Cornell University Library}

SF 257.583

The common sense of the milk question,

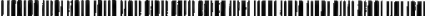

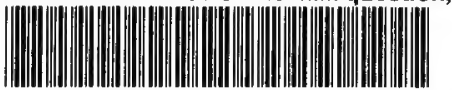

31924003112541 


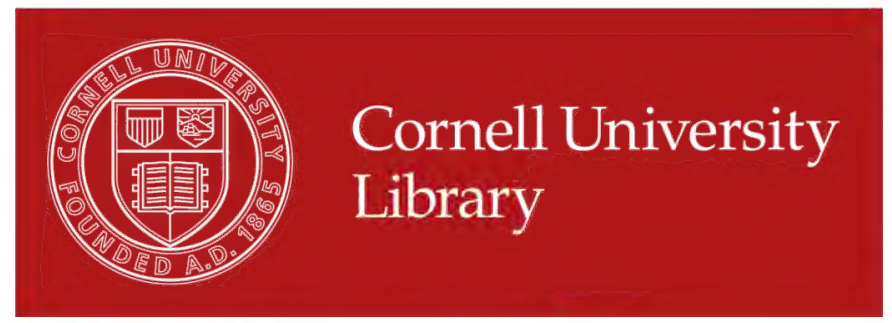

The original of this book is in the Cornell University Library.

There are no known copyright restrictions in the United States on the use of the text.

http://www.archive.org/details/cu31924003112541 


\section{THE COMMON SENSE OF THE MILK QUESTION}




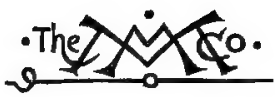

THE MACMILLAN COMPANY NEW YORK - BOSTON - CHICAGO ATLANTA - SAN FRANCISCO

MACMILLAN \& CO., LIMITED LONDON - BOMBAY - CALCUTTA MELBOURNE

THE MACMILlaN CO. OF CANADA, LtD. TORONTO 



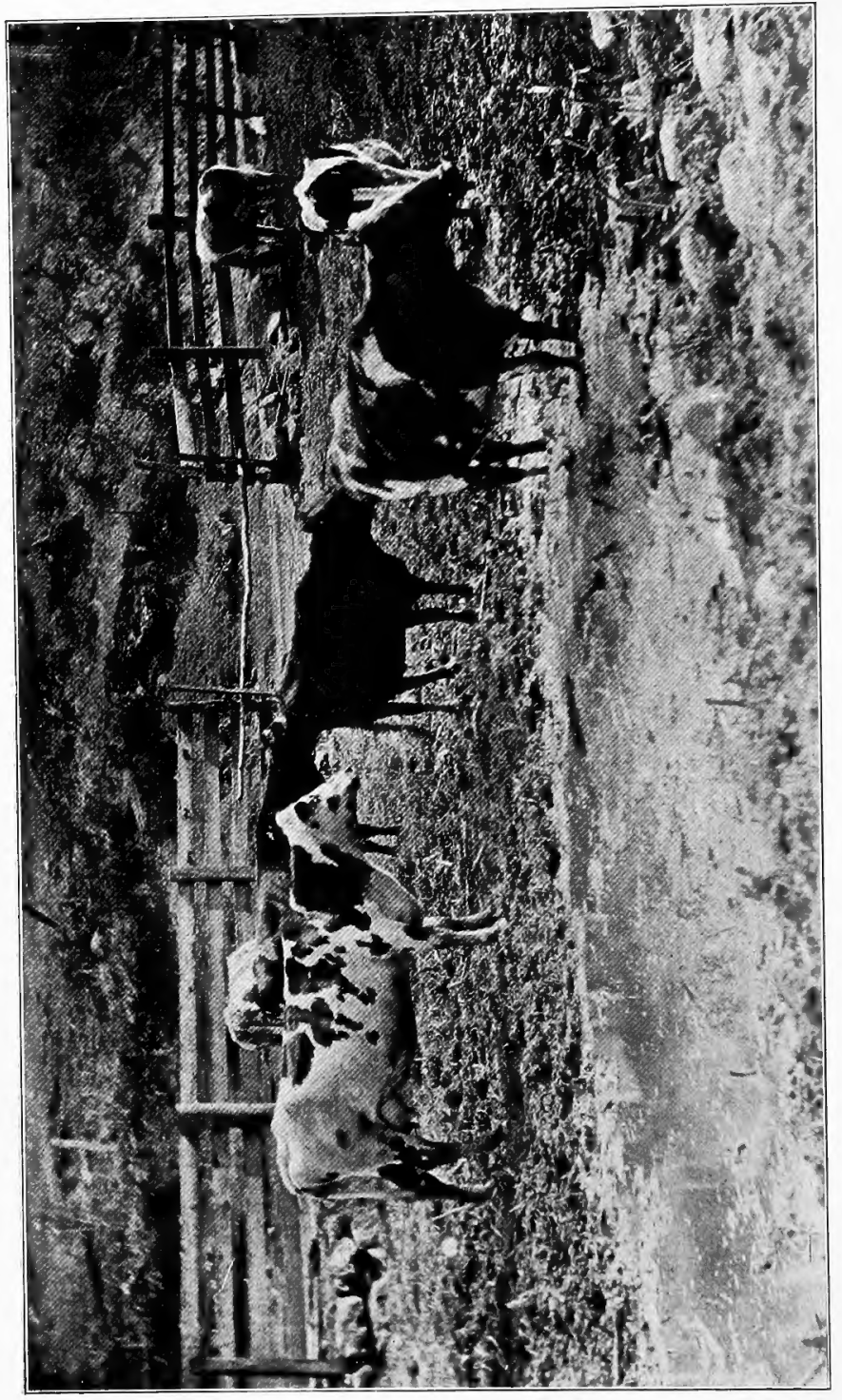

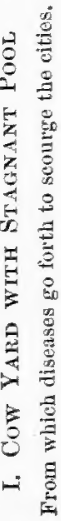




\title{
THE COMMON SENSE OF THE MILK QUESTION
}

\author{
BY \\ JOHN SPARGO \\ ADTHOR OF "THE BITTER CRY OF THE \\ CHILDREN," ETC.
}

Now 政ork

THE MACMILLAN COMPANY

1908

All rights reserved 


\section{Coptright, 1908,}

Bт THE MaCMILLAN COMPANY.

Set up and electrotyped. Published April, I908.

Norimoob 郎egs

J. B. Cushing Co. - Berwick \& Smith Co.

Norwood, Mass, U.B.A. 


\section{THIS VOLUME IS DEDICATMD}

To

\section{MR. NATHAN STRAUS}

A PIONEER IN THE GREAT WORK OF SAVING INFANTS FROM NEEDLESS SLAUGHTER

WITH THE AUTHOR'S PROFOUND ADMIRATION AND GRATITUDE 



\section{PREFACE}

The present volume owes its existence to a demand for the publication of various lectures upon the subject delivered by the author in many cities during the past seven years, and to a growing personal conviction of the need of a popular, easily understandable exposition of a subject which the lay reader finds fraught with many difficulties.

No apology is offered for the book - except for its many shortcomings, which none will deplore more than the author - nor for the fact that it is written by a layman for lay readers. There is a voluminous and bewildering literature wholly devoted to the subject, as may be inferred from the fact that one single bibliography with which I am acquainted contains no less than 8375 titles, and is still so incomplete as to cause the student a good deal of exasperation! Much of this literature - perhaps I should not be far wrong if I were to say almost the whole of it - is either not accessible to the ordinary reader, or, what is equally important, unintelligible to him.

Now, it is perfectly obvious that if ever we are to deal with the politico-social aspects of the milk problem, this must be remedied to the extent of pro- 
viding the average intelligent citizen with some statement of the question which can be readily understood and appreciated. To provide such a statement is the very modest aim of this volume.

By way of assurance to that public which I thus venture to address, I desire to repeat here a statement which I have made in almost every one of my lectures upon the milk question; namely, that there are no mysteries in the great problem of the relation of the public milk supply to the public health which need frighten away any intelligent layman. There are mysteries, unquestionably, many wonderful phenomena, which the physiologist, the pathologist, and the bacteriologist are as unable to explain as the humblest layman; there are also many means of investigation which require scientific and special training. The results of such investigation, however, can be so stated, I believe, that any reader of average intelligence can understand them. The social and economic aspects, of the problem belong to general civic knowledge, not wholly nor mainly to the medical profession.

In connection with the much-disputed subject of pasteurization, I have found it necessary to modify certain statements made in an earlier work, The Bitter Cry of the Children. In that work I expressed the conviction that the pasteurization of milk is "a grave mistake." I am still of that opinion in 
so far as I believe it to be a very serious mistake to trust wholly to the destruction of germs in milk, rather than to aim at a germless, clean supply, needing no such treatment. I am, above all else, an adherent of what is called "The Clean Milk School." Still, under existing conditions, I am (as indeed I have always been) an advocate of pasteurization as a precautionary measure. Pasteurization is a makeshift, not a solution of the problem, but I do not despise the makeshift on that account. In my earlier work I desired to lay special emphasis upon the desirability and the possibility of securing a safe and wholesome milk supply for all our cities, and I am grateful for the many assurances that have come to me of the fact that the volume in question contributed in some degree to the direction of public attention to that very important matter. I desire to state, however, that in my own family pasteurization has been practised, simply because I could not consent to the exposure of my children to the perils of raw milk as they are described in the following pages.

As far as possible, I have acknowledged my indebtedness to other writers, either in the text itself or at the end of the book. I wish it were possible for me to likewise acknowledge my indebtedness to all who have so kindly assisted me, but that is out of the question. Nearly a thousand correspondents, mostly physicians and veterinarians, have given me the benefit of their 
experience and advice; more than three hundred farmers and dairymen have kindly permitted me to visit their premises and helped me in many other ways; and, not less important, numerousmothers have given me their confidence and most loyal coöperation. To all of these I have tendered my thanks personally, and it remains only for me to make this public acknowledgment of valuable assistance freely and generously given.

To some of my friends I am so deeply indebted for special assistance that a word of acknowledgment, other than that given above, seems necessary. I desire, therefore, to take this opportunity of specially thanking the following gentlemen: Dr. Henry Dwight Chapin, Professor of Diseases of Children at the New York Post-Graduate Hospital; Professor R. A. Pearson, of Cornell University; Dr. George W. Goler, Health Officer, Rochester, N.Y.; Dr. Thomas Darlington, Health Commissioner, New York City; Dr. W. H. Park and William E. Burton, of the Health Department, New York City; Dr. E. F. Brush, of Mount Vernon, N.Y.; Dr. John B. Huber, of New York City; Dr. Arthur Greene, of the Straus Laboratories, New York City; Professor Gustav Bang, of Copenhagen; Mr. Lewis W. Hine, of Yonkers, N.Y., and Mr. William Wirt Mills, of the New York Evening Mail, who generously placed at my disposal a valuable collection of papers and reports.

YoNKErs, N.Y.

J. S. 


\section{CONTENTS}

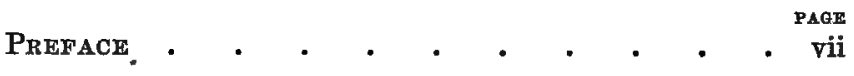
OHAPTK R

I. The Rise in the Valde of Babies. • . 1

II. When the Mothers FaIt . • . • . 14

III. Why Cow's Mrlk? . . . . . . 46

IV. Filth as Infants' Food . • . . . 82

V. Mrlk-borne Diseaseg . • • • • . 120

VI. A Brief Summary of the Problem . 151

VII. Remedial Theories and Experiments • . 174

VIII. Pure tersus Purified Mrk • • • . 241

IX. Outlines of A Policy of Reform . . . 267

Appendices . . . . . . . • . 307

$\operatorname{INDEX} \cdot \quad \cdot \quad \cdot \quad \cdot \quad \cdot \quad \cdot \quad \cdot \quad \cdot \quad \cdot \quad \cdot 341$ 



\section{LIST OF ILLUSTRATIONS}

PLATE

I. Cow Yard with Stagnant Pool . . Frontispiece FACLNG PAGE

II. An Unsanitary Cow Barn . . . . 34

III. Cow Barn where Cleanliness is Impossible. 42

IV. "Cheap" Milk-for the Babies of the Tenements . . . . . . . . 52

V. Manure heaped inside of Cow Barn where Milking is Done . . . . . . . . 62

VI. An Ideal Cow Stable . . . . . $\quad 72$

VII. Cows that Need Washing . . . . $\quad$. 85

VIII. Filthy Barn-yard with Pools of Liquid Matter • 95

IX. A Typical Retail Milk Store . . . . 105

X. Dirty Cow Barn . . . . . . . 112

XI. Diseased Cow, Milk from which was sold in New

York . . . . . . . . 124

XII. Effect of Raw Tuberculous Milk upon a Guinea

Pig . . . . . . . . . 130

XIII. Cow in Last Stage of Tuberculosis . • . 142

XIV. A Study in Headlines . . . . . . 154

XV. Bacteria in the Atmosphere . . . . 160

XVI. Same Interior as Shown in Plate V . $\quad$ - 166

XVII. Milk sold on the Open Sidewalk . • . 172

XVIII. A Straus Depot for Adults . . . . 186

XIX. "Clean Milk" Farm, Rochester, N.Y. 206

XX. Infants' Milk Depot, Rochester, N.Y. . 212 xiii 
XXI. Bottle-washing Tent, Rochester Depot . . 218

XXII. Rochester Depot-Packing the Milk in Ice . 228

XXIII. Straus Depots - Pasteurization Plant. - . 242

XXIV. Straus Pasteurization Plant-Filling Bottles . 250

XXV. One of the Straus Infants' Milk Depots . 264

XXVI. (a) Modest and Inexpensive Cow Stable - . 290

(b) A Railroad Milk Station - New York City . 290 


\section{THE COMMON SENSE OF THE MILK QUESTION}





\title{
THE COMMON SENSE OF THE MILK QUESTION
}

\author{
CHAPTER I
}

THE RISE IN THE VALUE OF BABIES

NEVER in the history of the world probably certainly not in modern times - was so much intelligent and earnest effort devoted to the welfare of children as to-day. In all civilized countries the physical, mental, and moral well-being of the children occupies a large and increasing share of the attention of thinkers and statesmen. There are still many little ones who needlessly suffer because of the ignorance and greed of parents and guardians, or because of distressing social negligence and ignorance; the bitter cry of wronged and despoiled childhood still rises in painful volume to rebuke us and lacerate our hearts. I would not minimize that cry of rebuking anguish, nor seek to hide from the vision of men one single trace of the agony of suffering childhood which torments us and goads us to do justice to the helpless victims. Heaven knows that amid the din and strife of our busy world 
the cry of the children is none too loud, that it is even now sometimes unheard so that we pass unheeding "The black sides of the pit, the quenchless fire."

Still, with my eyes upon the pit, I am conscious of the bright, kindly sun above, and know that the world is a better place for children than ever before in its history. Never before were the arms of society spread for their protection around the children as now.

The fact is that modern nations place a higher value upon child life to-day than they formerly did, or than any of the nations of the past. Instead of regarding the child as a burden, we regard it as an asset, and the death of a child we have come to look upon as a loss to the community. We think with horror of the widespread practice of infanticide, by Central Australians, Melanesians, Eskimos, Fijians, the Chicimecs of Mexico, and many other savage peoples, ${ }^{1}$ and utterly fail to comprehend the barbarous custom, or the economic conditions which inspired it. Obviously, to such people the coming of a child must have meant an additional burden, not an addition to the wealth of the group, family, or community.

Fortunately, among modern civilized nations it is otherwise. Universally, a steady increase of population by the natural propagation of the species is regarded with favor, and a stationary or declining birth-rate looked upon as calamitous. It is in no 
cynical spirit that I suggest here that our changed attitude toward the child is largely attributable to our fear of just such calamitous racial decline. For among the most impressive social phenomena of our time the diminishing birth-rate in most civilized countries holds a prominent place.

I would not take issue with those who glory in the increase of solicitude for the welfare of children as an evidence of the growth of pure altruism. At the same time, I cannot escape the conviction that there is much significance in the fact that France, the nation which feels most keenly the perils of a diminishing birth-rate, leads the world in those vast social experiments which aim, in the words of Sir John Gorst, "to make the most of such children as are brought into the world." 2 It is because of the very narrow margin of births over deaths that France values her babies more highly than any other country. ${ }^{3}$ In the great Australian commonwealths, the decline in the birth-rate during recent years has caused great anxiety and compelled statesmen and men of science to seek ways and means of preventing needless infantile mortality." When England was confronted by a dearth of soldiers the dwindling of the birth-rate became a matter of vital concern. Statesmen and scientists were forced to give it their attention, and, as in the other countries named, the question of properly caring for the children born was invested 
with a new and vital importance and urgency." In this country, likewise, our alarm at "race suicide" has given a very noticeable impetus to child study, and especially to the effort to save as many as possible of the tens of thousands of babies now needlessly, ignorantly sacrificed every year.

\section{II}

From the Malthusian cry of "overpopulation" to the Rooseveltian cry of "race suicide" is an astounding transition. Throughout a large part of the nineteenth century the influence of the Malthusian dread of an increase of population beyond the limits of the means of sustenance dominated the political economy of the English-speaking world, and, with the exception of France, most of the rest of the world included in the category of civilization. The idea was not restricted to the economists, but obsessed the popular mind in a most remarkable manner. Whenever it was proposed to do anything for the improvement of the conditions surrounding the lives of the masses, the cry was raised that nothing could be done until means were found to check "the devastating torrent of babies." 6

Now the pendulum has swung to the other extreme. There is universal concern and fear because of a steadily declining birth-rate, and the cry of race suicide 
terrifies the nations. Of the facts there can be no question; the decline in fertility of the human species in highly civilized countries ranks among the most challenging social phenomena which sociologists are trying to explain. That the birth-rate should be decreasing so rapidly in the newer countries is an astonishing condition of the problem. Canada, sparsely populated, with an immense empire of territory and practically boundless resources, presents an interesting study. There the decline in fertility seems to be greatest among people of Anglo-Saxon inheritance. In the Province of Quebec, which is mainly populated by French Canadians, the birth-rate per thousand in 1901 was 35, while in Ontario, a province populated mainly by people of British origin, the birth-rate in the same year was only 21.1 per thousand. ${ }^{7}$ In Montreal, in 1902, the birth-rate of each of the three classes into which the vital statistics of the city are distributed was as follows:-

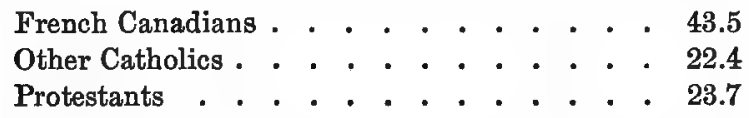

The great majority of the second and third classes were undoubtedly of British origin, so that the figures, taken in conjunction with those already cited, suggest a racial decline - the comparative infertility of the British descendants and the superiority of the French." 
How, then, shall we account for the comparative success of the French descendants in view of the notable failure of their blood relations in France? May it not be that the racial distinction suggested by the Canadian figures is an accident, of little or no influence, and that the real reason for the great difference in the birth-rate lies in the differences of social conditions and intellectual development? There is more poverty and much more illiteracy among the French Canadians than among the people of British origin, and these are conditions which favor a high birth-rate. If this be the real reason for the difference in fertility, Canada's experience conforms to a universal fact of tremendous importance, namely, that sterility almost invariably accompanies intellectual and material advance on the part of nations.

In England the decline in the birth-rate is principally due to the growing infertility of the richer, and not the poorer, classes ; ${ }^{9}$ in this country, likewise, the decline is chiefly among the better-favored classes, people of native American stock. ${ }^{10}$ There is no failure among the poor and often ignorant immigrants who crowd our cities, nor among the negroes. In South Africa, again, it is the intelligent, progressive, educated British who are infertile, ${ }^{11}$ just as it is the people of British origin, alert, educated, prosperous, and progressive, who fail to maintain a healthy rate of increase in the Australian states, despite all the advantages 
which a young and vigorous people must have in such immense and fruitful countries, where they are unburdened by oppressive militarism. In the whole range of modern vital statistics, I know of nothing more interesting to the sociologist than the striking decline in the Australasian birth-rates, shown in the accompanying table.

\section{TABLe I}

Australian Stateg: Birth-Rate per 1000 Popdlation*

\begin{tabular}{|c|c|c|c|c|c|c|c|}
\hline Prriod & $\begin{array}{l}\text { NEW } \\
\text { SouTH } \\
\text { W } \\
\text { WLEB }\end{array}$ & $\begin{array}{c}\text { VICro- } \\
\text { RIA }\end{array}$ & QUKENG $_{\text {LAND }}$ & $\begin{array}{c}\text { SoUth } \\
\text { A UBTRA } \\
\text { IIA }\end{array}$ & $\begin{array}{c}\text { WRET } \\
\text { A USTRA } \\
\text { LIA }\end{array}$ & $\begin{array}{c}\text { TABMA } \\
\text { NIA }\end{array}$ & $\begin{array}{l}\text { NEW } \\
\text { ZEA- } \\
\text { LAND }\end{array}$ \\
\hline 1871-1875 . . & 39.05 & 35.69 & 40.81 & 37.24 & 31.30 & 29.72 & 40.02 \\
\hline 1881-1885 & 37.65 & 30.76 & 36.37 & 38.52 & 34.57 & 35.02 & 36.50 \\
\hline 1891-1895 . . & 32.93 & 30.93 & 35.15 & 31.54 & 30.77 & 32.84 & 27.66 \\
\hline 1895-1900 . & 27.98 & 26.22 & 30.40 & 26.59 & 28.73 & 28.28 & 25.74 \\
\hline
\end{tabular}

That there is an increasing tendency to sterility in modern life, particularly among the more progressive nations, is shown in a most striking manner by the accompanying statistical table. It will be observed that while the percentage of decrease is greatest in the Australian states, their condition is no more alarming than that of France with its very small percentage of decrease. But France has long been confronted

* Adapted from the Report of the Royal Commission on the Decline of the Birth-rate and on the Mortality of Infants in New South Wales, 1904. 
by the spectre of a dwindling birth-rate, while for the Australian countries the condition is a new one. Race suicide is no longer a French phenomenon; it is universal.

\section{TABLE II}

Showing the Decrease of Birth-rateg per 1000 Popdlation in Various Countries in Ten Years

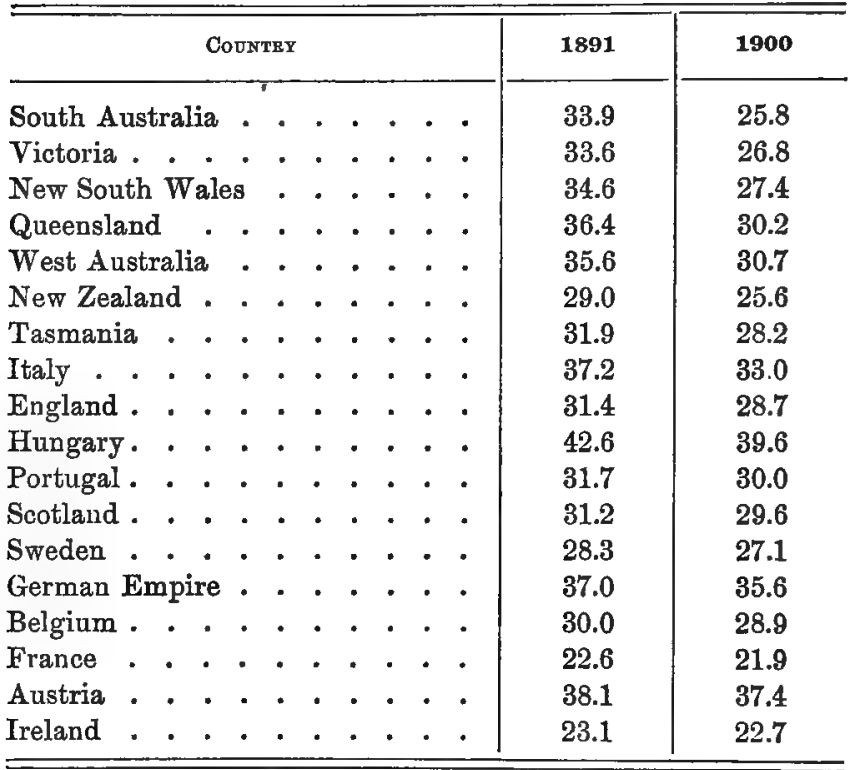

Whether we should regard the fact of a dwindling birth-rate pessimistically, as Mr. Roosevelt does, or optimistically, as Mr. H. G. Wells ${ }^{12}$ does, is too big a question for discussion here. It may be that, as Major Charles E. Woodruff and other scientists con- 
tend, the declining birth-rate is but the beneficent working of a great natural law, universally operative in all species, tending to keep population within the limits of subsistence. The birth-rate diminishes, but so does the death-rate. An increased or even stationary birth-rate with a decreasing death-rate would inevitably lead to overpopulation, according to this optimistic view. Formerly the birth-rate was very high because the death-rate was also high - conditions which still obtain in backward countries. To the holders of this view, the decline in the birth-rate is only a sign of Nature's mysterious and automatic adjustment to conditions.

This is a cheerful view to take of a grave condition, and one that is, moreover, seductively plausible. The chief objection to it is the tremendous assumption involved, that the death-rate can be continually reduced as fast as the birth-rate declines. While it is true, perhaps, that during the last fifty years the deathrate has steadily declined, so that in spite of the declining birth-rate the excess of births over deaths remains practically unaltered, few physicians, I imagine, believe that the same rate of decrease in the death-rate can be maintained for any considerable period. In this connection it is interesting to note that the death-rate in 1900 among the whites of native parentage in Connecticut, Maine, New Hampshire, Rhode Island, and Vermont exceeded the birth-rate 
by 1.5 per thousand, while among the whites of foreign parentage the excess of births over deaths was 44.5 per thousand. ${ }^{13}$ It is perfectly obvious that if this condition were common to all the states, the native stock would soon be entirely extinct.

\section{III}

It is a well-known fact that the fecundity of the poorer classes is always greater than that of the wellto-do classes. More than twenty years before the appearance of the famous and epochal work of Malthus, Adam Smith had pointed out in The Wealth of Nations that poverty seemed favorable to procreation. ${ }^{14}$ All authorities upon the subject agree that in all countries the wealthiest classes are the most infertile. Polybius attributed the decay of Greece to depopulation by this means. Like Mr. Roosevelt, he regarded the evil as a moral one:-

"In our times all Greece has been afflicted with a failure of offspring, in a word with a scarcity of men; so that the cities have been left desolate and the land waste; though we have not been visited either with a series of wars or with epidemic diseases. Would it not be absurd to send to inquire of the oracles by what means our numbers may be increased, and our cities become flourishing, when the cause is manifest, and the remedy rests with ourselves? For when men gave 
themselves up to ease, and comfort, and indolence, and would neither marry, nor rear children born out of marriage, or at most only one or two, in order to leave these rich, and to bring them up in luxury, the evil soon spread, imperceptibly, but with rapid growth; for when there was only a child or two in a family for war or disease to carry off, the inevitable consequence was that houses were left desolate, and cities by degrees became like deserted hives, and there is no need to consult the gods about the mode of deliverance for this evil: any man would tell us, that the first thing we have to do is to change our habits, or at all events to enact laws compelling parents to rear their children." 15

The decay of Rome has been attributed to the same cause by more than one historian. Seeley impressively describes the great Empire as suffering from a disease, a slow disease which tamed her hitherto invincible power. The disease was sterility. "Men were wanting ; the Empire perished for want of men." 1 Mommsen describes the same evil in a famous passage: "Celibacy and childlessness became more and more common, especially among the upper classes. . . We encounter even in Cato's sentiments the maxim to which Polybius a century before traced the decay of Hellas, that it is the duty of a citizen to keep great wealth together, and therefore not to beget too many children. Where were the times when the designa- 
tion 'children producer' (proletarius) had been an honor for the Roman?" 17

In our modern Rooseveltian campaign against race suicide there is evidently an expression of fear lest the experience of these great civilizations of antiquity be ours. Like Polybius, the statesmen and scholars of to-day, in overwhelming majority, regard the evil as being essentially a moral one. They attribute the decline in the birth-rate among the classes endowed with economic comfort, education, and leisure to an unwillingness to bear the responsibilities of parenthood. Personally, however, I cannot accept this explanation of the phenomenon. Presumptuous though it may be, I cannot escape the conviction that, while there are undoubtedly - as in all ages - many persons of whom the charge is true, the decline in the birth-rate is not due in any measurable degree to choice. The number of women unwilling to bear children is probably not greater than the number of women unable to bear children - the yearning Hannahs of "sorrowful spirit." There are tens of thousands of women who feel that to live and die childless is humiliating failure, who mourn bitterly that they cannot know

\footnotetext{
"A mother's pleasure in her infant race; But friendless and forlorn, alive descend Into the dreary mansions of the dead." *

* Sophocles, Antigone.
} 
It is probable that the decline of the birth-rate is due, as Adam Smith noted long ago, to socio-biologic rather than moral causes. There would seem to be some subtle physiological reaction, tending practically to the atrophy of the maternal function - not merely of child-bearing, but of child-nursing also - as a result of intellectual and nervous development, and the general complexity of life, which belong to a high state of civilization. It has been urged that intellectual development suggests artificial checks on generation, ${ }^{18}$ but he would be a rash man who would contend that such checks are more common among the richest than among the very poorest, or that foeticide is more common in the mansions than in the tenements. I, for one, do not believe it. ${ }^{19}$ It is much more likely that the difference is due to an automatic check upon the purely animal, or physical, functions of the human organism which operates with the extension of other functions, such as the nervous and intellectual.

Whatever reason may exist for the decline, there can be no doubt as to the fact, nor any as to the fear with which the spectre of race suicide oppresses almost every one of the progressive modern nations. It is that fear which, more than anything else, is responsible for the tremendous amount of social effort which is now being directed towards the promotion of the physical welfare of children, for that dominant tendency in the social legislation of our time which marks this as being preëminently the children's age. 


\section{CHAPTER II}

WHEN THE MOTHERS FAIL

A GREAT many factors enter into the stream of causes which makes the vast ocean of needlessly sacrificed baby lives. Poverty and ignorance are among the most important of these factors. The ignorance of many mothers is simply appalling. To hear a group of settlement workers, visiting nurses, and physicians relating their experiences and enumerating the many deleterious things given to young babies, is a tragic and heartrending experience. Babies a few weeks old given tea, beer, vegetables, bread, fish, candy, ice-cream - the awful list might extend almost indefinitely. ${ }^{1}$ Undoubtedly, ignorant and improper feeding is a prime factor in the problem of infantile mortality.

I say "ignorant and improper feeding," because I desire to draw a sharp distinction between feeding such as that described above, which is due to gross ignorance on the part of the mothers, and feeding which, while it proves to be unsuitable and produc- 
tive of ill results, and is therefore improper, is nevertheless not so much the result of special ignorance on the part of the mothers as of general human ignorance concerning some important aspects of a relatively new problem, the substitution of artificial foods for mother's milk. Every physician of large general practice knows of cases in which babies have died, literally of starvation, simply because science could not provide them with a proper substitute for the milk their mothers' flattened breasts refused to yield. I know of several cases in which medical men of large experience and unusual qualifications have seen their own children wither and die after the most heroic devotion to the task of saving them. This is a condition of ignorance, of course, but it needs to be sharply distinguished from the ignorance of the mother who blindly gives her child food which science and common sense alike have long associated with disease and death.

Among savage tribes in many parts of the world the custom has prevailed of killing suckling babes whose mothers died, or of burying the infant alive in the same grave as the mother. ${ }^{2}$ They knew no means whereby they could keep the child alive, except in those rare instances where foster mothers were available, as when a mother lately bereaved of her own child claimed the motherless little one to fill its place. Inability to nurse their own offspring is 
a rare occurrence among the women of savage tribes, practically unknown; and if such a thing happened the child would doubtless be allowed to perish. From certain passages in the New Testamentnotably Hebrews v. 2, 1 Corinthians iii. 2, and 1 Peter ii. 2 - some writers have inferred that among the Jews artificial infant feeding was by no means rare, the infants being fed upon the milk of animals, ${ }^{3}$ generally of goats, Proverbs xxvii. 27, or sheep, Deuteronomy xxxii. 14; but, so far as I am aware, there is no evidence that such artificial feeding was extensively practised, nor do the passages cited lend much support to the contention that the milk of goats and sheep was used as a food for young infants in place of human breast milk.

It is significant that Hebrew women have an exceptionally good record in this respect, failures to nurse their offspring being much rarer among them than among Gentile women of the same class, ${ }^{4}$ and also that the elaborate Rabbinical provisions concerning the dietetic use of milk and its hygiene make no special mention of milk intended for infants. ${ }^{5}$ While it is probably true that the artificial feeding of infants was sometimes resorted to in ancient times, it was never practised to anything like the extent with which we are familiar to-day. For with us the inability of a mother to nurse a child is not an occasional event; on the contrary, among the middle and 
upper classes in the progressive countries, it is so common as to almost become the rule, only the exceptional mother being able to nurse her offspring. It is for this reason that I have called the substitution of artificial foods for mother's milk a relatively new problem. The modern mother is growing more and more unable to nurse her child at her breast. For some subtle reason, this function of maternity is being atrophied in civilized women; and the higher their civilization, the less able are they to suckle their infants.

I am convinced that it is not, as is very generally supposed, that modern mothers are unwilling to nurse their offspring, setting social pleasures above maternal duties. I know that there are many eminent physicians and other competent observers who attribute the decline of breast-feeding wholly to social and economic causes: to a desire on the part of the leisured class to evade a responsibility which seriously interferes with social pleasures ${ }^{\circ}$ and to the necessity of earning a living which forces many women of the poorer classes to become wage-earners in factories, or other people's kitchens, to the neglect of their infants. ${ }^{7}$ I am of the opinion, however, that neither unwillingness due to indolence or personal or class vanity, nor the exigencies of wage-earning occupa- 
tions, and their incompatibility with the function of breast-nursing, nor both groups of causes combined, can account for more than a moderate percentage of these serious maternal failures.

As in the case of the birth-rate, the decline of breastnursing is most strongly marked among the leisured and well-to-do classes, and this fact probably accounts for the widespread opinion that love of social frivolities is responsible for the decline. But, while there is unquestionably a good deal of degeneracy among a section of our leisured class, whose unnatural orgies and sensational voluptuousness warrant the belief that they are abnormal in their mental development and capable of almost any perversity, it is simply absurd to charge that this is true of the leisured class generally. To bring such an indictment against the women of a whole class is out of the question. For it is a serious indictment: to charge a mother with deliberately sacrificing her baby for the sake of social frivolities is, after all, to accuse her of being inhuman and something of a monster. Such women do exist and have existed in all ages, but it is impossible to believe their number to be anything like so great as the number of mothers who do not nurse their own offspring.

Similarly, while the industrial occupations in which women are engaged away from their homes will account for a good many mothers not nursing their 
babies who would otherwise be able to do so, the number is by no means commensurate with the number of mothers who fail to nurse their infants. No one who is at all familiar with the facts will claim that all, or even most, women of the working class who do not nurse their infants at the breast are engaged in wage-earning pursuits. Such a claim would be preposterous upon its face.* The trouble with all such explanations is that, while containing a considerable body of truth, they are not adequate as explanations. Each of the causes we have considered operates in some degree, but even when taken together they do not suffice to explain the phenomenon.

With the vast majority of women who find themselves unable to discharge this important maternal duty the trouble is not social or economic, but physiological. This cannot be too strongly emphasized. We have to deal with nothing less fundamental than the absolute decay of the function itself. There is not, so far as I am aware, any considerable body of

* I have only discussed here the phase of the question which has been so much to the fore in England recently, 一the interference of industrial pursuits with maternal duty. There is a very much bigger question of the effects of industrialism upon the maternal functions, which I cannot undertake to discuss here, and which is not properly in place here: to wit, the physiological results of employment during girlhood in factories, stores, sweat-shops, and so on. It would be interesting to know whether such employment, especially when it is begun at a tender age and continued during several years, has not a prejudicial effect upon all maternal functions. 
statistical testimony in existence which can be cited as conclusive evidence upon this point. As was pointed out by the British Interdepartmental Committee on Physical Deterioration, notwithstanding that such knowledge may be regarded as essential to any comprehensive investigation of the problems of maternity and infantile health, the lacteal inability of mothers has received but scant attention from physiological investigators. ${ }^{8}$

The fact is admitted, however, by many of the leading medical authorities, though, as already pointed out, some eminent physicians hold to the view that the failure is due to social and economic causes, and not to any physiological failure. Hundreds of physicians of extensive practice among various social classes have assured me that in their experience the unwilling mother is rarely met, while the mother who is physically unable is common. Many pathetic stories of the mortification of such mothers have been told me, sometimes by the mothers themselves, and I am unable to resist the conclusion that physical disability accounts for more cases of failure to feed infants at the breast than all other causes combined. What the causes of this physiological development are, can only be conjectured in the absence of adequate scientific research and investigation.

Professor von Bunge, a famous German authority, 
with the assistance of over one hundred German, Swiss, and Austrian physicians, all of whom had been his pupils and were selected because of their reliability as observers, gathered particulars concerning two thousand cases in the countries named. His researches have convinced him that relatively few mothers refuse to nurse their offspring, and that by far the largest number of mothers who do not nurse their infants at the breast are physically unable to do so. He believes that more than half of the mothers in central Europe are physically unable to suckle their infants. ${ }^{9}$ In other words, he admits that the lacteal functions are being atrophied.

That there are some women who are physically incapable of lactation has never been seriously disputed. Engel has made careful study of the breasts of a number of women who died during lactation, most of them either during or soon after labor. $\mathrm{He}$ found a class in which the mammary gland was incompletely developed, the fibrous elements far outweighing the granular portion. No cause for the condition could be discovered..$^{10}$ The significant thing about Engel's researches is that they tend to confirm the theory of the atrophy of the lacteal functions.

In this country, Dr. L. Emmet Holt, a well-known authority upon all that relates to pediatrics, finds this incapacity to nurse infants at the breast to be 
increasing among all classes, but mainly among the well-to-do and leisured classes. Of the well-to-do and cultured, he tells us, not more than twenty-five per cent of those who have earnestly and intelligently attempted to nurse have succeeded in doing so for as long as three months. "An intellectual city mother who is able to nurse her child successfully for the entire first year is almost a phenomenon," he says. Dr. Holt finds a marked decline in nursing ability among the poorer classes in our cities, although not yet to the same degree as among those higher in the social scale. ${ }^{11}$

\section{III}

When, regarding the decline of nursing ability as a physiological phenomenon, we dismiss the alleged social and economic causes as being entirely inadequate, granting them only a subordinate influence as contributory factors, we must seek the primary cause or causes elsewhere. One of the first reasons to suggest itself to our minds is that it is due to improper dress, such as tightly laced corsets, unsuitable food, and unwholesome ways of living in general, ${ }^{12}$ especially dissipation. How far any or all of these enter into the problem has never yet been scientifically ascertained, and must, therefore, be the subject of a good deal of conjecture. It does not seem to me, however, that much can be attributed to the influence of dress. For this feeling there are several reasons: 
in the first place, the increase of athleticism among young girls and women, the extension of their education to the universities, and the opening to them of many new industrial and commercial occupations have done much towards rationalizing women's dress, so that they are probably better dressed, from the view-point of physiology and hygiene, than for many centuries past. Occasionally some monstrous and injurious feminine fashion appears, but it is usually short-lived because of its being ill adapted to the freedom of movement which characterizes modern women, especially in athletics. Secondly, the disability is, apparently, not the result of a gradual change in the anatomy of the female, such as might be produced by tight-lacing, for example, in the course of several generations. The human body is not structurally modified to any very great degree in a single generation.

But in considering the phenomenon of lacteal failure in women we have to bear in mind that it appears often in a single generation, fully developed, and as an apparently permanent condition of the sex. My friend, Dr. J. M. Morgan, who is a negro physician of large practice, assures me that among his people it is a very common thing to find young mothers entirely unable to nurse their babies at all, or, in other cases, for more than a few weeks, whereas their mothers never experienced any such difficulty. The 
same thing is true of our immigrant population. Any one who is familiar with the tenement population of our large cities will know that it is a common sight to see the immigrant mothers on the streets nursing their children. No matter how poorly nourished they may appear to be, as a rule they can nurse their offspring. But their daughters, when they marry, frequently cannot do this; and I submit that, even if their dress differed radically from that of the mothers, which is usually not the case, the time would not be sufficient to effect such a change in their physiology. A few years ago I gathered particulars concerning seventy-five women of foreign parentage, being mostly Slavs and Italians, whose babies were being fed artificially. Of the seventyfive there were twenty who had never had any milk of their own to give their babies; fourteen who had been able to nurse their babies less than a month; twenty-seven who had nursed their babies for periods ranging from one to three months, all the rest having been compelled to give up in less than six months. And there was only one woman among the number who had herself been "bottle-fed."

With regard to the influence of food there is likewise very little evidence. Upon the whole, dietetic standards are probably higher to-day than ever before. Certain it is that the majority of the immigrants who come to this country adopt a much better standard 
of living. ${ }^{13}$ The change is not so much one of form as of quantity and quality. Yet the immigrant woman does not generally cease to be able to nurse her offspring. If she could nurse her babies before coming to this country, she is usually equally well able to nurse those born after coming here. Where the struggle for a living is keen, or the child born in this country is one of a large family, her milk may be so poor that the children become rachitic, ${ }^{14}$ but in general she is as well able to nurse her offspring as before. The fact that she gets better, or at least different, food does not produce the disability to nurse her children which we find in her daughter, who gets substantially the same diet. Again, while there is a great difference between the standards of diet of the well-to-do class and the poor, both classes. suffer from the disability to discharge the maternal function of nursing.

Surprisingly little is known concerning the relation of food to lactation. We do not know by what physiological processes the constituents of food are transformed into milk constituents, either among human beings or the lower animals. Experiments conducted by Professor Jordan, at the New York State Experiment Station, showed the surprising result that the quality of a cow's milk was not influenced by the quality of the cow's food. When cows were fed upon poor food, deficient in fat con- 
stituents, it did not serve to reduce the amount of fat in the milk, nor, in the case of cows giving poor milk, could the amount of fat in the milk be increased by adding to the amount of fat constituents in their food. ${ }^{15}$ The question arises, How, then, are we to account for the fact that a cow's milk may be and often is rich in the very qualities in which its food is poor? It might be suggested that the cows draw upon their body fat in such cases, but Professor Jordan's experiments seem to disprove this, for among the animals observed by him there was no decrease in weight to indicate a withdrawal of the reserve fats of the body into the milk.

The evidence seems to be overwhelmingly against the popular notion that the feed given cows influences the quality of their milk more than anything else. It is much more easy to influence the quantity of milk by the adjustment of the feed than the quality. If the cow is naturally a "good milker," in the qualitative rather than the quantitative sense, her milk will remain of good quality under the most adverse conditions as regards feeding and hygiene, only disease or old age serving to make the quality poor. ${ }^{16}$ Similar facts have been so frequently observed in connection with nursing women, that it was for a long time believed that the analogy between the human and the bovine mother was so complete that it was useless to make any effort to improve the quality of 
breast milk. Physicians generally have prescribed a dietary for the sake of securing a sufficient flow of milk, but very few of them have studied the relation of diet to the quality of the milk, most of them believing that practically nothing could be done. The work of Dr. Thomas Morgan Rotch, however, establishes the fact that, while the science of lacteal regulation is in its infancy and a great deal of experiment needs to be carried on and carefully studied, it is possible to materially influence the quality of the human mother's milk by means of a careful regulation of the diet. $^{17}$ Possibly the experiments of Jordan do not represent the final judgment concerning the relation of diet to milk in cows; further researches along the same lines may establish the fact of the influence of nutrition upon the quality of the bovine lacteal fluid as conclusively as Rotch has in the case of the human mother.

There are, of course, many familiar phenomena which point to a very direct connection between nutrition and lactation. It is well known that if cows eat turnips, garlic, or onions, the milk is speedily and directly influenced, so that the pungent flavor can be tasted in the milk and butter. In like manner, nursing mothers not infrequently find that unripe fruits, or vegetables such as asparagus, ${ }^{18}$ eaten, even in the most moderate quantities, or laxative drugs taken for medicinal purposes, affect 
the milk and produce intestinal troubles, sometimes quite serious, in their infants. Diseases in the digestive tract of breast nurslings are sometimes traced to the mother's milk. The child does not thrive; its digestive system seems to be upset; there is diarrhœa and frequent vomiting; or, in other cases, constipation, perhaps accompanied by fever or convulsions. Analysis of the mother's milk may reveal that it is excessively rich in fat, and therefore indigestible; or, it may be, the milk is deficient in fat, causing constipation.

In an interesting study of the variations of fat in mothers' milk, Dr. Louise Tayler-Jones, of Philadelphia, cites the case of an infant, being nursed by its mother, who was gradually wasting away, losing weight daily. ${ }^{10}$ Analysis of the mother's milk showed that it contained far too much fat and too little protein. The mother had been industriously exercising and cramming herself with meat and drink in order that she might be able to nurse her offspring, an interesting case of commendable but misdirected zeal. The exercise was stopped to secure an increase of proteids, and the meat and drink reduced in order that the amount of fat might be decreased. The effect of ten days of this treatment is clearly shown by the following figures:-

Result of First Analysis

Pre Crant

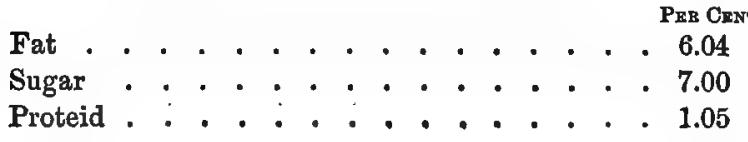


Result of Second Analysis in Ten Days

Pere CRKT

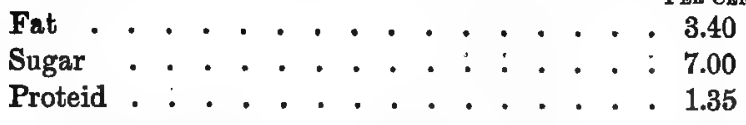

Many cases similar to the foregoing might be cited to show the influence of nutrition upon lactation, were further demonstration necessary. There is, doubtless, a very definite relation between the nutrient qualities of the diet and the nutrient value of the milk produced. This is true of the human species, and probably of the lower animals also. Nevertheless, it is certain that many mothers whose diet is alarmingly deficient in all the constituents deemed necessary to the proper nutriment of the body will produce milk which is apparently not deficient in those qualities; and other mothers whose diet appears to be in every way satisfactory will produce milk that is deficient in the very nutrients which in their food marks its superiority. Why this should be so we do not know, any more than we know why the milk of exceptionally robust women is in general of poorer quality than that of lean women. ${ }^{20}$ Science has not yet explored the vast domain of physiological chemistry very far.

Enough has been said in this connection to show that, while there is no present evidence of sufficient volume to justify the belief that defective nutrition is the sole cause, or even a very important contrib- 
utory cause, of lacteal failure in the human species, it would be rash to conclude that they are not in any manner related.

Another explanation, and one which seems to the writer quite fantastic, is that offered by Professor von Bunge, to whose valuable and monumental researches reference has already been made. $\mathrm{He}$ suggests that the decline of nursing ability is a sign of hereditary degeneracy, passing from mothers to daughters and caused mainly by alcoholism, usually that of the fathers. ${ }^{21}$ It is an interesting theory, doubtless containing important elements of truth, but, with all the deference due to such a profound scholar and patient investigator, it is impossible to resist the belief that the much overworked theory of heredity has once more been conveniently resorted to for explanation of a phenomenon which can only be properly explained upon other grounds. From the time of Hippocrates to the present the hereditary transmission of alcoholic taint has been held to be responsible for all kinds of degeneracy. ${ }^{22}$ The deformity of Vulcan as a result of Jupiter's intemperance marks the antiquity of the belief. In any case, it is by no means certain that the decay of the lacteal function in the human species is a sign of degeneracy, any more than that the decay of the vermiform appendix is a sign of degeneracy.

With this brief survey of some of the most impor- 
tant speculations concerning the causes of this interesting and important phenomenon, it is here suggested that, in all probability, it is analogous to the decline of fertility among certain classes, and due to precisely similar causes. Like procreation, nursing is a purely animal function; ${ }^{23}$ and, like the power to procreate, the ability to nurse offspring declines in the most marked degree among the leisured, cultured, and well-to-do classes. Among savages, as already noted, the condition is practically unknown, and among primitive people everywhere it is exceedingly rare. But as we ascend the scale of civilization it is met with in ever increasing degree. In the statement quoted from Dr. Holt, which has been corroborated for me by scores of physicians, emphasis is laid upon the fact that it is the well-to-do woman and the intellectual woman who most frequently fail to nurse their babies. As in the case of the birthrate, there would seem to be some subtle physiological reaction tending to dwarf the purely animal functions as a result of the development of other than animal functions in the human organism.

It might be urged against this view that the Jewish race has for a long time been singularly progressive in its mental development, and that, notwithstanding this fact, Jewish mothers are much more commonly able to nurse their offspring than Gentile mothers. But in this connection it must not 
be forgotten that, except in the more progressive nations during the past few years, the average Jewish woman has been secluded and uneducated; that for many centuries it has been customary to regard the mental development of the girls in Hebrew families as a matter of no consequence whatever. It would be interesting to know for certain whether among the minority of highly educated Jewish women the disability to nurse their children prevails. Several Jewish physicians have assured me that such is their belief; but the relatively small number of such women included in their practice, and the fact that none of the physicians had given the matter special attention, or kept records of the cases, forbid my attaching very much importance to their opinions, except in so far as they may be supported by scientifically reliable data.

It is important to remember in this discussion that the decay of the lacteal functions is not ascribed to education, but to the development of civilization. It is not merely that as we ascend the scale of civilization women are in general more highly educated, using the term in the strict pedagogic sense, but that they are subject to profound and far-reaching intellectual and nervous developments, in which education is only a factor. The factory workers of Lancashire or Massachusetts may not be educated much, if any, above the standard prevailing among 
the peasant women of Norway or Sweden, where breast-feeding is practically universal, and where the infantile death-rate is almost the lowest in the world as a consequence of that fact, ranging from 10 to 13 per cent. ${ }^{24}$ But there is an intellectual and nervous development in the case of the factory worker in which formal education plays a relatively small part. There is the excitement of the city life, the haste and strain, with its enormous psychological and physiological demands. The woman in the great industrial centres has the ostentation of wealth constantly thrust before her, stirring feelings of envy and of curiosity concerning the life of people who are not of her world, though belonging to her race. The great drama of life is ever before her with its excitation. In her own way, she becomes, quite unconsciously, a student of the greatest of human problems. Cheap newspapers, garishly decked shops, flamboyant posters, and sensational plays, all these and a thousand other things tend to make her life highly complex as compared with that of the placid peasant women of Europe. Surely, it is not too much to expect that this tremendous environmental difference, demanding as it does so much more from the one than from the other, should produce profound change in women's lives, both physiological and psychological. As the purely animal nature becomes less dominant 
in life and we develop a nature that is more complex is it wonderful or strange that some of the animal functions should undergo change?

Of course, the obvious thought suggested by such speculation as this is that there would seem to be no reason why the change should affect one sex only. Men have been subjected to very similar changes in condition; they, too, have passed from the simple stolid life of the ox, their placidity stirred only by the occasional outbreak of deep passion, to a life that is highly complex and full of continuous excitation. Why, then, it is natural to ask, should they be free from the mental and physical changes which these things have wrought in their sisters and wives? To which the answer is another question: Are they free from the changes? Do we know that the decline in fertility is a female phenomenon exclusively, rather than a human phenomenon, affecting both sexes? That women should undergo greater changes than men is only natural, for they have been far more violently uprooted from old and planted amid new conditions. It must not be forgotten that education and economic conditions have, in a very special degree, suddenly thrust new measures of responsibility upon women, making them self-reliant where they were subservient and dependent; equals where they had been inferiors. It may well be, it seems to me, that in such phenomena as the decline of 


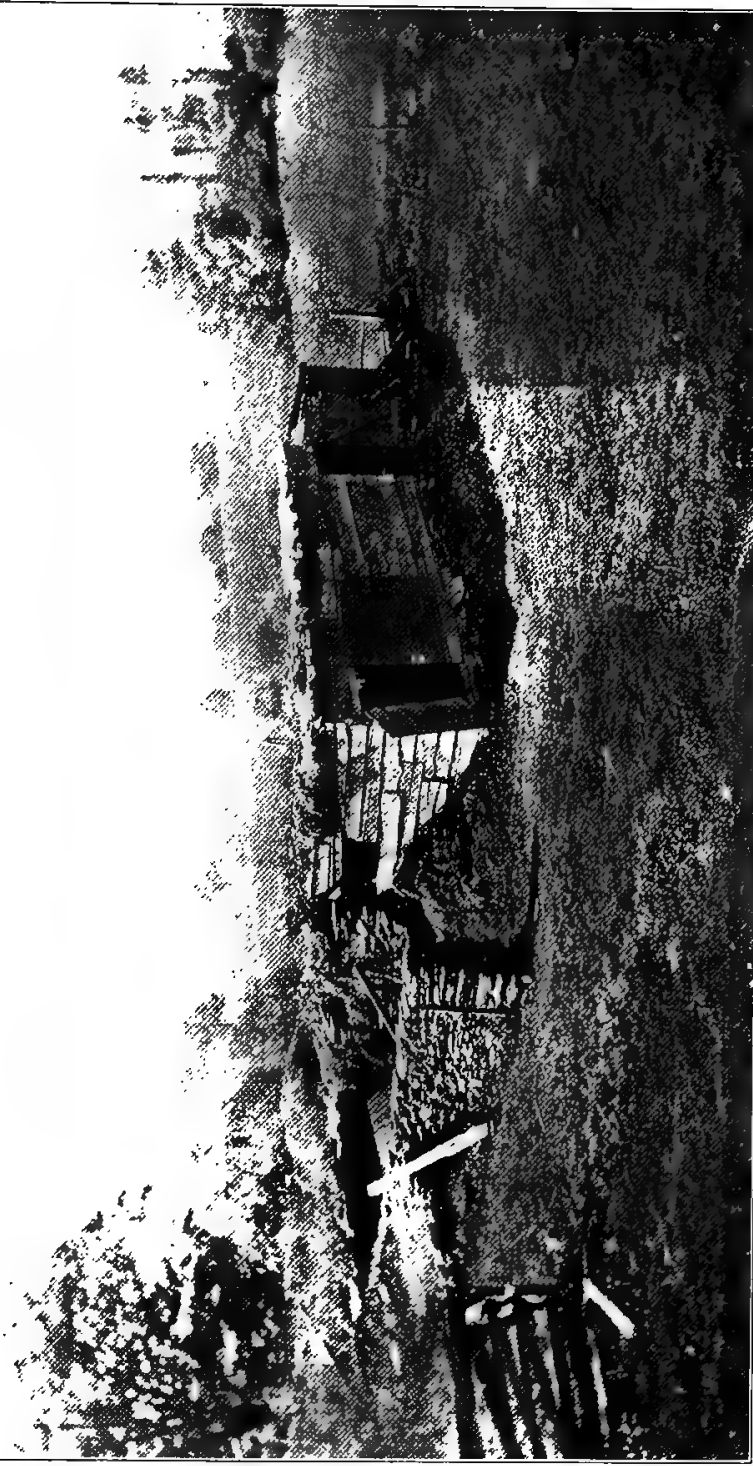



fertility and lactation the human race is only paying the natural price for its freedom to

"Move upward, working out the beast, And let the ape and tiger die."

Where there are so many complex and conflicting factors, few of which have been adequately explored, it is well to guard against hasty judgments based upon partial knowledge. It is with the utmost reservation, therefore, that I suggest the identity, or close relation, of the decline of lacteal ability with the decline of fertility. It is to be fervently hoped that, as advised by the British Interdepartmental Committee on Physical Deterioration, ${ }^{25}$ much closer attention will be paid to this question in the future than has heretofore been given to it; for it unquestionably is of fundamental importance in the study of many of our most urgent and vital problems.

\section{IV}

Whatever reasons for the decline of breast-feeding may be disclosed by subsequent investigation, and whether it proves to be a sign of degeneracy or of progress, of its importance there can be but one opinion. It necessitates the development of a system of artificial feeding for infants, really of artificial motherhood. Something of a sensation would be caused if it were announced by some reputable 
scientist that from henceforth, owing to some revolution in the physiology of the female sex, it would be necessary to take the human fotus from the womb at an early stage of its development and develop it by artificial means, in order to preserve the continuity of the race. Yet, one of the greatest living authorities, Dr. Henry Dwight Chapin, insists that "During the suckling period the infant should be looked upon as being a fœetus and not as a perfectly formed human being." ${ }^{26}$ In support of this view, Dr. Chapin cites the fact that among the lower forms of animal life there is often no placental connection between the mother and her young, but a mammary attachment, the fœtus growing fast to the teat and being nourished until it has acquired the power to suck independently, when it ceases to be adherent to the teat and sucks at will. ${ }^{27}$ Naturally, the baby is physiologically dependent upon its mother long after birth, for nourishment, as completely as during the fœtal stage of its development. In other words, to quote Dr. Chapin again, "From a physiological standpoint the artificially fed baby is a premature child, and anything but maternal milk is foreign to its digestive tract;" ${ }^{28}$ for it must be borne in mind that the human mother, like all mammals, furnishes her infant with milk suited to it at the various stages of its growth. The character of her milk undergoes 
subtle and important changes as the digestive tract of the infant changes in the course of its development.

It is for this reason that, in its natural state, the milk of one species is, in a sense, poison to any other species. Anything but maternal milk is a foreign substance in the digestive tract of an infant, liable to cause serious irritation and disorder; but when maternal milk cannot be had, if we are to prevent starvation and death, something else must be used, and an endeavor made to have that substitute as little poisonous as possible. Thus it is that the physiological chemist must set himself to the task of finding a food as closely resembling human mother's milk as possible at every stage of the child's growth so as to carry on artificially the work which Nature does in making blood, tissue, bone, and nervous energy. The digestive tract of a baby is a wonderful factory, where these processes are carried on by Nature by means of automatic machinery; and when Nature fails, man must assume the delicate task of carrying on the work by other and clumsier methods.

It is not impossible, nor even very unlikely, that in the course of a few generations artificial feeding of infants will be the rule in civilized countries and breast-feeding practically unknown. ${ }^{29}$ The evolution of the species proves that Nature is wonderfully adaptable, and there is no reason to fear that the 
change will prove disastrous to the human race. It is in the transition period that there is trouble; the consequences are frightfully severe in their morbidity during the period of experimentation, while science is patiently and slowly learning the secrets of Nature's wondrous processes. Doubtless a tremendous mortality attended the change from a diet of roots to a more varied diet, including grains and cooked meat, by our early ancestors in the far-away infancy of the race, but the species survived nevertheless. So it is not wonderful that the mortality among artificially fed infants at the present time is shockingly great; we have little more than begun the study of the problems of infant feeding.

Still, it is impossible to read the statistics relating to the mortality of artificially fed babies without a sense of sickening depression. To know that, according to Dr. H. M. Koplik, in our large cities more than half of the deaths of infants under one year are due to summer diarrhœa, almost exclusively caused by defective feeding, ${ }^{30}$ or that Chaterinkoff found that of 20,000 infants dying of intestinal disorders in France four-fifths were bottle-fed, ${ }^{31}$ is to realize something, but only a little, of the extent of the evil. We have seen that in Norway and Sweden the death-rate among babies is low in consequence of the almost universal practice of breastfeeding; now let us take some figures relating to 
bottle-fed babies: Drs. Hope, Meinert, and Ballard collected data relating to 1,943 cases in which death occurred during the first year, with the astounding result that only 61 , or 3 per cent, were found to have been breast-fed.32 Almost as startling are some figures published in 1905 by the Medical Officer of Health in Birmingham, England, giving particulars relating to 178 infants who died under six months old. Of the total number 16 were fed at the breast, 28 partially fed at the breast, and no less than 135 were artificially fed. The medical officer gives it as his opinion, based upon long and close observation, that the mortality of infants who are artificially fed is at least thirty times as great as among those who are nursed at the breast. ${ }^{33}$ Add to these terrible figures the fact that official statistics in Germany show the mortality in the first year among artificially fed infants to be 51 per cent as against only 8 per cent of those who are nursed exclusively at the breast, ${ }^{34}$ and no further evidence of the serious part which artificial feeding plays in infantile mortality rates will be necessary. The old temperance cry, "There is death in the bottle!" has a new and terrible signification in the case of the bottle-fed baby.

Facts like these have led philanthropists in many instances, and public authorities in a few instances, to try various schemes for the promotion of breast- 
feeding. Among the most interesting of recent private experiments is that conducted by Messrs. Bhir and Bhir, owners of a large manufacturing establishment at Elbeuf, France. Large numbers of married women are employed, and those with young babies are encouraged to nurse them at the breast. They are urged to keep the infant in the municipal crèche, near the works, during the daytime, and are allowed to take the time necessary at regular intervals during the day to nurse them. For every child who is exclusively breast-fed in this manner right up to the age for weaning, one hundred francs is deposited in a bank by the firm. According to Professor Budin, the results of this system have been quite encouraging. Except for the financial part of the scheme, and the fact that the crèches are frequently right on the premises, the same system is followed in most of the government factories and workshops connected with the match and tobacco monopolies, the postal telegraph and telephone services, and the like. ${ }^{35}$

In Cologne, Germany, such women are persuaded to stay at home, and as long as they continue to suckle their babies and to care for them properly in other ways, they are paid by the city out of the municipal funds. ${ }^{38}$ It is frankly recognized that efficient motherhood is a valuable service to the state. Much the same course is followed in several 
French municipalities. ${ }^{37}$ It is not believed that by such methods the number of those who fail to nurse their children because of physical disability will be materially lessened, but rather that all who are physically able to do so, but who would be otherwise prevented, owing to the necessities of earning a living, will be enabled to do their full maternal duty. But the value of babies in sterile France is very high!

\section{v}

A bewildering array of proprietary artificial foods, most of them cunningly advertised, with all sorts of impressive names, tempts the mother who is unable to nurse her baby as Nature intended. Of the great majority of these "foods" it is safe to say that they are positively dangerous, little better than poisons, in fact. Of the very small minority of them which do not deserve this sweeping denunciation, there is probably not a single one which can be given with perfect safety to every child, or with reasonable expectancy of good results. Those containing a large proportion of baked wheat or barley flour may often be used with advantage as diluents, that is, they may advantageously be used in conjunction with a liberal quantity of milk; ${ }^{38}$ but their use is uneconomical, as will be seen from the fact that it is only the flour in them which it is either necessary or desirable to use, and that can be bought much 
more economically of the grocer than at a druggist's, put up in a fancy box at an enormous price.

Among our best medical authorities there is a consensus of opinion upon this point. Dr. Chapin is exceedingly moderate in his language when he says that "From a nutritional standpoint these foods by themselves are almost without exception inferior to the best grades of condensed milk." ${ }^{39}$ Careful analysis of some of the very best and most expensive of these proprietary foods shows them to contain very little more fat than condensed skim-milk.40 Practically every one of the patent infant foods upon the market to-day is deficient in fat; most of them cause scorbutus; most of them contain too large a percentage of sugar. Added to this list of complaints against them is the fact that a majority of them - some of the best among the number contain such foreign elements as starch, maltose, and so on. ${ }^{41}$

These facts are not so well understood by the general public as they ought to be, but the medical fraternity knows them very well. To their lasting honor, the leaders of that great profession, especially those who devote themselves to the problems of pediatrics, have spolin out boldly upon the subject. But it is equally to the dishonor of thousands of medical men that they go on supporting what they know, or should know, to be a pernicious evil. The 


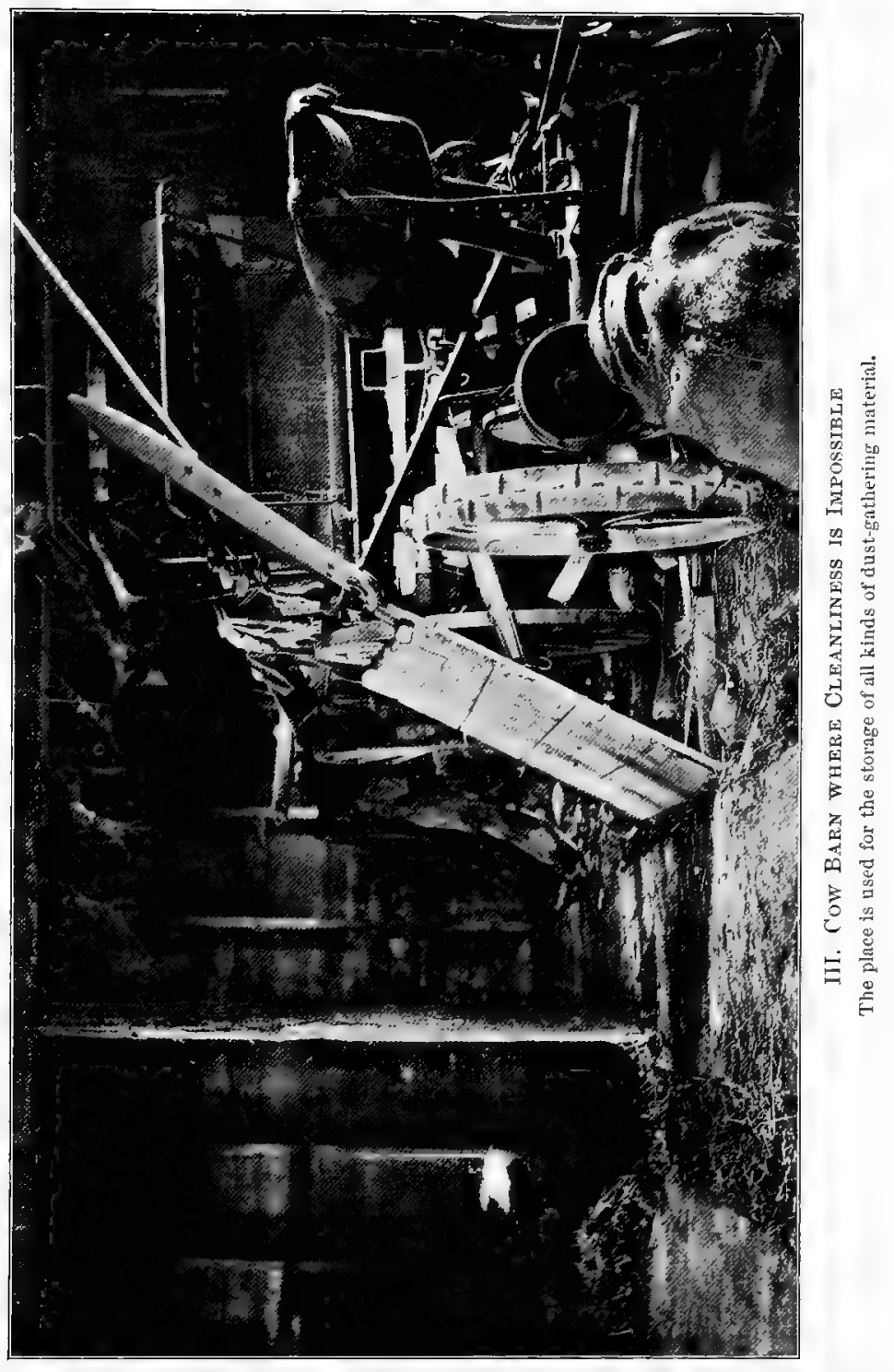



columns of the medical papers are full of advertisements of these concoctions, which are at best swindles and often deadly, as the facts cited show. As one prominent physician wrote me, commenting upon a magazine article which I had published upon the subject, when you "look over the medical journals, many of them of the highest repute, and see the glaring statements of infant foods set forth, you wonder that there is an American mother left willing to nurse her child."

Then, also, there is the dishonest connection between the manufacturers and the health bureaus of the country. No sooner is a baby born than the advertisements of patent foods begin to pour in upon the mother. Sometimes, in big cities, not more than twenty-four hours pass before the torrent of literature begins to flood the house. The diffculties of breast-feeding are glaringly presented; wonderful stories of successful feeding upon this, that, or the other food are enumerated, backed up by illustrations of over-fattened babies in a manner that reminds one of the live-stock pictures which one sometimes sees adorning farmers' kitchens. The mother wonders how the manufacturers and vendors could have secured her name, how it was possible for them to know of the baby's birth. How, except from the local health bureau or the physician? There is an alliance between the manufacturers and some 
of the health bureaus of the country - a form of graft that is more than ordinarily detestable.

Among the rich it has always been customary to secure the services of a wet-nurse in cases where the mother was either unable or unwilling to nurse her child, and the practice is very commonly recommended in such cases by medical men. For the poor, of course, such substitution is out of the question. While the practice has many advantages, it has also many disadvantages, and it is open to very serious question whether careful artificial feeding is not, upon the whole, safer and better.42 In the first place, as we have seen, the mother's milk is continually undergoing changes which correspond to the needs of the infant. It is practically impossible to secure a wet-nurse, in this country at any rate, whose baby is not either considerably older or younger than the one she undertakes to nurse, and there is often trouble in consequence, her milk being unsuited to the child. Sometimes several nurses have to be tried before one is secured whose milk agrees with the baby, and the constant disturbance, often extending over several weeks, is always a disadvantage and not infrequently a peril. Then, too, there is the fact that there is always danger of syphilitic infection, for even the most careful examination will sometimes fail to reveal syphilis in a woman. Even in the present state of semi- 
enlightenment upon the subject of artificial infant feeding, it is probably quite as safe as substitute breast-nursing. The humble and docile cow is the foster-mother, or wet-nurse, of the modern infant. In the striking phrase of Dr. McCleary, "The human infant tends more and more to become a parasite of the milch cow." 4 


\section{CHAPTER III}

\section{WHY COW'S MILK?}

\section{- I}

The use of the milk of animals as food by the human race is of great antiquity. It probably began with the domestication of animals, which Morgan has described as one of the four preëminent accomplishments of barbarism, ${ }^{1}$ even if it did not precede that great achievement and serve as one of the causes which led to it. In any case, the dietetic use of milk is one of the oldest of human customs, being incalculably aged. The earliest Hebrew Scriptures and Homer's Iliad contain abundant evidence of its widespread prevalence in very early times. ${ }^{2}$.

Biologically considered, milk is a whitish, opaque, living liquid which is secreted by the mammary glands of the females among all the animals called "mammals" for the nourishment of their young. Man is a mammal and belongs, biologically, in a class with apes and monkeys, dogs and cats, sheep and goats, camels and elephants, horses and cows, and even whales, porpoises, and dolphins. It is the fact that all these animals, as well as many others, suckle their young which causes them to be thus 
classified. But while all the mammals are milkproducing animals, rearing their young to a state of comparative independence upon the lacteal fluid secreted by them in their mammary glands, the milk which they produce varies greatly according to the variations in the animals themselves. The differences in the appearance of the milk of different species are not very great. Some kinds look a little yellower than other kinds, or perhaps a little thicker, but in general the milk of all animals bears a very noticeable resemblance. This is all the more remarkable when we think of the great differences in the appearance of the animals themselves. There is little likeness between a woman and a camel or an elephant, and the contrast between the human being and the porpoise is quite as marked. That a cat's milk should closely resemble the milk of a cow or reindeer in appearance is remarkable in view of the absence of any likeness between the animals, and, more especially, the great differences in food and habits which characterize them.

If, however, we make an analysis of the milks of some of these animals to ascertain their chemical constituents, and then compare them, we shall find that there are much greater differences in the composition of the various kinds of milk than would be supposed by one who judged them only by their looks. This is what we should naturally expect, 
for of course the milk must contain proper nourishment for the young of the animal producing it, and we could not expect that the same kind of nourishment would do for a kitten and a young elephant; that the food intended by Nature for a young porpoise would suit the stomach and nutritional needs of a human infant.

But before we proceed to examine the constituents of the milk of various animals we must consider carefully a most significant fact. In the preceding chapter it was pointed out that there are many important variations in the composition of the milk of women. Not only are there differences in the milk of a woman at various stages of her baby's growth, but one woman's milk at a given period of lactation will frequently differ in marked degree from the milk of another woman at the same period of lactation. We also observed that cow's milk is subject to much the same variation. Not only do the various breeds differ in this respect, but the milk of one cow is frequently much richer than the milk of another cow of the same breed in the same herd. ${ }^{3}$ It will be readily understood, therefore, that a good deal of latitude has to be allowed if we are to talk of the "average" composition of any kind of milk. The table which follows is probably as satisfactory as any that could be compiled, but it is only one chosen from among a large number in which there are more 
or less important differences. In a general way, however, the figures given are satisfactory and will serve our purpose admirably if we only bear in mind that the milk of individual animals differs at various stages of the lacteal period: that there is considerable variation in the character of the milk produced by individual animals of the same species, and even of the same parentage; that among the domestic animals there are marked differences in the quantity and quality of the milk produced; that many factors besides those named, such as age, health, food, and probably climate, influence the quality of the milk. It is therefore a somewhat "rough and ready" measure with which we have to deal.

\section{Table III}

Composition of the Milk of Different Animals

\begin{tabular}{|c|c|c|c|c|c|c|c|c|}
\hline \multicolumn{2}{|c|}{ Arimaz } & WATER & Bourds & $F_{A T}$ & CABGIN & ${ }_{\text {MIN }}^{\text {ALIS }^{2}}$ & $\underset{\text { SUGAR }}{\text { MuruK }}$ & ABH $_{\text {B }}$ \\
\hline Woman & . & 87.4 & 12.6 & 3.8 & 1.0 & 1.3 & 6.2 & 0.3 \\
\hline Cow & . & 87.2 & 12.8 & 3.7 & 3.0 & .5 & 4.9 & .71 \\
\hline Goat & . & 85.7 & 14.3 & 4 & 3.2 & 1.1 & 4.4 & .8 \\
\hline Buffalo & . & 81.4 & 18.6 & 7 & & .3 & 4.1 & .9 \\
\hline Ewe . & . & 80 & 19.2 & 6. & .0 & 1.5 & 4.9 & .9 \\
\hline Llama & . & 86.5 & 13.5 & 3. & 3.0 & .9 & 5.6 & .8 \\
\hline Mare & . & 91.5 & 8.5 & 1. & 1.2 & .1 & 5.7 & .3 \\
\hline Ass. & . & 89.6 & 10.4 & 1. & .7 & 1.6 & 6.0 & .5 \\
\hline Camel & . & 86.6 & 13.4 & 3.1 & 4.6 & 4.0 & 5.6 & .7 \\
\hline & & 84 & & 4 & & 7.2 & 3.1 & 1.1 \\
\hline Elephant & & 67.9 & 32.1 & 19.6 & 3.1 & 3.1 & 8.8 & .6 \\
\hline Porpoise & . & 41.1 & 58.9 & 45.8 & 11.2 & 11.2 & 1.3 & .6 \\
\hline Dog . & . & 75.4 & 24.6 & 9.6 & 6.1 & 5.1 & 3.1 & .7 \\
\hline Cat. & & 82.1 & 17.9 & 3.3 & 3.1 & 6.0 & 4.9 & .6 \\
\hline
\end{tabular}


Perhaps it may be well to add to the foregoing table a few words of explanation. While the analysis simply divides the constituents of milk into water and solids, fat is really a semisolid. The solid constituents proper are sugar, casein, albumin, and mineral matter, called ash, or salts. Casein is a protein compound of very great importance, forming with albumin the chief nitrogenous value in milk. Curd is formed of casein through the action of acid. It forms one of the principal ingredients of cheese about 25 per cent of its bulk - when coagulated by the action of rennet. The ash or salts in milk consists principally of phosphates and chlorides of soda, potash, and lime.4

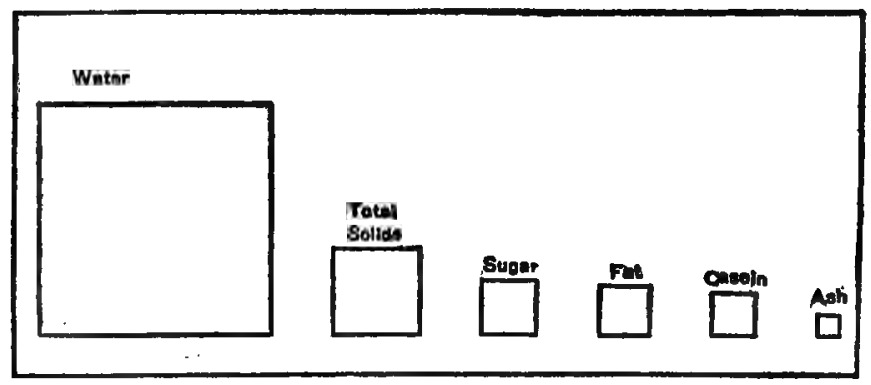

Dingram showhe Components of Cow's Milk

With this explanation it will be easy to appreciate the nutritive values of the various milks described. It will be quite obvious, for instance, that the enormous percentage of fat in the milk of the porpoise - more than eighteen times that of woman's milk 
- entirely removes it from the digestive capacity of the human species. So, too, in the case of the elephant, whose milk contains more than five times the fat contained in human milk. On the other hand, the milk of the mare and the ass are deficient in fat, though the milk of both animals has been more or less extensively used as a food in some parts of the world, ${ }^{5}$ and the milk of the ass is even used occasionally in this country as a food for very feeble infants. ${ }^{8}$ Now, the principal animals whose milk has been used by mankind for food are the cow, the goat, the sheep (ewe), the ass, the camel, and the reindeer. Most of these would have been selected from the foregoing table of analysis by any layman called upon to select those which in their composition most nearly resembled human milk.

Let us, then, take the milks of these species and compare them a little more closely with reference to their food values. As we have seen in an earlier chapter, the important task before the man of science is to find some substitute for breast milk which closely resembles it; something that will make blood, tissue, muscle, bone, and nervous energy in as nearly as possible the same manner as mother's milk. In analyzing the food values of the principal domestic animals and comparing them with human milk, we are taking the first important step toward the solution of our problem. 
We may divide food into four great classes, as follows: (1) protein, sometimes called proteid, or albuminoids; (2) fat; (3) carbohydrates; (4) mineral matter, usually called ash or salts. ${ }^{7}$ In addition to these, water is a very important ingredient of food, entering as it does into the composition of every part of the body, the bones even containing more than 10 per cent of water. ${ }^{8}$ It follows, therefore, that the large percentage of water contained in all kinds of milk is not wholly waste and without nutrient value. Protein is the muscle-building element and is of prime importance, as the word itself indicates.* It contains carbon, hydrogen, oxygen, and nitrogen and, generally, but not always, sulphur. Sometimes there is found in addition to these phosphorus and iron. Fat, as most people know, is composed of carbon, hydrogen, and oxygen only. Carbohydrates is the name given to a compound of hydrated carbon. The carbon is compounded with hydrogen and oxygen in the proportion of two to one, the proportion in which these two elements combine to form water. All the glucoses and sugars are carbohydrates, therefore the sugar in milk, which differs from cane sugar very materially, belongs to that class. The mineral matter in milk, the salts or ash, is principally useful in building and hardening bone. This is by no means a very complete or exact analysis of food elements, * Protein = I take the first place. 


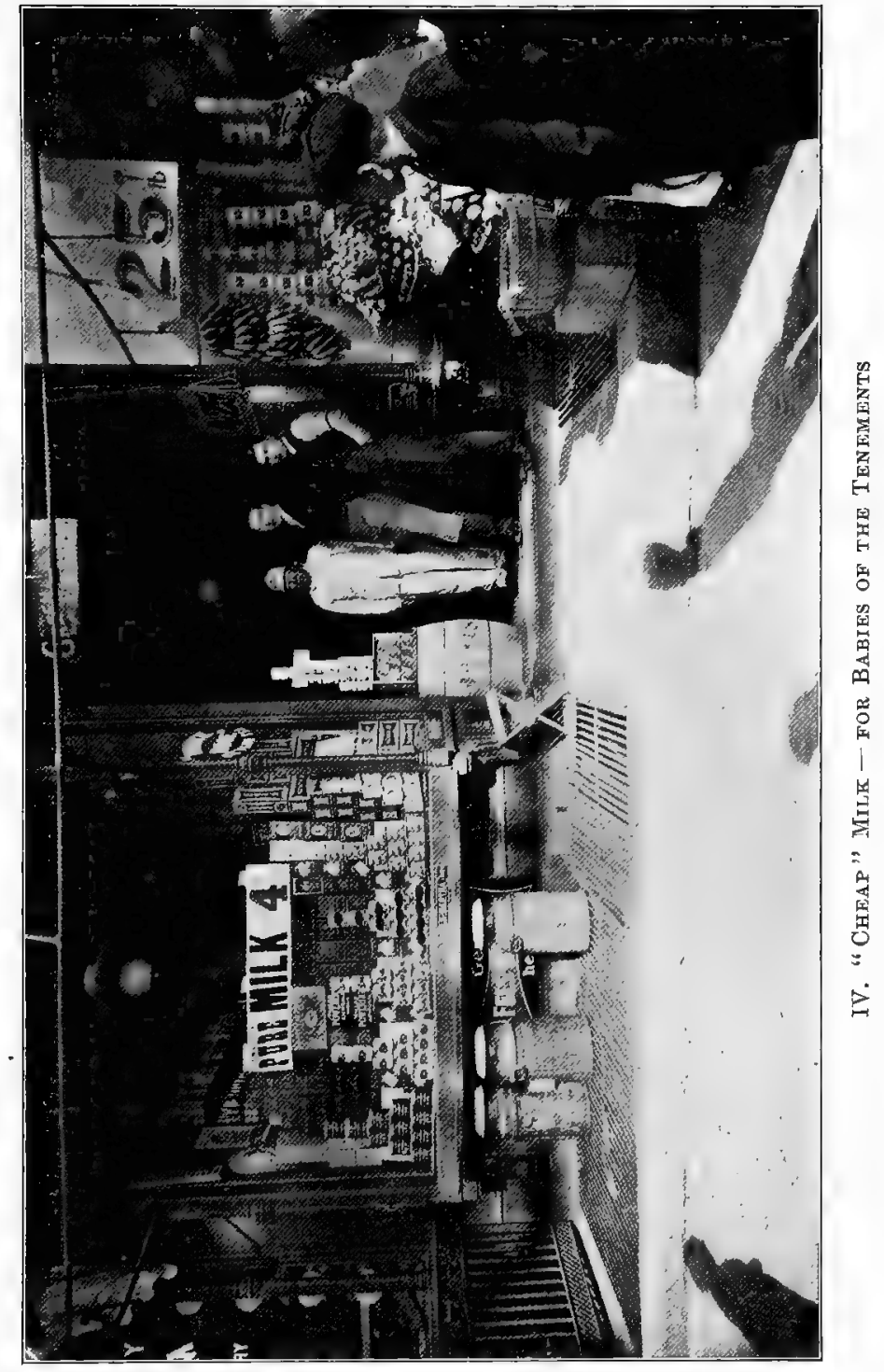



but it is sufficient for our purpose in trying to grasp the essentials of the milk problem. In the following table the relative percentages of protein, fat, carbohydrates, and mineral matter in the principal milks which are used as human food are shown:-

\section{TABLE IV}

Food Constituents of Different MrLks

\begin{tabular}{|c|c|c|c|c|c|}
\hline ANmaL & & Protserin & $\mathbf{F}_{\Delta \mathbf{T}}$ & Milk Dugat & Minheal MatThy \\
\hline Woman & , & 1.6 & 3.4 & 6.1 & 0.2 \\
\hline Goat. & & 3.7. & 4.3 & 3.6 & 0.8 \\
\hline Cow . & & 3.5 & 3.7 & 4.9 & 0.7 \\
\hline Ewe & & 4.9 & 9.3 & 5.0 & 0.8 \\
\hline Mare & 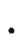 & 2.0 & 1.2 & 5.7 & 0.4 \\
\hline Ass . & - & 2.2 & 1.6 & 6.0 & 0.5 \\
\hline Camel . & - & 4.0 & 3.1 & 5.6 & 0.8 \\
\hline Reindeer & - & 10.4 & 17.1 & 2.8 & 1.5 \\
\hline
\end{tabular}

It will be seen that all the animals included in the above table, which comprises the principal species that have been kept wholly or partly for their milk, yield milk that is much richer than woman's milk in the muscle-forming element, protein. If we were choosing a milk for this one quality, chemical analysis would indicate the wisdom of selecting the milk of either the mare or the ass, which are nearest to woman's in that one particular. But when we consider these with regard to the percentage of fat contained in them, they are seen to be very notably deficient. Strangely enough, the milk of the camel and the cow 
are about equally near mother's milk, the slight. deficiency of fat in the first being about the same as the slight excess in the second. Next in order comes goat's milk, so that we may value them in the following order: (1) cow's milk; (2) camel's milk; (3) goat's milk. In carbohydrates all three are notably deficient, but the camel is nearest, with the cow second and the goat third.

The tremendous excess of protein and fat in the milk of the reindeer as compared with human milk and that of all other animals included in the table would seem to render its use as human food impossible. But it is extensively used by the Laplanders, ${ }^{\circ}$ various Eskimo tribes along the coasts of Siberia, ${ }^{10}$ and, to a limited extent, by the Eskimo tribes in Alaska since our own government introduced the reindeer there nearly twenty years ago to provide the people with some protection against possible famine. ${ }^{11}$ Whether the milk is ever given to infants, and, if so, to what extent and in what manner it is modified, I have been unable to ascertain. Nor have I been able to obtain any analysis of the milk of Eskimo or Laplander women to compare with that of reindeer milk. It is not improbable, I think, that the difference between the two is very much less than our figures suggest. The reindeer is a native of the coldest climates and needs the seemingly excessive fat for heat. We know that 
the human inhabitants of these arctic lands consume enormous quantities of blubber and other animal fats for the same reason, and it may be found that the milk of the women contains an amount of fat that is far in excess of that which is common in more temperate climates. ${ }^{12}$

\section{II}

Now, it is evident that even if the nomads of Africa, Asia, and India possessed the information concerning the chemical composition of the various kinds of milk which is now before us, it would not take them long to decide in favor of the camel. Economically speaking, they would have no choice, since the camel is the only one of the animals included in the comparison which is adapted to the peculiar conditions of the desert. The reason why practically all the numerous Biblical references to milk are to the milk of either the goat or the sheep, indicating that the cow was not the common milch animal of Palestine, is simply that the country was, as a whole, not suited to the pasturing of large cattle, though wonderfully well adapted to the needs of sheep and goats. ${ }^{13}$ In this country efforts made to domesticate the camel failed, the animal being uneconomical:.14 For this reason, of the three animals whose milk most nearly resembles that of the human mother in its chemical composition, one is unavail- 
able so far as the inhabitants of Europe and America are concerned.

There are two species, then, whose lacteal secretion more nearly resembles woman's milk than that of any other species available for general milch purposes, namely, the cow and the goat. The milk of the latter is very extensively used in some parts of the world, and a great deal can be said in its favor as a substitute for human breast milk: It is not, however, very much used in this country. As between the two animals we have chosen the cow. The reasons for this choice are probably in large part sentimental and to some extent economic. It is commonly believed that the goat is not a clean animal, especially in its dietetic habits. While most authorities upon the goat declare this to be a gross libel upon a very clean animal, ${ }^{15}$ there can be no doubt that it enters into the popular prejudice against the goat and partly accounts for the discrimination against the animal. True, the male goat has almost always an offensive odor, but this objection does not apply to the female. Horace, the Roman poet, long ago set the world an excellent example by truthfully imputing the offence to the male goat alone, calling the females

"The ladies of the unfragrant lord."

Again, many persons who have never tried goat's milk, either as a beverage or as a food for them- 
selves or their infants, have an idea that the milk has a peculiar and unpalatable taste. This likewise is unjust to the gentle animal which has been most aptly called "the poor man's cow." There is a very serious objection to the goat in the fact of its undeniable record as a destroyer of young trees and shrubs, but this can be overcome by tethering, and presents no very great difficulty.

On the economic side, the objection that there is no demand for goat's milk to justify goat-keeping upon a large scale, in a commercial way, is trite. That is an economic consequence of the prejudice against the animal. Doubtless there are many persons in all our villages and small towns, where goat-keeping is practicable, who are reasonably free from prejudice and open to conviction upon the subject of the animal's worth, especially as the provider of an excellent milk for infant feeding, who are simply ignorant of its economic merits. The yield of milk is not large enough compared with that of the cow to be attractive, though in proportion to its size and weight the goat yields not less than the average cow. A fairly good goat will yield two quarts of milk or more daily, two or three milkings a day being necessary. ${ }^{18}$ It is not an expensive animal to buy and is probably the cheapest animal of its size in the world to maintain. The average American laughs at the idea of valuing the goat for 
its economic qualities, but it is doubtful whether, all things considered, there is a more economical domestic animal anywhere.

There are several reasons why goat's milk is superior to cow's milk as a substitute for breast milk in infant feeding. In the first place, while the cow is particularly subject to a specially virulent form of tuberculosis, which dread disease it is, as we shall see later, capable of acquiring from man and of transmitting to man in its milk, through the infection of the digestive tract, the goat is practically* immune from the disease. Professor Nocard has observed that of 130,000 goats and kids brought to the slaughterhouses of Paris the meat inspectors failed to find a single one suffering from tuberculosis and requiring condemnation. ${ }^{17}$ The testimony upon this point is overwhelming, and if there were no other advantage in goat's milk, this immunity from the disease which scourges mankind ought to make it popular, providing that its milk proved equally as nutritious and digestible as cow's milk. If we were choosing a foster-mother or wet-nurse for an

* I say "practically immune" in view of the fact that goats have been successfully inoculated with bovine tubercle bacilli by Arloing, and with both bovine and human tubercle bacilli by De Jong. Nevertheless, instances of successful inoculation with either variety are so rare as to call attention to the striking degree of immunity enjoyed by the goat. See "Some Cbservations on the Tuberculosis of Animals," by D. E. Salmon, D.V.M., Maryland Medical Journal, February, 1904. 
infant, and there were two candidates apparently equally desirable in all other respects save this one, both being plentifully supplied with good milk, but one of them the victim of an active and malignant disease, is there any intelligent being who doubts what the choice would be? Yet, in the case of choosing an animal to be virtually the wet-nurse of the nation, we have chosen the one infected with disease and constantly passing on the infection to the little ones.

Goat's milk is superior in richness and flavor to that of the cow, but what of its digestibility? In the milk of both animals the percentage of casein is very much greater than in human milk, the averages being:-
HUMaN
Cow
GoAT
1.0 per cent
3.0 per cent
3.2 per cent

This indicates a tougher and harder curd, casein being the curd-forming element in milk. Now, note the reason for this difference in the toughness and hardness of the curd in the three milks: both the cow and the goat have four stomachs, while man has only one! The digestive apparatus of the human infant is adapted to the assimilation of a soft-curded milk, while the young of the cow and the goat have digestive systems equally well adapted to the assimilation of milks containing hard, tough, fibrous curds. 
We shall have reason to return to this important subject of the relation of milk to the digestive system, but for the present it is enough to note the fact that goat's milk is rather harder in curd than cow's milk, and that both are very different to woman's milk in that respect, taxing the digestive organs accordingly.

To offset the slight inferiority to cow's milk due to the harder and tougher curd, Dr. J. Finley Bell has shown that goat's milk has other advantages. ${ }^{18}$ Not only is the milk much less subject to bacterial contamination, but the fat in it, while the percentage is higher than in cow's milk, seems to be much more nearly akin to the fat in human milk than is that contained in cow's milk. As a result of the success which attended the use of goat's milk in cases of infantile diseases of the digestive tract, after cow's milk had failed, Dr. Bell undertook an investigation into the subject of the relative digestibility of the milk of cows and goats. He found that the milk fat of the two species differed from each other and from that of the human species in that they melted at quite different temperatures. The temperature at which the fat of goat's milk melted was much nearer to the melting-point of human milk fat than the melting-point of the bovine milk fat. The temperature (centigrade) at which each melted was: human, $36.5^{\circ}$; goat, $34.5^{\circ}$ to $36.0^{\circ}$; cow, $38.0^{\circ}$ to 
$40.5^{\circ} .^{18}$ By a very simple and rational method of experiment Dr. Bell thus showed why, in spite of its slightly tougher curd and larger percentage of fat, goat's milk proved superior to cow's milk from the standpoint of digestibility.

In many parts of Switzerland and France it is customary for babies to take their nourishment directly from the goat's udder, just as they would from their mothers' breasts. ${ }^{20}$ The udder and teats of the goat are carefully cleaned by washing, and then the child sucks the teats as other children do their mothers' nipples. According to the British Medical Journal, the results are in every way satisfactory. ${ }^{21}$ Among the Italians who come to this country in such large numbers goat's milk is very highly esteemed as an infants' food, especially in times of sickness. ${ }^{22}$ Down amid the crowded tenements of New York City, when a little Italian baby is sick, weakened by diarrhœa and much vomiting, the distracted mother will very often take the frail sufferer in her arms across the ferry into New Jersey, in quest of goat's milk, which she generally finds in one of the many straggling Italian settlements on the outskirts of near-by towns. In this connection it is interesting to remember that among the ancient Hebrews many curative properties were attributed to the goat. Just as the blood of the male goat was believed to be more like human blood than that of 
any other animal, ${ }^{23}$ so the milk of a goat, freshly drawn from the udder, was regarded as a cure for pains of the heart, ${ }^{24}$ while the milk of a white goat was regarded as having special properties as a cure for many ills. ${ }^{25}$

All things considered, then, the neglect of the goat as a milch animal, especially as a provider of milk for infants, is very much to be deplored. The animal seems to be altogether well fitted to be the wet-nurse of the human infant, much more so than the cow, and it is a great pity that ignorance concerning its habits and qualities should stand in the way of its more general employment. . That an extensive use of its milk in place of that of the cow would lead to a considerable reduction in the enormous mortality from the various forms of tuberculosis which afflict infants is highly probable, indeed, practically certain. It is to be hoped that the Department of Agriculture at Washington, and the several state bureaus, will see fit to make known the truth concerning the much maligned goat, and to encourage its breeding and use for milch purposes.

\section{III}

Cow's milk, then, is the staple diet of a very large part of the infant population of this and other countries. Moreover, the number of children fed upon it is continually increasing. No matter how earnestly 


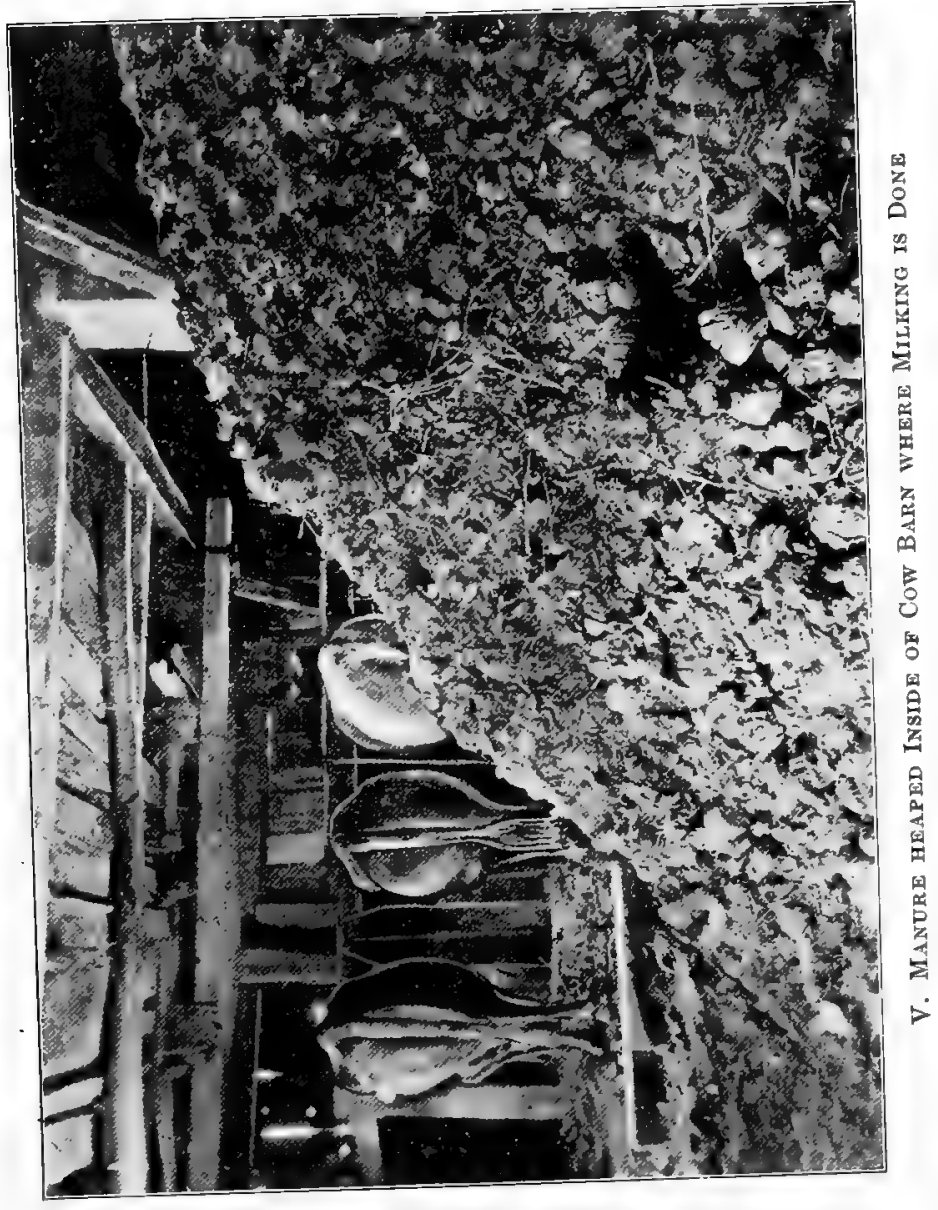



we may desire to see the milk of some other animal tried in its stead, for a long time to come cow's milk will be the staple diet of a majority of bottle-fed babies. It is computed that of the $18,000,000$ cows in this country, the milk of more than $5,000,000$ is used as milk, ${ }^{26}$ most of it in a raw state. What the constituents of cow's milk are, and how it compares in its chemical composition with the milk of other species, we have already seen. There remain, however, some other important aspects of its use by man as a food to be considered.

Milk, by which is here meant cow's milk, is often spoken of as though it were a perfect food. That the milk of any animal is normally a perfect food for its own young is true, so there is no doubt that cow's milk is a perfect food - for calves. But as a food for human beings it is far from perfect. Milk contains the four classes of nutrients necessary for man, protein, fat, carbohydrates, and mineral matter, in more nearly the correct proportions than any other single food material. A quart of milk contains about the same amount of nutritional value as twelve ounces of beef or six ounces of bread. But the nutriment is better balanced than in either bread or beef. For while in the meat there is protein and fat, and in bread protein and carbohydrates, milk has all three in about equal proportions. ${ }^{27}$

The protein is present in larger quantities than the 
human body demands, however. A moderately active man of average build requires about 0.28 of a pound of protein daily, but the milk required to give just that amount of protein would yield too little of the necessary fat and carbohydrates to provide the body with proper energy. On an average, 3400 calories of energy are required, but the milk which would provide that would also provide too much protein, 0.34 of a pound. To get just 0.28 of a pound of protein it would be necessary to take an amount of milk deficient in energy-making elements to the extent of 700 calories, or nearly twenty per cent of the total. ${ }^{28}$ Other reasons why milk cannot be regarded as a perfect food for adults are, first, that the quantity of water contained in it is so great that it would be necessary for a man to drink at least four or five quarts daily to obtain sufficient nourishment from it; second, that it has not enough solid bulk. It seems to be a law of nature that man in common with most animals needs a certain bulk to his food. The distention of the stomach appears to be necessary and the bulk of the solids in man's food to play an important part in promoting the peristaltic action of the intestines. ${ }^{29}$

As an element in the diet of the human adult, milk and its products may be said to be invaluable, but milk is not of itself a suitable food for the normal man or woman. For invalids and very young chil- 
dren, however, it is practically a perfect food - as nearly perfect as anything of which we know. Its advantages are well known: it is as a rule easily digested, it does not irritate the alimentary canal, and by using a milk diet the physician is better able to regulate both the quantity and the quality of the nourishment given to an invalid or an infant than in any other way. Of all animal foods milk is the most easily digestible. It has been found that, on an average, an adult digests about 97 per cent of the protein, 95 per cent of the fat, and 98 per cent of the carbohydrates in milk. According to the experiments made by our American authorities, a child one year old digests less -90 per cent of the protein, 96 per cent of the fat, and 86 per cent of the carbohydrates. $^{30}$ These figures, it may be added, represent the digestion of a healthy child with whom cow's milk àgrees.

But the enormous death-rate among bottle-fed babies shows that it is exceptional rather than usual for cow's milk thus to agree with young infants, especially during the first few weeks of life and during hot weather, when there is a certain depression of the digestive system and when it is difficult to keep milk pure and sweet owing to the rapidity with which it decomposes. One cause of. difficulty is the hardness of the curd as compared with that in breast milk, the infant's natural food. Dr. Chapin's investiga- 
tions of the relation of infant dietetics to the comparative anatomy of the digestive tract have revolutionized the whole science of infant feeding. He has conclusively demonstrated that the milk of each species is suited to the structural character of the digestive apparatus. He points out that in each of the species the "milk of the mother behaves in the young animal's stomach very much as the food of the mother behaves in her stomach." ${ }^{31}$ By this method, he believes, the young animal is being taught to digest its food in just the same way as it must when it is grown up.

The cow, the goat, and the sheep have each four stomachs. Taken together, these four stomachs form about 70 per cent of the digestive tract. But while the horse and the ass eat much the same kind of food as the cow and the sheep, they have only one stomach, which forms about 8 or 9 per cent of the digestive tract. This stomach holds less than onehalf of a meal. Like the horse and the ass, man has but a single stomach, and this forms about 20 per cent of the digestive tract as compared with 70 per cent in the case of the cow and only 8 or 9 per cent in the case of the horse. ${ }^{32}$ Do these great variations in the kind and size of the digestive organs of the different species mean anything? do they signify variations in the manner of digesting food which will help us to explain why it is that so many infants die every 
year of illnesses caused by diseases of the digestive tract?

Let us examine a little more closely the digestive tract in a cow, a horse, and a man, and note briefly some of the most important features in the digestive process in each case. In the cow we have four stomachs, each connected with the others, and occupying altogether 70 per cent of the digestive tract. The fourth stomach has its outlet into the intestine, and careful examination will show that the outlet is so small that only liquid, or semi-liquid, food can pass through it. If we could watch the working of this complicated apparatus in the case of a young calf, we should find that the process of digestion goes on about as follows: when the milk of the mother goes into the first stomach it clots with a firm, hard curd. As this clotted mass passes from stomach to stomach, the curd is gradually reduced, until, from the fourth stomach, it passes into the intestine in a digested, liquid form.

Taking next in order the horse, we find at the outset a very different apparatus. Here is a single stomach, very small, and occupying only about nine per cent of the digestive tract. The outlet from the stomach to the intestine, instead of being so small that only liquid or semi-liquid food can pass through it, is very large. If we could watch the stomach at work during the time the horse was taking a meal, we should find 
that, while the animal was eating, the stomach emptied its contents, altogether undigested, into the intestine. At the other end of the intestine is a very large cæcum, or gut, which occupies about 60 per cent of the digestive tract. The digestion of the food in this case is not performed by the stomach, but by the intestine. Now, if we could only observe the working of this digestive system in a very young foal, we should find the mare's milk forming, not a hard clot like the cow's, but a clot very soft and like jelly. This jellylike clot passes at once into the intestine from the stomach and is there digested. Now, then, suppose that instead of letting the mare nurse her offspring, we take it away and feed it upon cow's milk, or the milk of some other animal which resembles it in having a hard, tough curd. As the hard clots of curd pass into the intestine, which is suited only to the digestion of a soft, jellylike curd, what happens? Why, obviously, intestinal irritation and inflammation. The hard curd is a foreign substance in the intestine; it cannot be digested. Thus in the stomach of the foal the milk intended for a calf by Nature becomes an irritant and a poison.

Now, let us take the human infant. Here, again, we have a young animal with a single stomach, which occupies about 20 per cent of the entire digestive tract, or less than one-third the proportion occupied by the four stomachs of the calf in its digestive tract. 
We notice at once that, as in the case of the calf, the outlet from the stomach to the intestine is very small. As we watch the milk from the mother's breast pass into the infant's stomach, we observe that it does not clot in a hard, tough curd like cow's milk, nor in a jelly as in the case of mare's milk, but in a soft mass, broken into numberless small particles. It is neither hard and solid, nor soft and gelatinous, but flocculent. In this state it passes into the intestine, where the process of digestion is completed. If, instead of mother's milk, speedily precipitated into this flocculent form, cow's milk with its enormously harder curd enters the tender stomach, what happens? Why, the stomach is overtaxed trying to break the curd into particles small enough to enter the intestine, and there is disorder until the foreign substance can be got rid of, with resulting nausea or diarrhœal illness. Such portions of the curd as have been broken and passed into the intestine are very liable to cause just the same kind of disturbance there, with serious, if not fatal, result.

From the foregoing discussion it will be perfectly apparent, even to one who has never given the matter the slightest thought before, that in looking for a substitute for breast milk upon which to feed our 
babies, it is necessary to pay attention to other factors beside the percentages of protein, fat, and carbohydrates which the substitute contains. Even if we could secure a milk the chemical composition of which was exactly the same as that of human milk, it would still be far from a perfect substitute, unless it behaved similarly in the digestive process. It is evident, then, that while a chemical analysis is necessary and helpful, it is not, by itself, competent to warrant the fitness of the milk of any animal as a food for any other than its own young. Comparative anatomy of the digestive organs, and a close study of their functioning, must go hand in hand with chemical analysis. ${ }^{33}$

Furthermore, the chemical analysis of milk must be carried much farther than is necessary to determine the proportion of the various food constituents contained in it. That is but the beginning of physiological chemistry as it bears upon the problem of the artificial feeding of infants. There are many other matters of profound importance which need to be just as carefully studied. For example, there is in all milk fats a substance of a phosphorescent nature, called lecithin - from the Greek root, lekithos, yolk of an egg. This substance is contained in human milk to a much greater degree than in the milk fat of other animals, such as the cow and the goat. That there is a very good reason for this may be presumed, for Nature's economy is exceedingly scientific 
and wise; the relative abundance of lecithin in the milk of the human mother is not a whim or an accident, but an important fact which we cannot properly ignore.

We ask ourselves, then, what is the purpose of lecithin? what does it do? Science reveals the fact that it is this substance which forms a very large part of the brain and nerves. So another question arises, why should there be less of it in the milk of cows, goats, sheep, and horses than in woman's milk? For answer to this question, let us compare the newly born offspring of these various species: "Within half an hour after birth a calf, lamb, kid, or colt can stand, and in a day or two runs around and sees, hears, and smells about as well as its mother. In other words, it is born with a fully developed nervous system. But a baby is very different in this respect, and it needs material for building up its nervous system, and this is found abundantly in woman's milk, but not so much in other milks.". Thus Dr. Chapin answers our question. ${ }^{34}$

There are other wonderful elements in milk which are not disclosed by ordinary analysis. In fact, the story of a drop of milk, could it be fully told, would prove one of the great romances of science. We cannot even enumerate these wondrous elements in the present discussion, but there is one without some notice of which we shall not be able to understand subse- 
quent chapters. It is well known that breast nurslings are remarkably immune from infectious diseases; even though their mothers may be infected during the lactation period..$^{35}$ Mothers suffering from typhoid fever, diphtheria, measles, scarlet fever, and many other diseases which are highly infectious, frequently continue nursing their infants without infecting them in the slightest degree. In many isolation hospitals it is the rule not to separate the nursing infant from its mother, even though the mother is suffering from such a disease as diphtheria and the infant is perfectly healthy. Professor Roger, an eminent French authority, has published a list of forty-nine cases of nursing mothers admitted with their infants to his isolation hospital. Fifteen had measles, nineteen scarlet fever, eight tonsilitis, one diphtheria, five erysipelas, and one mumps. With the exception of one very debilitated child, who contracted erysipelas, no child contracted disease, notwithstanding that all were suckled by their mothers. ${ }^{36}$ It is believed that this immunity of breastfed babies from infectious disease is due to the fact that the mother's milk carries into the infant's body certain protective anti-toxins which are called, in the technology of the laboratory, "anti-bodies."

When an animal is attacked by poisonous bacteria, certain neutralizing qualities are formed in the blood, which, to a certain degree, produce an active resistant against the poison. In a healthy animal the blood 


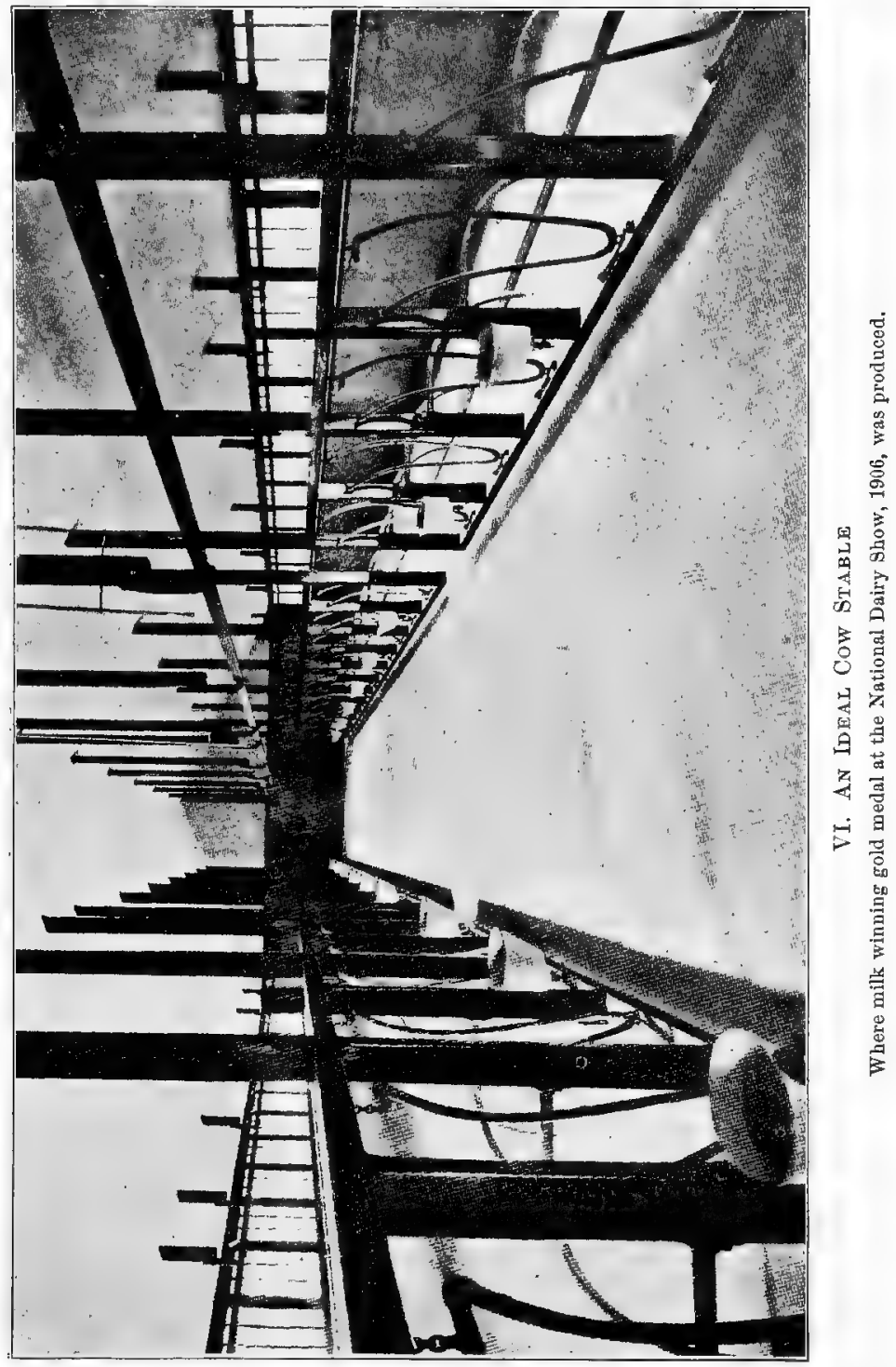



thus develops considerable bactericidal powers, enabling the animal to resist the attack. Now, if it be true that these anti-bodies are secreted in the lacteal fluid of the mother and carried into the digestive tract of the infant, to be distributed throughout the body, we have another very important reason for the superior advantages enjoyed by breast-fed over bottle-fed babies in the struggle for existence. For while the milk of the cow may likewise contain these useful anti-bodies, they are effective only in protecting its own offspring and of no advantage whatever to the human infant, its parasite. ${ }^{37}$ Far from protecting the baby against disease, there is an astounding mass of convincing evidence that cow's milk is frequently the medium by which the human infant is infected, many of the deadliest diseases being conveyed by means of milk, especially among young infants wholly dependent on a milk diet.

Summarizing, briefly, the principal points in this discussion thus far, it is evident that as a substitute for mother's milk some other milk is desirable, though there is no other milk which is as good as mother's milk and able to serve the infant in so many ways. While foods may eventually be made, consisting wholly or largely of vegetable matter, in which the proportions of protein and other food elements are perfectly balanced, still, they cannot take the place of milk, which must form the basis of any satisfactory 
74 THE COMMON SENSE OF THE MILK QUESTION

infant food. The milk of the cow is generally used in this country, though it is in some respects inferior to goat's milk. But whether cow's milk or goat's milk be employed, it must be modified to make it as nearly like human milk as possible, alike as to its nutrient qualities, the mannel of its digestion, and the content of ferments which aid and stimulate assimilation. This is the task to which the modern physiological chemist and the physician must address themselves. There can be no reasonable doubt that the standard which Nature sets is the one which should be aimed at; that the nearer we get to human milk, the more satisfactory the result will be.

\section{$\mathbf{v}$}

It is no part of my purpose to provide mothers and nurses with a manual of instruction in the practice of infant feeding. We are concerned with the problem in its social and political aspects only. If many of our excursions into the realms of chemistry, physiology, pathology, and bacteriology seem at first to be foreign to that purpose, it will require but little reflection to show that these are very important phases of the problem we are trying to solve, the problem of securing a safe and wholesome public milk supply; and, especially, such a system of producing and distributing the milk upon which so many 
of our babies must be fed as will stop the needless waste of life, the stream of little baby lives that flows each year into the great ocean of death and loss. It requires no elaborate argument to show that a clear comprehension of the problem is the first essential condition of its successful solution.

It is, therefore, not proposed to enter upon a discussion of the various milk formulas which have been prepared by different authorities upon infant dietetics, such as the venerable and learned Jacobi, Rotch, Chapin, Holt, and others. ${ }^{38}$ Nor will any attempt be made to determine the merits of the controversy between those who favor a very high percentage of fat, using "top-milk" only, or adding cream to the milk, and those who favor a low percentage of fat. There is doubtless a danger line in either direction, and the milk of the human mother is not very likely to be improved upon as a standard. For the reasons stated, our concern with the modification of milk for infants is very slight. We have nothing to do with the technic of its formulas, but only with those aspects of it which have a socio-economic significance.

The practice of modifying milk has, in a crude way, been carried on from very remote times. Long before the rise of a school of physicians devoted especially to the study of pediatrics, mothers, finding that their babies could not retain the milk of 
the cow when given in its pure, undiluted state, followed their instinct and common sense and diluted it by the addition of water. It was a crude method of modifying milk, to be sure, and the tally of its victims will never be recorded. It is significant, however, that the mothers, long before the subject received the attention from scientific minds which is now common, discovered that, according to the age of the child and its strength, cow's milk needed some dilution to adjust it to the child's need. But among French physicians, led by such men as Budin, Variot, and Dufour, there is a very widespread opposition to any attempt to lessen the differences between human and bovine milk by any process of modification, or, as the English say, "humanization." They prefer to give the cow's milk unmodified, even to very young infants, but insist that it must be either sterilized or pasteurized. ${ }^{39}$ In following the other method of modifying the cow's milk to suit individual requirements, American and English physicians are doing in a scientific way what maternal instinct and experience used to do in a crude, haphazard way with disastrous results. They are minimizing the inevitable differences between natural and artificial food, reducing the loss of the bottle-fed baby to the minimum.

In percentage-feeding as practised by such authorities as Rotch and Chapin and their numerous 
followers, milk modification has reached its highest development thus far. The leadership of American physicians upon this question is universally recognized outside of France. Indeed, the science of the whole milk question is very much further advanced in America than in any other country, however backward we may be in the practical application of scientific knowledge to our milk supply. We are not, after all, a very practical people, much as we love to hug the delusion that we are. Social science is nowhere making the progress that it is making in America to-day, Germany having lost its leadership long since. But the practical application of that science, actual social experiment, is neglected here as nowhere among the great nations.

Percentage-feeding is in reality a highly individualized system of milk modification. Starting from the idea that the mother's milk is immeasurably superior to any other food for an infant, percentagefeeding is an attempt to so modify cow's milk that it will approximate mother's milk in its composition. Under the old haphazard methods, when it was found that undiluted cow's milk could not be properly digested by the infant, it was simply diluted until it "seemed to suit the stomach" of the child. It was not understood that it was the excess of protein in the milk, intended by Nature for a very different organism, which caused the indigestion, nor that in 
the process of simply diluting the milk with water there was danger, not merely that the dilution would be carried too far, thus reducing the amount of protein below what was actually necessary, but also that the amount of heat and energy-producing elements, fat and sugar, was likewise reduced to a degree inconsistent with the health and proper development of the child. ${ }^{40}$ Such babies pined and wasted away, with the result that cow's milk was held to be an unsuitable food and generally discredited. Very often anxious mothers resorted to some of the many proprietary foods, upon which, owing to the amount of sugar contained in them, there was generally a gain in weight. Thus the proprietary foods obtained a hold upon public confidence. How could the mother be expected to realize that the fatness and weight of her baby were both deceptive; that its food was lacking in protein, the element that gives strength and resisting force? How could she be expected to know that, under such conditions, her child must be exceedingly liable to become rachitic, or to succumb to the first attack of a serious nature through lack of fortifying strength ? ${ }^{11}$

This very grave defect in prepared foods for infants is one reason for the excessive mortality which invariably results from their use. When pigs are fed upon a diet that is low in protein, they succumb to disease much more easily than do pigs fed upon a diet 
containing protein in proper proportion. The pigs fed upon the low protein diet may be fatter and heavier, but they are weaker. ${ }^{42}$ This is what common sense would suggest, of course, in the case of babies as well as that of pigs, and demonstrates very forcibly how misleading the advertisements of all proprietary foods are. Pictures of babies showing them to be very fat, and figures showing them to be very heavy, may deceive mothers and the lay mind in general; but the medical man and the student of physiology know that these are not the only conditions of sound health.

One of the great merits of percentage-feeding is that a general knowledge of its principles will do much to educate the public to a realization of the danger which lurks in proprietary foods, even the very best of them. The great obstacle at present is the fact that the principles have not been simplified enough to make them popular. They are too complicated, and involve too much computation and study, for the very mothers who most need to understand and practise them. It must not be forgotten that directions which appear simple and lucid enough to the college woman will seem very complicated and difficult to the mind of the poor tenement mother. Quite the most lucid and simple instructions for percentagefeeding which I have seen fail in this vital particular. The physician who can prepare a truly ssimple and 
popular statement which will enable the average mother of the working class to understand percentage-feeding, so as to practise it intelligently, without having to undergo a very complicated system of calculation, will confer a great boon upon humanity.

As it is, where mothers are intelligent enough to use modified cow's milk they frequently do not understand that the extent and manner of the modification must be determined by two factors mainly - the quality of the milk in its undiluted state and the age and physical development of the child whose diet it is intended to be. Many of the cases of children failing to thrive upon the modified milk provided at a low price at the Infants' Milk Depots maintained by private philanthropy in this country, and by municipal enterprise in England, are due to the ignorance of the mothers upon these points and the lack of an effective supervision of the distribution of the milk mixture. Dr. F. M. Fry tells, in the Archives of Pediatrics, ${ }^{43}$ of a physician who sent an order to the Walker-Gordon laboratory, that "four ounces of modified milk" be sent daily to a certain address. No instructions were given as to the ingredients desired, nor anything said concerning the age of the infant for whom the milk was required. Doubtless the physician desired and expected good results for the baby as a result of the use of modified milk, which 
term apparently meant to him simply - modified milk.

If it is possible for this to happen in the case of a physician, is it at all strange that it should frequently happen that mothers fail to appreciate the fact that the milk mixture which suited her baby at six weeks will not suit it at six or nine months; that merely increasing the quantity of the mixture will not do, but that its composition must be changed? A lax method of distributing modified milk from the depots conducted by philanthropic persons and societies in many cities is a weakness which must be remedied before a maximum of good can be obtained from them. 


\section{CHAPTER IV}

FILTH As INFANTS' FOOD

Thus far we have considered only those disadvantages in the use of cow's milk as a substitute for mother's milk which are inherent in the differences between the human and bovine species. That the very best cow's milk obtainable, modified by the most expert physician, is not a perfect substitute for the liquid which the lacteal cells of the mother secrete from her food, to become the food of her offspring, is only another way of saying that, so far as we have yet progressed, there is always an element of danger in the use of any substitute for breast-feeding. The danger is by far the greatest when any of the manufactured foods are used and least when the milk of the cow or the goat, properly modified by the use of diluents containing either alkaline elements or the gruel of cereals is used. But at best there is some danger.

Now we must consider some other elements of danger which are very important, and which differ from those we have been considering in that they are 
not due to the differences in the human and bovine organisms, but mainly to conditions resulting from our ignorance, to the highly dangerous and unscientific manner in which we permit the production and distribution of milk to be carried on. The dangers which we are to consider under this head are very much greater and more numerous than those which are the inevitable result of the use of a substitute for the natural food of the infant, and which we can scarcely hope ever to wholly avoid. But while they are more numerous and more frequently fatal, they have this hopeful feature: they can all be successfully combated whenever enough civic interest has been awakened to a recognition of peril and remedy to insure the earnest and intelligent coöperation in remedial effort of all the forces in society. Parents cannot accomplish the task alone and unaided; physicians cannot do it; farmers and milk dealers cannot do it; it cannot be done by the governing bodies of our cities and states, or of the nation itself. But all these forces combined, earnestly and wisely working together, can do it; and so bring about one of the greatest triumphs of life over death, of health over disease, ever accomplished in the whole stretch of human history.

But before there can be any effective movement aiming at the attainment of this noble ideal the nature of the evils to be attacked must be known; before 
we can do anything we must know what there is to be done and how to do it. In making a statement of the evils to be attacked, therefore, and describing some of them with a certain amount of detail, it is not my purpose to pander to a demand for morbid sensationalism, nor to provide materials for the excitation of the public mind in the intervals between other "exposures" or sensational campaigns. What I want to do is to place before the American public a calm and dispassionate statement of certain curable ills as a basis upon which to rest an earnest plea for action; to waken, if possible, all those dormant and neglected powers and impulses for good which need to be called into active coöperation in order that the evils may be remedied. And, terrible as some parts of that statement may be, sickening as some of the details are, it is perhaps necessary to assure the reader that they fall far short of truth. For a truthful statement of conditions, that is, a complete statement of all the evils, given with photographic accuracy, would be unprintable and unreadable. The worst that was said about the conditions existing in. the meat-packing houses of Chicago during recent exposures, does not excel, even if it equals, what might truthfully be said of the conditions which attend the production and distribution of the milk supply of our cities. It is a calm and studiously moderate statement of fact to say that dirt and disease germs are 


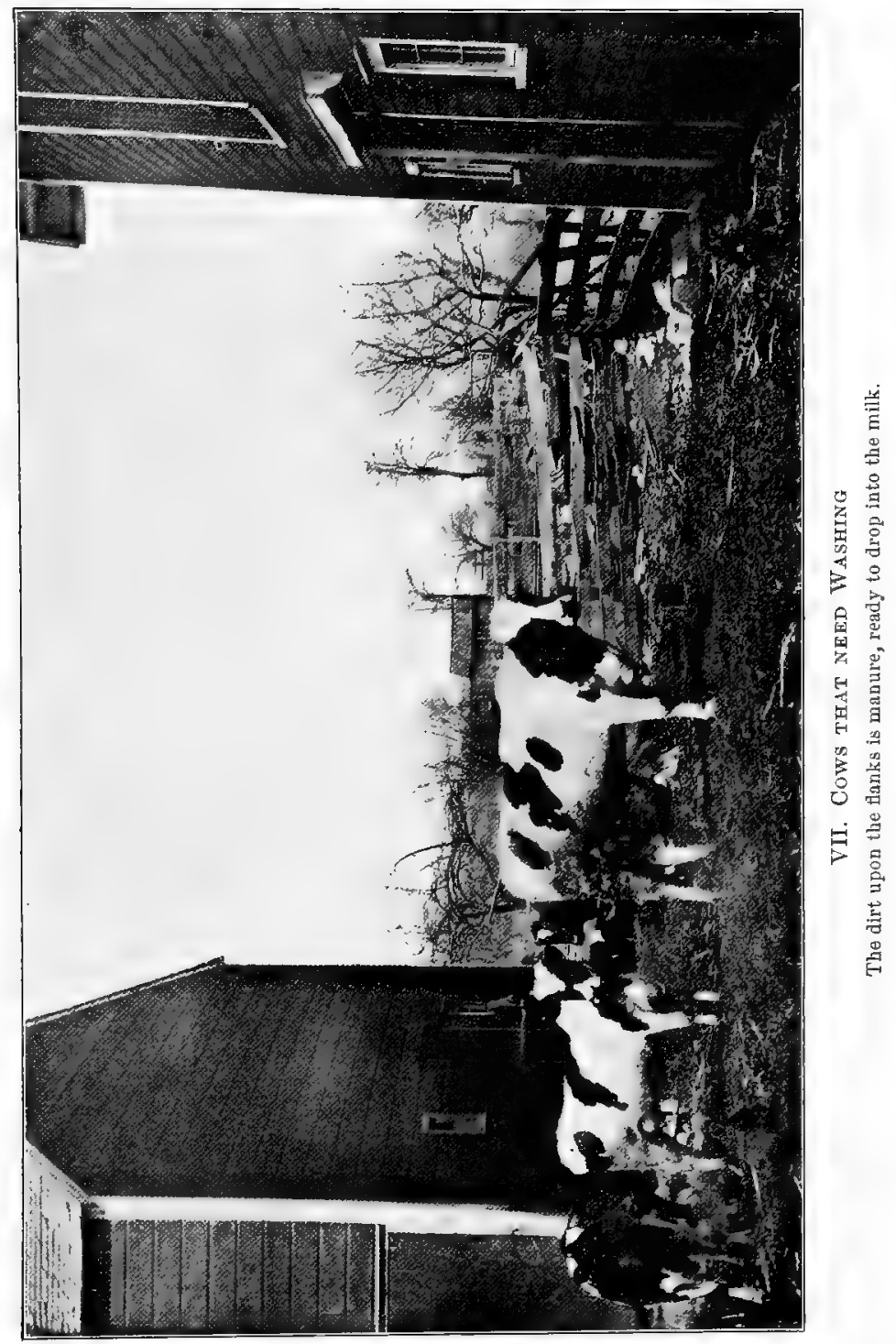



fed to the vast majority of bottle-fed babies in this country.

Dirt and disease are the two great perils of our milk supply. Dirt from the cow giving the milk, and dirt from the human beings by whom the milk is handled, and disease from both bovine and human sources are distressingly common in the milk upon which we feed our infants. To this cause more than to any other must the enormous mortality from intestinal disorders among bottle-fed babies be attributed. More than a century ago, Smollett, the English novelist, himself a physician, described the conditions surrounding the milk supply of London in terms of unqualified, scathing denunciation. Who that has read the description, in Humphrey Clinker, of the food dainties of Covent Garden can forget the following passage of brutal, eloquent realism?

"I need not dwell on the pallid contaminated mush which they call strawberries, soiled and tossed by greasy paws through twenty baskets crusted with dirt, and then presented with the worst milk, thickened with the worst flour, into a bad likeness of cream; but the milk itself should not pass unanalyzed, the produce of faded cabbage leaves and sour draff, lowered with hot water, frothed with bruised snails, carried through the streets in open pails, exposed to foul rinsings discharged from doors and windows, spittle, snot, and tobacco-quids, from foot-passengers, overflowings 
from mud-carts, spatterings from coach-wheels, dirt and trash chucked into it by roguish boys for the joke's sake, the spewings of infants, who have slabbered in the tin measure, which is thrown back in that condition among the milk, for the benefit of the next customer; and, finally, the vermin that drops from the rags of the nasty drab that vends this precious mixture, under the respectable denomination of milkmaid."

The "literature of exposure" is not a new development. Nothing ever printed concerning the milk supply of this or any other time or place, by the most sensational of "yellow" newspapers, can outdo this account of London's milk supply by Smollett. How much of the description we may accept as a fairly just account of actual conditions, and how much we must ascribe to Smollett's love of exaggeration, we need not trouble to fathom. It is enough for us to know that the conditions were bad enough to provoke Smollett to attack them with all the superb, if vulgar, vehemence of which he was capable.

\section{II}

It will be observed by the careful reader that all the filthy conditions which Smollett enumerated in his sweeping condemnation were of human origin, due 
to carelessness and ignorance, and not to any defects in the animals from which the milk was drawn. That is a fundamental characteristic of the problem everywhere. In every case, wherever there is impure milk, the failure of human intelligence is responsible. When milk is contaminated, man is to blame, and not the humble animal from which the milk comes. In its original state, as contained in the udder of the cow, the milk is pure and sweet and free from all foul and dangerous matter, assuming that there is no disease of the mammary gland or udder. ${ }^{1}$ Lister showed as far back as 1873 that milk, while in the mammary gland of the healthy cow, is absolutely free from bacteria and, being sterile, if it could be drawn from the udder and kept in that pure state, would never sour nor ferment. As a matter of actual experience, it may be said that milk is rarely drawn from the cow absolutely sterile and free from bacterial life. Bacteria are so numerous and omnipresent, being found in the cow's teats, on the hairs of the cow, in the milk pails in cracks and rims, as well as in the air, that only by methods which seem almost miraculous and impossible in ordinary practice is it possible to produce milk that is absolutely sterile in its natural state. It is by no means uncommon, however, for milk to be produced, in small quantities, and under special conditions, in which no bacteria can be found by the ordinary methods of microscopic observation. Dr. Park 
has examined samples of such milk from one model dairy, as well as many others from the same dairy with a bacterial count of less than 100 per cubic centimeter. ${ }^{2}$ Dr. C. M. Seltzer, also, has noted similar apparent absolute sterility in two or three samples obtained in the state of New York, out of a dozen samples examined. $^{3}$ At the National Dairy Show, in 1906, milk in which no bacteria could be discovered by the ordinary methods of microscopic observation was obtained.*

Now, milk that is sterile will keep good for a very long time, provided that it is kept under proper hygienic conditions, in vessels that are sterilized, and kept at a low temperature, say 40 degrees Fahrenheit. These are obviously ideal conditions which are not always obtainable in this far from ideal world. At the Paris Exposition, in 1900, one of the most significant of all the food exhibits was that of American dairy products, particularly of milk and cream. European authorities were astounded: they simply could not understand how it was possible for milk and cream, raw and in the natural state, without preservatives of any kind, to be shipped all the way from New York, New Jersey, or Illinois to France, to be in good condition upon its arrival, and to remain as pure and sweet as milk freshly drawn from the cow for long periods after arriving at the end of the long transatlantic journey. ${ }^{5}$ The French agriculturists were dumb- 
founded, for they could not bring their milk a distance of little more than a hundred miles and have it in good condition for more than forty-eight hours, under the most favorable conditions. In the midsummer season they were barely able to keep their milk sweet for twenty-four hours after its arrival. Major Alvord, who was in charge of the exhibit, found it no easy matter to convince the milk experts on the jury that. the millk was in its natural state, uncooked and undoctored; that nothing but "cleanliness and cold" was used to attain such wonderful results."

When milk decomposes and turns sour in a relatively short time, as is most common, the decomposition is due to the action of bacterial life in the milk, to the presence in it of organisms that are not indigenous to it, but as foreign as the dangerous chemicals which the unscrupulous dealer sometimes adds to his milk to keep it from souring, or the coloring that is sometimes added to give the milk the appearance of having more "body" and being richer than it actually is. To put the matter still more plainly, when microscopic examination shows the presence of a large number of bacteria in milk, regardless for the moment of the nature of such bacteria and their influence upon those who consume them in the milk, it is indisputable that the milk is foul and dirty and fit for the sewers rather than to be used as food. ${ }^{\text {? }}$ 


\section{III}

Most persons have at some time in their lives been fascinated by the observation of a drop of water through a microscope. They have seen many forms of animal life which were quite invisible to the naked eye, and some forms of plant life of a still lower order than the animalcula. These are bacteria, exceedingly minute little organisms of plant life, belonging to the fungi order. Infinitesimal as they frequently are, the bacteriologist in his laboratory finds that they differ very materially from each other, that there are classes of bacteria as distinct as the classes among the higher forms of life. Some are in the form of tiny spheres, others like little rods, and still others like miniature corkscrews. In short, there are many variations in shape and general appearance observable when bacteria are closely examined through a very powerful microscope.

Not only is it possible to note physical differences in bacteria, but their characters have, to some extent, been likewise studied. While it is not yet known just what effect many of them have upon our food, or when they are taken into our system, ${ }^{8}$ other varieties have been more successfully studied. This is especially true of the varieties of bacteria which are called "pathogenic," that is, disease-producing. The chief reason why we know more concerning the pathogenic 
varieties than concerning others is that in recent years the germ origin of disease has been very extensively investigated. Many of the worst diseases are caused by these tiny bacteria, or bacilli, which have been very closely observed in consequence.

Take, for example, the dread disease, tuberculosis, or consumption. As far back as Hippocrates, who lived four hundred years before the Christian Era, this disease was known as the most fatal of all diseases. ${ }^{9}$ Isocrates, also a Greek physician, who lived about the fifth century before Christ, wrote of the disease as one which was transmissible through contagion. ${ }^{10}$ Thereafter we find in the history of medicine and pathology constant and growing recognition of the fact that the disease can be transmitted from one person to another in many ways. Then, in 1865, a celebrated French physician, Villemin, proved that tuberculosis could be produced in animals by inoculation, not in the lungs merely, but in various parts of the body. ${ }^{11}$ Thus it was demonstrated that the disease is transmissible from man to beast, therefore probably also from beast to man. It was also evident that the disease must be caused by a specific germ, or bacterium. This germ was not actually isolated and identified until 1882, when Professor Robert Koch, the eminent German physician, announced the discovery of the Bacillus tuberculosis, a discovery which has since been verified by numberless physicians in all lands. ${ }^{12}$ 
Now, when this germ was thus identified its habits could be observed. All over the world, physicians and bacteriologists began to devote themselves to the study of the tiny micro-organisms which ravage the world with so much deadly effect. In 1890 Professor Gustav Bang, of Copenhagen, demonstrated the presence of the germ in cow's milk, showing that, without knowing it, all persons who drink milk are liable to swallow the germs of the most deadly of human diseases, and that we feed such germs to our babies when they are fed on cow's milk. ${ }^{13}$ Following Bang, came Dr. German Sims Woodhead and Professor Macfadyean, who not only found the tubercle bacilli in milk, thus confirming Bang's discovery, but also that a large number of cattle brought to the public slaughter-houses of Edinburgh were tuberculous, as were many of the milch cows, so that it was shown that people without knowing it were eating the flesh of tuberculous animals and drinking the milk from them. ${ }^{14}$ It will be understood from this brief sketch of the history of the tubercle bacillus how one of the pathogenic varieties of bacteria came to be so intimately and carefully studied.

We do not need to consider in such detail the various stages in the study of the germs by which other diseases, notably typhoid, scarlet fever, erysipelas, diphtheria, and cholera are produced. Our illustration will suffice to explain why it is that men of science 
have identified a certain number of varieties of bacteria and classified them as being pathogenic, and why they believe many other varieties to be harmless and incapable of causing disease, having observed them very closely and in large numbers without detecting any ill effects from their presence. It will be understood, too, why it is that they are uncertain about some other varieties and do not yet venture to classify them as being either pathogenic or harmless. Some of the harmless varieties, it should be observed, are only harmless from a pathogenic standpoint. They do not cause disease, but they are very troublesome in many ways. They cause milk to turn sour, for example, inflicting quite severe losses upon the farmer or milk vendor sometimes. We are apt to blame the souring of the milk upon the weather, particularly if there has been a thunderstorm, rather than the real culprit, the little micro-organism in the milk. Man has even found some of the bacteria useful and cunningly availed himself of the fruits of their labor, for the various kinds of cheese which we consume are all produced from milk, partly by bacterial action. Cultures of bacteria for cheese-making are now regularly sold on the market. ${ }^{15}$

But how, it may be asked, is it possible for bacteria to get into the milk in large numbers? To answer that question it will be necessary to describe the process of milking the cow, and the transportation of the 
milk to the consumer, somewhat in detail. Let us, then, take an imaginary journey to a typical cow stable, watch the milking operation as it is carried on there, and then follow the milk along some part at least of its journey. It is late afternoon in the early summer and Farmer Jackson's cows are driven across the yard into an open shed to be milked. There is dirt upon the hind quarters of some of the cows, thick, hard cakes of dirt matted in the hair, while all the animals are very dusty. We observe that the yard also is very dirty and pervaded by a strong odor of manure. In the middle there is a big heap of cow dung and straw from the stables, upon which fowls are scratching and over which flies are swarming. Many more flies are buzzing around the cows as they stand in the shed, and tails are going in a constant swishing motion, whisking them off. It is not a very clean sight, this typical farmyard!

Presently, along comes Bill, the farmer's man, pail in either hand, to milk the cows. He is a slow-moving fellow, is Bill, bronzed by his outdoor life, strong as an $\mathrm{ox}$, and just as stolid and indifferent to all the world outside as the ox is. As he comes out of the farm kitchen, he lingers on the step a moment and rinses one of the pails with hot water, which he then pours into the other pail, rinsing it in the same way. He throws the water away and comes down the yard and stops a moment at the well, not far from which is a 


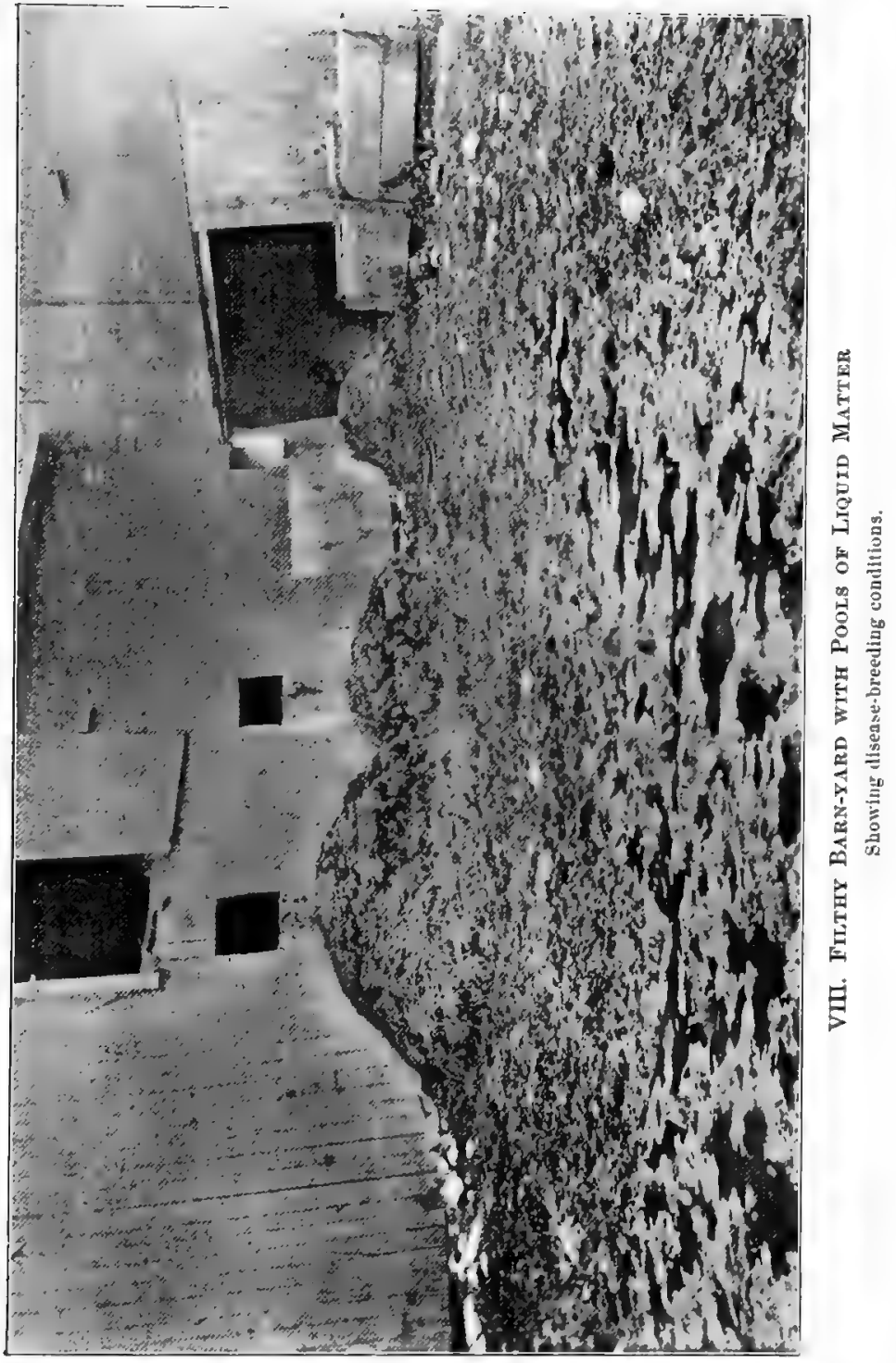



stagnant pool containing a liberal infusion of manure. Very deliberately he draws up a pail of water from the well and rinses out his milk pails once more, this time to cool them. Now Bill comes to the shed: if you ask him whether the pails are clean he will tell you that they are. Most assuredly they are, for did you not see him wash the pails, first with hot water and then with cold? How could you expect poor Bill, who doesn't know a bacterium from an elephant, to know that his pails are not really clean; that in the angles and spaces where they are seamed - for you note that the pails are very badly made - there are thousands, probably millions, of bacteria?

Bill's clothes are dirty, it is true, but you cannot doubt that Bill himself is an unusually clean sort of a person. Did you not see that when he rinsed his pails with the cold water he was careful also to rinse his hands in the water before throwing it out? True, he wiped his hands upon the sides of the legs of his trousers, just as he later wiped his nose with the back of his hand, but, like chewing tobacco, which Bill also does while he works, these are just habits which concern Bill and Bill only. When he has properly and comfortably seated himself upon a milking stool which is filthy, saturated with dirt and teeming with bacteria, Bill moistens his hands with spittle and begins milking. In the case of the first cow, you observe that he lets the first "draw" go to waste upon the 
ground, but later, when he comes to the other cows, he does not pursue the same course. It would be interesting to know just why he did it in the case of the first cow; perhaps only because that is the custom, for it is not to be supposed that Bill knows that there are hundreds and thousands of bacteria secreted in the teats since the last milking, and that these should be "milked out" before any of the milk should be allowed to enter the pail. Bill is not a bacteriologist, as we have already observed.

Bill does not know that the cows ought to have been very thoroughly brushed; that the udders and teats ought to have been carefully washed, as well as the tails, in some good antiseptic wash; that his own hands ought to have been similarly treated and the dirt removed from under the finger nails; that the pails ought to have been differently made in the first place and that the very best of pails need to be perfectly sterilized before the milking, preferably by steam power. He does not know that as the cows whisk the flies away from their own bodies with their tails they are filling the milk with bacteria and dirt which drop from their own hairs and his clothes; that the flies are busy carrying bacteria from the manure heap into the milk; that the shed is not a fit place for milking cows in. Bill has been milking cows for upwards of thirty years and he never heard that there was any necessity for putting on a nice clean suit to 
milk cows in, or to clean his finger nails and wash his hands in water containing boracic acid or some other disinfectant. Should you tell him these things, he would only think you were trying to be funny at his expense - unless he suspected that you were crazy.

If a fly goes into the milk, or if the cow should whisk a lump of dung into it, Bill is quick to dip his fingers in and take it out, if he observes it. And if he does not observe it, everything will be all right, for, you know, the milk will be beautifully strained through the nickel-plated strainer which Farmer Jackson bought at the Dairy Show for the purpose, and of which he is extremely proud. If you are curious enough later on, you can see for yourself the round ball of dung and hair which will be cleaned out of the milk. Yes, these strainers are wonderful inventions; they "take out all the dirt and make the milk perfectly clean"!

Because Bill doesn't know anything about bacteria and their manner of increasing, every step he takes is an aid to their work and their rapid multiplication. His first pail filled, he places it aside, uncovered, and begins to fill another. Nobody ever told him that there were such things as bacteria in the air, little plants similar in many ways to the mushrooms that spring up in a night, and that these little plants are often very deadly to human beings. And, since nobody ever told him, he is not to blame for not knowing 
that when the milk comes from the cow, at a temperature of 100 degrees Fahrenheit, it is admirably suited to the incubation of these bacteria, that in such a temperature they will multiply very rapidly, one bacterium producing as many as three thousand others in less than six hours. ${ }^{18}$ If he knew these things, and knew that to reduce the temperature of the milk would hold the bacteria in check, that at a very low temperature they increase very slowly, or not at all; ${ }^{17}$ he would have done his best and taken the full pail out of the dust and, in the absence of ice, placed it to stand in a tub of cold water from the well. But he does not know. And the ignorance of such as Bill is a very big factor in the milk problem.

\section{IV}

If any reader thinks this is an exaggerated description of an ordinary farmyard, or of milking as it is commonly carried on, I have only to say that it is a very literal account of an actual case which I know to be far from exceptional. An interesting experiment may be tried by any reader. Let him go out into the country and closely observe conditions for himself, checking the various points in the above sketch according to his observations. He will find many farms to which my fanciful sketch will not apply, but he will find many more of which it is a moderate and restrained description. I know that the inspectors 
connected with the health boards of all our large cities will bear me out when I say that such conditions as I have described are by no means unusual: they are the rule, almost, rather than the exception.

Here, for example, is a terse description of a dairy, published by the Bureau of Animal Industry of the United States Department of Agriculture:-

"The herd consists of forty native cows, fed corn meal and brewers' grains. The stable is poor and very dirty, and the cows are filthy and packed closely together. A pile of manure as high as the window surrounds the stable and the yard is correspondingly faulty. Two hundred and forty quarts of milk are produced daily. It is carried to the house, nearly a quarter of a mile away, and cooled in a tank of icewater, being at $50^{\circ}$ to $60^{\circ}$ when sold. The well is near the house and less than one hundred feet from a privy vault. This water supplies the stock and all other purposes." 18

Conditions such as these are not peculiar to this country, but are more or less common throughout the civilized world, wherever cows are kept. Dr. Leslie Mackenzie only states the truth very forcibly when he says:-

"To watch the milking of cows is to watch a process of unscientific inoculation of a pure, or almost pure, medium with unknown quantities of unspecified germs. Everywhere throughout the whole process of milking 
the perishing, superbly nutrient liquid receives its repeated sowings of germinal and non-germinal dirt ... and this in good dairies. What must it be where the cows are never groomed and the udders are never washed, where the byres are never even approximately cleaned, where ventilators are never opened, where the pigs are a few feet away, where cobwebs are ancient and heavy, where hands are only by accident washed, where heads are only occasionally cleaned, where spittings are not infrequent, where the milker may be a chance comer from some filthy place, where, in a word, the various dirts of the civilized human are at every hand reënforced by the inevitable dirts of the domesticated cow?" 19

The British Medical Journal employed a commissioner to investigate the conditions under which the milk supply of a number of the large British cities is produced, and the following is quoted from the report of one dairy:-

"The operation of milking was in full swing, three dirty-looking boys being hidden away behind their respective cows. ... I looked about for pails of water, soap, towels, or anything which might give the lie to the filthy state of the cows' udders and the milkers' hands, but in vain. The clothes which the boys wore were equally dirty, and the stalls . . . were several inches deep in manure and foul-smelling straw. ... The hind quarters of the cows were 
coated with filth. ... I was horrified to see the filthy state of the milk as it flowed out of his pail. It was discolored with grit, hairs, and manure. 'Look at that,' I said, pointing to a specially large bit of manure. I regretted my zeal, for Tom dipped his whole hand into the pail, and, as he brought it out said, 'Oh, that ain't nothing; it's only off the cow'!"20

The English Local Government Board issued, in 1904, a report on the sanitary conditions of cow sheds and dairies in Ireland, which enumerated very similar evils to those described above. ${ }^{21}$ It may be taken for granted that the great majority of milk producers, dealers, and retailers know so little as to amount to practically nothing at all of the nature of milk and the extremely grave perils which result from its careless and improper handling. And yet, as Dr. F. Lawson Dodd has pointed out, ${ }^{22}$ such knowledge is essential to the public safety. In some of the states the plumber has to pass an examination and obtain a certificate before he is allowed to pursue his calling, it being realized that ignorance on the part of a plumber may endanger many lives. Doubtless this is a wise provision, a safeguard few persons of intelligence would desire to remove; but what of the dangers to which we are exposed when the dairyman and the milk vendor are ignorant? That these are far greater and more numerous is certain, but I know of no state which requires that a milk 
producer or a milk vendor must be similarly qualified.

I know that I have visited hundreds of farms where just such unsanitary conditions and carelessness in the handling of milk as described above were observed, and if further testimony upon the point should be necessary, I need only refer the reader to the various reports upon the milk supply of American cities issued by the Department of Agriculture, which, despite official reticence and conservatism, tell the same story of inadequate equipment and gross ignorance and inefficiency. I shall not forget one instance which came under my observation, because the circumstances were such as to illustrate in a very vivid manner the extent of popular ignorance of hygiene in relation to the production of milk. Visiting a friend who had acquired a country place within seventy-five miles of New York City, I found him exulting in the fact that now, owning his own cows, he was sure of a supply of pure milk for his baby. He was so proud of his new stable and the three cows he had purchased that I was somewhat anxious to inspect them. I discovered that the tuberculin test had not been applied to the cows to ascertain whether they were free from tuberculosis. Later, at my suggestion, this was done and two of the three cows were found to be affected. The new stable of which my friend was so proud was 
about as unfit a place for cows to be kept in as human perversity could have devised. It was low, illventilated, and poorly lighted; the food storage was at one end, quite exposed to all the odors of the place; there was no drainage except a very shallow wooden gutter, and the floor being of wood such a thing as flushing was next to impossible. That the floor must be absorbent and soon saturated with filth that could not be cleansed was altogether too plainly evident. I watched the milking of the cows by a very dirty laborer who had only a few minutes before been wheeling a barrow, and observed that neither did he wash his own hands nor the cows' udders. Yet my friend had moved into the country, built a stable, and bought cows at considerable expense, just to be certain that his baby would be getting pure milk and spared the perils which city babies are exposed to, and was all the time getting milk that was infected as well as dirty.

Later, when we discussed the matter, and the owner of the cows realized for the first time how many shortcomings there were in his stable, and how many more in the hired man who had charge of the cows, he undertook to have the changes made in the stable which were necessary to make it as hygienic as those belonging to some of the best model dairies. But on the labor side he hardly dared hope for improvement: "I can get the stable made over," 
he said, "but I cannot get Joe made over." Joe was the hired man, reputed to be the best milker and stableman for many miles around, and other farmers in the neighborhood would be very glad to get him if they could, at quite high wages. As for getting a laborer who could milk cows and who would take all the precautions necessary to insure the purity of the milk, understanding why the precautions were taken, such good fortune could not be hoped for. Why, it would take a college graduate to be a milkman! And truly, the difficulty of getting efficient and intelligent labor at any price which the farmer can ever hope to pay is an important aspect of the problem.

But let us return to the milk which we saw our friend Bill draw from Farmer Jackson's cows. Two miles from the farm is the little Erie railway station, upon the platform of which the cans of milk stand, without anything to keep them cool, waiting for the milk train. Then, when the "milk special" comes along, they are loaded into close, stuffy refrigerators, very inadequately supplied with ice, and taken to the city. And during all this time the bacteria multiply as only bacteria can.

For, as we have already observed, there is no fear of race suicide among the bacteria that grow in milk. 


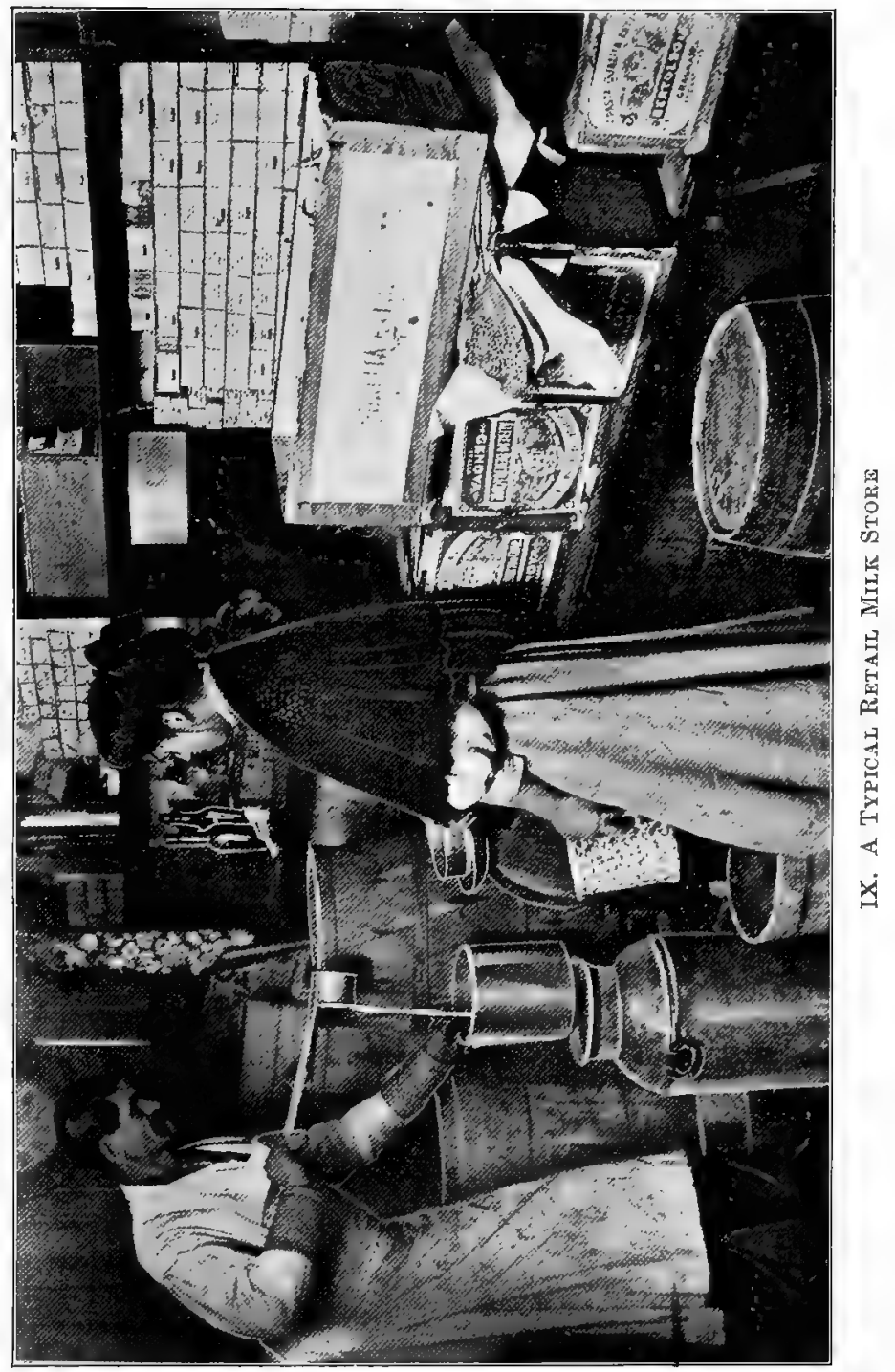



They multiply in a manner which makes the Malthusian formula of geometrical increase look ridiculously like failure to maintain the population. We are all more or less familiar with those interesting speculations which at one time played such an important part in the discussion of the so-called Malthusian law of population, concerning the number of descendants of a pair of pigeons or a pair of guinea pigs which would exist in the course of a given number of years if nothing interfered to check the increase; but I venture to say that the progeny of the most prolific animals ever used as terrifying Malthusian arguments would not, in fifty years, equal the number of bacteria produced in milk by a single bacterium in as many hours. If there was nothing to interfere, a single bacterium would produce, in twenty-four hours, seventeen million others ! ${ }^{23}$ While this prolific rate of increase is probably never actually maintained, the normal increase of bacterial population in milk having a high temperature is so astounding that it defies the mathematical intelligence of an ordinary mind. A cubic centimeter, or about fifteen drops, as much as a quarter of a teaspoonful, will often contain many millions of bacteria.

It will be understood from this that when the milk in which we are interested at this moment reaches New York its bacterial content is very high. If we could take a sample as soon as it reaches the city, 
we should probably find that it contained at least five million bacteria for each cubic centimeter, or quarter-teaspoonful! When the milk was drawn from the cow it was contaminated in the process, and further contamination has occurred at every step since. What was, in the cow's udder, a sterile and pure liquid, through human carelessness and ignorance is now a polluted, dangerous mixture. But the milk is not yet at the end of its journey. Before it reaches the child who is to be nourished by it, there are other fertile sources of contamination. In the little grocery store in the tenement district, and then later, in the foul-smelling mockery of a refrigerator in the baby's home, millions of new germs will be added to the milk by addition from without and by natural increase; by unrestricted immigration and by the normal excess of births over deaths, so to speak.

In Mrs. Goldstein's little grocery store, on Allen Street, you can buy almost anything, from a pail of coal to five cents' worth of cooked meat; from a package of pins to a pair of shoes for the baby. The long, dark, stuffy little store is, in its way, as many-sided as the big department store on Broadway. Naturally, Mrs. Goldstein sells milk, for only the aristocratic and "stuck up" folks can afford to buy bottle milk and have it left at the door. Poor folks must buy their milk at the store. It costs two cents a quart less, and you don't have to buy a quart if 
a pint will do. And Mrs. Goldstein is so obliging that, if you only have two cents to spare, you can buy two cents' worth. The milk is kept in a big can in the corner of the store, near to where the coal-box and the barrel of pickles are. Sometimes the cover is left lying for hours on the little shelf above, when Mrs. Goldstein is so busy that she forgets to put it right back. The dipper is usually hanging alongside of the can, but occasionally one of the Goldstein children takes it away so that Mrs. Goldstein has to go all over the place to look for it before you can get your milk. Of course, millions upon millions of bacteria can get into milk in a store like this not to mention some bigger things! - but then, Mrs. Goldstein does not know. She never heard about bacteria in milk or anywhere else. When the milk is placed in Mrs. Jones's pitcher and handed to her by Mrs. Goldstein, neither woman knows that there are more than a hundred and thirty-three millions of germs to every fifteen drops,* many times more than would be found in an equal quantity of sewage water. Yet such is the case.

Now, Mrs. Jones takes the milk out into the street, where the air is full of germs, in an open pitcher, thus making it possible for more bacteria to enter it. Through the long hallway, up three flights of stairs,

* An actual occurrence. See p. 116. 
she takes it, more bacteria entering at every step. Then, being a careful woman, she places it in the ice-box alongside the tiny bit of ice, which does not suffice to cool the temperature in the box perceptibly below that of the kitchen itself. Poor Mrs. Jones! she has not got a thermometer, and she would not know its use if she had one. It would not help her very much, therefore, if you told her that the temperature in her ice-box is very comfortable for most of the bacteria, being about seventy-five degrees Fahrenheit.* After a little while the baby cries, and you are horrified to see the filthy mixture given to the little one in a bottle. Now you can understand why Mrs. Jones lost her other two babies and why this one looks ill. You can understand, too, her fatalistic resignation to the fact that "Some folks allus loses their babies in summer, 'cause they'm built that way."

VI

All this is, of course, very terrible and exceedingly painful. But it is by no means the worst that is

* There was an outbreak of diarrhœeal disease in one of the New York hospitals, which caused the authorities much worry. The most careful investigation of the milk supply failed to show anything wrong, and it was not until, in desperation and as a last attempt to explain the epidemic, one of the physicians placed a thermometer in the refrigerator that the cause was discovered. Although apparently plentifully supplied with ice, the "refrigerator" had a temperature of over seventy degrees! 
to be said of the milk which goes into thousands, aye millions, of American homes to be used as a food for infants, that it is reeking with filth, some of it of an unmentionable character. Much more terrible is the fact that much of it is charged with the germs of the worst diseases that scourge mankind. To go back to our study of the conditions on Farmer Jackson's farm for a moment, it was impossible to tell from their appearance whether the cows were all healthy or not. What if some of them had tuberculous udders and milk ducts, so that the milk inevitably contained the tubercle bacilli in large numbers? Or what if the cows had been wading through water polluted by typhoid germs, or if there were typhoid germs in the water Bill used to rinse the milk pails, and some of these remained in the pails to infect the milk and to multiply therein? These things happen sometimes, you know. And what if Bill's clothing or his person should have infected the milk with the germs of diphtheria, or scarlet fever, brought by accident from the bedside where his little daughter tossed and moaned all the night - before? You cannot blame Bill for nursing his little girl, nor yet for being ignorant of the fact that he might carry the germs of the disease in his clothing, to drop later into the milk pail and from thence to spread the disease like a plague in some far-off city. This is a very black picture; well calculated to 
frighten any but the most callous. And because it is my purpose not to create sensational effect, not to draw lurid pictures, but to make a calm appeal for constructive, remedial work, I would gladly omit it if I could. But it belongs to the description of conditions as they are, and I have no right to suppress it. If the transmission of diseases like tuberculosis, typhoid, scarlet fever, diphtheria, and others by such means as I have indicated were rare, so that the risk could be regarded as practically non-existent; if the cases of infection by such means were so few that they could be ignored,-I would most gladly have omitted this painful catalogue of terrors. But, as we shall presently see, such is not by any means the case. It will be necessary for us to give careful attention to a body of well-authenticated evidence which proves that the dangers of milk-borne diseases are very real and too numerous to be lightly passed over.

But before we proceed to the consideration of the part which milk plays in the dissemination of disease, at the risk of some repetition, I desire to warn the reader against being frightened into a state of unnecessary panic by the enormous bacterial content of milk indicated by some of the figures used in this discussion. To most lay readers the word "bacteria" immediately suggests disease, and to permit that impression to remain would give a wholly false 
value to the statistics cited. It is not necessary to exaggerate the dangers of impure and infected milk.

It must be very evident that only a small proportion of the bacteria in milk can be regarded as actually dangerous, otherwise there would be enough death in a quart of milk to depopulate the nation. When it is said that some of the milk sold in our cities and used for infants' food contains more bacteria than the worst sewage water, serious as such a statement is, it must not be interpreted to mean that sewage water would be better or less dangerous to an infant, that there is more harm in the milk than in the sewage water. ${ }^{24}$ Such an interpretation of the statement is wholly false and misleading. It is not true that sewage would be less injurious than the milk that contains such astounding numbers of bacteria, for there are important differences in the kinds of bacteria which have to be taken into account. But the figures do warrant the statement that the milk contains a large percentage of matter which ought to have gone into the sewers instead of into the milk pail. Such milk is as dirty as sewage water, but not necessarily as dangerous.

Now, while it is true that there are many useful bacteria upon which we depend for making cheese and butter, it is a matter of very grave doubt whether these bacteria are useful in milk when it is used as milk for food. It is fairly certain, moreover, that 
bacteria which are in themselves quite harmless to man, according to all observations yet made, do, when they are present in milk in very large numbers, produce toxic changes which to some extent adversely affect the intestines of young children and cause diarrhoal diseases. ${ }^{25}$ Recognition of this fact has led to various attempts to draw the danger line in bacterial content, to fix upon a maximum number per cubic centimeter of which it can be said: "Beyond this number there is danger and death. Milk with a larger number of bacteria than this standard sets must not be given to an infant." If it is true that serious gastro-intestinal troubles are caused by an excessive percentage of bacteria, even of the kinds which, in small numbers, are harmless, what standard ought to be adopted?

Upon this point, Professor von Behring has proclaimed that milk which contains more than one thousand bacteria per cubic centimeter is never fit for infant consumption and should on no account be given to a baby. ${ }^{26}$ Most authorities agree, however, that, while Professor von Behring's test represents a standard of purity that is very attractive as an ideal, it is not likely to be attained on a large scale for many years to come-some pessimistically say that it will never be realized. It is perfectly true that milk with an even smaller bacterial content has been obtained in many places, in Rochester, 


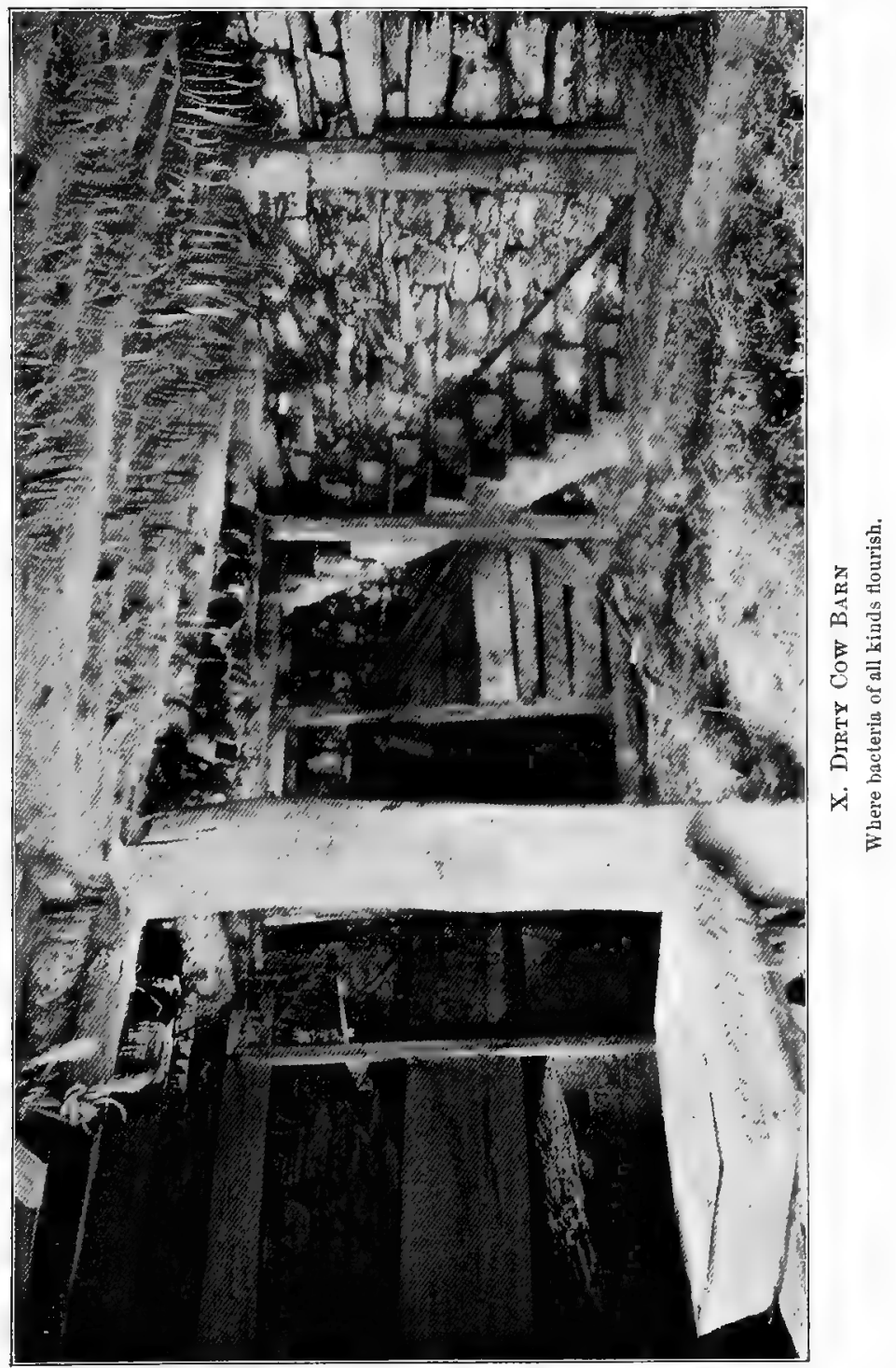



N.Y., among others. ${ }^{27}$ The milk, already referred to, which was exhibited at the Paris Exposition, easily came within the limit set by von Behring. It is certainly possible to attain to the standard set by the great physician occasionally and experimentally, and personally I am strongly of the opinion that with a proper organization of the milk industry upon scientific lines it could be done as a general thing. It is one thing, however, to get these results experimentally, under special conditions, and quite another thing to get them as a matter of common, normal practice. And, in the present state of the milk industry, with milk production largely in the hands of men ignorant of the most elementary principles of hygienic science, it is not possible to maintain anything like that standard.

In connection with the Certified Milk Movement, of which Dr. Chapin and Dr. Coit may be regarded as the principal exponents, it has been agreed to adopt, for the present, standards varying from ten thousand to thirty thousand bacteria per cubic centimeter, and while that is very far above the limit set by Professor von Behring, it is generally acknowledged that either of the two standards named would revolutionize the milk supply of the world if it could be lived up to. Compare these standards with those that have been adopted by the few American cities in which there has been intelligence enough to bring about 
the adoption of bacteriological standards as well as standards regulating the percentages of fat, and then compare them with actual conditions in the world's greatest cities. Such a comparison cannot fail to be of interest and value.

Boston is exceedingly proud of the fact that it was a pioneer in this important reform. It has a bacteriological standard and reproaches New York for not having followed its example. That it is to the shame of New York that it has no bacteriological test, that it has not advanced beyond the stage where it is illegal to water milk of to adulterate it with chemicals, but not illegal to pollute it with dirt or to infect it with disease germs, so that to sell milk with too little fat is a crime, while it is not a crime to sell pus and dirt, I cordially agree. But I am not at all sure that Boston's standard of "purity" is not more shameful still. For Boston is in the position of having, in the name of cleanliness, indorsed a standard which represents filth and danger. Boston is satisfied with milk that contains not more than 500,000 bacteria per cubic centimeter! In other words, Boston accepts as sufficiently clean and pure milk containing five hundred times the amount of germ life which von Behring believes to be the limit of safety for infants' food, and more than fifteen times that accepted by the leaders of the Certified Milk Movement as a compromise, a step toward better conditions! 
Cambridge and Brockton, both Massachusetts cities, have adopted Boston's standard of 500,000 bacteria per cubic centimeter. But Milwaukee does much better, with a standard of one-half that of Boston, 250,000 per cubic centimeter. Now, I know perfectly the arguments which will be adduced in defence of these standards; that it will be shown statistically and otherwise that good has resulted from them, that there has at least been some improvement. But, giving these claims the fullest possible consideration, and allowing them all due weight, I cannot resist the conclusion that the harm done by, the adoption of bacteriological standards which do not represent purity but filth, not safety but danger, is far greater than the good; that when a city adopts such absurdly high bacteriological standards immense harm is done by creating an impression in the minds of the citizens that the goal of purity has been reached, that the milk supply is safe and pure. For my part, I would prefer no standard at all rather than a deceptive one such as Boston and the other cities named have adopted. I speak from experience when I say that the average Bostonian is a much more difficult person to interest in the important subject of the purity of the milk supply than the New Yorker, simply because he has been lulled into a false sense of security by that "clean milk" standard of 500,000 germs per cubic centimeter. 
The British National Health Society, which has among its membership many of the leading physicians of Great Britain, at its meeting held at University College, London, in December, 1906, under the chairmanship of Sir Frederick Treves, had presented to it the report of some investigations made into the state of the milk supply in some of the chief cities of the world. The report showed that the best quality London milk, used by those who can afford the best that is obtainable in the general market, averaged $3,000,000$ bacteria per cubic centimeter; that in Munich, milk which was tested at the farm soon after milking and found to contain an average of 200,000 bacteria per cubic centimeter had, when it reached the retail stores, about 6,000,000; that in Amsterdam the tests showed 2,500,000 soon after milking and as many as 10,000,000 when tested, ten hours later, in the retail stores. In Warsaw, milk which at the farms showed only from 10,000 to 20,000 bacteria per cubic centimeter had 4,000,000 per cubic centimeter when purchased in the shops. In New York City, milk was purchased at one place, a grocery store on Allen Street, on thirteen successive days, and showed the awful average of 133,233,000-one hundred and thirty-three millions, two hundred and thirty-three thousand-bacteria per cubic centimeter! ${ }^{28}$ And all these filthy mixtures were fed to infants, notwithstanding the opinion of one of the foremost 
authorities in the world that 1000 bacteria per cubic centimeter marks the limit of safety in considering cow's milk as a food for infants !

\section{VII}

It is, of course, true that milk containing very few bacteria may be more dangerous than milk containing an extraordinarily large number. Among the millions it is quite possible that there will not be a single pathogenic germ. On the other hand, among the bacteria in the milk which contains very few there may be no harmless ones, practically all being active pathogenic germs. It is quite conceivable, however improbable it may be, that a sample of milk might contain only a single bacterium, and that prove to be one of the most virulent and deadly kind, such as a tubercle bacillus; while, on the other hand, not a single bacterium known to be harmful might be found in a sample of milk with a bacterial count running into the tens of millions. These are all extremely improbable happenings and certainly do not describe any conditions ever recorded in actual experience.

It is also true that many of the worst pathogenic germs may be taken into the digestive tract without infecting it in any way, just as we breathe millions of them sometimes in badly infected air and remain uninfected. Impaired digestion, lowered vitality, slight intestinal disturbances, predisposing weakness, 
these and many other factors greatly increase the risks of infection. It is, however, quite evident that no matter how much we may be disposed to discount the risk of infection, there is an element of danger which it is prudent and wise to avoid if possible. And it is still important that a minimum of bacteria be insisted upon, first, because large numbers of bacteria in milk always indicate filth and carelessness in handling, and, second, because it is reasonable to suppose that under such conditions the dangers of infection by disease germs will, as a rule, be greatly increased. For if a farmer or dairyman is so careless and ignorant as to let his milk become so contaminated, he is not likely to be very particular about the health of his cows or of those who attend them. ${ }^{29}$

The ancient Hebrews, though they knew nothing of our modern science of bacteriology, were thoroughly alive to the dangers of impure milk. The elaborate Rabbinical regulations concerning the manner of its keeping and use indicate that they had a wider knowledge of milk hygiene than most modern nations possess. Permission to drink milk was by the Rabbis regarded as an exception (hiddush) to the general rule which forbade the eating of anything which came from the living animal. This was, doubtless, due to a keen recognition of the dietetic value of milk. It was forbidden to use milk which came from an animal suffering from any visible malady, a wise 
regulation which anticipated by thousands of years the findings of modern science. The extreme importance attached to cleanliness may be judged from the strict regulation which forbade the Jew to drink milk bought from a non-Jew, unless the milking process had been carried on, or at least watched, by a Jew. Milk was one of the seven articles of food named as being especially liable to receive impurity by exposure and contamination; and it was one of the three beverages which, if left over night uncovered, should not be used, "because it is possible that a serpent may have left its venom therein." All these Rabbinical regulations concerning the use of milk ${ }^{30}$ are quite in harmony with the requirements of modern science, a fact which is in itself a wonderful tribute to Rabbinical wisdom and to the Jewish people. 


\section{CHAPTER V}

MILK-BORNE DISEASES

IT is a commonplace of pathological science that milk often plays an important part in the dissemination of many of the diseases which assail the human race. Not only are many of the diarrhœal diseases which are responsible for such an appalling number of infant deaths each year due, in many instances, to impurities in the milk which set up serious disturbances in the digestive tract, but there is also specific infection from beast to man as well as from man to man through the medium of the milk of the beast. Epidemics of scarlet fever, diphtheria, measles, and typhoid have been traced directly to the milk supply, and it is now very generally believed that tuberculosis is spread by the same means.

It is sixty-five years now since Robert M. Hartley, one of the founders of the New York Association for Improving the Condition " of the Poor, wrote The Cow and the Dairy, dealing with the relation of impure and infected milk to the excessive infantile death-rate, a book which became famous as the text-book of 
that-long campaign against "swill milk" which culminated in the enactment of laws against adulteration by the state legislature, in 1864." That was our first great public agitation for pure milk. Hartley found that the babies of the tenements died at an astonishing rate, and his soul rebelled against what he termed the "frightful waste of human material." He traced the connection between the death-rate of infants and the conditions in which cows were kept throughout the state. He found that the cows were housed in unsanitary stables and fed upon distillery refuse. He wondered what sort of milk could be obtained from cows so housed and fed. He found in one place "in low flat pens over 500 milch cows closely huddled together, inhumanly condemned to subsist on slops smoking hot from the stills," and wondered what sort of milk could be produced from "this unnatural, disgusting food." He found that the distillers "would not risk the lives of their own families by using the produce of their own dairies," but that twenty-five thousand babies in the tenements were fed upon it, nevertheless. ${ }^{2}$

Hartley at once began an investigation. The deathrate of babies was high, frightfully so. It had kept on increasing for a number of years, though foreign cities reported a decrease in the infantile death-rate. Was it a mere coincidence that the period of increasing infantile mortality was coincident with the increase 
of the practice of feeding milch cows upon distillery refuse? Hartley, with true scientific spirit, had the milk of the cows fed on distillery grains analyzed and found that it was lacking in food value, and then, for twenty-three long years, he waged war upon the "swill milk," succeeding finally, in 1864. The fight so well begun by Hartley was not maintained, with the result that to-day, more than forty years after Hartley's great victory, we are still grappling with the same problem. And our great need is for Hartleys, - for men with his courage, his intelligence, his patience, and his enthusiasm.

\section{II}

Of all the diseases which afflict humanity, tuberculosis, suggestively named "The Great White Plague," is the most fatal. It has been conservatively estimated that each year there are 1,095,000 deaths from this disease throughout the world, representing 3000 each day, two for every minute. ${ }^{3}$ In the United States there are, according to Mr. Frederic L. Hoffman, actuary of the Prudential Life Insurance Company, 150,000 deaths annually, at an average age of thirty-five years. Each of these deaths represents a loss of thirty-two years, so that the loss of life measured in time units annually amounts to the startling total of 4,800,000 years. In terms of earning capacity the loss cannot be set down as less than 
$\$ 240,000,000$ annually, from this one disease in the United States alone." Tuberculosis kills as many people, young and old, each year as diphtheria, croup, whooping-cough, scarlatina, measles, and typhoid fever taken together. ${ }^{5}$ It is, therefore, a social problem of great magnitude.

During recent years, it is very gratifying to observe, this problem has been receiving an increasing amount of earnest attention. Whereas only a few years ago it was neglected, practically no social effort being made to combat its ravages, every civilized country has now its organized movement devoting itself to the study of the disease, the spread of information concerning it, and the instruction of people how to avoid it by adopting proper precautions, and how the afflicted may be cured, as well as to the support and increasing efficiency of curative institutions. Particular attention has been given, both in this country and in Europe, to the study of the means by which the tubercle bacilli are distributed; and some of the principal means, such as reckless spitting, have been brought within the provisions of the penal codes of the various nations.

It has long been known that tuberculosis can be acquired by ingestion as well as by inhalation and inoculation, but the part played by cow's milk in the spread of the disease has only recently begun to receive serious attention. That many persons, old 
and young, have been infected with tubercle bacilli through the milk of cows suffering from the disease is one of the best-attested facts in modern pathology, but the extent to which children are the victims of this peril is only now being recognized. Jacobi, a conservative authority, has long held that feeding children upon milk from tuberculous cows is undoubtedly one of the causes of infection to which close attention should be given. Professor von Behring " goes very much further, and says that "the milk fed to infants is the chief cause of infection." *

It may be that the conservatives are right in regarding this opinion of the famous Marburg teacher as extreme. It is not an unusual thing for a great teacher who finds the bow bent too much one way to bend it too much the other in his zeal to set it straight, - to adopt the phrase in which Malthus made his notable confession long ago. But, while it may be true that Professor von Behring makes this mistake when he declares that the milk fed to infants is the "chief" cause of tuberculosis, most of the world's leading pathologists agree that it is one of the sources of infection, and an important one; and that, as such, it ought to be given careful attention. The British Royal Commission appointed to inquire into "The

* Dr. E. F. Brush, one of our best authorities, regards all tuberculosis as being of bovine origin. See Human and Bovine Tuberculosis, by E. F. Brush, M.D., p. 12. 


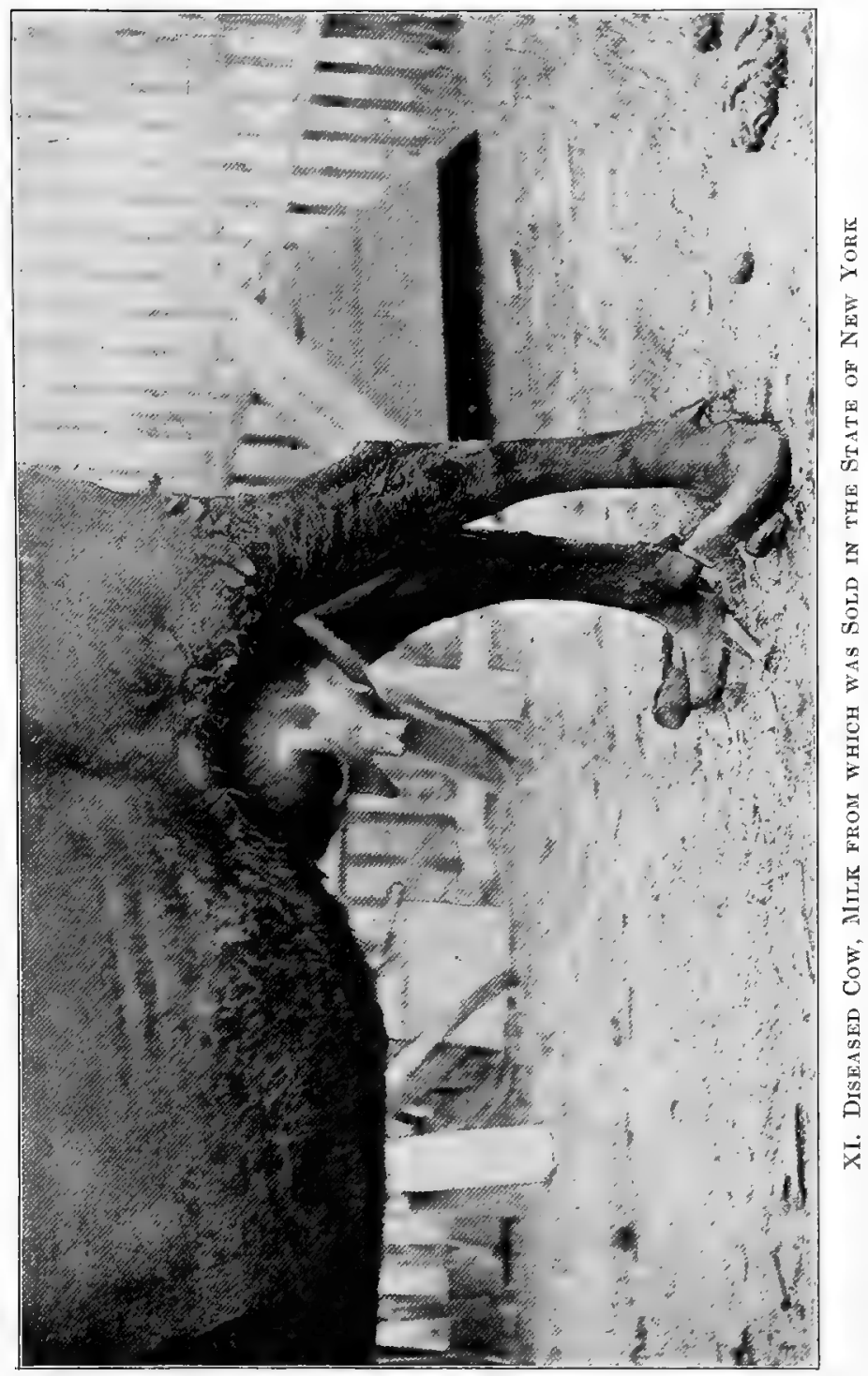



Effect of Food derived from Tuberculous Animals upon Human Health," consisting of the most eminent physicians and physiologists in England, together with one of the foremost veterinarians, after careful examination of many famous experts, and some of the most extensive and thorough experiments ever attempted, unanimously reported, in 1895 ; that they believed "that an appreciable part of the tuberculosis that affects man is obtained through his food," and that "No doubt the largest part of the tuberculosis which man obtains through his food is by means of milk containing tuberculous matter." 7 .

Another British Royal Commission, appointed to inquire into the subject of "Controlling the Danger to Man through the Use as Food of the Meat and Drink of Tuberculous Animals," reported, in 1898, its unanimous agreement with the findings of the former commission, quoted above. ${ }^{8}$ And the Royal Commission of 1901, appointed to inquire into the "Relations of Human and Animal Tuberculosis," demonstrated conclusively that bovine tuberculosis can be transmitted to human beings, that there is no essential difference in the tuberculosis which afflicts human beings and that which afflicts bovine and other animals. ${ }^{*}$

Dr. Jacobi, discussing the dangers of infection from milk drawn from tuberculous animals, ${ }^{10}$ quotes the case recorded by Dr. Olivier, of Paris, in which thir- 
teen schoolgirls, belonging to a Paris boarding school, were infected. Six of the girls died. It was found that in several cases the bowels were first attacked, and the outbreak was traced to the milk supply, which came from a cow with a badly affected udder. He quotes also a case recorded by Johne, a great veterinary anatomist, of the death from tuberculosis of a little girl two and a half years old. She had been fed upon the milk of a cow which her father, a farmer, had specially selected on account of the animal's splendid appearance. Later, it was found that the cow was tubercular, but not until it was too late, the child having died."11

III

Notwithstanding the mass of such testimony as the foregoing, which might be almost indefinitely extended were it necessary, there are still many persons whose opinions command respectful attention who do not believe that there is any danger of tubercular infection through meat or milk which comes from tuberculous animals. Their theory is that the disease as it is found in cattle is very different from the disease as it occurs in human beings, and that it is impossible for the tubercle bacilli which infects a cow to likewise infect a human being, and vice versa. This view has been strenuously championed by no less an authority than the great Koch himself, to whom the world is 
lastingly indebted for the discovery of the bacillus tuberculosis. To the splendid fame of Koch the theory doubtless owes much of the vogue it has enjoyed for a brief period, until completely discredited by numerous conclusive researches and experiments.

Prior to 1896 the transmissibility of the disease from man to the lower animals and from the lower animals to man was generally accepted as a fact. The Wise Preacher of the Bible had observed many centuries ago that, in their pain at least, man and beast are closely related: "For that which befalleth sons of men befalleth beasts; even one thing befalleth them: As the one dieth so dieth the other; yea, they have all one breath, so that a man hath no preëminence above a beast." * Villemin, the French physician who, in 1865 , inoculated various animals with tuberculous matter from human beings, was led by his experiments to echo, in the name of science, what the Preacher had proclaimed many generations before and to say: "Man shares with cattle the sad privilege of perpetuating tuberculosis." 12

In 1896 Dr. Theobald Smith, of the Bureau of Animal Industry at Washington, called attention to the fact that the human and bovine varieties of the tubercle bacillus have certain very marked characteristics by which they are easily differentiated. ${ }^{13}$ The discovery attracted a good deal of attention at the * Ecclesiastes. 
time and led many investigators, in Europe and this country, to make experiments and investigations along the lines indicated by Dr. Smith's work. Few are the workers in this field of research who have not given special attention to the differences which characterize the two varieties of tuberculosis, and the result of their combined efforts may be briefly summed up as follows: There are certain physical differences to be noted, the human bacillus being long and slender and the bovine bacillus thicker and shorter. The bovine bacillus also stains more evenly in the laboratory. The principal difference, however, is not physical but pathological. While there are some animals which seem to be equally susceptible to the attacks of both kinds, - notably guinea-pigs and swine, other animals are almost invariably more susceptible to the bovine variety than to the human. This is especially true of monkeys. There seems to be no case in which an animal has been found more susceptible to the human tubercle bacillus than to the bovine, and it is concluded, therefore, that the bovine bacillus is much more virulent than the human. This is the opinion of our foremost American investigators, as well as of the British Royal Commission appointed to investigate the subject, under the leadership of Sir Michael Foster, professor of physiology in Cambridge University. ${ }^{14}$

The discovery made by Dr. Theobald Smith had 
an important and far-reaching influence in many directions, but in nothing quite so noteworthy as the effect produced upon Professor Koch. Following Smith, Koch developed the comparative study of the different types of tubercle bacilli, and in 1901, at the British Congress on Tuberculosis, he made an announcement which created a great sensation in medical circles. With sweeping and startling emphasis, he declared the tuberculosis of man and the tuberculosis of animals to be different diseases; that it is impossible to transmit human tuberculosis to cattle, and, that, consequently, man need not fear infection from cattle, either by inhalation or ingestion through eating tubercular meat or drinking tubercular milk. ${ }^{15}$ It was in consequence of the sensation produced by this memorable utterance that the Royal Commission on the subject was appointed soon after the Congress closed.

IV

The sensation which the sweeping, optimistic declaration of Professor Koch created will be understood best by those who are familiar with certain earlier experiments in the inoculation of animals of different species, made by the same great teacher and pointing to a radically different conclusion. Chaveau, in 1868, had taken cattle from the Jura Mountains, where tuberculosis among cattle seems 
to have been unknown, and inoculated them with tuberculous material from man, successfully transmitting the disease. ${ }^{16}$ Bollinger followed, in 1879, with similar experiments, ${ }^{17}$ and since that time there have been many workers along the same lines. In short, there is probably no fact in the whole range of experimental pathology better attested than the transmissibility of human tuberculosis to cattle. Since the publication of Koch's startling theory there have been numerous instances of this transmission by inoculation, as well as by ingestion. Cows and many other animals have been fed upon food containing human tuberculous matter and thereby infected with the disease. Dr. Mazyack P. Ravenel, the well-known bacteriologist of the Pennsylvania Live Stock Sanitary Board, ${ }^{18}$ Dr. German Sims Woodhead and Professor Macfadyean in England, ${ }^{18}$ and the Commission of the Imperial Sanitary Office of Germany ${ }^{20}$ have all done what Koch declared to be impossible; and there are many others whose names might be given were it necessary to pile up testimony of this kind.

Not only have these men succeeded in infecting cattle with human tuberculosis by laboratory methods, but the same thing has been done accidentally many times. My friend, Dr. S. A. Knopf, whose work in combating tuberculosis has placed him in the very front rank of living authorities upon the sub- 


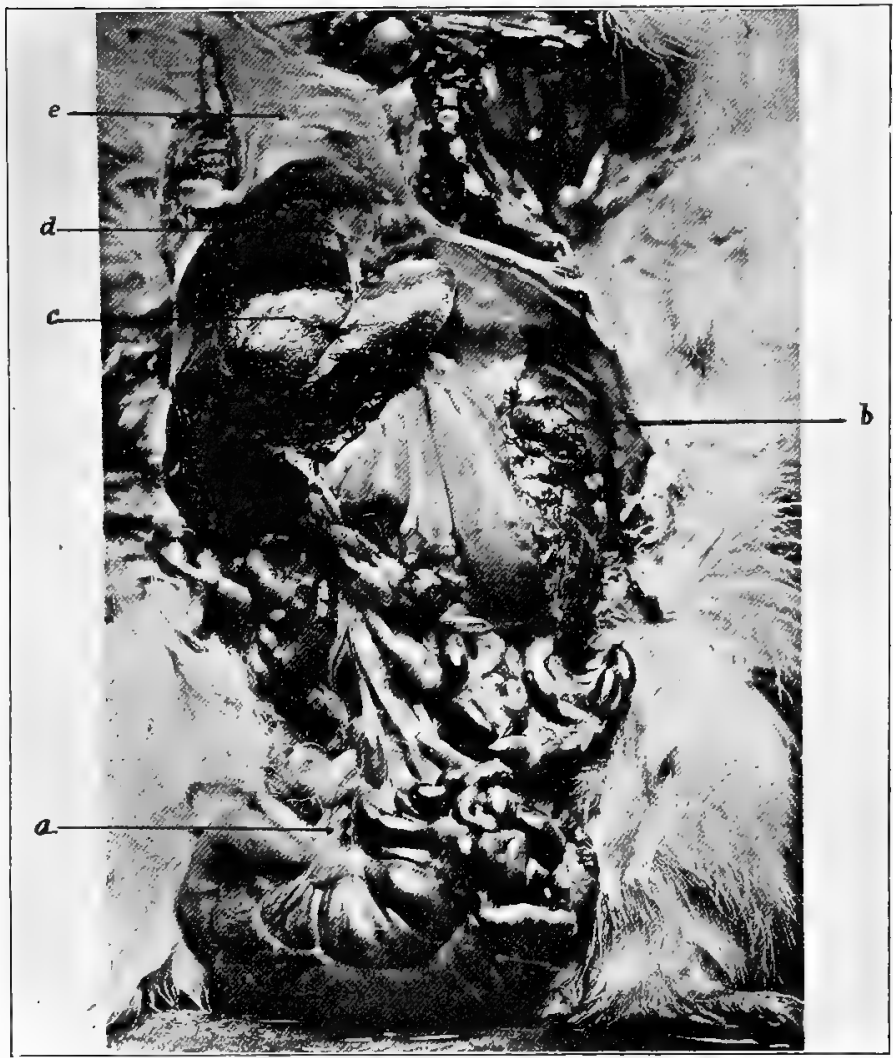

XII. Elfect of Raw Tuberculous Mick upon a Guinea Pig

This interesting photograph illustrates one of the experiments conducted by Dr. Woodbead for the Royal Commission on the Effects of Food derived from Tuberculous A nimals. Milk was taken from a cow with diseased udder, supplied for the purpose by Professor Bang, and used to inoculate a perfectly healthy guinea pig. An intraperitoneal injection of 1 c.c. of the railk in its raw state caused the death of the guinea pig in 58 days. Some of the mesenteric and mesocolic glands $(\alpha)$, spleen $(b)$, liver $(c)$, and under surface of the diaphragm $(d)$, showed well-marked tubercle. The glands bebind the manubrium sterni and along the left side of the sternum (e) were also tubercular. Microscopic examination revealed tubercle bacilli. - Rep. of Cow., Part III, pp. 195, 225, 282. 

ject, tells of a charitable institution for consumptives where the rules as to expectoration were not strict, except as applied to the house itself. When the patients went across the meadows for their daily walks they were at liberty to expectorate anywhere they chose. Now the farmer to whom the meadows belonged had bought five healthy cows which had been tested with tuberculin. After a little while it occurred to him to have them retested, when, to his loss, he found that all five were infected. He had the animals slaughtered, the stable cleaned and disinfected, and forbade the patients of the sanatorium to walk upon his property, with the result that the disease did not reappear. ${ }^{21}$ A very similar experience is related by Dr. Thomas Darlington, Health Commissioner of New York City, who was connected, as visiting physician, with a hospital where the consumptive patients were permitted to play quoits in a pasture near the hospital. They did not use sputum cups at the time, and the result was the infection of nine out of a herd of ten cows. ${ }^{22}$ In the same way, fowls have been infected through eating food offals from consumptive patients, and their flesh has, in turn, infected healthy persons with the disease..$^{23}$

According to all known laws, if it is possible for cattle and other animals to acquire the disease from man, it must be possible for man to acquire the 
disease from animals. But, obviously, it is not practicable to try experiments upon human beings in the same way as upon dumb animals. There are, however, many cases on record where human beings have been accidentally inoculated with bovine tuberculosis, with fatal result. Ravenel testifies ${ }^{24}$ to having personally observed four such cases, two of them occurring among assistants in his laboratory. He also quotes a case recorded by Troje, which, it appears, was reported to Koch, who agreed that there was no flaw in the evidence. It relates that a young butcher, of good health, with no hereditary taint so far as could be ascertained, wounded his forearm while working on a tuberculous cow's carcass and contracted tuberculosis in consequence. ${ }^{25}$ That human beings can acquire tuberculosis by inoculation from bovine sources seems to be a completely established fact.

Finally, let us consider the possibilities of infection by ingestion, by eating meat or drinking milk from tuberculous animals. We know very positively that healthy cows fed upon food which contains tuberculous matter of human origin become infected with the disease ${ }^{26}$ and it is reasonable to suppose, in the absence of conclusive proof to the contrary, that human beings can be similarly infected by the ingestion of bovine tuberculous matter. Such would be the only warrantable inference, even if we had not 
positive cases on record. But here, again, the positive evidence is not lacking. The case of Gosse, the famous physician of Geneva, is well known. His little daughter was infected by drinking the milk of a cow upon his own farm and died. With rare courage, the physician himself conducted a post-mortem examination and conclusively demonstrated that the cause of infection was the milk upon which she had been fed, and which proved to have come from a cow with tuberculosis of the udder. ${ }^{27}$ Dr. George M. Kober tabulates 86 cases of tuberculosis, showing the transmission of bovine tuberculosis to human beings through milk. ${ }^{28}$ Added to these specific cases and those cited elsewhere in the present chapter, is the fact that the bovine tubercle bacillus has been found in an active state in the intestines of young infants, so that the chain of evidence may be regarded as complete in every particular.

These facts, and others of a like nature, are well known to physicians. But to laymen they are, naturally, not so well known; and since I am appealing to the lay, rather than the medical, public, I could not avoid this long and, I fear, somewhat tedious discussion. It remains only to be added, by way of emphasis upon the important inference these facts inevitably suggest, that the conclusive evidence of the frequent presence of tubercle bacilli 
in cow's milk, and the fact that they are sometimes found in the digestive tract of young infants, point to a direct connection between the use of cow's milk as food and the spread of consumption.

\section{$\mathbf{v}$}

The seriousness of this danger is apparent, once the foregoing conclusions are reached. Few persons, I suppose, outside of a very limited circle of specialists, have any idea of the prevalence of tuberculosis among cattle. Some of the statistics upon this point are terrible in their significance and menace. It is not necessary for us to make any elaborate survey of these statistics; a few figures, taken almost at random, will probably be quite sufficient for our present purpose. In the state of New Jersey, during the last ten years, particular attention has been given to this subject, though it is admitted upon all hands, even by the farmers themselves, that the inspection is by no means perfect as yet. The tuberculin test is used, except where the condition of the animal is such as to make that test unnecessary, and from statistics issued by the New Jersey Tuberculosis Commission it appears that something like 16 per cent of the cattle examined have been found to be suffering from tuberculosis. The following table tells its own story, and needs no comment:- 
TABLE V

\begin{tabular}{|c|c|c|c|}
\hline Yrar & $\mid \begin{array}{c}\text { NUMBER OF OATTLE } \\
\text { EXAMINED }\end{array}$ & $\begin{array}{l}\text { NOMBER CON- } \\
\text { DEMNED }\end{array}$ & $\begin{array}{c}\text { ANOUNT PAID AS COMPBMTE- } \\
\text { TION }\end{array}$ \\
\hline 1895 & 750 & 140 & $\$ 4,227.46$ \\
\hline 1896 & 1,219 & 159 & $4,149.74$ \\
\hline 1897 & 865 & 134 & $3,299.99$ \\
\hline 1898 & 1,433 & 345 & 5.093 .20 \\
\hline 1899 & 1,415 & 232 & $5,363.25$ \\
\hline 1900 & 2,333 & 339 & $7,385.87$ \\
\hline 1901 & 2,512 & 342 & $7,260.75$ \\
\hline 1902 & 2,500 & 370 & $8,123.62$ \\
\hline 1903 & 2,450 & 473 & $11,435.35$ \\
\hline 1904 & 2,099 & 394 & $8,663.25$ \\
\hline 1905 & 2,733 & 467 & $10,518.00$ \\
\hline Total & 20,309 & 3,295 & $\$ 75,525.48$ \\
\hline
\end{tabular}

Statistics relating to the prevalence of tuberculosis in cattle vary considerably, according to the system of inspection adopted in various countries and states and the degree of thoroughness with which the work is done, as well as to climatic conditions and other causes. The tuberculin test is by no means always efficiently employed. Professor Doane ${ }^{20}$ found in Southern cities that the test was obviously very poorly applied. $\mathrm{He}$ found that in Norfolk, Va., for instance, less than one per cent of the number of cows examined were reported to be infected, an incredibly low percentage under any circumstances, and all the more incredible when it is remembered that most of the Norfolk cows had been imported 
from Maryland, where the tuberculin test uniformly reveals a high percentage of infected cattle. It is not suggested, therefore, that the figures here given have any value as showing the comparative distribution of the disease, but merely as establishing the fact that a very considerable proportion of cattle are tuberculous. Pearson and Ravenel estimated that, in 1900,3 per cent of all the cattle in Pennsylvania were tuberculous. ${ }^{30}$ They added that "The disease causes more losses than all the other infectious diseases of farm animals that exist in Pennsylvania at this time." ${ }^{31}$ There is good reason for believing that the disease is much more prevalent than would be indicated by the estimate of these two careful observers.*

In Saxony, no less than 30 per cent of all cattle are believed to be infected by this disease. ${ }^{32}$ In Copenhagen, Professor Bang has shown the disease to be very prevalent, making it a matter of vast importance in a country so largely dependent upon dairy farming. Some years ago the percentage of tuberculous animals in Denmark was estimated at

* Professor Bang pointed out that in large herds of fifty head of cattle and above as many as 60 per cent were tuberculous. He goes so far as to say that, in dealing with large herds in which tuberculosis has existed for many years, it is a waste of time to test with tuberculin the full-grown animals, as they are practically all affected. Quoted in The Suppression of Tuberculosis, by Professor E. von Behring, p. 5 . 
about 17 per cent, ${ }^{33}$ or little more than the New Jersey figures.* That percentage has been very materially lowered, however, as a result of the strenuous efforts made by the Danish government to stamp out the disease. In Leipzig, Germany, out of 22,918 cattle over one year old slaughtered in 1895, the enormous number of 7,619 , or more than 33 per cent, were found to be tuberculous. ${ }^{34}$

These figures are by no means exhaustive, but they sufficiently indicate the prevalence of bovine tuberculosis to be so great as to warrant the serious attention which we have given to the subject. The prevalence of the disease among dairy cattle is no doubt due mainly to the conditions under which the animals are housed during a great part of the year. Tuberculosis is essentially a house disease, and the housing of cattle has been of the most unsanitary kind, extremely favorable to the propagation of the disease. Man, then, has brought tuberculosis to the cow by his careless and ignorant management; and if the cow, in turn, spreads the disease among human beings, it is nothing more nor less than a

* During the year 1906-1907 the New York State Agricultural Department tested 2753 cattle with the tuberculin test, with the result that 23.81 per cent responded to the test and were killed. According to Dr. Verenus A. Moore, of the New York State Veterinary College at Cornell University, no less than 72 per cent of all the herds in the State are infected and 30 per cent of the milch cows. See New York Times, Dec. 19, 1907. 
terrible retribution. It is a well-known fact that the disease is comparatively rare among cattle kept in the open air, as, for example, in Jersey and Finland. ${ }^{35}$ The cattle in both these places are almost wholly exempt from the disease. That this exemption is not due to any inbred immunity is seen from the fact that they are just as susceptible as any others when brought within the area of infection, and placed under the conditions which prevail where the disease is common. ${ }^{36}$ As Oliver Wendell Holmes says:-

"God lent his creatures light and air, And waters open to the skies; Man locks him in a stifling lair And wonders why his brother dies."

It is probable, also, that a certain number of cases are due to the infection of calves by ingestion, through being fed upon tuberculous milk. At least, the Royal Commission of 1895 came to that conclusion and recommended that all milk should be boiled before being given to calves. ${ }^{37}$ Finally, it has been suggested by a writer in the New York Times, ${ }^{38}$ that one important factor in the production of tuberculosis among dairy cattle is the breeding of young and immature animals. It is common to permit early breeding, the average age at first breeding being from two to two and a half years, whereas it ought not to be permitted before the cow is fully 
three years old. Several breeders, dairymen, and veterinarians to whom I have submitted this point have unanimously concurred in the opinion that early breeding does, in some degree, contribute to the spread of tuberculosis among dairy cattle.

VI

It is not believed that there is any very great danger of infection through drinking the milk of cows afflicted with pulmonary tuberculosis. Prudence and common sense alike suggest the avoidance of milk coming from animals known to be afflicted with tuberculosis in any form, but the element of danger is not very great unless the udders and milk ducts are affected. ${ }^{39}$ In many instances experiments have been tried with a view of ascertaining whether the milk of cows suffering from pulmonary tuberculosis is dangerous, when fed to other healthy animals. So far as I am aware, none of these experiments have shown the danger to be very great, though isolated cases of infection have been reported by various observers, in which cows suffering from pulmonary tuberculosis only, and free from any disease of the udders, have given milk that has infected other healthy animals.

But the danger from the milk of cows affected with tuberculosis of the udder is very real and grave, as the experiments of Martin and numerous other 
investigators prove. Reporting to the Royal Commission on the Effect of Food derived from Tuberculous Animals on Human Health, Dr. Martin writes: "The milk of cows with tuberculosis of the udder possesses a virulence which can only be described as extraordinary;" 40 and Dr. Woodhead, confirming this opinion, shows that butter made from such milk is equally virulent and dangerous - a fact of vital significance when it is remembered that milk that is condemned as unfit for use, as milk, is frequently made into butter. ${ }^{11}$ Where there is infection of the udder the result is uniformly bad in the butter and cheese no less than in the milk from which it is made.

When the staid and conservative British Medical Journal published an article bearing the sensational caption, "Pus as a Beverage," 42 there were a great many unfavorable comments. Many persons who had not read the article felt that the title was too brutal and alarming. The article referred to a very serious outbreak of sore throat, often accompanied by abscesses in the neck, at Woking, England. The Medical Officer of Health traced the epidemic to the milk of a number of cows that were suffering from inflammation of the udder. Pus from the diseased udders entered the milk in considerable quantity, and there was no difficulty in accounting for the sore throats and abscesses of the unhappy 
victims. "Pus as a Beverage" is not a very attractive title, but of the terrible truthfulness of the phrase there can be no doubt.

Wherever there are tuberculous cows such conditions must prevail to a greater or lesser degree. From a score of American cities I could quote instances of conditions quite as bad as those set forth in the Woking report. I content myself with a single illustration of the use of pus as a beverage, and, it is safe to infer, as a food for little children:"In the Department of Health in Buffalo... we have a bacteriological examination of three hundred samples of milk every month. On the 19th of October (1906) the bacteriological examination showed streptococci and pus in a sample of milk sent in from the country. I sent a man out there the next day and he reported that one of the cows had a dilation of the udder and that there was pus in the milk. ... On November 13, another sample very much the same was reported to me as containing streptococci and pus. I sent an inspector in whom I had the greatest confidence to the farm and he came back with this report: That he found one cow with one of the teats giving a milk which was almost transparent, like water; the other three a milk which to the ocular inspection and to taste looked and seemed perfect. He, however, brought that milk in to be examined. The cow's udder was 
perfectly healthy (sic); there was no sore nor any ulcer of any kind. The cow was in good flesh, but yet there was a large amount of pus and streptococci in this milk. That had never been discovered in the city of Buffalo before this year, because we never had a bacteriological examination of milk, and we have been drinking that kind of milk ever since we have had milk coming into the city. If that cow was tubercular, if the lacteal ducts contained tuberculosis, people drinking that milk were very likely to be infected with tuberculosis." 43

This quotation from an address which I was privileged to hear Health Commissioner Greene, of Buffalo, make at a Milk Conference in the Academy of Medicine, New York, in November, 1906, is a very mild description of a condition which is widespread and common, almost beyond belief. Not long ago, I heard of a wealthy man in New Jersey who kept several high-grade Holsteins, of which he was very proud. One of the animals, a particularly fat and fine-looking cow, was specially selected to provide the milk for his infant daughter. But when the tuberculin test was applied, it was found that each of the cows was affected. The owner could not believe the report and was only with difficulty persuaded to have his favorite cow slaughtered and a post-mortem examination made. Not only were there abundant evidences of generalized tubercu- 


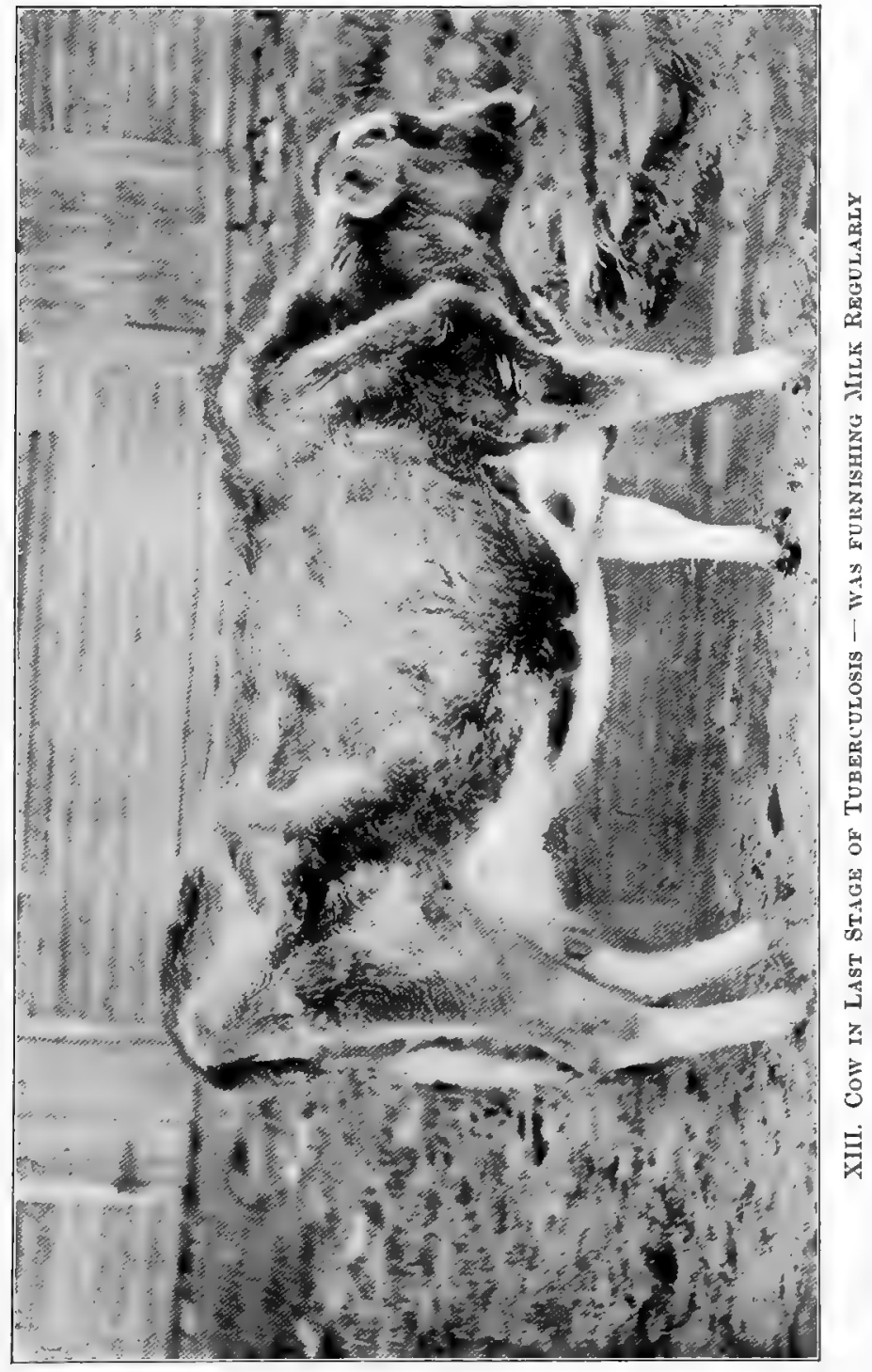



losis, but, to his horror and amazement, more than a pint of pus was taken from the cow's udder. These are typical of numerous cases which might be cited to prove the prevalence of these dangerous conditions.

From the foregoing résumé of the most important parts of the mass of evidence which has been gathered, the reader will be able to understand the unanimity with which investigators have come to regard milk as one of the most important factors in the spread of tuberculosis. An imposing list of medical and other scientific commissions and congresses which have given official expression to this opinion might be compiled, but I enumerate only a few of the most important. They are: The Royal Commission on the Effect of Food derived from Tuberculous Animals, 1895; The Royal Commission on Administrative Procedures for controlling Danger to Man through the Use as Food of the Meat and Milk of Tuberculous Animals, 1898; The Royal Commission on the Relations of Human and Animal Tuberculosis, 1906; the International Medical Congress, Paris, 1907; and the International Milk Congress, Brussels, 1907.

\section{VII}

So much for the spread of tuberculosis by the milk of diseased cows. We must not forget, however, 
that even the milk of perfectly healthy cows may spread the disease when it is contaminated and infected by human bacilli. Persons attending the cows, milking them, or handling the milk at any stage, may infect it, and so spread the deadly germs. This is important in view of the fact that very many tuberculous persons take up farming and dairy work in the hope that they will be benefited by the openair work and the simple, wholesome life which we associate with farming. The consumer should be protected against the danger of infection by human tubercle bacilli conveyed in the milk, as well as against infection by bovine bacilli.

Nor is tuberculosis the only disease that is disseminated by means of infected milk. There have been many epidemics of diphtheria, for example, traced to an infected milk supply. ${ }^{44}$ Whether, as contended by some English authorities, diphtheria is directly transmissible from cattle to human beings, or whether in all cases where the epidemics have been traced to the milk supply the latter was first infected with material from some human sufferer, subsequent to the milking, is a disputed point upon which we need not dwell. All authorities are agreed as to the fact of the spread of the disease through the medium of infected milk. The first positive discovery of this fact seems to have occurred in 1878, when there was a severe outbreak of the disease at St. John's Wood, 
England, which was traced beyond the possibility of reasonable doubt to the milk supply. Over two hundred and fifty persons were attacked, of which number thirty-eight died. ${ }^{45}$ Since that time numerous outbreaks of the disease have been traced to infected milk. While, as stated, the existence of bovine diphtheria is still a moot question, there can be no doubt as to the spread of the germs of the disease through the medium of infected milk. And it has certainly been shown by epidemics of sore throat, such as that at Woking already referred to, and many others, that a very slight disease in the cow may produce a very severe epidemic of sore throat among the users of its milk.

Of typhoid epidemics, so many of the worst have been traced to infected milk that the moment an outbreak of the disease occurs the milk supply is at once suspected. To-day, as these lines are being written,* the afternoon paper contains an account of an outbreak of the disease in a neighboring village. The newspaper report contains the very significant statement by the local health officer that steps are being taken to see "that all milk cans in which milk is brought ... are cleaned thoroughly and that no water which might contain typhoid germs is put into them." It is a lamentable fact that it always takes an outbreak of disease, more or less serious, to cause * November 15, 1907. 
such elementary rules of hygiene to be adopted. Why should it take an epidemic of typhoid to make the authorities of a city or town see that "milk cans are cleaned thoroughly and that no water which might contain typhoid germs is put into them"?

Cows do not suffer from typhoid, therefore the typhoid bacilli, which in milk multiply with alarming rapidity, must enter it from an outside source, after it is drawn from the cow. They may enter the milk through the use of infected water to dilute the milk or to cleanse the utensils; from some person suffering from the disease, - an attendant, for example, whose infection has not been discovered, or one who has returned to work too soon,- - or from some one who has come in contact with a typhoid patient and borne some of the germs away upon his clothing or person, which afterwards accidentally get into the milk. These are the principal means of infection. An illustration of the ease with which typhoid may be spread through infected milk was seen in the epidemic of the disease in Allentown, Penn., during February, 1907. It was shown that a case of typhoid occurring in the home of a milk dealer was concealed, with the result that cases later occurred in twenty-five houses at which that dealer delivered milk." *

* No attempt has been made to burden these pages with cases of typhoid and other diseases which have been definitely traced to the milk supply. The reader who is interested in this 
Toward the end of January, 1907, a great epidemic of scarlet fever and diphtheria swept over the city of Chicago like a mediæval plague. Altogether, in a month, more than ten thousand cases of infectious diseases were reported, including several hundred cases of diphtheria and more than four thousand cases of scarlet fever. There were over three hundred deaths. It was proved that the outbreak was due to infected milk, which came from two small places in Wisconsin where there were cases of diphtheria and scarlet fever, namely, Basset Station and Genoa Junction. ${ }^{47}$ The former is a dairy-farming district where for months scarlet fever had been prevalent, yet milk was regularly shipped, without warning of any kind, to Evanston and Chicago, with terrible results. The milk, it is interesting to notice, was shipped by way of Genoa Junction, where an outbreak of the disease took place, thirty-two cases being reported out of a total population of something like seven hundred. From these two places the epidemic which assailed Chicago spread with awful virulence.

In connection with this Chicago epidemic it is worth noticing that, in the bottling house of one of

phase of the subject will find much information in the Report on the Origin and Prevalence of Typhoid Fever in the District of Columbia (Hygienic Laboratory, Bulletin No. 35), and the Report of a conference on Sanitary Milk Production-Bureau of Animal Industry, Circular 114. See Appendix 1. 
the largest dairy companies in the world, a man was found working, notwithstanding that he was visibly suffering from scarlet fever, the characteristic "rash" being evident. Milk was also being received by the same company from two farms in which there were cases of scarlet fever. Inter alia, in view of the fact that this great company has been successful largely on account of the reputation for cleanliness and care established by its founder more than half a century ago, and so many are thereby lulled into an altogether unwarranted feeling of safety, it may be well to mention the fact that, on April 2, 1907, or only two months after the Chicago epidemic, which ought to have been a solemn warning to the company, milk was left at my own house by the agents of this great concern in which there were thousands of visible creatures, many of them as large as millet seeds, and not unlike them in appearance. My wife was preparing to pasteurize the milk for our baby, when, in the course of gently rocking the bottle to properly mix the contents, she observed the unusual conditions.

Without opening the bottle, we called for the agent of the company and showed him the milk. At first he tried to persuade us that what we saw were "little bits of slag, blown in the glass," whereupon I opened. the bottle in his presence and, with a probe, moved many of the creatures, taking one of them out. 
Later, over the telephone, the local management informed us that nothing to equal it had ever been seen in the office, and that "somebody would get into trouble for putting the milk into a foul bottle." But that, it is needless to add, would be of little benefit to our baby or ourselves if we had given that poisonous, filthy liquid to the little one.*

The responsibility of impure milk for a very large proportion of infantile diarrhcal diseases has already been touched upon in a previous chapter. In bringing to a close this catalogue of the perils attendant upon the use of cow's milk, and closing this indictment, of which I have barely sketched the evidence, I desire only to add that epidemics and individual cases of infection properly traced to the milk supply constitute only a small part of the awful sum of disease for which impure and infected milk must be held responsible. There are, it can scarcely be doubted, many fatalities which are never recorded against impure and infected milk. Countless baby graves might be marked with the epitaph, "Slain by Foul Milk," if we only knew the truth in every case - and had

* I have since seen three samples of bottled milk, supplied by three different companies, exactly like the one described above. One of these was shown me by Inspector Burton in the office of the Health Department, New York City. Mr. Burton discovered that the creatures were maggots which breed in decayed food. Their presence in the bottles points to unsanitary conditions in the cow barns, to carelessness in cleaning the bottles, and to bottling the milk near where the feed is kept. 
the courage to express it. How many of the cases of fatalities from eating "poisoned candy" of which one reads are in reality due to poisonous milk, will never be known.* And then, too, as Dr. F. Lawson Dodd observes, "the evil is by no means all recorded in the deaths." 48 Among those who barely manage to survive the milk-borne diseases of infancy and childhood, there are probably many physically incompetent to meet the issues of the great life struggle, - men and women of enfeebled health and dwarfed physique, whose miserable state is due to the same subtle and unseen dangers which lurk in the infant's bottle and the milk can.

* As an instance of this I note the case of the alleged poisoning by means of candy of the children of three families in Brooklyn, N.Y., in July, 1906, which was due, not to poisonous candy, but to poisonous and infected milk, according to the investigation made by Dr. Lederle. See The Evening Mail, New York, August, 1906. 


\section{CHAPTER VI}

\section{A BRIEF SUMMARY OF THE PROBLEM}

IN the preceding chapters we have touched upon many phases of a very complex and difficult problem, or, to be accurate, of a number of related problems which in the texture of life are bound together by intricately woven threads of vital phenomena. Before we enter upon the quest for a solution and discuss remedial measures, it may be well to make a brief summary of the evidence, to recapitulate the most important and significant facts, so that we may decide wisely upon the action that needs to be taken for the cure of the ills which confront us. It is only in this spirit that we can hope to succeed, conscious that

"Tis thus the spirit of a single mind

Makes that of multitudes take one direction."

Our concern is with the milk supply as it affects the public health generally, but more particularly as it affects the health and lives of the babies who are wholly, or almost wholly, dependent upon it for food. 
Whether the milk which we ourselves drink is clean or unclean; whether we take into our systems only nourishment when we drink a glass of milk, or the germs of virulent diseases which may at any time find in some weak spot the soil fitted for their parasitic existence, so that they blossom in deadly illnesses; whether we drink only a pure, life-giving beverage or a polluted mess, reeking with the filth of sewers, - are questions of very great importance. We wake to a recognition of their terrible significance only when disease and death ravage our cities, when great epidemics of typhoid or some other milk-borne disease menace our lives.

But epidemics come and go, and with their going we are prone to forget that the enemy is ambushed and always ready to make a new attack. We forget that it comes silently and swiftly and that "eternal vigilance is the price of liberty" in this as in every other human struggle. During the epidemic which raged in Chicago less than a year ago, I talked with a citizen of that city who was in a perfect rage over the peril which had come to every door in the city as a result of the neglect of the milk supply by the authorities. A few months later, I met the same man again and spoke of the importance of milk inspection. But he was not interested as before. Then he was literally afire with indignation and protest, but on the second meeting he was apathetic and cool. The 
scourge had passed away, and he was apparently content to let things take care of themselves, trusting to Providence and the Health Board.

Among the babies there is always an appalling death-rate compared with which the worst epidemics that assail adults are slight. There is a plague that is universally endemic and which preys upon the cradle. It claims more victims than any of our epidemics, more than the great mediæval plagues of which the old chronicles tell in terms we read to-day, after the lapse of centuries, with blanched cheeks and throbbing hearts. Sometimes, it is true, there are epidemics of infantile diseases, such as that of infant paralysis lately so alarmingly prevalent, by which we are terrified as we see the little funeral processions in the streets or read the statistics of mortality in the papers. But we ought not to forget that the epidemic diseases which rage during more or less brief periods separated by long intervals are not nearly so terrible as those diseases that are always present, which year after year continue to sweep the babies from their cradles into graves.

Why is it that we inure ourselves to great plagues and almost ignore them, while we are alarmed beyond measure by outbreaks of disease that are relatively unimportant? If ten babies in any one of our cities should die in a week from some unusual disease, - if, for example, there were ten cases of anthrax poison- 
ing among infants fed upon cow's milk, - there would be general consternation and alarm. But should a hundred babies die of diarrhcal diseases in the same city the fact would pass almost unnoticed, even though the hundred deaths could. be as surely ascribed to cow's milk as the ten cases of anthrax. Mr. Nathan Straus says truly: "When a few cases of cholera find their way into one of our ports, there is a great outburst of public excitement, and money is lavishly spent to ward off the danger. Yet there is eminent authority for the statement that there are more deaths from the preventable diseases of children occurring each year in any city in this country than the total number of deaths caused by Asiatic cholera, in the same city, from the first visitation of Asiatic cholera to the last" 1 - that is to say, during a period of nearly seventy-five years.

It is a well-known fact that in this country, notwithstanding all our boasted progress, one-third of all the babies born die before they reach the age of five years. Suppose, then, that one could mass all the infants in the country on a given date in one vast throng, and then go through the throng selecting the victims destined to die within the five-year period. Taking the first and second and setting them aside,. one might say: "You may have your chance to live; your chance to run all the dangers which mock our civilization. Live long, if you can." And then, tak- 


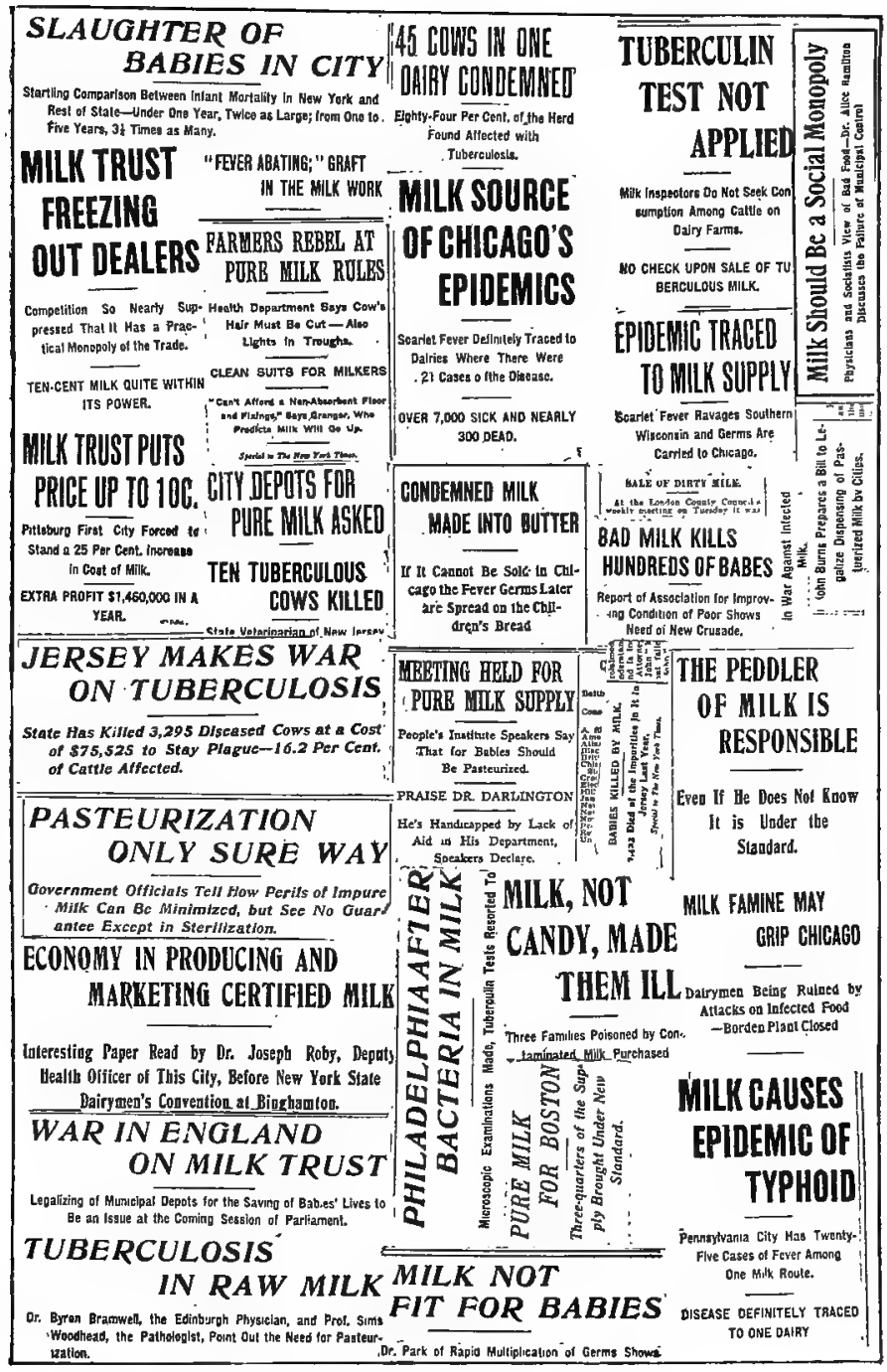

XIV. A Study in Headlines 

ing the third child, one might brand it, setting upon its brow the mark of death. When all the children had thus been sorted out, and one-third of them all gathered into a multitude of branded victims, each wearing the death symbol, would there be a single man or woman in the land with soul unstirred by grief? Would there be a human heart that did not throb with the agony and shame of the carnage?

And yet, in a less dramatic fashion, that very thing is happening every year. One-third of all the babies are taken by death before they reach the age of five - and the nation hardly heeds the fact. Why? Apparently because the dramatic element is lacking. There are no stage effects. There is no great holiday devoted to a slaughter of the innocents; the babies are not massed in one great throng, but scattered over the land, lying in a hundred thousand cradles or playing in tens of thousands of homes; there is no brand upon their brows to mark them off from other babies. Of course, there is less that is dramatic when babies, instead of being set aside and branded with a deathmark, just pine and die in their tenement homes. But they die, nevertheless, and I cannot think of our frightful infantile death-rate as being anything less than terribly, shamefully wrong, every citizen sharing in the crime and shame who does not work for better conditions.

It is not merely that one-third of the babies die 
before they reach the age of five years. That is bad enough, but it does not reveal all the awful truth. The death toll is not so evenly and impartially exacted, from rich and poor alike, as it would be if the babies were massed and every third baby chosen for the fatal branding. There would be in that case a splendid, inflexible justice and the tears of the rich and proud would mingle with the tears of the poor and humble in a great democracy of grief and bitter acknowledgment of the supremacy of death. "The gods always throw the dice impartially," declared Sophocles, the profound thinker who raised the Greek drama to its highest intellectual level, and modern science is coming more and more to that view. The gods are impartial. Ninety per cent of all the babies born into the world are, at the time of their birth, fairly healthy and well nourished. When they come into the world, the babies of the rich are in their physical inheritance no richer than are the babies of the poor. ${ }^{2}$ Hereditary diseases, like syphilis and alcoholism, are fairly equally spread over all classes. But, unlike the gods, man is partial and, to use the simile of Sophocles, plays unfairly with loaded dice. So there are vast differences in the death-rates of the babies. There are streets in all the great cities of the world where instead of one-third, one-half of the babies born perish during the first five years, or even during the first year; there are courts, alleys, and 
tenements where the infantile death-rate is higher still. $^{8}$

\section{II}

In another place * I have suggested that at least 30 per cent of the infantile death-rate in the United States might be prevented; that out of every hundred deaths occurring during the first five years of life at least thirty are due to socially preventable causes. This means that as a nation we permit something like 95,000 babies to die annually. I say we "permit" them to die, to express very deliberately the thought that is in my mind, that the deaths of those 95,000 babies each year ought to be set down as due to murder permitted by society.

Terrible as I know the figures to be, nothing is more certain than the fact that the estimate is a very modest one. Most physicians who have carefully studied the matter would, I think, agree that it could be said conservatively enough that 50 per cent of the infantile death-rate represents a needless sacrifice of precious human material. And that would raise the number of victims whose tiny graves bear witness to our social shame and crime to more than 158,000 ! It has been estimated by French authorities that threefourths of the infantile deaths in that country might be prevented; that in five years France lost 220,000

* In The Bitter Cry of the Children; ch. i. 
lives, equal to the loss of an army corps of 45,000 annually, through ignorance and neglect." Suppose that we knew that so many infants were actually murdered in France during that time; should we regard the French people as being civilized? Or should we be regarded as civilized if we slew, with knives and axes, 95,000 , or the larger total, 158,000 , babies a year? And yet, why should we not face the truth that it is not necessary to use knives or axes in order to do murder - that it is just as easy to murder babies with artificial foods that are poisons, or with milk that is reeking with germs and filth, as with any other weapons - just as easy and just as wrong?

That impure and infected milk is one of the chief factors in the causation of excessive infantile mortality is not questioned, so far as I am aware, by a single living authority. Whether we take Russia with its terrible death-rate of 272 per thousand ${ }^{5}$ of infants under one year old, Austria with its 227 per thousand, ${ }^{\circ}$ or New Zealand with its 82 per thousand, ${ }^{7}$ it is universally admitted that the frightful mortality among bottle-fed babies as compared with breast nurslings is due largely to diarrhoeal diseases caused by dirty and contaminated milk, or to other diseases caused by the ingestion of pathogenic bacilli contained in milk drawn from infected cows or handled by infected persons. And the fact of a universally declining birth-rate adds to the gravity with 
which a needlessly high death-rate must be regarded.

That infantile mortality would be greatly reduced if all babies were breast-fed is certain. Wherever the relation of infant feeding to infant mortality has been investigated, it has been demonstrated that the baby fed at its mother's breast has a better grip on life, a much better chance to survive, than the baby fed upon cow's milk or any other substitute for its natural food. Such investigations have been made in many cities, especially with reference to deaths from diarrhoal diseases, and uniformly point to the conclusion that maternal breast milk is the safest, as it is also the most natural, food for a baby. And when some great event has occurred in any large city to liberate many mothers from industrial pursuits, so that they might nurse their babies as Nature intended, the death-rate of infants has been enormously reduced. That was what happened in Paris, in 1871, during the great siege, when the infant death-rate was decreased by 40 per cent. $^{8}$ That was what happened, too, during the great strike in the cotton mills of Preston, England, in 1853, and during the great Lancashire "cotton famine" caused by our own Civil War. ${ }^{\circ}$ To some extent it happens whenever a strike occurs in which a large number of women are engaged for a considerable period. And where private philanthropy or public funds have been devoted to the encouragement of 
breast-feeding the results have been very gratifying.

Those who have read, or seen a performance of, Ibsen's play, The Master Builder, will remember that one of the most touching moments is when Halvard Solness, the master builder, tells that elfin-like creature, Hilda Wangel, the story of the calamity which wrecked his wife's life and made her the pathetic wraith of a woman she is. He laments that his wife has lost her vocation; for she, too, was a builder. Her vocation was to build up the souls and bodies of little children, and that vocation she has lost. In all the tragedy which enters into this problem of infantile mortality, nothing seems quite as terrible as the lost vocation of motherhood - the fact that so many mothers who ought to be the builders of the souls and bodies of little children, inspirers and nourishers of the race, are giddy human moths flitting around the flame of social pleasure, at one end of society, or industrial slaves, at the other end, bound to wheels.

That the education of a woman who refuses to nurse her baby has been radically defective is obvious, whatever the remedy may be. And it is not less obvious, I think, that there is something radically defective in a social system that takes a mother away from the most important service she can possibly render to the state, and makes her care for a machine in a factory; denies her the opportunity to pursue with wisdom and love her vocation as a builder of divine temples of 


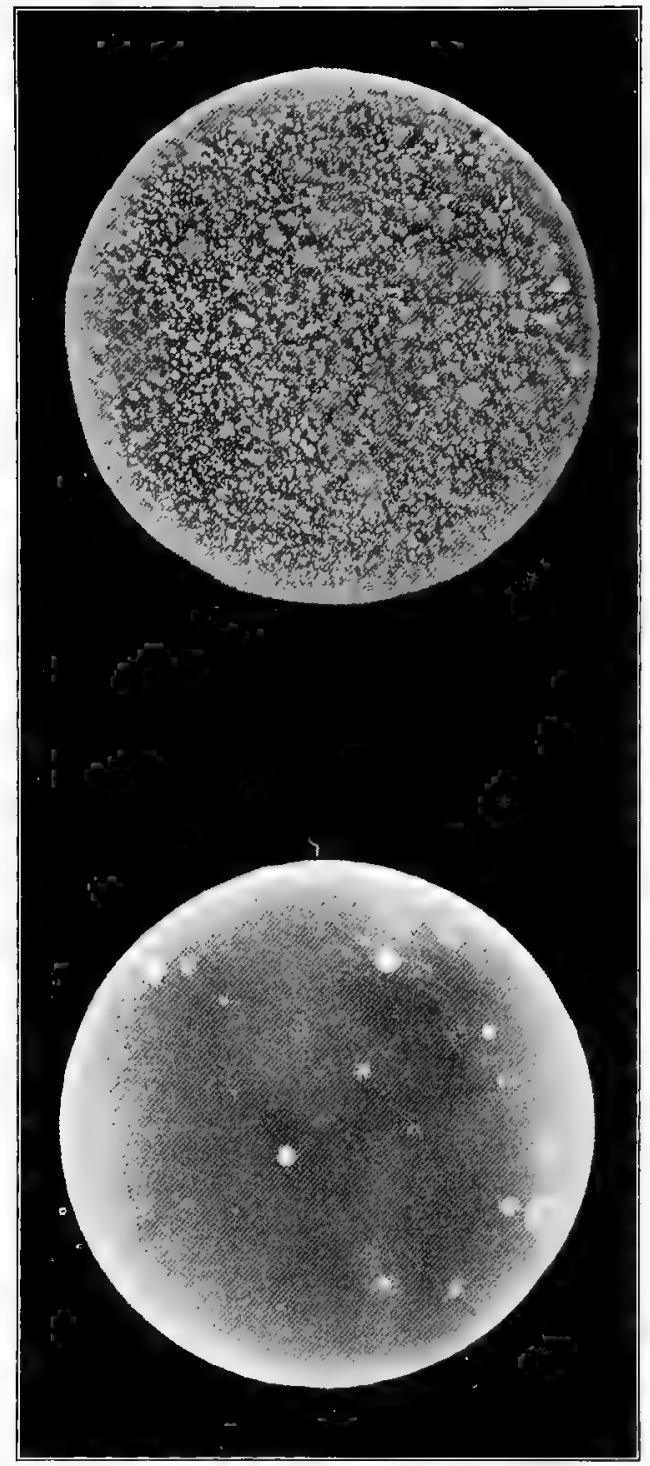

\section{Bacteria in the ATMusphere}

The upper plate shows the immense bacterial content of the atmosphere on Hester Street, a crowded district on the lower east side of New York City. The lower plate shows the relative purity of the atmosphere in a choice residential section, Madison Avenue and Sixty-sixth Street. 

perfect manhood and womanhood, and compels her to bea drudge in an office, a mere adjunct of a machine, a maker of paper bags in a sweatshop, or a charwoman. Whenever we become sufficiently civilized to properly evaluate human life, to regard the matter of dividends as being of infinitely less consequence than the matter of infant mortality, our present attitude toward motherhood will be a hideous memory of days that we shall not fail to pronounce barbaric.

But it seems to be a well-established fact that, in addition to the mothers who will not nurse their babies, preferring to purchase pleasure at the cost of the little infant lives, and to the mothers who cannot nurse their babies because they are needed in the industrial world to furnish "cheap" labor, - which is, from a social viewpoint, very costly labor, - there are many who cannot nurse their babies because the lacteal function itself is atrophied in them. They are physically unable to be mothers in the full sense of the. word "motherhood." And thus it is that artificial infant feeding becomes more and more common, and the importance of securing a proper substitute for mother's milk is constantly increasing.

III

Startling figures, terrible in their impressive eloquence, condemn the patent foods which flood the market, tempting the mother who is unable for any 
reason to nurse her baby. Professor Rotch is well within the truth when he says that these foods are "kept in the market by the physician rather than the manufacturer. The latter is only doing what any capitalist interested in a business venture would do. The former, it seems to me, is, perhaps unintentionally, aiding the business ventures of others at the expense of his own reputation as a scientist." 10 There is absolutely no necessity to-day for the use of a single one of the infant foods which are so extensively advertised. They are practically all inferior to the best grades of condensed milk - and equally as harmful as the worst grades. Personally, I wish that it were possible to enlist the women of America in a great crusade against these "foods" to the extent of boycotting the physician advising their use and every newspaper and magazine publishing advertisements of them.

For the milk of the mother the best substitute is the milk of some animal, such as the goat or the cow, modified to resemble the human milk as closely as possible. Of the two animals the goat is in many respects superior, but for various reasons it is not generally used as a milk provider, and the cow is practically the only animal so used in this and many other countries. Superior though the goat may be, it is extremely improbable that it will assume the place of the cow as the wet-nurse of the American baby at 
any time which may be regarded as belonging to a near future. And since we are not here concerned with the milk supply of a far-off future, but with that of the living present, our problem resolves itself into one of getting the best result from cow's milk and of overcoming its limitations and disadvantages as a substitute for the milk of the human mother. To that end we need both science and

"Good sense, which only is the gift of Heaven, And though no science, fairly worth the seven."

Science lays an unerring finger upon the disadvantages of cow's milk. It watches the infant human stomach at work trying to digest what was intended for an infant of a very different species, and a flood of light is shed upon some of the most difficult aspects of the problem of substitute feeding. By means which in other ages would have been called miraculous, science reveals the secret of each drop of milk; and where the layman, like another Peter Bell, sees only a drop of milk and nothing more, the man of science sees a little world teeming with life and wonders as profound as any in the universe. He finds in the air we breathe myriad living forms which no human eye unaided can see. He notes the manner in which many of these infinitesimal creatures enter man's food, and how some of them carry disease and death wherever they go. He takes a single drop of milk which is fair and pleasing to the eye, divides the drop, and spreads 
its parts upon his gelatin plates and then, by the aid of his microscope, shows that the smallest division of a drop is full of life, mysterious life in which good and evil are at war as in all the great universe.

A baby dies and the scientist finds in the little body sores and lesions which he does not understand until he has learned by repeated observation that in every sore and lesion there are numerous little living microorganisms, exactly like some of those contained in the drop of milk, and that there are very similar sores and lesions in the body of the cow from which the milk was drawn. Or a number of babies die as a result of an epidemic of some gastro-intestinal disease for which there seems to be no explanation, until the scientist, examining the digestive tract in each little body, finds in each a number of these micro-organisms, bacteria of various kinds, which are similar in all respects to those found in the dirt of the stables where the cows upon the milk of which the babies were fed are kept, or to the bacteria that are present in the dirt found in the babies' homes. Dr. Booker, of Baltimore, ${ }^{11}$ found thirty-three different kinds of bacteria in the intestines of little victims of that deadly foe of babyhood which mothers call "summer complaint" and the doctors call "cholera infantum." This is only one of a great many illustrations tending to prove that the diarrhœal diseases which kill so many babies - half of those that die in the big 
cities - are due to the presence of dirt in the milk.

It is natural that the mothers who swelter in the tenement homes of our cities during the torrid summer heat, as they watch their babies pine and wilt like flowers in parched earth, should think the heat responsible for the suffering and death of their little ones. But the heat is not the only cause, nor even the most important cause, of summer diarrhcea, though it doubtless is a factor. That this is the case can be very readily seen by comparing the number of deaths from acute diarrhoeal diseases in New York State in the two years, 1900-1901, in the period from May 1 to November 1, inclusive. The summer of 1901 was exceptionally hot, but the deaths from diarrhœal diseases in the state, outside of Greater New York City, numbered little more than half of the deaths recorded during the same period, in the same area, in 1900, when the heat was much less intense. On the other hand, the number of deaths in Greater New York and suburbs from the same diseases was very nearly doubled. The figures were:-

\section{TABLE VI}

Deatho from acute Diarregal Diseases, May 1 to November 1, INCLUsive

\begin{tabular}{l|l|l}
\hline \hline & 1900 & 1901 \\
\hline Country Districts • • $\dot{A} \cdot \cdot \cdot \cdot$ & 3202 & 1898 \\
Greater New York and Suburbs . & 3867 & 6115 \\
\hline
\end{tabular}


It is very evident from such figures as the foregoing that heat is not the sole cause of summer diarrhœa among infants. Dr. Chapin suggests that the reason for the tremendous increase in the number of deaths from this cause in Greater New York in 1901 was the presence of an unusual amount of dust and dirt, contaminating matter of all kinds, in all parts of the city, owing to the fact that from one end of the city to the other streets were torn up, and sewers constantly being opened, in course of the construction of the subway. ${ }^{12}$ The explanation seems to be a good one, but whatever the reason may be, there is no disputing the facts. It is likewise indisputable that diarrhoeal diseases are much more common among bottle-fed babies than among babies that are breast-fed, and there have been numerous observations which warrant the assertion that such diseases are largely due to bacterial contamination of the milk upon which they are fed. Science and good sense both proclaim the undesirability of filth as a food for infants.

With regard to the transmission of tuberculosis, typhoid fever, scarlet fever, diphtheria, measles, sore throat, and many other specific diseases of both human and bovine origin, science has conclusively shown that numerous perils attend the use of milk that is drawn from diseased cows or brought into contact with the germs of any disease, either human or bovine in its origin, no matter whether the method 


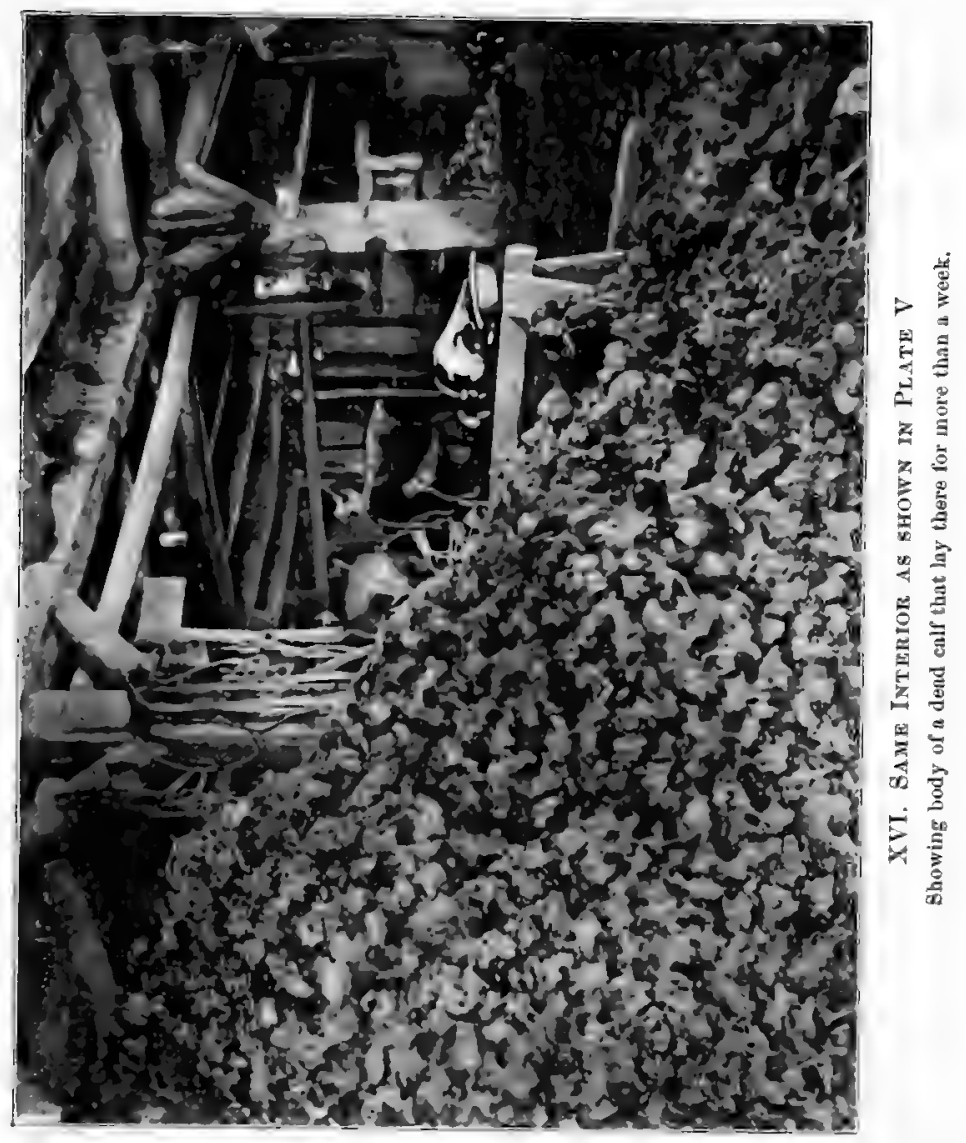



of infection is through tubercle bacilli from the cow's udder, bacilli accidentally carried into healthy cows' milk in small particles of the droppings of other, diseased, cows,* or disease germs conveyed to milk from the clothing of persons handling it, or in infected water. Whatever the method of infection, the danger is very real. We know, as surely as we know anything in the whole range of pathology, that tuberculosis, typhoid, scarlet fever, diphtheria, and some other virulent diseases are spread by means of infected milk. Science and good sense again unite, proclaiming that milk that is infected with the germs of disease is not a safe food, either for infants or adults. It is the chief advantage of the man of science over the layman that he has the power, though often only at great expense, to discover the danger. He is thus in a position to guard against dangers which to the layman are invisible.

\section{IV}

In this hasty summary of the disadvantages and perils of cow's milk as a substitute for mother's breast milk, there is one which we have not touched upon, and which is too important to be wholly ig-

* Shroeder has shown that if into a pail of milk drawn from absolutely healthy cows a very small portion of dung from a tubercular cow is dropped and the milk at once strained, a few drops of the milk injected into a healthy guinea-pig will successfully inoculate it with tuberculosis. 
nored. We have noted the difficulties due to the physiological differences which characterize a human infant and a calf, and the serious dangers arising from the susceptibility of milk to contamination, and from the ignorance of the most elementary principles of hygiene on the part of those who have much to do with its production and distribution. Likewise we have observed the very great dangers indicated by the presence in milk of pathogenic germs in large numbers, and the numerous, well-authenticated instances of the transmission to human beings of the diseases of cows in their milk, and the transmission of disease from one human being to numerous others through the accidental infection of cow's milk. Finally, to close our catalogue of difficulties and dangers, we must add a few words concerning adulteration and the use of preservatives.

We are all more or less familiar with the ancient jests at the expense of the dairyman whose most profitable animal was "the cow with an iron tail," and the milk pedler who raised the price of milk because of an advance in the price of chalk. These stories express in jests the common notion of the methods by which milk is adulterated. The addition of chalk and similar substances is rarely, if ever, resorted to in actual life; but the addition of water, removal of a part of the cream, or mixing skimmed milk with good milk are, on the other hand, forms of 
adulteration that are very common. Although most communities have drastic laws making these practices illegal, the laws are not always well enforced. Professor Doane found that in some of the cities in which he investigated the conditions of milk production and distribution these forms of commercial dishonesty were very common. The ethical opinion of the public was at such a low stage of development that this petty cheating was commonly tolerated. One dairyman told a group of his fellow-citizens, some of whom were his customers, that he always added water to his milk in common with every other man in the business, the rate of adulteration being one gallon of water for every four gallons of milk ! ${ }^{13}$

Now, adulteration of this sort is chiefly objectionable because the consumer does not get the amount of food value represented, and, in the case of added water, there is always the danger that the water itself is not pure. As Professor Pearson says, "If a dairyman is dishonest enough to water his milk, he will probably not be careful about the purity of the water added." 14 In most places the commoner forms of adulteration are practised to a more or less serious extent. Even where, as in New York and Ohio, the authorities are alert and aggressive, punishing all such offences with impartiality and vigor, there can be no doubt as to their extensive practice.

The use of preservatives is a form of adulteration 
which may be sharply distinguished from the forms of petty dishonesty above described. The dairyman or dealer who adds water to his milk, or mixes skimmed milk with milk of good quality, is deliberately robbing his customers. He is a petty thief of a very odious type. But the dairyman or dealer who puts "preservatives" into his milk is commonly actuated by no such dishonest motives. It is not because he is desirous of cheating anybody that he adds chemical compounds to his milk to keep it from turning sour. Speaking generally, he desires to please his customers by supplying a milk that will keep sweet a long time; to avoid expensive purchases of ice and the more or less frequent loss of profits caused by having quantities of milk become sour and unsalable. Frequently he buys a preparation which has been seductively advertised or personally recommended to him, bearing some such fine name as "Iceline," "Freezine," "Preservaline," and so on through a long list of compounds, most of which contain chemicals that are injurious to the digestive organs, especially of infants.

The average milkman does not know that "Iceline" and "Freezine" contain dangerous quantities of that powerful germicide, formaldehyde; that "Preservaline" of one brand contains boracic acid, while other brands contain salicylic acid, sodium sulphite, benzoic acid, and formaldehyde, the latter varying from 1.99 per cent to 10 per cent in different samples of 
the same brand $!^{15}$ He does not know that the souring of the milk is caused by bacteria most of which have entered it as a result of unhygienic conditions. Of course, he may have heard of the requirements of the Board of Health - better stables, new-fashion milk pails, white duck suits for milkers, washing cows' udders and tails, and many other "new-fangled notions" which he disbelieves in and regards contemptuously as fads of the "young doctors." Such things were never heard of until lately, and people have used cow's milk for ages !

He really does not know that the use of salicylic acid grew to be so common in France that the public health was affected and that a commission appointed by the government to inquire into the matter reported emphatically that, "The addition of salicylic acid or its derivatives, even in the most minute amounts, to foods, solid or liquid, should not be authorized." 16 He does not know that the United States Dispensatory says, "Salicylic acid has been used for the preservation of various articles of food, but the employment of it should be interdicted." 17 $\mathrm{He}$ is quite ignorant of the fact that formaldehyde has been shown to impair the digestibility of the casein in milk, causing serious intestinal diseases in young babies. ${ }^{18}$ He does not know these things - and if he did, there is the great economic motive. Milk so pure and clean that it will not sour for a very 
long time is, for him, an unattainable ideal. He has not the money to spend on the necessary improvements; he has not the education and knowledge required. He represents in his person and in his particular interests the old and outgrown, facing the coming of a new era, and resisting it with all his powers.

You cannot wonder, therefore, that preservatives are used, despite all laws to the contrary. The chances of detection are frequently remote, and the saving is great. Sometimes the dairyman himself adds "Iceline," and the wholesale dealer, not knowing that fact, adds "Preservaline"; while, later on, the retailer, guarding his own interest, adds to the same milk some "Milk Sweet" or "Freezine." Such a case is reported by the Department of Agriculture, discovered as a result of the illness of several children who drank the "milk." 10 The use of preservatives is prohibited by the laws of many states, as well as by the national food and drugs act, the so-called Pure Food Law, of June 30, 1906. What the effect of the last-named law will be remains yet to be seen. The state laws have not sufficed to put a stop to the pernicious practice, even in those states where the greatest activity has been displayed in enforcing them.

Such then, briefly stated, are the principal disadvantages and dangers attendant upon the public 


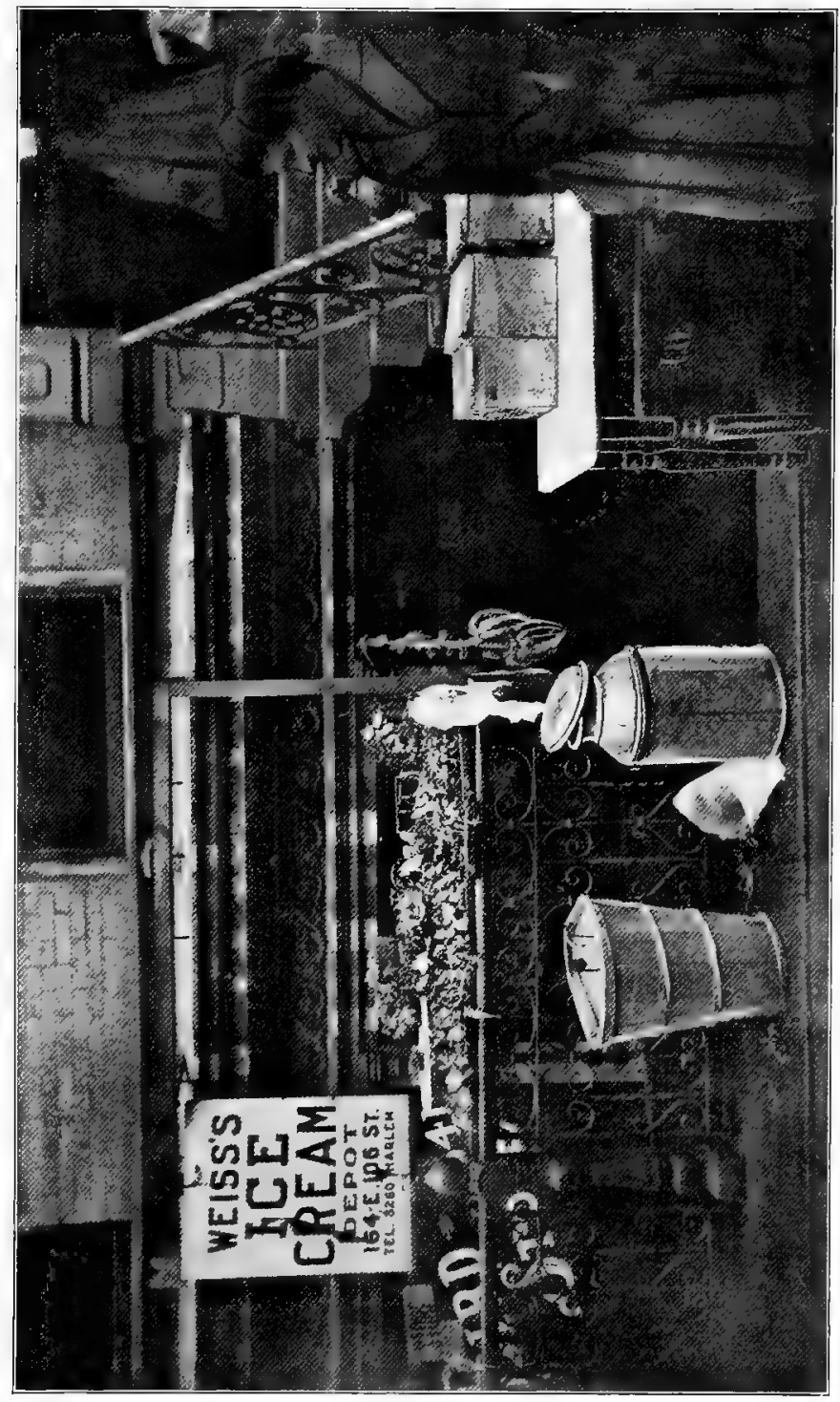

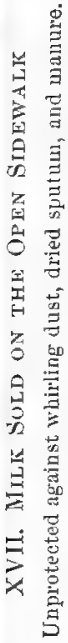



milk supply of the average American city. The careful reader will have observed that the perils are practically all hidden ones. It is impossible to tell from the appearance of milk, or from its taste, whether it has the deadly germs of typhoid in it, tubercle bacilli, or other pathogenic germs, or whether it has been "doctored" by the use of dangerous chemicals. Science alone can reveal the dangers lurking in the milk can or bottle. The average man is helpless: to test milk chemically and bacteriologically is a long, difficult, and expensive process, beyond the powers of the layman. A formidable list of dangers has been compiled by science, and now comes the questioning of the layman:-

"O Star-eyed Science! hast thou wandered there, To waft us home the message of despair?" 


\section{CHAPTER VII}

REMEDIAL THEORIES AND EXPERIMENTS

IN most progressive communities the public water supply has been brought under public control. The evolution of the public water supply may, for the purposes of this discussion, be divided into three periods, as follows: (1) The ante-organization period, with private springs and wells used by individual families and by groups of families; (2) first organization period, with private companies, operating under agreements made with public authorities, supplying water from some central source at a given price; (3) second organization period, in which the service is undertaken by the public authority in place of the private company. ${ }^{1}$

Now, one of the most potent factors in bringing about the organization of the water supply was the fact that polluted wells occasioned a great many serious outbreaks of disease. It was practically impossible to guarantee the safety and purity of the water supply under the old system of individual wells. In like manner the need for a more rigid and 
effective supervision of the quality of the water supply has had much to do with the change to municipal ownership and control. ${ }^{2}$ Whatever may be said of the prevailing demand for the municipalization of certain public monopolies, and whatever charges may be brought against municipal ownership by its opponents, retainers of vested interests and others, it is incontestable that the change to municipal ownership in the case of the water supply has had the beneficent result of reducing the dangers of epidemics from polluted water.

Nor can it be denied that, in this country at least, private ownership of the water supply is frequently attended with serious dangers that menace the health of the communities in which such private ownership prevails. Outbreaks of typhoid are much less common where the water supply has been for some time in the hands of the municipalities than where it is privately owned and controlled. And it is noticeable that where, under municipal ownership, the deathrate from typhoid is high, it is much easier to get effective steps taken toward remedying the condition than in the case of similar conditions existing under private ownership. The case of Ithaca occurs to mind as showing the fact that when the water supply of a city is in private hands and managed for private profit, many of the most influential citizens, who would otherwise be found fighting for betterment, 
are invariably on the side of evil. In Ithaca's case the authorities of a great American university, who should have been in the very vanguard of the fight for better conditions, were either actively defending the private company or indifferent to the public welfare. If, as a great American physician has said, "every time there is a death from typhoid somebody ought to be hanged for murder," it is safe to say that in Ithaca the application of that drastic rule would have taken away many of the "good citizens" and seriously depleted the ranks of the faculty of the university in that city. ${ }^{3}$

As Dr. F. Lawson Dodd has said, "It was epidemics and not epigrams that caused the municipalization of the main sources of our water supply," a remark as applicable to this country as to England. So far as the relation of the milk supply to the public health is concerned, there is no argument which can be used in support of the municipalization of the water service which is not equally valid and forcible when used in favor of municipal milk. The perils involved in the use of infected or impure milk are, as regards infants, very much greater than those involved in the use of polluted water, for the very simple reason that babies in many cases are wholly dependent upon the milk supply for food. Moreover, water, so far as is known, never carries the germs of tuberculosis, while, as we have seen, milk very commonly does. 
These considerations have led many very earnest reformers to advocate the municipalization of the entire milk supply of our towns and cities. During the Chicago epidemic there were a great many persons, by no means disposed to call themselves Socialisț, who supported the demand of The Chicago Socialist for the municipalization of the milk supply, and agreed that the milk trade should be a social monopoly. ${ }^{5}$ The London Fabian Society, which, contrary to current opinion in this country, is a very conservative organization, officially puts the case for municipalization more cogently than I have seen it elsewhere, in the following words:-

"If we want good milk, let us establish our own dairy farms in the country and our milk stores in the city. Many of our large towns have spent enormous sums of money to provide their citizens with water; why should they not also provide them with milk? The arguments in favor of municipal water apply with greater force to municipal milk. We want municipal dairy farms in the country, managed by dairy experts, and supervised by medical officers and veterinary inspectors. We want carefully selected, healthy cows to give us milk; and we want them kept under proper conditions. On our municipal dairy farms we could see that these conditions were fulfilled. A municipality would have no interest in adding dirty water to milk to make 
two gallons look like three. Milk municipalization would be a comparatively simple business. No powerful companies would have to be bought, and no compensation for loss of license could arise. Milk production does not require the use of complicated and costly machinery. The milk trade pays well, and its concentration would give rise to an increased economy in working. We should get cheaper as well as better milk. On the municipal farms we could insist that the laborers were paid a fair rate of wages." "

As a matter of pure theory there is no disputing most of the claims made by the Fabian Society. That the difficulties are beautifully minimized by the writer is evident. If the Fabians really be- lieve the milk business, conducted as it ought to be, is such a simple one, a time of disillusionment awaits them. On the contrary, the scientific production of milk is a very complicated and delicate business, as any one who has ever closely watched the many processes, and observed the almost innumerable precautions, necessary to the production of good milk, such as is produced on the best experimental farms, could tell them. Comparatively speaking, the distribution of water is a very easy matter. Doubtless milk ought to be distributed by the municipality as water frequently is, and for precisely 
similar reasons. Such, at least, is my personal conviction. It is idle, however, to expect that any large municipality in America will be persuaded to undertake the production and distribution of its milk supply for a long time to come.

In the first place, the industry itself must first undergo great changes in the direction of concentration before such a plan will become practicable. It is a well-established law of economic evolution that collective ownership and control follows when the organization of the machinery of production and distribution has been more or less perfected under capitalistic ownership and control. There are exceptions to this, as to every other rule, but only enough to establish its general validity. Now, economically, the milk trade is one of the most primitive and undeveloped of all our great industries, as it is also scientifically the most backward. Milk production has scarcely been touched at all by the tendency to concentration manifested in so many other branches of industry. It is an unorganized, petty industry, carried on by a large number of small capitalists, many of whom are little better off than ordinary wage-workers. Skilled labor, though it has been shown to be absolutely necessary to the realization of good results, has not yet been introduced into the industry, and, in fact, does not exist. Mechanical appliances, such as milking 
machines, are as yet in the experimental stage. In short, the production of pure milk is up to the present a laboratory achievement, not an industrial and commercial result, ripe for collective ownership and control.

In many of our smaller towns and cities, and in rural districts, a considerable proportion of the milk used is a home product, many families keeping cows for their own service. In such cases, as a general rule, the conditions under which the milk is produced are even worse than are common in the commercial production of milk. Adulteration and the use of preservatives are, naturally, practically never known when people own their own cows: but the stables are often filthy in the extreme; the animals are not well cared for, are specially subject to tuberculosis as a result of being badly housed; the equipment is often of the poorest kind, and the ignorance of milk hygiene so great that the contamination of the milk to an unusual extent seems to be almost inevitable. Furthermore, there is practically no inspection of the milk produced in these cases, no check upon the quality either as regards the content of fat or of pus and dirt. The most thoroughgoing advocates of the municipalization of the milk supply would not, presumably, go so far as to insist upon the suppression of this private production for home consumption, so that their plan would still leave very serious avenues 
of danger open. True, other means might be taken to regulate these and so secure proper conditions. But once that is admitted, it seems to me, from a hygienic standpoint, there is no reason why similar methods of control, without ownership, should not be applied to the whole industry. This is, of course, the theory of our present system of milk inspection, which has so signally failed to accomplish the desired result.

So much for the production of milk. When we come to examine its distribution, we find that there is a certain measure of organization and concentration. Except in very small centres of population, few dairymen retail the milk produced upon their farms. For the most part milk is sold to dealers who, in turn, supply the retail trade. Then there are great distributing companies, so-called "milk trusts," some of them operating upon a national scale, which are often oppressive to producer and consumer alike. Many of these concerns have so organized the distribution that they are receivers, wholesalers, and retailers. It has been estimated that from 80 to 90 per cent of the milk sold in New York City is handled by 125 dealers, and the tendency is undeniably toward further concentration. ${ }^{7}$ The business of milk distribution is much more nearly ripe for collectivism than is that of milk production, but there would, obviously, be very little advantage, 
from a health point of view, in having the municipality take over the business of supplying milk of doubtful quality, distributing ever so efficiently impure and disease-breeding milk.

\section{III}

The municipalization of the general milk supply, for the reasons stated, seems to me a proposition of little more than academic interest at present. Eventually, I believe, we shall come to that, but first of all there must come the concentration of production, with the inexorable crushing out of the small and inefficient producers and dealers, - the creation of conditions which will make municipalization practicable.

It does not follow, however, that no part of the milk supply should be brought under municipal management and control. On the contrary, there are very urgent and convincing reasons why, in nearly every city, some parts of the milk supply should be immediately municipalized. So far as the municipality itself is a consumer of milk it should aim to supply its own needs. In almost every city a certain quantity of milk is used in connection with municipal institutions, such as hospitals, asylums, sanatoria for consumptives, and so on. The common practice is for the public authority to contract for this milk supply, generally by public tender. Practi- 
cally all such contracts insist upon a certain standard of composition, that used by the Department of Agriculture being frequently adopted. In some cases there is also a bacteriological standard stipulating that the milk supplied must not contain more than a certain maximum of bacteria, the number ranging from 100,000 to 500,000 per cubic centimeter. There seems to be no good reason why this should not become a municipal function.

Why should not every town and city in which there is need for it have a municipal farm, stocked with perfectly healthy cattle, and conducted upon scientific principles throughout, for the supply of all its public institutions now depending upon a commercial product of very doubtful purity at best? Indeed, there is no apparent reason why the municipality should not supply from its farm those institutions of a public character not conducted by the city, such as hospitals, maternities, crèches, kindergartens, diet kitchens, and all similar philanthropically conducted institutions, in which the purity of the milk supply. is a matter of vital importance. Such milk could and should be supplied at cost.

Now, this is not a theoretical proposition, novel as it may appear to many American readers, but one that has been thoroughly tested in actual practice in several European cities. For example, the city of Nottingham, England, keeps about a hundred 
milch cows upon its own farm and supplies its hospitals and asylum, in addition to which it sells milk and butter to the value of something like $\$ 12,500$ per annum. ${ }^{8}$ The city of Reading conducts a dairy farm in connection with its sewage farm, ${ }^{9}$ as also does the city of Birmingham, which sold in 1903-1904 over sixty thousand gallons of milk, valued at about $\$ 9470 .^{10}$ These English cities have, it seems to me, begun at the right end. Instead of attempting the impossible task of municipalizing all the milk trade, they have started by supplying their own wants and selling only the surplus. The result of these experiments has been that, in addition to securing a safe and wholesome supply for the municipal and other hospitals and similar institutions, they have provided private producers with a useful object lesson, a standard of cleanliness and scientific methods of the highest value.

No matter how carefully drawn the contracts which our public institutions make with farmers and milk dealers may be, nor how honest and competent the system of inspection employed, these are not sufficient. They have not proved sufficient either in this country or in Europe. All the processes involved in the production of the milk used in such important institutions ought to be under such direct control and supervision of the sanitary authority as is impossible, except at a ruinous and needless 
waste of money, under the present system. ${ }^{11}$ The municipal farms would serve a double purpose, it must be remembered, not only providing pure and safe milk for the institutions where milk is largely used for dietetic purposes, but setting up a standard which private enterprise would be compelled to emulate. It is not difficult to see that a city producing milk having an exceedingly low bacterial content would be able to enforce the observance of a bacteriological standard otherwise impossible of realization. Even if such a farm did not pay, - though there is no honest reason why it should not if properly managed, - the influence for good which it exerted upon the private dairies would probably equal, in any fairly large city, what could be accomplished by several inspectors,

\section{IV}

That there should be established in every American city having a population of 25,000 or over municipal depots for the supply of milk intended especially for infant consumption is, I believe, one of the most vitally important lessons which we have to learn from the many experiments that have been tried in this country and in Europe. That the infantile deathrate can be very materially reduced by such means is unquestionable; and that is only another way of saying that our cities to-day are directly responsible 
for a considerable proportion of the awful yearly loss of babies - that, to put it plainly, our civic authorities stand in the position of murderers and accessories to the murder of thousands of infants every year.

Infant milk depots have been pretty thoroughly tested, in this country and in Europe, so that in advocating their establishment upon a more generous scale, as a municipal duty, I am not putting forward a beautiful theory which is likely to prove disappointing in actual practice. Had we nothing to guide us but the experience of Mr. Nathan Straus, and his magnificent record of successful life-saving in New York City by means of his infant milk depots, and the splendid results obtained in the city of Rochester, New York, under Dr. Goler's fine leadership, there would be little or no excuse for the failure of any city of 25,000 inhabitants or over to establish such depots.*

* Perhaps I ought to explain here that it is not suggested that such depots are unnecessary in smaller cities and towns. The milk supply in the small towns is often worse than in the big cities, and the infantile death-rate is frequently very high. But while I am fairly certain that any city of 25,000 inhabitants, or over, should make such provision for its infants' milk supply, I know that some smaller towns could not successfully maintain special depots for the supply of milk for infants. In some cases, too, they can deal with the milk problem as a whole in a satisfactory manner along other lines which would render special infants' depots almost, if not quite, superfluous. Perhaps I need scarcely add that the standard of 25,000 is, necessarily, somewhat arbitrarily chosen, merely to provide a proper basis for discussion. 


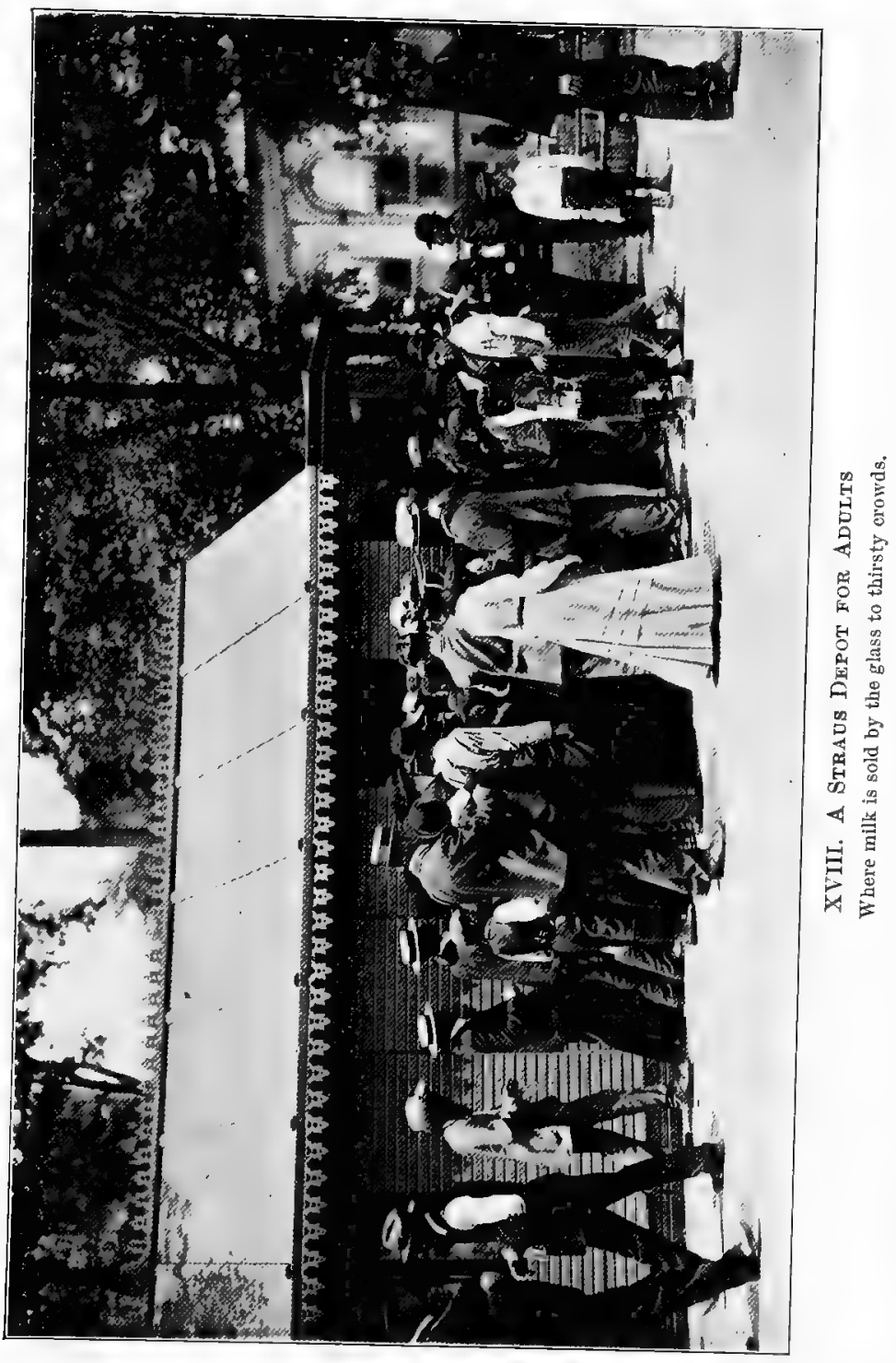



Instead of which we have the experience of hundreds of other cities, in many different lands, to guide and inspire us.

It is not essential that we should enter into a detailed history of the movement for the establishment of milk depots for infants. Other writers, notably Dr. McCleary, ${ }^{12}$ have done this work with a fair degree of thoroughness, and, moreover, a very brief outline will be enough to give the reader a fair idea of the various types of depots and the principles underlying their management. There are many variations in these institutions, but in a general way they may be said to conform to three types, which may be briefly described as follows: -

(1) Consultations de Nourrissons. ${ }^{13}$ The first of these institutions was established in 1890, by Professor Herrgott, who in that year founded at Nancy L'EEvre de la Maternite, a charitable maternity hospital. All children born in this hospital were required to be brought back for medical examination at the end of the first month, when, providing satisfactory progress had been made, the mothers were rewarded with small sums of money. Some idea of the scope of the work done by this institution may be gathered from the fact that in the ten years, 18901900 , the amount distributed was 25,382 francs and the number of maternity cases 2052. Professor Herrgott's idea was nothing more than to encourage 
as far as he could the very poorest of mothers to make the best of exceedingly adverse conditions in caring for their babies.

Two years after the beginning of Herrgott's Nancy experiment, in 1892, Professor Budin, of the Charité Hospital, Paris, started a Consultation de Nourrissons upon a somewhat more carefully studied plan in connection with that institution, and this proved so successful that he has since established others in connection with the Maternite Hospital, 1895, and. the Clinique d'Accouchement Tarnier, 1898. As there . are many of these Consultations de Nourrissons in Furope, usually maintained by public-spirited accouchers and philanthropic societies, all conducted upon the same broad lines, though differing in details of management, a description of those conducted by Professor Budin will sufficiently describe them all. Where they differ in very important particulars from others, the nature of such differences will be pointed out. The Consultations of Professor Budin are attached to maternity hospitals and limited to the children born in them. The mothers are admitted to the maternity institutions free of charge, but they must agree before entering the institutions that after their discharge they will bring their babies to the hospital for examination at least once each week until the end of the second year. At childbirth the mothers are carefully examined to see whether they are 
physically able to nurse their infants, and all the influence of the medical staff is exerted to persuade them to do so where it is not clearly a physical impossibility. The encouragement of breast-feeding is the primary purpose of the work.

At birth and during their stay in the hospital prior to the mothers' discharge, the infants are weighed and their weights and measurements and general physical conditions carefully noted and recorded. Then, after the mothers have been discharged, they have to bring the babies to the hospital weekly for further examination, so that week by week the record of growth is kept and the physician knows exactly the progress any child is making. The number of infants who are bottle-fed is relatively small, for the proportion of mothers who are unable to nurse their infants at the breast through physical disability is, in view of other statistics upon the subject, surprisingly small. According to Dr. Maygrier, of the 527 infants cared for at the Clinique d'Accouchement Tarnier during the years 1898-1902, no less than 448 were breast-fed and only 79 bottle-fed. But we must not forget, in considering these figures, that the women were all charity patients, coming from the very poorest classes, among whom the decline in nursing ability is commonly least marked. Where breastfeeding is impossible, the Consultations de Nourrissons supply sterilized milk for the infants in bottles daily, 
each bottle containing enough for a single meal and no more, the quantity depending upon the age, weight, and physical condition of the child and being prescribed by the examining physician. Sometimes, following the lead of Professor Herrgott's Nancy experiment, gifts of food or money are made to encourage breast-nursing. This description of the work of the Consultations de Nourrissons established by Professor Budin in Paris applies to almost all others, except that in some instances they are not attached to maternity hospitals, existing as separate institutions, and are free to all infants, no matter where born. In some cases, also, the milk given to the infants that must be bottle-fed is pasteurized instead of sterilized, and, in a few places, modified.

It will be seen from the foregoing description that the Consultations de Nourrissons can hardly be classified as milk depots, except incidentally. Their primary purpose is to discourage bottle-feeding as much as possible. Naturally, they do a great deal in the way of lessening the death-rate among the very limited number of infants with which they deal. When one thinks of the careful, devoted, and highly efficient skill which surrounds them when they are born, and then of the expert and conscientious weekly examination during the first two years of life, biologically the most important years of all, it is evident that these pauper infants are in many ways to be 
envied, being far better cared for than many infants of the rich and well-to-do classes.

Nevertheless they are paupers. Interesting as the Consultations de Nourrissons are, viewed as an experiment, it is quite obvious that they do not solve the problem of getting a milk supply for infant feeding that is safe and pure. They are well-intentioned, and highly illuminating, efforts made to improve the lot of the worst-conditioned classes of infants. Our need in America is not the establishment of such charities, though it would doubtless be a good thing if, in connection with well-managed infants' milk depots, at which people of all classes could buy safe and wholesome milk for their infants, we had a similar system of advising mothers and supervising the health of their infants.

(2) Gouttes de Lait. ${ }^{14}$ As their name implies, the Gouttes de Lait are primarily milk depots. Like the Consultations de Nourrissons, they encourage mothers to suckle their offspring wherever that is possible, and, like them, they exercise a good deal of supervision over the child during the nursing period. But they provide principally for the babies who must be artificially fed, and it is a rare occurrence for a mother who is able to nurse her baby to take it to the Goutte de Lait. The first of these institutions was founded in 1892 by Dr. Variot, in connection with the Belleville Dispensary, Paris. It was an offshoot, or 
perhaps it would be more correct to say a modification, of the Consultation de Nourrissons which Budin had established shortly before at the Charité Hospital. In 1894 Dr. Léon Dufour established a similar depot in Fécamp, the first to have an independent existence of its own, being unconnected with any other institution. Dr. Dufour named his depot Goutte de Lait, and the name has been generally adopted throughout France.

There are to-day Gouttes de Lait in over a hundred French towns and cities. In Belgium they are common institutions, under the name of Laiterie Maternelles, and in Spain, under the name of the Gota de Leche, we find the same institution flourishing. Under various names, there are similar depots in St. Petersburg, Odessa, and other Russian cities; in Roumania, Bulgaria, Italy, Germany, Switzerland, Denmark, Holland, Norway, Sweden, Portugal, and England, among European countries; as well as in Canada, the United States, Argentina, and Morocco. Some of these are very small institutions, incapable of materially affecting the death-rate. It would be quite impossible to present statistics of the work of these depots upon anything like a uniform plan, for the reason that in some cases none have been kept, and the vital statistics of different countries are not fairly comparable in many instances. It is only fair to say, however, that wherever records have been kept, the 
infantile death-rate has been lowered in consequence of the work of the milk depots.

As a rule, the French Gouttes de Lait have served as the models for other countries. They are usually philanthropic organizations, supported by voluntary contributions and managed by volunteer committees. Frequently they are subsidized by the municipalities in consideration of the economic value of their work, while in some instances, notably Nantes and Elbeuf, they have been altogether taken over by the municipalities. Three classes of children are served at most of the Gouttes de Lait: (1) Those whose parents are too poor to pay anything, for whom milk is provided free of charge; (2) those whose parents can pay some part of the cost, usually one-half; (3) those whose parents are perfectly able to pay the full price, and who use the milk supplied by the depots simply because they recognize its superiority over the commercial product. Often very wealthy persons avail themselves of this advantage. The proportion in which the three classes are found among those served at the Gouttes de Lait varies greatly, according to the localities in which they are situated. In thus catering to the indigent as well as to those who can afford to pay, the French system is very much like that adopted in this country at the Straus depots.

At the Fécamp Goutte de Lait, which has served as the model for hundreds of others in all parts of the 
world, the milk is modified and then sterilized. The formula used is, one part of water to two parts of milk, with 15 grammes of centrifugal cream, 35 grammes of lactose, and 1 gramme of salt added to each liter of the milk and water mixture. This mixture is bottled and then perfectly sterilized, being kept at a temperature of 102 degrees centigrade for forty minutes. In some of the Gouttes de Lait, including, I believe, practically all those in Paris and Havre, the milk is sterilized but not modified; while in places like Beauvais and Pol-sur-Mer the milk is pasteurized and unmodified. Upon the whole, as noted in an earlier chapter, the French are opposed to the modification of milk.

Most of the philanthropic infants' milk depots in this and other countries may be said to belong to the class of Gouttes de Lait here described. The depots established and maintained in New York City by Mr. Nathan Straus belong to this class; so also do those in Philadelphia, Chicago, Yonkers, N.Y., and some other cities. The milk is generally pasteurized and modified, following the leadership of the Straus depots. While there are some very poorly managed Gouttes de Lait in France and Belgium, I should say that, speaking generally, the methods of distribution in those countries are far better than anything we have in the United States. Insufficient care is exercised in distributing the milk in our American charity depots, 
so far as I have observed or been able to ascertain. Anything more incompetent than the management of some of them it would be impossible to imagine, and I seriously question the value of the work some of them are doing.

Elsewhere* I have called attention to the fact that there is no efficient supervision of the distribution in connection with some of these charities. I observed in Yonkers that the modified milk mixture was sold in drug stores to whoever applied for it. There was no registration of the children receiving it, some babies receiving it more or less regularly, others only occasionally. Little children, often not more than seven or eight years old, sent to the drug stores for "modified milk," got whatever the person serving them thought fit to give them. There was nothing to prevent a three-months-old baby getting a mixture intended for a year-old baby, or vice versa, and, of course, no medical supervision of the babies or system of advising the mothers. Inquiry showed that these conditions were not exceptional; that they were, on the contrary, pretty general. Even in the work of the Straus depots, as Mr. Straus perfectly realizes, there is lack of efficient supervision of the distribution and of a proper medical system of examining and watching the progress of the infants. And where the

* In The Bitter Cry of the Children, pp. 237-238. 
modified milk from the depots is distributed through the medium of such voluntary agencies as some of the smaller social settlements and charitable societies, conditions are worse still. In short, there is a good deal of bungling in connection with the distribution of modified milk by some small charities and room for great improvement in connection with the very best. As a whole, our methods of distribution lack the efficiency of the French. This is all the more regrettable as I believe we have a much better supply to distribute than the French have.

(3) Municipal Infants' Milk Depots. These require no special description. In the French and Belgian cities where there are municipal depots the only differences between them and the depots maintained by private philanthropy subsidized by public funds is that their maintenance is a public function and they are controlled by the municipal authorities. Frequently the volunteer committees are retained to assist in the distribution of the milk, visiting the homes of the children, and so on. The difference is one of fiscal policy mainly. Less hampered by lack of funds than those dependent on voluntary contributions, they are sometimes more efficient and generally better able to meet the demands for service. 


\section{v}

Several English municipalities have established depots for the supply of infants' milk. The movement began with the city of St. Helens, Lancashire, which, under the able leadership of the Medical Officer of Health, Dr. F. Drew Harris, adopted a plan somewhat similar to the Gouttes de Lait of Paris, in the summer of $1899 .{ }^{15}$ I was residing at the time in Glamorganshire, and I remember with what interest we followed the new experiment. Every indication of a lowering of the infantile death-rate was regarded as a sure sign of the early triumph over needless infant mortality, and I recall with what enthusiasm I lectured upon the new movement and secured the adoption of resolutions in its favor. Since that time the idea of providing a special milk supply for infants as a part of the business of the municipality has made rapid progress. After two years' successful experience at St. Helens had demonstrated that infants' milk depots were not to be pooh-poohed and scorned, but must be seriously regarded, the cities of Liverpool, Ashton-under-Lyne, and Dunkinfield established depots. That was in 1901. The year following Battersea opened a depot and was followed in 1903 by Leith and Bradford and in 1904 by Burnley, Glasgow, and Dundee. This is not a complete list of the municipal infants' milk depots in Great Britain, but it sufficiently indicates the great progress of the idea 
and the fact that the cities adopting it are among the very first in importance.*

In most of these British depots the milk is modified, or, as they prefer to say in England, "humanized." The milk mixture is sterilized, as a rule, and sold at something less than the actual cost of production, the deficit being met out of the municipal funds. Generally the municipal authority, through its Medical Officer of Health, or a committee elected for the purpose of controlling the depots, makes a contract with some farmer for milk of a certain quality in quantities which must be either increased or decreased within reasonable limits at very short notice. Cows have to be tested with the tuberculin test and the stables and dairies to be subject to very strict supervision. The udders and tails of the cows have to be thoroughly washed, utensils scalded, and the kind of food to be fed to the cows is prescribed. In most instances, though there is no rule that I am aware of which forbids the sale of the milk to whoever asks for it, the children who get the milk get it as a result of medical advice. ${ }^{16}$ The vast majority of the infants supplied are sick when they begin to take the milk. This is a universal condition and must be taken into account when the relation of the milk depots to infantile

* There are several private philanthropies in England which carry on work very similar to the Gouttes de Lait, notably one at York, led by Mr. Seebohm Rowntree. 
mortality is considered. In Paris, it is the mother whose baby does not thrive upon the proprietary foods or the ordinary cow's milk that seeks the Goutte de Lait. In New York City such mothers go to the Straus depots, and in Liverpool or Battersea to the municipal depots. As a rule, the children who manage to get along with ordinary milk are not taken to the infants' milk depots anywhere.

Most of the British depots have some system of registration, and the homes of children receiving milk from them are from time to time visited by lady visitors, sometimes paid, but often volunteer workers. The depots are in charge of women, in many cases trained nurses, and it is their duty to advise the mothers to nurse their babies at the breast if possible and to keep a record of the children's progress. Naturally, however, they can only make a very superficial examination of the children, by no means equal to that customary in connection with the French depots, where there are regular medical examinations. It is not insisted upon, moreover, that the children be brought to the depots for regular examination. This phase of the work is done in a manner that is far from satisfactory, a fact which is recognized very clearly by the authorities themselves. There is a growing desire for the adoption of a system of medical supervision in connection with the depots, somewhat similar to that obtaining in France. The more pro- 
gressive leaders of the movement, like Dr. McCleary of Battersea, are also urging the necessity of controlling the whole process of production as well as the distribution of the milk, - regulating and managing every step taken, from "the cow to the child's bottle." 17

In Battersea and some other places the mothers are provided with cards upon which to record the changes in the weight of their babies, and they are urged to bring them to the depots to be weighed at least once a week. It seems, however, that British mothers do not as yet take kindly to this idea, and very few infants are brought to the depots for that purpose. Possibly they could, by means of simple lectures and friendly talks in their homes, be interested in this and awakened to. a realization of its importance; or something might be done in the way of stirring up a healthy local rivalry among mothers, for it is well known that, once they are started, mothers are very proud of the gains made from time to time in the weight of their babies.

So far as I know, there is no municipal infants' milk depot anywhere which is entirely self-sustaining. The aim is to supply milk at a very low cost and of a high standard of excellence. Naturally, there is a good deal of expense attached to the bottling and cleaning of bottles when, as is generally the case, the milk is put up in small bottles, each holding the proper amount for a single meal. Wire baskets are supplied 
for carrying a day's supply, forming quite an item of expense. Then, too, there are breakages, which also involve considerable expense. The losses differ greatly, according to the scope of the work, the amount spent upon visitors' salaries, and the number of children served, varying from a weekly loss of less than $\$ 1.50$ in Leith, ${ }^{18}$ to a loss of more than $\$ 10,000$ a year in Liverpool. ${ }^{19}$ The deficit in Liverpool seems very high and has been the subject of much criticism. It must be understood, however, that the yearly expenditures are so made up as to include cost of machinery, alterations of buildings, and other items usually charged to capital stock, and also that the Liverpool depot is the largest of its kind in England, and, I believe, in the world. The average yearly deficit of the St. Helens depot during the four years $1900-1904$ was about $\$ 875$ and the average number of children on the books about 240 , whereas Liverpool had in two and a half years 6295 infants on its books who were supplied from the depot during that time. It is interesting in connection with this question of finances to observe that in some cities, notably Bradford and Ashton-under-Iyne, unmodified sterilized milk for older children is sold in pint bottles at a profit which helps to reduce the loss on the infants' supply. ${ }^{20}$ Bradford also sells milk wholesale to the municipal hospitals and cream and eggs to the public at the depot, the profits on which reduce the deficit on the 
infant milk supply. ${ }^{21}$ This is, of course, a considerable step in the direction of municipalization advocated earlier in the present chapter.

\section{vI}

Now let us compare, briefly, the formulas of some of the more important depots, philanthropic and municipal, at which sterilized or pasteurized mixtures are distributed.

In the French Gouttes de Lait, it may be well to repeat, modification is unusual, the practice being to give milk of full strength, even to very young babies, but either to sterilize it, as in Paris and Havre, or to pasteurize it, as in Beauvais and Pol-sur-Mer. In Fécamp, however, modification is practised, the formula being: ${ }^{22}$ -

$$
\begin{aligned}
& \text { Water . . . . . . . . One part } \\
& \text { Milk. . . . . T Two parts }
\end{aligned}
$$

with

$$
\begin{aligned}
& \text { Centrifugal Cream. . . . . . } 15 \text { grammes } \\
& \text { Lactose. . . . . . . . } 35 \text { grammes } \\
& \text { Salt . . . . . . . } 1 \text { gramme }
\end{aligned}
$$

to each liter.

This is heated to a temperature of $102^{\circ}$ centigrade, and kept at that temperature for forty minutes.

In the Straus depots, New York City, the following formulas are chiefly used, all mixtures being pasteurized by heating to a temperature of $167^{\circ}$ Fahrenheit, and exposing it to that temperature for twenty minutes. ${ }^{23}$ Formula No. 1 was prepared by Dr. 
Rowland G. Freeman and Formula No. 2 by Dr. A. Jacobi.

Formuta No. 1:

Sugar of milk, 12 ounces

Lime-water, one half-pint

Filtered water up to one gallon

Milk, one gallon

Formula No. 2:

1 gallon milk

1 gallon barley water

8 ounces white (cane) sugar

tounce salt

In the English municipal depots a very different system of modification is adopted. As will be seen from the subjoined tables, showing the formulas of the Liverpool and Battersea depots, they approximate percentage-feeding, as it is termed in this country. Furthermore, in most cases, when requested by medical men, the usual formula is altered to suit individual requirements. ${ }^{24}$

Table VII. Modified Milk Formula - Battersea Depot

\begin{tabular}{|c|c|c|c|c|}
\hline AGE of CHILD & Modifiontion & $\begin{array}{c}\text { No, OF } \\
\text { BoTTLES } \\
\text { DAILT }\end{array}$ & $\begin{array}{c}\text { AMOUST } \\
\text { PER } \\
\text { BOTTLE }\end{array}$ & $\begin{array}{c}\text { AMONAT } \\
\text { PER } \\
\text { DAY }\end{array}$ \\
\hline During 1st fortnight & Milk 1 part, water 2 parts & 9 & 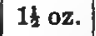 & 13t oz. \\
\hline During $2 \mathrm{~d}$ fortnight & Milk 1 part, water 2 parts & 9 & 21 oz. & $221 \mathrm{oz}$. \\
\hline During 2d month & Milk 1 part, water 2 parts & 9 & $2 \frac{1}{2}$ oz. & $22 \frac{1}{2}$ oz. \\
\hline During $3 \mathrm{~d}$ month & Milk 1 part, water 1 part & 9 & 3 oz. & 27 oz. \\
\hline During 4th month & Milk 1 part, water 1 part & 8 & $4 \mathrm{oz}$. & $32 \mathrm{oz}$. \\
\hline During 5th month & Milk 2 parts, water 1 part & 7 & $5 \mathbf{~ o z}$. & $35 \mathrm{oz}$. \\
\hline During 6th month & Milk 2 parts, water 1 part & 7 & $5 \mathbf{~ o z}$ & $35 \mathrm{oz}$. \\
\hline During 7 th month & MILK UNMODIFIED & 6 & $6 \mathrm{oz}$. & 36 oz. \\
\hline During 8th month & MILK UNMODIFILD & 6 & $7 \mathrm{oz}$. & $42 \mathrm{oz}$. \\
\hline
\end{tabular}


Cream and sugar are added to the modified milk to bring the proportion of fat and sugar to about 3.2 and 6 per cent respectively. The dilutions and amounts given were based upon a leaflet issued by the Medical Committee of the Great Ormond Street (London) Hospital for Sick Children. Since 1904 unmodified milk has been given to children over six months of age, and the change has been beneficial.

Having been filled into sterilized bottles, this mixture is heated to $212^{\circ}$ Fahrenheit, in a sterilizing chamber, where it is kept for a period of from fifteen to thirty minutes. The bottles are then taken out and rapidly cooled. The milk is given out in wire baskets, each containing a supply for twenty-four hours, from six to nine bottles. In the winter time the supply for Sunday is given out on Saturday, but in the summer time it is prepared on Saturday evening and given out on Sunday morning.

The Iiverpool preparation is as follows:-

Table VIII. Modified Mili Formula - Liverpool Municipal Depot

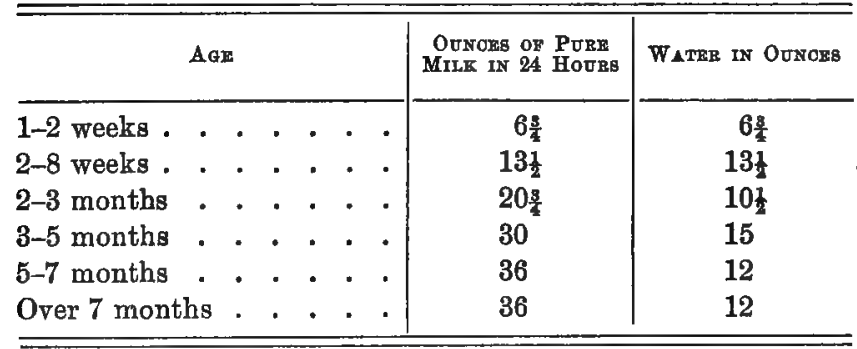

To each gallon of mixture add $\frac{1}{2}$ oz. cream, $1 \frac{1}{2}$ oz. sugar, and oz. salt. 
As in the case of Battersea and most other English depots, Liverpool sterilizes the mixture sold at the infants' depot. The mixture is bottled and then sterilized, the temperature of the sterilizer being $210^{\circ}$ Fahrenheit and the exposure from twenty to thirty minutes.

A municipal infants' milk depot of a very different kind from either those of England or any of the countries of Continental Europe is the one in Rochester, N.Y., which deserves special attention because of the fact that it has discarded pasteurization and achieved remarkable results through supplying clean, raw, modified milk. The fame of Rochester's infant milk depot * has spread throughout the world, so that today its Health Officer, Dr. George W. Goler, is probably even better known to the leaders of the medical profession throughout Europe than in this country. ${ }^{25}$

To understand the "Rochester System" of supplying

* Throughout this discussion I have used the singular noun for the sake of simplicity. In some cities there is a single depot, i.e., one place where milk is distributed. In other places there are several. When I speak of the "Liverpool depot," the "Rochester depot," and so on, the reader will please bear in mind that there are sometimes several depots in some cities; while in others, as in Rochester, there is a central station, or depot, with a number of branch distributing stations. I could not get the number of these branches in every case, - and, anyhow, the number varies from year to year, - so I judged it best to use the singular noun with this explanation. 
clean, raw, modified milk for infants it is necessary to know something of the city and the steps by which the system has been developed. Rochester is a city of nearly 200,000 inhabitants. There is something of the freedom and progressiveness of the West about it, shot through with the conservatism of New England. With about five thousand births per annum there must be at all times nearly twenty thousand children under five years of age in the city. Its daily milk supply is drawn from something like seven hundred farms, all lying within a radius of fifty or sixty miles. It is distributed by two hundred and twentyfive retailers, each of whom is licensed and pays an annual fee of $\$ 2$. Its milk problem is, therefore, radically different from that of our greatest cities, like New York or Chicago, and is much more typical of the average American city.

They have no legally established bacteriological standard for millk in Rochester. It is part of the Rochester creed that a high bacteriological standard, say of 500,000 per cubic centimeter, is a good deal less desirable than none at all. If they had a city ordinance forbidding the sale of milk containing more than 100,000 bacteria per cubic centimeter, it is probable that they could not successfully enforce it, and the result would be general demoralization. But they have in Rochester a very active and progressive Milk Commission, established in 1900 

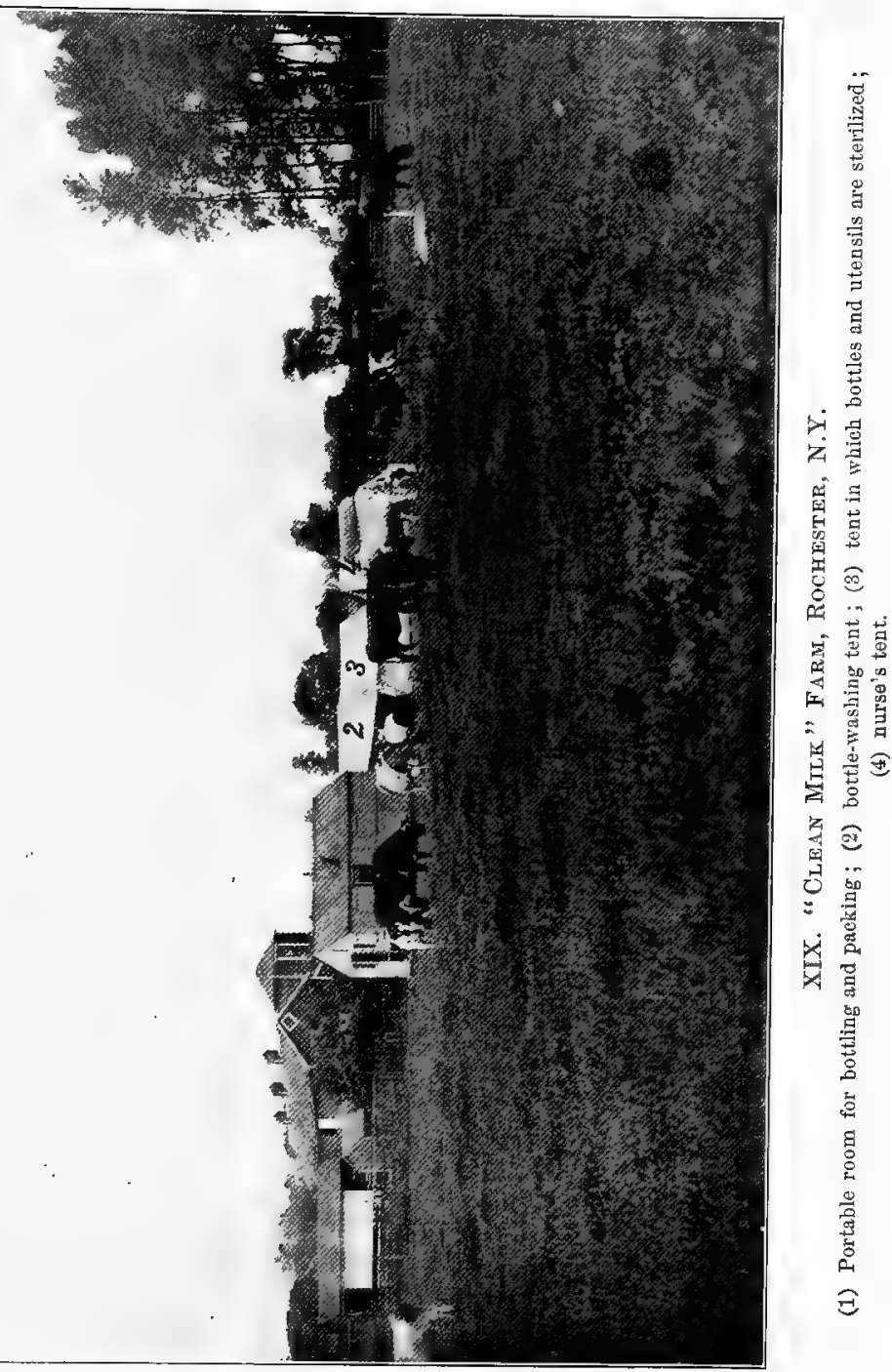

by the Rochester Academy of Medicine, that certifies milk of a specially good grade which, as "certified milk," readily sells for a few cents a quart over the average price paid for city milk. The requirements of the Milk Commission are very rigid, and its certificate is a guarantee to the consumer of :-

(1) Character of stables and feed of cattle, health of milkers, and care of utensils used.

(2) A negative tuberculin test.

(3) A bacterial standard not greater than 10,000 bacteria per cubic centimeter.

(4) A nutritive value of $12 \frac{1}{2}$ per cent solids, of which 4 per cent must be fats.

The influence of this Commission extends far beyond the small proportion of the milk supply which it certifies as fulfilling these requirements. The Commission has, among other things, created a good deal of public interest in the milk supply, which has been of enormous advantage to Dr. Goler and his assistants in their efforts to get a city milk supply with a bacterial count not greater than 10,000 per cubic centimeter.

Moral suasion is the force upon which the greatest reliance is placed. Dr. Goler has wisely recognized all the conditions resulting from the ignorance of milk producers and retailers, and set himself to teach all who are teachable how to produce a better class of milk. In order to do this he has had to show them 
the importance of cleanliness in producing and handling milk to the public health, a gigantic task in which he has been splendidly aided by his assistants. When moral suasion fails, as it sometimes does, then resort is made to sterner measures, such as arrests, fines, and revocation of licenses.

As a background to the infants' depot, then, we have in the first place the Milk Commission with its educational influence, and, secondly, the Health Bureau with its alert and progressive officials working as follows: (1) examining four or five thousand samples of milk annually for nutrient value; (2) making bacteriological examinations of about one thousand samples of milk annually; (3) inspecting dairies and stables for cleanliness; (4) registering against the name of each milkman the number of families with infectious diseases to whom he supplies milk, so that the danger of the milkman's carrying scarlet fever, diphtheria, or typhoid fever to his customers may be minimized; (5) through ordinance and license and educational means trying to get the milkman to raise his standards, and when these fail resorting to sterner measures. It will be seen, therefore, that Rochester is an exception among cities in the intelligence and breadth of the measures adopted for the improvement of its milk supply.

Prior to 1897 the infantile death-rate in Rochester was, as in most cities, very heavy, notwithstanding 
the many physical advantages of the city. There was a system of milk inspection, it is true, but it was wofully inadequate and inefficient, as is customary in American cities. There were one or two inspectors with whom sobriety was not a strong point, and they were known to "borrow" money occasionally from milkmen. That they should protect the milkmen in return for these favors was a natural result. From 1888 to 1896 inclusive, a period of nine years, the number of children under five years of age dying from all causes was 6629 . I put the figures this way, giving the total number of deaths under five years of age from all causes, because it is the Rochester way of looking at the question. It is part of the Rochester creed that whenever a child under five years of age dies from any cause not accidental or violent, the death may be assumed to have been due, partly at least, to the dirty and unwholesome character of its food.

In 1897 Dr. Goler established an infants' milk depot for the two months, July and August, during which the tide of infant mortality always rises. The work began in a very primitive way, and the total cost to the city was $\$ 300$. A store was rented in a very thickly populated district and fitted with running water, gas stoves, counters, and shelves. Two of the hospitals of the city each placed a nurse at the disposal of Dr. Goler, and they pasteurized the milk, 
cooled and bottled it, and sold it at cost to the mothers who came for it. A little pamphlet, a model of wisdom, brevity, and lucidity, entitled "How to take Care of Babies," was printed in four languages and freely distributed. We know now in a general way just how the money was spent. The results are roughly indicated, but not scientifically measured, by the statistics which follow. ${ }^{26}$ In order to get the fairest possible idea of the influence of the infants' milk depot upon the mortality of infants in the summer months, I have divided the period from 1888 to 1896 inclusive into three three-year periods and given the mortality of infants in each of the years for the months of July and August. Then, for purpose of comparison I have given similar figures for the three years, 1897 to 1899 inclusive, the period during which the milk sold at the infants' depot was pasteurized.

Table IX. Showing Total Deaths of Children onder 5 Years of Age in the Summer Period before and After the Establishment of Infants' Dhpots for the Supply of Pasteurized Milk.

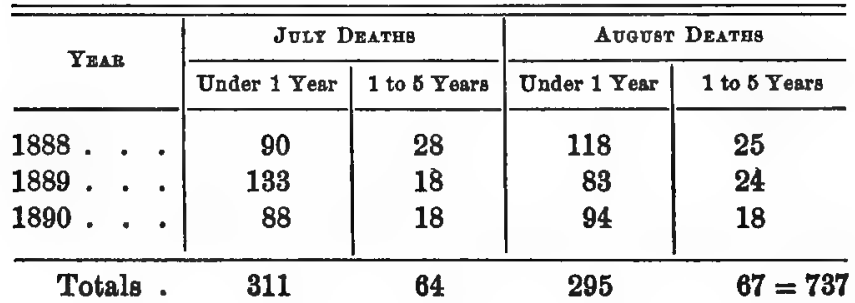




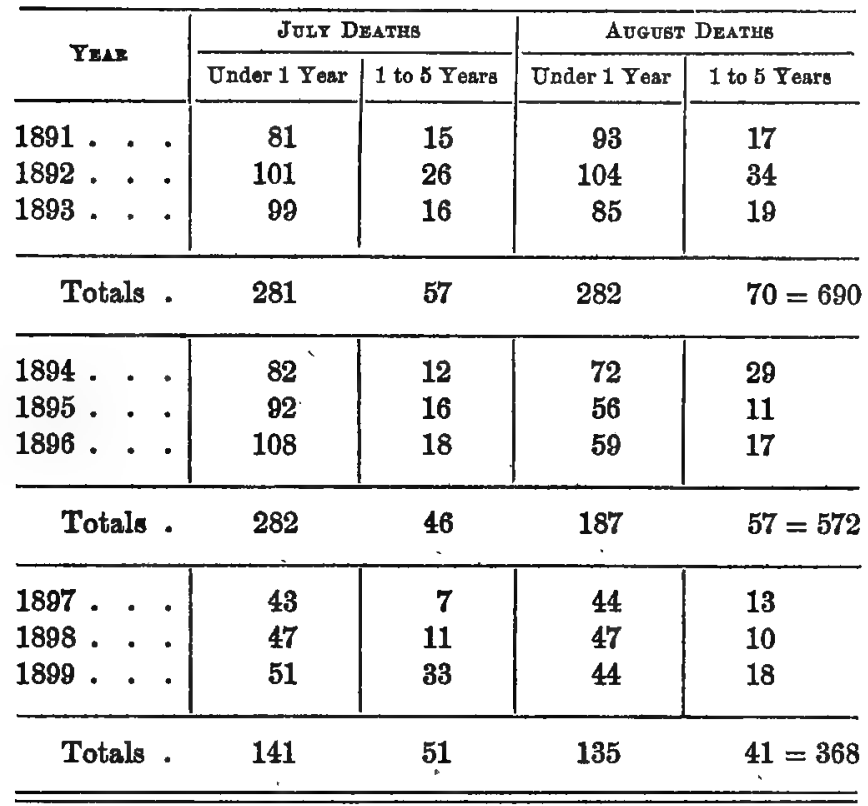

The year before the establishment of the infants' milk depot the total number of children under five years of age dying during the months of July and August was 202, but the number during the same period of 1897 was 107 . But if we take the average of July-August deaths for the nine-year period, 1888. to 1896 , we find the number of deaths to be considerably higher than in 1896, the number being 222 . Now, whether we compare the 107 deaths recorded in 1897 with the number recorded during the same period in the year preceding it, or with the average number 
recorded during the same months in the nine-year period, the result is to show a remarkable decline. Perhaps, however, the fairest comparison would be between the three years, 1897 to 1899 inclusive, and the three years, 1894 to 1896 inclusive. In the latter period there were 572 deaths of children under five years of age recorded in the months of July and August, as shown in the preceding table. In the three years, 1897 to 1899 inclusive, the number of such deaths was 368 , a decrease of over 35 per cent!

It is not contended that the remarkable decrease of infant mortality indicated by these figures was due entirely to the distribution of milk from the infants' depots. It is never possible to completely separate the factors entering into mortality statistics. Doubtless the distribution of simple instructions to mothers on the care of their babies and the friendly advice given by the nurses helped a good deal, while the improvement in the general milk supply of the city and the intelligent public interest in the subject were also factors of very great importance. Rochester's system must be considered as a whole if we would understand it.

There were a good many wiseacres who thought that the irreducible minimum of infant mortality had been reached, that further progress could not be expected. I suppose that most men would have been satisfied with so great an achievement, but not so Dr. 


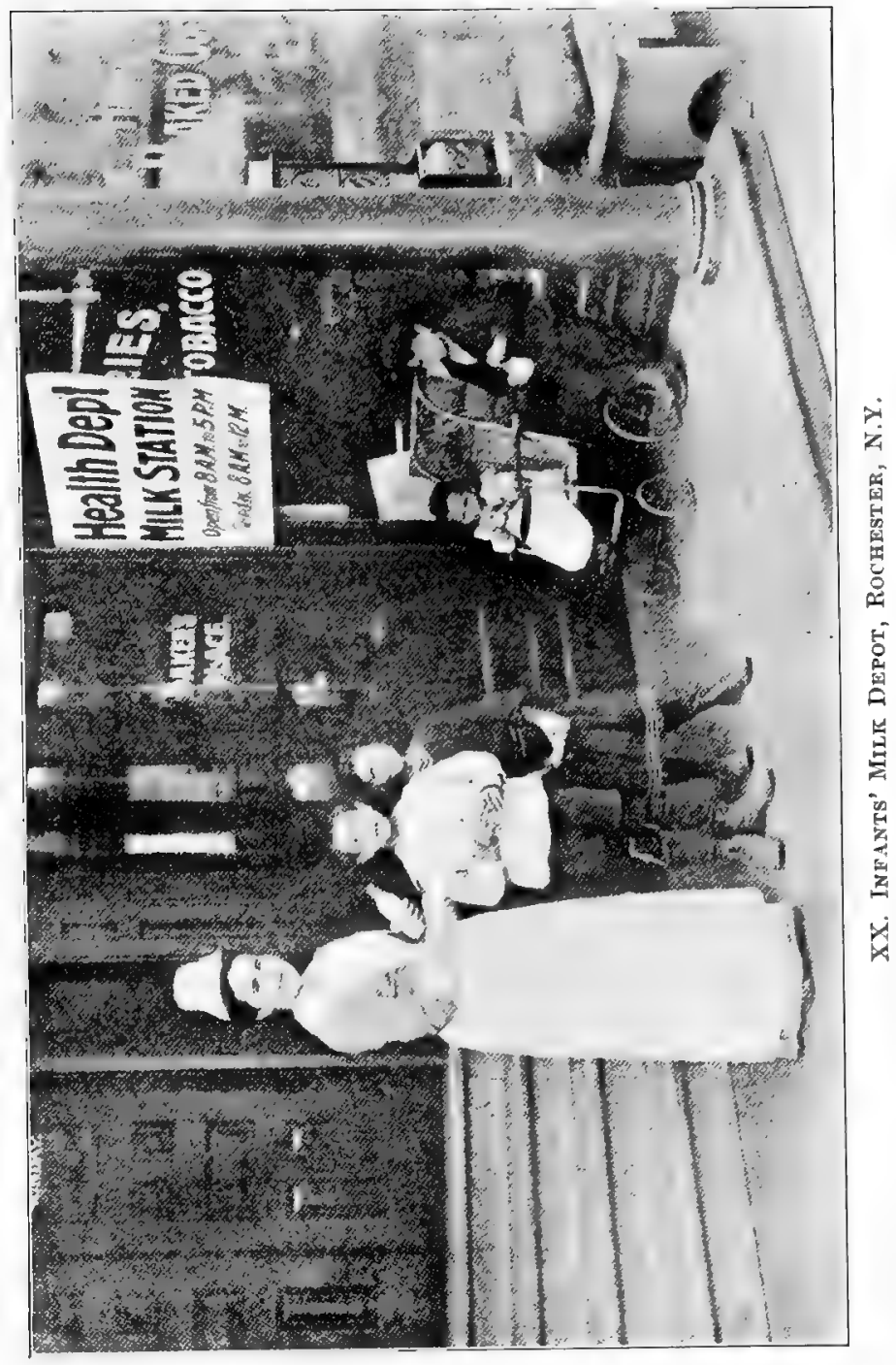



Goler. While satisfied with the return made for a ridiculously small sum of money invested, a dividend in human lives rarely equalled, he would not, could not, believe that the limit had been reached. An idea obsessed the mind of this earnest and far-seeing offcial: "Pasteurization is good for dirty milk - dead disease germs are less harmful than living ones; but why have filth in milk at all - why not aim at clean milk which needs no pasteurization?" That simple idea of cleanliness has made Rochester famous wherever men and women are seriously trying to grapple with the problem of keeping the babies alive. It is the essence of the political economy of saving babies' lives.

So, in 1900, instead of pasteurized milk for the infants, Dr. Goler tried clean raw milk. A contract was made with a farmer for all his milk at so much per quart, upon condition that he would observe all the hygienic directions of Dr. Goler and his assistants, which were purposely made as simple as possible, demanding a minimum of outlay. A portable laboratory, consisting of an old, discarded election booth, was set up on the selected farm. Outside the house, under canvas, a sink and running water were set up for washing the bottles. Then there was a tent for sterilizing purposes, with sterilizers each containing two gross of nursing bottles - for here, instead of sterilizing the milk, they sterilize the bottles and cans. 
$\Lambda$ nother tent was provided for the nurse in charge to sleep in, the entire "plant" costing between $\$ 500$ and $\$ 600$. Strangely enough, this very simplicity of the system, which is its strongest feature, is the feature which I have heard most disparaged; visitors are frequently disappointed that there is nothing to see except a shed, some tents, and people trying to be clean in handling milk.

The result of the experiment was watched with great interest that first season; could Dr. Goler maintain the low death-rate attained as a result of pasteurizing the infants' milk sold at the depots, or was he gambling with the lives of babies? Many were the dire prophecies made concerning this vital matter. I recall receiving a letter from an interested observer of the Rochester experiment which dolorously ended somewhat as follows: "Dr. Goler's decision is unfortunate. Failure is inevitable, and the work of years will be thrown away. Could not something be done to dissuade him?" But, fortunately, Dr. Goler was not dissuaded. He had counted the cost and pinned his faith to clean milk as a result of profound study. His policy was revolutionary, but it was vindicated when it was shown that, not only had the gains made during the three preceding years been maintained, but actually improved upon. I give the figures for the six years, 1900 to 1905 inclusive, divided into threeyear periods for the purposes of ready comparison. 
Table X. Showing Total Deaths of Chimdren tnder 5 Yearg of Agr in the Summer Pertod under Pagteurization and Climan Milk Methods

\begin{tabular}{|c|c|c|c|c|}
\hline \multirow{2}{*}{ TxaR } & \multicolumn{2}{|c|}{ JULT DEATHS } & \multicolumn{2}{|c|}{ AUGUGx Dratra } \\
\hline & Under 1 Year & 1 to 5 Years & Under 1 Year & 1 to 5 Years \\
\hline $1897-1899$ & 141 & 51 & 135 & $41=368$ \\
\hline 1900 & 50 & 16 & 54 & $14=134$ \\
\hline 1901 & 37 & 12 & 38 & $8=95$ \\
\hline 1902 & 26 & 5 & 43 & $20=94=223$ \\
\hline 1903 & 32 & 16 & 34 & $18=100$ \\
\hline 1904 & 15 & 11 & 43 & $6=75$ \\
\hline 1905 & 53 & 10 & 60 & $13=136=311$ \\
\hline $\begin{array}{l}\text { Totals for } \\
\text { six years }\end{array}$ & 213 & $70^{\circ}$ & 272 & $79=634$ \\
\hline
\end{tabular}

When it is remembered that these figures give the total number of deaths, and that the population of Rochester is an increasing one, the remarkable character of the statistics becomes evident. During the period 1894-1896 inclusive, there were 572 deaths, an exceptionally favorable showing under the old conditions. During the period 1897-1899 inclusive, when the milk depots were in operation, supplying pasteurized milk, there were 368 deaths recorded during the same two months for the year; in the period 1900-1902 inclusive, with infants' depots supplying clean, unpasteurized milk, the number was 223, a remarkable decline in view of the decline made dur- 
ing the preceding period. During the next three years, 1903-1905 inclusive, the number was greater, 311 , but still appreciably less than in the pasteurization period.

Looked at in another way, the figures make an even more remarkable showing. During the nine years, 1888 to 1896 inclusive, there were 1999 deaths of children under five years of age in the months of July and August; but during the period 1897 to 1905, the following nine years, distinguished by the work of the infants' milk depots, the number of deaths in the same months was only 1000 ! The number of deaths was just half, notwithstanding that the population had increased something like twenty per cent! I know of nothing to equal this record in the history of any city in the world. And the cost of this great work to the city has been barely a thousand dollars a year, less than the salary of a good inspector.

In the manner indicated by our analysis of the statistics it is possible to obtain an approximate idea of the extent to which the mortality of infants has been reduced, but no figures can ever show the gain to society through the prevention of needless suffering, or the number of children who have been enabled to start life fairly, without the handicap of weakened constitutions, as a result of the work done by the city in providing them with a safe and wholesome food at a critical period in their infancy. Nor can the 
effect of the work upon the ordinary milk supply of the city be properly measured. Each year, for educational reasons, a different farm has been selected, so that each year one farmer has had practically two months' personal instruction in milk hygiene. Gradually the farmers are learning the lesson; learning to trust the man who pooh-poohed their smart copper and nickel appliances, their silver-plated centrifugal machines which gathered balls of dung and hair from the milk. They are learning that it is better and more economical to keep their barns and stables clean, to wash the udders of their cows, to see that the milkers are clean; they are learning that when these things are done, and all utensils are perfectly sterilized, less babies die in the city.

\section{VIII}

There are still some persons who believe that there is no necessity for the establishment of infants' milk depots. Their position is that, bad as conditions undeniably are, the proper thing to do is to secure a better general milk supply; that the ordinary milk supply of any city can be so improved as to do away with the need of making special provision for infants. The objection seems plausible enough at first, but I have yet to learn of any city, either in this country or abroad, having such a milk supply. There is not in the world, so far as I know, a single city with a milk 
supply so pure as to be a safe food for babies. The question arises, what is to be done in the meantime; are we to go on letting the babies needlessly die until such time as we have perfected our milk supply?

Personally, I do not believe that the youngest reader of these pages will live to see the time when the ordinary milk supply of any large city will be satisfactory for infant feeding. With Dr. Brush, I believe that we need a separate dairy for producing milk fit for infants' food, that we need to separate the production of milk for infants entirely from the commercial milk supply. ${ }^{27}$ As Dr. Brush has pointed out, the dairy cow is a tuberculous animal, and as a rule, the tuberculous cow is a more abundant milkgiver than the non-tuberculous cow. ${ }^{28}$ The reason for this is that we have bred cows solely for dairy purposes, inbreeding to an extent which has weakened them. One can go into almost any large dairy establishment when animals are condemned for slaughter as a result of the application of the tuberculin test, and discover for himself that the condemned animals are, in many cases, among the best and most abundant milk-givers in the herd. Everything has been sacrificed to getting an abundance of milk containing a high percentage of fats and solids at the cheapest possible rate. Very often the cow that is undesirable for ordinary dairy purposes, her milk being of small quantity and deficient in fats, would make a 


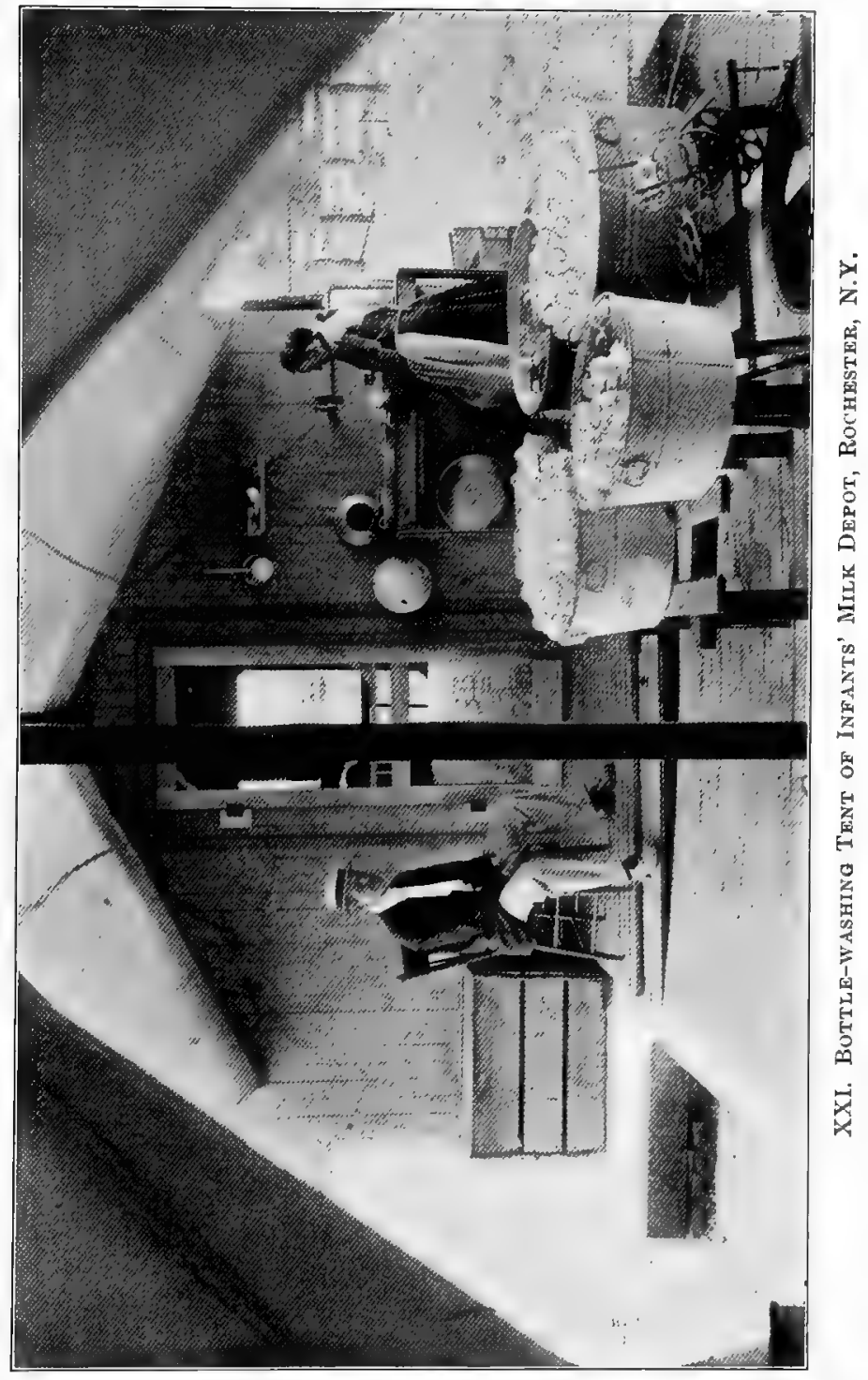



most desirable animal for supplying milk specially. intended for infants.

Further, to get a really satisfactory milk for infant feeding, we must have what Dr. Roby has called "the application of surgical principles to the milk business." 28 The Certified Milk Movement has shown, however, that it is practically impossible to get any considerable number of milk producers to observe its requirements, and then only at a price which makes the milk an unattainable luxury for all except the favored few. They have one or two farmers producing such milk for Rochester, but when the best city milk was sold for six cents a quart, the certified milk was sold for nine cents a quart. In Newark, N.J., under the direction of Dr. Coit, they have a Milk Commission which certifies the milk from one farm. But when the best grades of bottled milk were sold in the city for eight cents a quart, the certified milk brought fifteen cents a quart. Fifteen cents is the usual price of certified milk in New York City, but there are some firms that charge twenty cents, as against eight cents for the best grades of bottled milk supplied by the ordinary trade. 'It is not surprising that the quantity of certified milk sold in any city should be as "a drop in a bucket," that out of $1,500,000$ quarts of milk consumed in New York City each day not more than 8000 quarts should be certified. 
I am firmly of the opinion that it is the duty of the municipality to undertake the production and distribution of milk specially intended for infant consumption, equal in quality to the very best that can be produced by private producers, at a price within the reach of the people, a price which would not be greater than the average price for ordinary market milk, so that no child might be exposed to danger as a result of the ability of its mother to buy "cheaper" milk. Whatever deficit might be incurred by this means would, of course, be a public charge to be met as all other such charges are met. Further than this I do not believe any eleemosynary features should go. We do not need infants' milk depots as charitable institutions, but rather as common, public necessities to be used by all classes in the community as the public schools now are. For the indigent, those who cannot pay anything or only part of the price, some system should be adopted by means of which all charged with the relief of poverty could issue orders for milk, to be paid for by the public department, charitable organization, or individual issuing the order.

If I appear to lay undue stress upon the opinion that the infants' milk depot should be a municipal enterprise, and not a charity conducted by some voluntary philanthropic agency, it is because, in the first place, I believe that, outside of very narrow limits, which I propose to indicate, such philanthropies are morally 
indefensible, and detrimental to the development of a spirit of civic righteousness. Investigation and experiment are very proper spheres for voluntary action such as that which led to the establishment of hospitals, crèches, maternities, milk depots, and so on through a formidable list of social services which have been assumed by voluntary agencies. It was eminently right and proper for Mr. Straus - to use a concrete illustration - to establish milk depots for infants in order to find out whether the excessive infantile mortality could be reduced by such means. On the other hand, it is decidedly wrong and improper, in my judgment, that the city of New York should allow the work to remain in the hands of $\mathrm{Mr}$. Straus, or any other individual or society. Not only is the work inadequately done and its continuance dependent upon too slender a thread, but, far more important, a great city is demoralized to the extent of shifting its collective responsibility on to other shoulders than its own. In the case of an individual we readily enough recognize the demoralization of this kind of thing, but, for some reason not obvious, we do not recognize it in the case of a community.

Then, also, there are the more immediately practical objections, that nobody ever has a means of knowing readily whether the work is adequately or efficiently done, and that voluntary agencies, as Sir John Gorst points out ${ }^{30}$ as the result of a long and 
intimate experience with them, become, almost invariably, conservative and hostile to progress. There are several reasons for this. In the first place, it is perfectly natural for people who have organized themselves into an association for doing certain work, when it is proposed that the work shall be done by the community as a whole through its constituted authorities, to say: "That is our work. We are doing it as well as it can be done. If the public want it better done, let them support us more liberally." That is the most humble and the least arrogant position they ever take.

The more common position is that the work is being done and there is no further need. This feeling is fostered by interested secretaries, directors, collectors, and other officials, who feel, rightly or wrongly, that they have vested interests to protect against attack. For example, take the Society for the Prevention of Cruelty to Children and its attitude toward juvenile probation in this state. I am a member of the Board of Directors of the Westchester County S.P.C.C., and, it is superfluous to add, thoroughly in sympathy with the aims of the organization. But everybody knows that the leaders of the society have consistently opposed the appointment of probation officers other than its own officials and thwarted the development of a very important work, partly from jealousy, and partly also as a result of the agita- 
tion carried on by interested officials. Infants' milk depots have passed the experimental stage; and there is no good reason why the cities should shirk their responsibility in this matter and leave the work to private enterprise to be done well or ill, completely or incompletely, according to the will or the mental or physical equipment of those undertaking it.

\section{IX}

There has been so much statistical juggling with regard to the influence of infants' milk depots upon the infantile death-rates, alike by friends pleading their cause and opponents attacking them, that I am tempted to leave the matter alone, except in so far as it has been touched upon in preceding pages. I know of no subject in connection with which figures have been used with more recklessness than that of the influence of infants' milk depots upon the mortality of infants. So many factors, which no statistician can properly evaluate, enter into the infant mortality rate that unless the greatest care is exercised wrong conclusions are almost inevitable. For example, in a certain city there has been, during a period of five years say, a marked decline in the number of infant deaths, and it happens that the period of decline is coincident with the period during which an infants' milk depot has been in operation. It is not unnatural that in such circumstances the 
milk depot should be given all, or nearly all, of the credit for the decline, especially by its enthusiastic advocates. But the student must move slowly and take account of many other matters. What, for example, were the climatic conditions? Was there any improvement in the sanitary system? Were the streets kept cleaner than formerly? Was there a general decline throughout a large part of the country, due to a marked freedom from epidemics? Was there any industrial change which enabled more women to care for their babies? Were there other agencies beside the depot in operation, such as crèches and day nurseries, district nursing, children's hospitals, or dispensaries? In a word, the student must take into account all the facts.

Again, figures are sometimes published in connection with criticisms of infants' milk depots, professing to give the mortality among children fed upon milk supplied by the depots and invariably showing a high rate of mortality. Such figures are quite deceptive, for the reason that, as stated elsewhere in this chapter, most of the infants brought to the depots are more or less sick and debilitated already, so that the mortality rate, like the mortality rate among hospital and dispensary patients, would naturally be high. Further, the number of infants receiving milk from the infants' milk depots in many cities is too small to have any appreciable effect upon the mortality rates. 
Take the French depots, for example. Dr. Peyroux, a keen critic of the Gouttes de Lait, has pointed out that they have not very materially reduced the infantile death-rate, so far as can be ascertained from the complete mortality returns of some of the cities where they are established. ${ }^{31}$ But it could hardly be expected that a depot should materially affect the infant mortality rate of the city, when the number of children attending it is ridiculously small in proportion to the total infant population. In Paris, for instance, there is an infantile population of over 40,000 , but not more than 800 or 900 are cared for by the Consultations de Nourrissons and Gouttes de Lait. $^{32}$ At Grenoble, to cite the case of a smaller city, the average number of births during the years 18911901 was 1357, but only 72 infants per annum were fed from the Goutte de Lait. ${ }^{33}$ That these depots do prevent a considerable number of infants from dying is unquestionable, I think, by any person who has studied them. At the same time, they touch only a very small proportion of the infantile population. Professor Budin has compiled statistics to show that at his Consultation at the Clinique Tarnier during five years the death-rate shown among the children attending was only 46 per thousand as against 178 per thousand for the whole of Paris. ${ }^{34}$ Unfortunately, the figures are rather inconclusive, for the very vital reason that the death-rate of 178 per thousand cited 
for Paris applies to children under one year, while some of the children attended the Consultation up to two years of age. The Consultation, moreover, cannot be fairly classed with the infants' milk depots.

Turning to the English depots, we are confronted by the same difficulties. Either too few children are connected with the depots, statistics are not intelligently kept, or they are open to serious question owing to the fact that many factors are unaccounted for. Some figures were published in connection with the Liverpool and Battersea depots three or four years ago which will go far to illustrate the latter point. From 1896 to 1900 inclusive, the average death-rate per 1000 births of children under one year old was 188. In 1901 the first Liverpool depot was opened, and the rate for that year was also 188 per 1000 births. In 1902 a second depot was opened and the work greatly extended in its scope. That year the deathrate' of infants was only 163 per 1000 births, and in the following year there was another decline, to 151 per 1000 births. $^{35}$ Battersea's depot was opened in 1902. Prior to the opening of the infants' milk depot, the average mortality among infants under one year old, during the five years immediately preceding, was 161.8 per 1000 births. In 1902 , the year of the opening of the depot, the number fell to 136 and the following year it again declined to 135 per 1000 births." These figures by themselves would indicate an un- 
qualified success on the part of the infants' depots, but, as a matter of fact, while it is believed the depots helped, climatic conditions were especially favorable in those years, and there was a general decline in the infantile death-rate throughout the country, so that the depots can only be credited with a part of the decline, a part not to be determined and separately set out.

Dr. Newman, in the most serious study of the problems of infantile mortality published during recent years, gives a very careful account of the Finsbury infants' milk depot and shows the mortality among children attending the depot, during the first year of life, to have been equal to 59.1 per 1000 births as compared with a mortality of 148.6 for Finsbury, but only 169 infants used the milk. There were among these 13 deaths, equivalent to a death-rate of 76.9 per 1000 births, but as three of the children were dying when first brought to the depot, so that their case was hopeless from the first, these should properly not be counted. ${ }^{37}$ Now, small as the numbers are, when it is remembered that 75 per cent of the children were ill when they were brought to the depot, such results are astonishing. Dr. Newman quotes, with apparent approval, the claim made for the depot at Fécamp, France, of a death-rate of 121 per 1000 births, as compared with 240 for the city as a whole, and the claims of St. Helens of a mortality of 103 per 1000 
births as compared with 173 per 1000 births for the city, and Liverpool of a mortality among depot babies of only 89 per 1000 births. $^{38}$ As a matter of fact, the Liverpool figures are-even more favorable to the depot than that. Dr. Hope published particulars concerning 4453 babies kept under close observation, showing a mortality of 78 per 1000 births as compared with an average of 167.3 for the city as a whole. ${ }^{39}$

Upon the whole, the figures show plainly enough that the infants' milk depots do lessen the mortality of infants, their influence upon the total infantile death-rate of a city depending, naturally, upon the proportion of the infantile population supplied by them. The difficulties which confront us when we try to separate the influence of the depots from other influences are perfectly natural. We can no more hope to determine the exact share of each individual agent in the progress that is made, than we can hope to determine the exact share of every unfavorable condition in forcing the death-rate of infants up to such distressing heights. The remedial forces, like the forces of ill, are blended and interwoven. There is no means whereby we may weigh each factor, either in the sum of ill or the sum of good.

Much more satisfactory are the statistics relating to the experience of Rochester, already cited. In this case, also, we are aware that other factors beside 


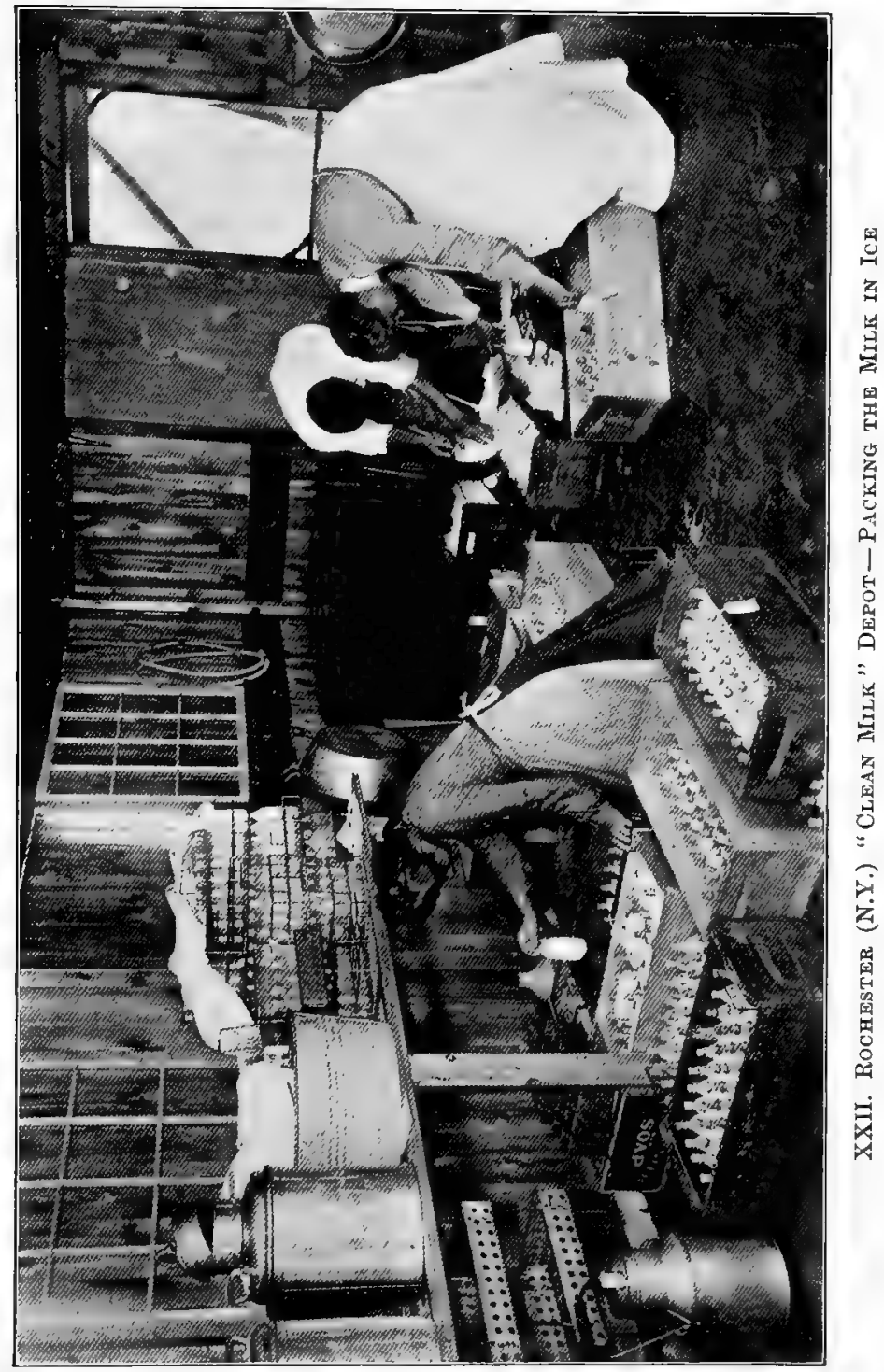



the infants' milk depot contributed to the splendid advance made in the direction of reducing the infantile death-rate to a minimum. It is significant that in connection with the work at Rochester and the work of the depots conducted by Mr. Nathan Straus we have the most emphatic and satisfactory evidence of the enormous reduction which can be made in the infantile death-rate through the establishment and maintenance of wisely managed infants' depots. We must conclude our summary with a brief examination of some important facts established by the Straus depots.

I do not propose to enter upon any discussion of the claims made from time to time as to the influence of the Straus depots in reducing the infantile death-rate in New York City. I content myself by saying that I am firmly convinced that the work of the depots has been a very important factor in bringing about that reduction, a statement which will not be seriously disputed by anybody who has given an hour to the study of the subject and who is candid and unbiassed. To my mind, the most exacting test to which any such institution has ever been put is furnished in the figures which relate to the work done by Mr. Straus on Randall's Island some years ago. That experiment and the investigations made by Drs. Park and Holt are universally regarded as being among the most important, if not altogether the most important, 
tests of the value of infants' milk depots yet made. Mr. Straus himself, in a paper read at the Congrés International des Gouttes de Lait, held in Paris, in 1905, has cited statistics which show that in New York City during the ten years, 1894-1904, there was an annual saving of 6982 infant lives, and I believe that of all the factors contributing to that great result, the most important single factor was the work of the Straus depots.

The experiment on Randall's Island is important because it affords much more direct and convincing testimony upon the influence of a carefully supervised infants' milk depot upon the rate of infant mortality. The experiment was condusted under test conditions practically, so that we are able to judge the effect of the milk depot without having to make discounts in favor of other factors. In the early nineties the death-rate among the infants in the Infant Asylum at Randall's Island was so high as to become a matter of very serious reproach to the city. The death-rate among these tiny victims of poverty and crime became the shame of the city. The babies died like flies; and it became a grim pastime among the attendants when a child was brought to the hospital to estimate its chances of living. The officials attacked the problem with seriousness and intelligence, but made painfully slow progress. The death-rate among the babies was 
42 per cent in 1895, 39 per cent in the year following, and 44 per cent in 1897. The death-rate seemed to remain in the neighborhood of 40 per cent as if fixed by some terrible fatalism.

In consequence of the results obtained through the depots he had established in various parts of the city during the two or three years previous, Mr. Straus, who had formerly been president of the Board of Health, secured permission to establish a complete pasteurization plant on the island in connection with the asylum. That was early in 1898. Immediately the spell was broken and the terrible death-rate of babies began to show a well-marked decline. Mr. Straus was proving to the great city and to the world that the power which exacted a death-toll of 40 per cent was the power of ignorance. As stated, the death-rate in 1897 had been 44 per cent, and in 1898, the first year of the experiment, the rate dropped to less than 20 per cent! The following table shows very clearly the results attained during a period of seven years, proving that the decrease was not a temporary or accidental one. It should be said that, while there were some changes in the later years, during the first two years at any rate, there were no other changes of any kind, either in respect to hygiene, management, or feeding. So far as human intelligence could perceive, the improvement was due solely to the better milk supply. 
232 THE COMMON SENSE OF THE MILK QUESTION

Table XI. Showing the Infant Death-rate on Ravdali's Island, New York City, from 1895 to 1905 INCLUSIVE

BEFORE THE ESTABLISHMENT OF THE STRAUS SYSTEM

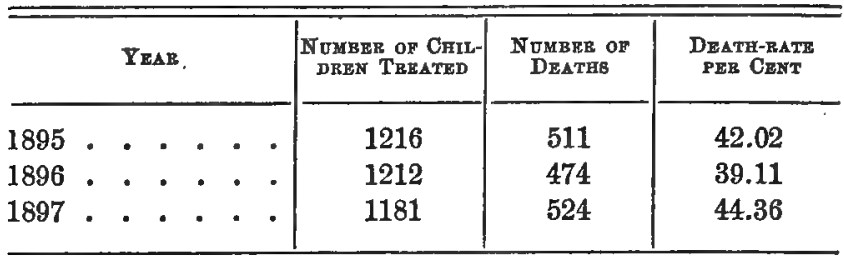

AFTER THE ESTABLISHMENT OF THE STRAOS BYSTEM

\begin{tabular}{|c|c|c|c|c|c|c|c|c|c|}
\hline 1898 & . & . & . & . & . & . & 1284 & 255 & 19.80 \\
\hline 1899 & . & . & . & . & . & . & 1097 & 269 & 24.52 \\
\hline 1900 & - & . & • & . & - & . & 1084 & 300 & 27.68 \\
\hline 1901 & . & . & . & . & . & . & 1028 & 186 & 18.09 \\
\hline 1902 & . & . & . & . & . & . & 820 & 181 & 22.07 \\
\hline 1903 & - & . & - & . & . & . & 542 & 101 & 18.63 \\
\hline 1904 & . & . & . & . & . & . & 345 & 57 & 16.52 \\
\hline
\end{tabular}

Now, it is a very simple matter to reckon the significance of these figures. During the seven years, 1898-1904, there were 1343 deaths, but had the death-rate been the same as during the three years previous to the establishment of the infants' milk depot in connection with the asylum, the number would have been 2604 . In other words, out of a total infant population of 6200,1261 lives were saved through the establishment of a proper milk supply, 
a saving of more than 20 per cent of the total number of children. ${ }^{40}$ Such figures as these do not need to be enforced by weighty argument. They are eloquent and impressive preachers of a social lesson of vast significance, and, above all, of sublime inspiration to all who seek to save the children of the nation from needless suffering and death.

The investigations conducted by Park and Holt have been so often described, and the detailed results are so accessible to the general reader, ${ }^{41}$ that it is unnecessary to do more than summarize them here. The object of the investigation was to study the manner of feeding infants in the tenements and its relation to infant mortality. Ten physicians, working under the direction of Drs. Park and Holt, during the summers of 1901-1902 and the intervening winter, kept a number of children under close observation for an average period of three months. The total number of children observed was 632 , of which number 340 were six months old or under, 265 ranging from seven to twelve months, and 47 a little over twelve months. Care was taken to select perfectly healthy children to begin with, and each child was visited by a physician twice every week. The weight of each child was taken at regular intervals and other physical conditions noted. It need scarcely be said that this medical inspection of the children, and the special interest in their children which the doctors' 
visits awakened in the mothers, were unusually favorable to all the children. Since the children fed upon milk from the Straus depots would in any case be under some supervision, a fact noted in the report of the investigation, it is fair to assume that there was a balance of advantage in favor of other kinds of feeding; in other words, that they were tried under particularly favorable conditions.

The result of the investigation was to show that, in summer, the worst results of all, the highest mortality and the greatest amount of illness, occurred with the dirtiest milk, that which was purchased at grocery stores in the neighborhood. The next poorest results were obtained from condensed milk; while by far the best results of all were obtained from the milk supplied by the infants' depots. In addition to the statistics summarized in the accompanying table, which speak for themselves, the unanimous opinion was expressed that, "Of methods of feeding now in vogue, that by milk from central distributing stations unquestionably possesses the most advantages, in that it secures some constant oversight of the child, and since it furnishes the food in such a form that it leaves the mother least to do, it gives her the smallest opportunity for going wrong." 42 The establishment of more numerous depots, by the municipalities, at least during the summer months, was unanimously recommended. 
Table XII. Illustrating The Results of Drfferent Kinds of Infant Feeding as found by Drs. Park and Holt

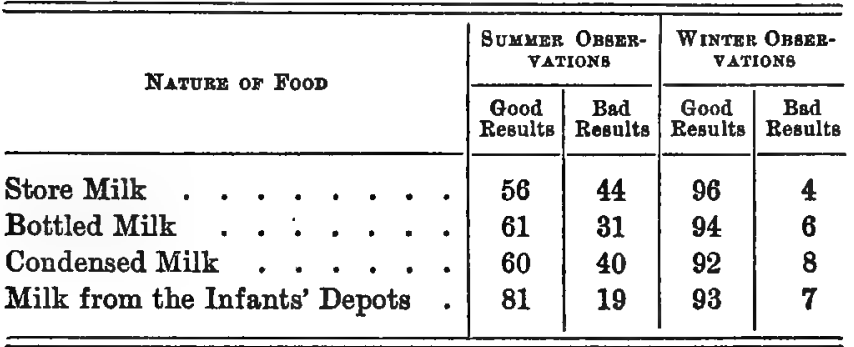

One of the most serious objections yet urged against the establishment of infants' milk depots is that they tend to discourage the practice of breast-feeding, whereas society should do everything in its power to encourage mothers to suckle their infants at the breast. ${ }^{43}$ Theoretically at least, the objection is of the greatest importance, and if it can be shown that the depots do have such a result the wisdom of establishing them is open to very serious question. But do they? Not a single fact has ever been cited to prove that they do. The objection is based entirely upon a priori reasoning. As a working woman I talked with on the subject at one of the depots said to me, "The doctors as says that only guess what they'd do themselves if they was women."

It would, I know, be almost impossible to bring 
direct evidence in support of such an objection, owing to the extremely delicate nature of the investigations which would have to be pursued in order to obtain it. I have submitted the matter to upwards of fifty physicians in England and this country and received replies from forty-three. Of this number nine did not "care to express an opinion"; two thought "such a result likely," but had no personal knowledge of any case in which such an effect had been produced; one was "opposed to all such socialistic folly" as infants' depots; the other thirty-one were unanimous in saying that they had no fear of such a result. All the physicians questioned were men whose practice gives them an opportunity to note the work of the infants' depots, and, while the consensus of their opinion is not conclusive evidence, it has, I think, considerable value. It is scarcely likely that such effects could be produced in any considerable number of cases without being noticed by some of the men whose replies are included in the above summary.

And if we may meet a priori argument with $a$ priori argument, it seems highly improbable that the infants' depots discourage breast-feeding in any way. In practically every case, when a mother makes application to have her child supplied from the infants' milk depot, she is questioned as to her reasons for not nursing the baby herself, and warned that the milk supplied by the depot is only a poor substitute 
at best for the baby's natural food. She is given simply worded literature pointing out the great advantages of breast-feeding and the dangers of all other kinds of food for infants, and physicians and nurses urge the same truths upon her. This is the normal, everyday practice of nearly every infants' milk depot I have ever known of, and it seems not unlikely that the depots are producing a result the very opposite of that feared by many critics.

That the influence of society should be exerted to encourage breast-feeding is true, of course. Possibly we shall yet be able to develop our school system in this country along lines making for physical efficiency as advocated by Dr. Gulick, ${ }^{44}$ and, in the last years of school life, do what we can to educate our girls so that they may not enter upon wifehood and motherhood so utterly unequipped as they now do. I have no doubt that a great deal could be done to educate mothers upon this and many other matters of vital importance - that much could, and therefore should, be done. But what are we to do with the women, rich and poor, who decline to nurse their babies, and with the babies themselves? Shall we, like that ruler of Finland who, in 1755, issued a royal edict prescribing a fine of ten dollars to be imposed upon mothers who through neglecting to suckle their babies for at least half a year lost them, ${ }^{45}$ make a mother's refusal to nurse her baby a criminal offence? 
And, whatever we may or may not do to the mothers, the question of providing for the children must be faced. Are we to join the mothers in a conspiracy against the children, or are we to protect the interests of the child when the mother fails?

And what of the working mother, who, even though physically able to nurse her baby, cannot because she must work away from home? The Austrian peasant woman who left her own baby to take its chances upon a diet of "horrible pap" and went out to act as wet-nurse for the child of a wealthy woman ${ }^{\text {is }}$ had no objection to nursing babies, apparently. It is fair to assume that she would rather have nursed her own baby. The women of Finland who suspended horns filled with sour milk over their babies' cradles and let them take their chances, might have nursed their babies but for the fact that they had to work in the fields and woods, or starve. ${ }^{47}$ So, too, with the factory worker and the charwoman. Are we prepared to subsidize breast-feeding, to make motherhood an occupation under the control of the State? And if not, if we are not prepared to do something like this, to do upon a big scale what Cologne and a few other European cities do on a small seale, what is to be done for the children? Finally, what of the children whose mothers cannot nurse them because of physical reasons? No matter whether the cause of their inability to nurse their young is the accumu- 
lated sins of their ancestors, or environmental conditions into which they have been forced by powers as remorseless as Fate; no matter, even, if the cause of their inability to nurse their babies is their own ignorance and folly, against which there was none to warn them, - the fact remains that the babies must be provided for. Do whatever we may to encourage breast-nursing, we cannot escape responsibility for the babies that languish and die because they are fed upon dirty and disease-producing milk, or substances more deadly still.

For more than ten years I have been haunted by the terrible consciousness that thousands of baby lives are needlessly sacrificed every year in the great cities of the world, while we boast of the progress of our civilization. For more than ten years I have grappled with the problems of infantile mortality according to my ability and strength, patiently and carefully studying the results of investigations made by others and making investigations on my own account. For more than ten years I have watched the experiments made by earnest men seeking to find the remedy for the evil of excessive infant mortality, mourning at every failure and glorying in every gain, however slight it might be. As a result of these years of study I feel entitled to say with assurance that impure milk is one of the most powerful factors making for a high infantile death-rate, 
240 THE COMMON SENSE OF THE MILK QUERTION

that its victims are more numerous than the victims of the great plagues, and that it is possible to save tens of thousands of baby lives each year, in the United States alone, through the establishment of infants' milk depots conducted upon scientific principles. Private philanthropy has shown the way; is there civic enterprise to follow? 


\section{CHAPTER VIII}

\section{PURE VERSUS PURIFIED MILK}

\section{I}

From the foregoing summary of the remedial experiments made in this country and in Europe it will be seen that the advocates of reform in the methods of producing and distributing the public milk supply may be roughly divided into two classes. While the nomenclature may be open to criticism, for the purpose of this discussion these classes may be defined as radical idealists and opportunists: the one class demanding a pure milk supply and decrying every proposal which stops short of that ideal; the other class taking the conservative view that in this far from ideal world pure milk is impossible as a general rule, - a very beautiful ideal, but unattainable, except for a favored few, for many years to come, if ever at all. And because they believe this, they urge that, while aiming at absolute purity, it is necessary in the meantime to purify the milk.

This broadly defines the issue upon which the reformers of the milk supply of the great cities have split into separate and sometimes bitterly hostile 
camps. In the United States especially the controversy between the two schools has been furiously waged, often with what the onlookers have felt to be much unnecessary vehemence. Often, indeed, there has been nothing but mutual misunderstanding to account for the bitterness of the war of words waged between the two schools. In reality they have not been so hopelessly at variance as the bitterness of their words would imply.

I remember addressing a mass-meeting upon the subject when there were strong partisans of both sides in the audience and upon the platform. The object of my address was to promote a better feeling between the two factions and to create a more friendly relation between them, based upon mutual understanding, with a view to their uniting upon a common platform. It was gratifying to have the spokesmen of both sides declare their entire satisfaction with the position I had taken and their full acceptance of the working programme I had hastily sketched. Upon several occasions it has been my good fortune to bring about similar harmony and confidence between groups of workers on both sides, so that I am disposed to take a hopeful view of the situation. It is my hope that the present volume will do something in that direction on a larger scale. Without attempting to minimize the differences, it can, I believe, be shown that the points of agreement are 


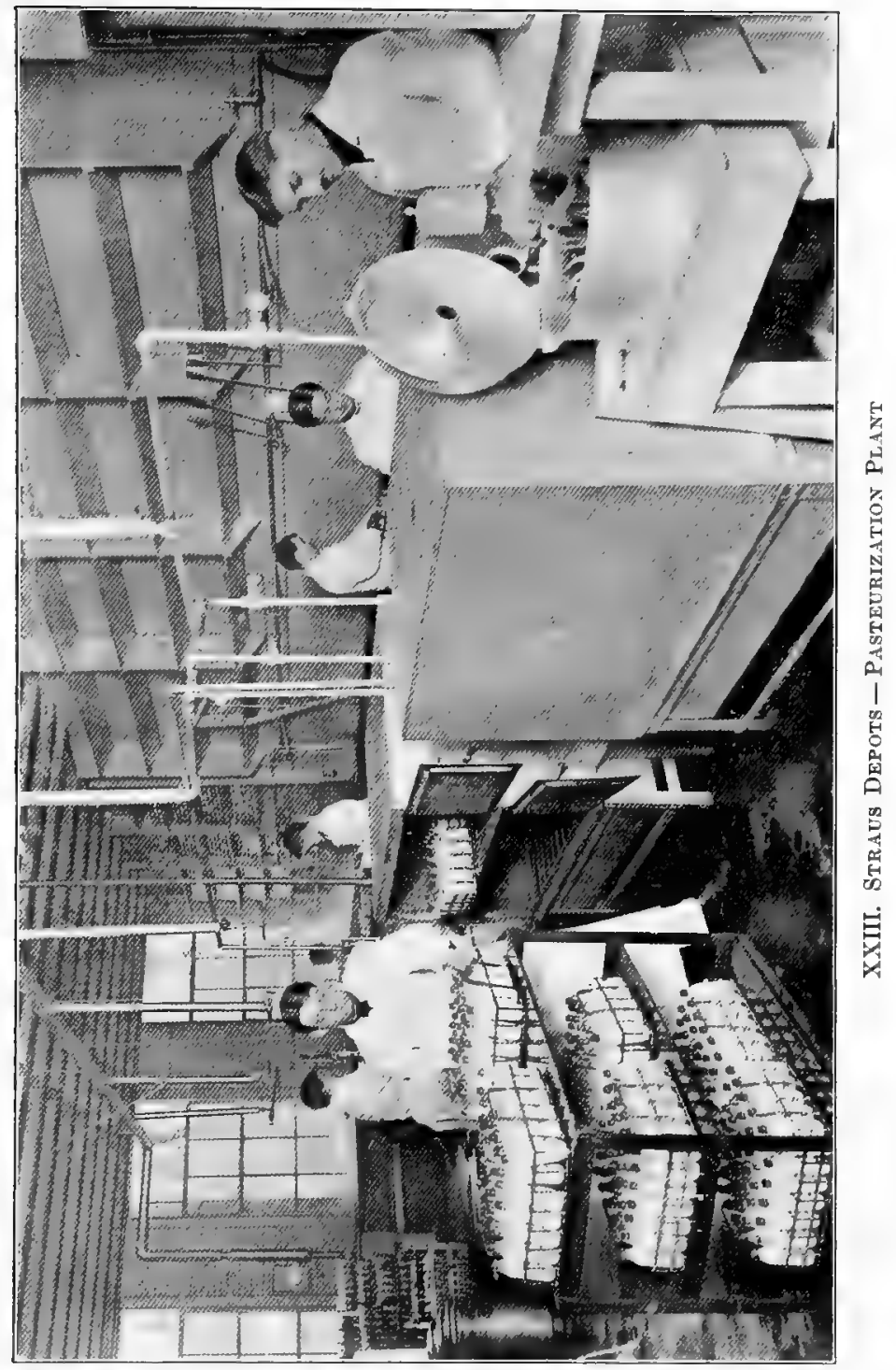



quite as numerous and important as are the points of difference.

It is upon these points of agreement I would have the two schools unite. It is not necessary for either side to enter into any sort of a compromise, to truncate its principles. That is wholly unnecessary, and, in my judgment, undesirable. But it ought to be possible for the leaders of both parties, all of them earnest and sincere men, to come together and say: "Here are so many points upon which we can agree. Let them constitute our immediate, common platform, but let nothing be put in the way of those who aim at an ideal milk supply which shall need no purification."

\section{II!}

In order that there may be a better understanding between the two schools of reformers, it is necessary that the issue between them be clearly defined; that the position of each side be correctly set forth. Fair and lucid statement of a problem is an important contribution to its solution.

The position of the radical school, the "clean milk" advocates, who oppose pasteurization, is indicated in their name. They are keenly alive to all the evils of the present conditions, some of which have been described in these pages. They have done yeoman service in pointing out the abominably 
unhygienic conditions under which our public milk supply is produced and distributed; they have done much of the investigation into the causes of contamination, and shown by actual experiment how unnecessary those conditions are; they have forced upon public attention the menace of a polluted milk supply to the public health and the highly important part milk plays in the spreading of disease. No reasonable man in the other camp will attempt to deny that the clean milk agitation has had all these merits. ${ }^{1}$

Now, these radicals of milk reform say that it is possible to secure a practically germless milk supply which is absolutely safe and clean. They say that, however utopian it may sound to conservative ears, it is possible, in a little while, given the right spirit of civic coöperation, to get a public milk supply which will come well within Professor von Behring's zone of safety, having a bacterial count of less than 1000 per cubic centimeter. This, they believe, is by no means an impossible ideal, even for the general milk supply of any city. In support of their contention they point to the numerous experiments similar to those outlined in the present volume which prove that it is possible to produce practically sterile milk. Given such milk, they argue, it would not be necessary to resort to pasteurization or any other method of purification, and the advocates of pas- 
teurization admit the contention. The radicals, in a word, want pure milk, not purified milk.

Pure milk, say the radicals, is obtainable with the knowledge we now have. The risk of transmitting the germs of any disease, either of human or bovine origin, to the consumers of milk, whether they be adults or infants, would be reduced to zero practically. And while cow's milk cannot be considered an ideal and absolutely safe food for infants, however pure it may be, except when modified and distilled through the lacteal glands of the mother, milk of the standard of excellence described would be as safe as science knows how to secure it, and the mortality of infants would be much lessened as a result of its general use.

So much for the point of view of the radicals. Now let us turn to the opportunists, to the advocates of purification. The methods of purification usually employed upon a large scale, and recommended by reformers, are pasteurization and sterilization. The latter method is almost universally used in France and England and some other European countries in connection with the infants' milk depots. In this country the former method prevails, sterilization being rarely or never practised. The principle involved in both methods is the same, the difference being in the degree of heat to which the milk is exposed and the length of the exposure. 
It will be sufficient for our present discussion if we consider the point of view of the advocates of pasteurization, which differs only from that of the advocates of sterilization in that the latter claim to be more "thorough" when they carry the process farther.

Like the clean milk partisans, the advocates of pasteurization are thoroughly alive to the evil conditions which almost universally exist. They, too, have done much to direct public attention to the unhygienic conditions which surround the milk supply from the cow to the table at every stage of the long and tedious journey. With the zeal of enthusiasts, they have agitated for reform and lost no opportunity of calling attention to the perils of polluted and infected milk. If they have done less original investigation in this field than their clean milk rivals, they have abundantly balanced accounts by the work they have done as popularizers of the truth. $^{2}$ No fair-minded opponent of pasteurization in the radical camp will deny that the advocates of pasteurization have done most of the pioneer work and created most of the existing sentiment for reform. They were the radicals of a few years ago, and met with the ridicule and opposition which radicals must always encounter and endure.

Nowadays, among the reformers, they are conservatives. They frankly admit that pasteurization 
is a makeshift - a necessary evil. They readily admit, as all sane men must, that it would be vastly better to have clean and uninfected milk, rather than milk which has been, so to say, cleansed and disinfected. They do not for a moment dispute the claim that milk so pure as to need no purifying process is the ideal to be aimed at; that milk ought to be so pure as not to need any pasteurization. All these things they admit without question." So far the two schools are in perfect agreement.

But they do not share the optimism of the radicals. Not for many years, if ever at all, they say, shall we get the milk supply of our cities so pure that it will need no purifying. So far as it is possible to judge the future, contend the opportunists, there are no probabilities of such ideal conditions being attained within the lifetime of any now living. They point to the fact that we go on quite contentedly drinking milk which contains many millions of bacteria per cubic centimeter, even giving it to our babies. They take such statements as that made by Professor Conn that the milk of our cities contains more bacteria than their sewage does," and they urge that now, until we can get a pure and wholesome supply, entirely safe and free from infection, pasteurization is necessary - especially for the milk intended for infants.

The proposition is an exceedingly simple one. 
Here is milk which, if properly drawn from a healthy cow, under hygienic conditions, would be clean, sterile, and free from disease germs. Not being so drawn, however, it is foul and teeming with germ life, some of which may be fatal to a child. There are the germs of diseases from which the cow suffers, and germs of diseases from which human beings coming into more or less direct contact with the milk suffer. Granted that "cooking" the milk does not make it clean, it at least kills the germs. Granted, too, that some of the germs are harmless, that some of them may even be helpful to the digestive processes, it is best to kill them all if that is the only way of destroying the dangerous germs once they are in the milk. The gain which ensues from the destruction of the dangerous germs far more than compensates for any loss which may result from the destruction of healthful germs that are aids to the digestive system. And in support of this contention they point to the impressive and convincing figures which show the reduction made by pasteurizing their milk in the mortality of infants.

It will be seen that there is no criticism of the position of the radicals in this, except that it is utopian and idealistic. The advocates of pasteurization have no attack to make upon their rivals of the clean milk school, their only criticism being that they are holding out an ideal that is unattainable 
within any computable time. And for that they do not care provided only that in the meantime milk is pasteurized. This statement of their position will, I believe, be generally accepted by the leading representatives of both schools, and is, indeed, based upon the statements made to me by the leading exponents of both groups for the purposes of this discussion. It is highly important that the fact that the only criticism of the clean milk school which comes from the advocates of the pasteurization of milk is that they are utopians and visionaries. The bulk of the criticism in the controversy comes from the radicals. They have placed the advocates of pasteurization on the defensive.

\section{III}

There is no need to dwell further upon the criticism of the position of the radicals by their opportunist rivals who believe in pasteurization. That is all summed up in a sentence and can be comprehended by a child. But not so the criticism of the opportunists by the radicals. Here we have a body of very serious criticism which cannot be so easily summarized and comprehended.

It is not my purpose to attempt to give a complete synopsis of this very long and complicated controversy, much of which has little vital significance. I propose only to state the most important points of 
the attack upon pasteurization and to consider them in relation to the available evidence.

(1) It is urged that pasteurization does not kill all the disease germs. It is claimed that the most harmful germs survive, those killed being the least harmful, the harmless, and the useful.

Now, it is obvious that, if true, this is a serious, though not necessarily fatal, objection. I say, that it is not necessarily a fatal objection, because it might be claimed with good reason that if pasteurization did not kill all the most dangerous germs but only a few of them, it would still be advantageous if it killed a very large number of disease germs. The weight of the criticism, however, cannot be denied. In bacteria land, as in most other places, the wicked flourish and the good die too easily. The disease germs which men most fear in milk are those of the dread tuberculosis, and it is alleged that the pasteurizing process does not kill the tubercle bacilli. It is not denied that it kills the germs of scarlet fever, typhoid, and diphtheria, but it is contended that one of the greatest dangers to be feared is the presence of tubercle bacilli in milk, and that the fact of milk being an important factor in the spread of tuberculosis has been one of the most cogent arguments for pasteurization. If, therefore, the process does not kill the tubercle bacilli, that danger is not removed, and the utility of the process is very much less than is claimed by its friends. 


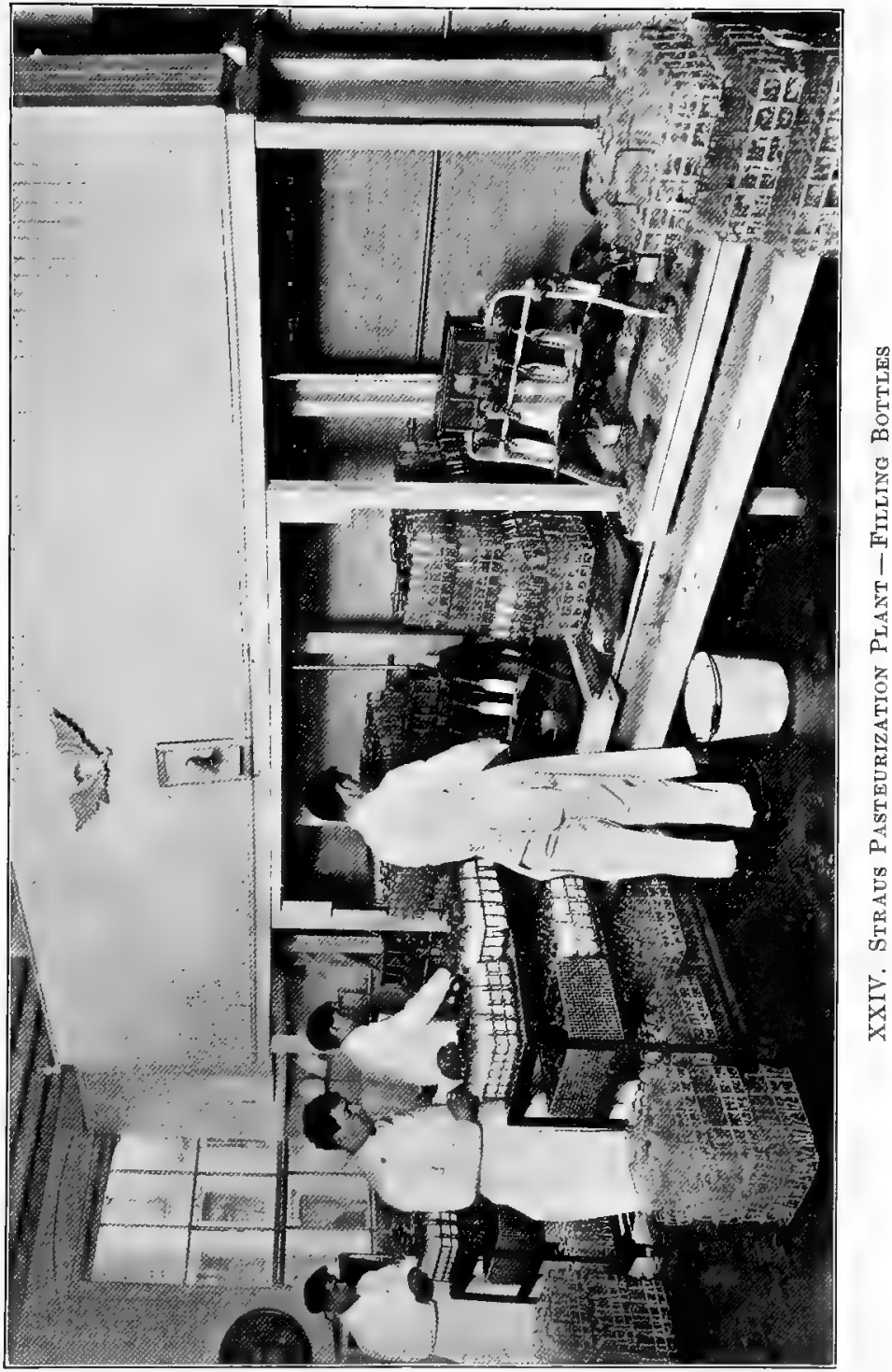



Before making any attempt to judge the value of this criticism, let us first of all make sure that we mean the same thing by the use of the word "pasteurization." There is no legal definition of pasteurization. There is no city or state anywhere, so far as I know, which has established a legal standard of what constitutes pasteurization. The result is that every dealer is entitled to adopt a standard of his own. There is less difference between raw milk and some kinds of pasteurized milk than there is between different kinds of pasteurized milk. A great deal of the milk which is commercially produced and sold as pasteurized milk is simply heated to a temperature of about $150^{\circ} \mathrm{Fahrenheit}$ for twenty or thirty seconds and then rapidly cooled. It is admitted that this does not very greatly reduce the number of tubercle bacilli, though it may kill practically all the germs of scarlet fever, 95 per cent of typhoid and diphtheria germs, and as much as 90 per cent of all the bacteria. ${ }^{5}$ Of the tubercle bacilli a very large proportion are not killed."

So far, then, much of the criticism is justified when directed to a great deal of milk ordinarily sold as pasteurized milk. It does not follow, however, that it also holds true of scientific pasteurization, such as that practised in many foreign cities and at the Straus laboratories in this country. This scientific method is to keep the milk at a temperature of $167^{\circ}$ 
Fahrenheit for at least twenty minutes, sometimes for thirty minutes. It has been found to be impracticable to raise the temperature above $167^{\circ}$ without impairing the taste of the milk, and that exposure for twenty minutes to that temperature does effectually destroy the tubercle bacilli. The greatest living authorities, including Professor Bang, ${ }^{7}$ Theobald Smith, ${ }^{8}$ Professor Pearson of Pennsylvania," Drs. Park, ${ }^{10}$ Holt, ${ }^{11}$ and Freeman, ${ }^{12}$ are agreed as to this. There are, I believe, records of experiments which appear to controvert this, but they are of very doubtful value. ${ }^{13}$ The evidence is overwhelmingly in favor of the claim that scientific pasteurization does destroy all disease germs.

It has never been suggested by any competent authority that any considerable number of tubercle bacilli survive exposure for twenty minutes to a temperature of $167^{\circ}$ Fahrenheit. Even if a few escape under exceptional conditions, it would still be quite fair for the advocates of pasteurization to urge its claims upon the basis of its germicidal value. With all my sympathies on the side of the radicals, I cannot resist the conclusion that a candid study of the facts will destroy the value of the criticism we are considering, when it is directed against scientific pasteurization. It is most unfortunate that efficient pasteurization should be discredited on account of a commercial imitation to which the 
name ought never to be applied. I have long held that there should be a legal definition of what constitutes pasteurization. Such a definition would go far toward protecting the public against what is, under all the circumstances, practically a fraud, as I said at the Milk Conference held in the New York Academy of Medicine in 1906.

(2) It is alleged that pasteurization destroys some of the nutrient qualities of the milk, renders it difficult to digest, destroys the lactic acid bacteria which are of great importance, and leads to diseases like scorbutus and rachitis in infants.

I place this group. of objections together for the reason that they are, ultimately, only different statements of the same difficulty. I place them second only to the objection considered above for the reason that, intrinsically, this group of charges undoubtedly are second in importance only to the charge that the germicidal action of pasteurization is inefficient. But it is only fair to add that this mass of criticism is.less often met with than formerly, so that it is of less relative importance than it was at one time.

There is a bewildering mass of contradictory testimony on both sides from which either party to the controversy could select enough to make out a very strong and seemingly conclusive case. It is, however, scarcely worth while attempting to sift it, for two reasons. In the first place, because no conclusive 
result could possibly be reached, and, in the second place, because the criticism is being very generally abandoned. A brief survey of a few of the calient and essential facts will suffice to do justice to the reply which the friends of pasteurization have always made to this body of criticism.

It is admitted that the process destroys the lactic acid bacteria with the more dangerous kinds of bacterial life. That is admitted by that vigorous antagonist of the "raw food cult," Professor Metchnikoff, who likewise admits that the milk thereby loses something of value."14 Just how valuable lactic acid in milk is cannot be accurately determined. Metchnikoff exalts it so that it becomes practically the most important item in diet. It is, according to the great French physician and apostle of human longevity, a specific against the germs of more deadly diseases. The weight of medical opinion seems to be that lactic acid bacteria in milk are not injurious, that their presence in the intestines in moderate quantities is rather desirable than otherwise, since they prevent the fermentation of the milk in the intestines assuming putrefactive forms injurious to health by reason of inducing intestinal disturbances.* So important does Metchnikoff regard it that, after destroying all bacteria by pasteurization, he puts lac-

* For a contrary view, argued with much weight, see Brush, Milk, pp. 43-50. 
tic acid bacteria into the milk. ${ }^{15}$ It will thus be seen that the advocates of pasteurization admit that the process destroys bacteria which may be very useful to the consumer of milk. It must be remembered, however, that the advocates of pasteurization do not disguise the fact that pasteurization is a necessary evil in their judgment; that milk whickeneeded no such treatment would be far better. It is the familiar case of enduring the lesser evil to be rid of the greater.

In view of the fact that diseases of the digestive system are responsible for a terrible proportion of infantile deaths, it is fairly obvious that if pasteurized milk were more difficult to digest than raw milk, the mortality from intestinal troubles among infants fed upon it would be above the average greater than the mortality among infants fed upon raw milk. This would undoubtedly be the result unless there were other advantages which more than compensated for this serious disadvantage. And should there be such a balance of advantage it would, of course, justify pasteurization and destroy much of the force of the criticism. The issue must be decided by an appeal to fact rather than to theory.

Now, what are the facts? Is the mortality from diseases of the digestive system greater among infants fed upon pasteurized milk than among infants fed upon raw milk? In this, as in so many other matters, 
it is well to apply the common sense test of actual experience. That our test may be fair and just we must compare the results of feeding upon pasteurized milk with the results of feeding upon the ordinary raw milk of commerce, and not with the results of feeding upon raw milk of exceptional purity. For the advocates of pasteurization have never denied that pure raw milk would be better than milk of doubtful purity pasteurized. A conclusive answer to our questions, it seems to me, is contained in the universal experience that where the milk supply is poor, pasteurization leads to a diminution of infantile mortality. The figures cited in the previous chapter afford a sufficient answer to the criticism that pasteurized milk is harder to digest than raw milk. If this were true, we should find a larger mortality from digestive trouble among infants fed upon it, and the fact that we get a result the very opposite of this tends to show that either the alleged indigestibility is a fiction, or that pasteurized milk has other advantages which outweigh the disadvantages - even when diseases of the digestive system alone are taken into account.

In point of fact the criticism never rested upon anything more scientific than guesswork. So far as I am aware there never existed the conditions which could provide a fair basis for a comparison of the merits of raw milk with those of pasteurized milk as a food for infants. Much of the argument rests upon. 
a fallacious basis. Long before the time of Pasteur, the mothers of a great part of Europe heated the milk given to their babies, generally boiling it. To-day in the tenement homes of all our cities milk is most generally boiled before being given to babies, almost invariably so in summer. The researches of such men as Drs. Park and Holt ${ }^{16}$ show this, and Dr. Darlington, the Health Commissioner of New York City, has had the matter carefully investigated with the result, he informs me, that he finds boiling to be the general rule.

I am not unmindful of the fact that this argument may be a two-edged sword, that it may react against pasteurization, at least so far as the establishment of infants' milk depots is concerned. It may be urged with reason and sincerity: "If practically all the milk is boiled before it is given to the babies, what need is there for pasteurizing it - why not leave that to the mothers?" It must not be forgotten, however, that the actual pasteurization is only one of the services performed by the depots. There is the careful, scientific modification of the milk, the supervision of the babies, the constant advice to mothers, and, hardly less important, the invariable practice of securing the highest standard of excellence in the production of the milk itself. Then, also, it is important to bear in mind that the careful, scientific pasteurization of the milk is very different from the haphazard and frequently 
careless "heating" and "boiling" practised by mothers in their homes. Much of the scurvy attributed to pasteurization should be properly attributed to over-boiling, as Jacobi, ${ }^{17}$ among others, has pointed out.

In connection with this criticism it is significant to note that in the great London hospitals milk is almost invariably either pasteurized or sterilized before it is given to children, and none of the evils complained of have been encountered..$^{18}$ It is also worthy of note that in France, in connection with the Goutees de Lait, there has been a decrease of scorbutic diseases among infants rather than an increase. ${ }^{19}$ I have been assured by the most competent medical observers that the disease is quite as rare as in this or any other country. Dr. Jacobi advocates the boiling of milk, but is careful to point out that over-boiling leads frequently to scorbutus. I know a physician whose sister's child suffered from a severe scorbutic disease. He was called to attend the child and decided that the trouble arose from the use of pasteurized milk. Henceforth he became an opponent of pasteurization. Raw milk was ordered and tried, but the baby did not improve in any way. Another physician was called in and at once ordered that pasteurized milk be given. $\mathrm{He}$ was told of the former experience and decided that he would make an investigation. I need not here describe his investigation in detail as he de- 
scribed it for me; suffice it to say that he found out that the servant who prepared the child's food had a notion that "so long as the milk was well boiled it was all right." She "thought it could not be boiled too much." I could give particulars of several other cases very similar to this one.

To sum up: It seems reasonably certain that pasteurization, sterilization, or any other process of heating milk to a temperature high enough to have a germicidal effect impairs it to some extent. On the other hand, there is abundant evidence to show that the gain is far greater than the loss. And it is a most significant fact that among the radicals, the advocates of such methods of inspection as will insure clean milk, there is universal agreement that, until we can obtain milk of the desired standard of purity, cleanliness, and freedom from disease germs, it is best to pasteurize milk for infants.

(3) It is objected that to establish depots for the sale of pasteurized milk would be a mistake for the following reasons, among others: (a) It is an extension of paternalism. The city or state ought to leave that to the mothers, taking care only to see that the supply is pure and good. (b) Where there is so much doubt as to the efficiency of the process, it should be optional with parents whether they give their babies pasteurized milk or unpasteurized milk; (c) The effect of pasteurization would be to make the milk producers and milk dealers careless, 
causing them to rely too much upon pasteurization, rather than upon cleanliness.

Considering these objections in their order, not much need be said with regard to the first. The bugaboo of "paternalism" has been raised whenever any advance has been proposed. It was raised against the proposal to make education free and compulsory; it was raised against the establishment of municipal hospitals and dispensaries, parks, playgrounds, baths, recreation piers, and lodging houses for the homeless; it was raised against the factory acts; it has been raised against every proposal to bring the great corporations under public control. On the other hand, it is difficult to see that pasteurization of milk for infants would be more paternalistic in principle than the elaborate system of inspection necessary to insure pure milk.

With regard to the second objection, that the use of pasteurized milk ought to be optional with the parents, since there is some doubt as to the efficiency of the process, it need only be observed that only a very small minority of the advocates of pasteurization would dispute that claim. Most advocates of the establishment of infant milk depots for the sale of pasteurized milk would be quite willing, I am convinced, to have raw milk also sold at the depots, provided that it reached a certain high standard of excellence. No objection, I imagine, would be raised to the 
sale of raw milk having a low standard of bacterial content, approximating the standard set by Professor von Behring, and free from disease germs. As to the principle involved of giving the parents an option in the matter, it is rather suggestive that the advocates of laissez faire in this particular do not suggest that the rule should be generally applied. There is at least quite as much dispute as to the efficiency of vaccination, but they do not suggest that parents should be allowed an option in the matter of the vaccination of their children; there is a not inconsiderable body of unbelief in doctors and medicine nowadays, but those who oppose pasteurization upon the ground that the parents ought to be given an option do not, I have observed, admit the right of the Christian Science believer to have an option in the matter of calling a doctor for his sick child. In all other matters they recognize that the child belongs to society rather than to the parents.

So much for the principle involved. As a practical question, theories of parental laissez faire and the responsibility of society for the child's welfare enter into it hardly at all. Except by a few individuals, perhaps, it is not proposed that parents should be compelled to give their infants pasteurized milk and forbidden to give them raw milk. It is proposed simply that municipalities should face the fact that the ordinary milk supply is a menace to childhood, 
and that they should establish depots for the sale of pasteurized milk scientifically prepared, and educate mothers as far as possible to the importance of using it for their babies. I have discussed the matter with many of the leaders of the radical school, and I have not yet met one of them who did not agree to the following propositions: (1) the milk supply of no American city can be considered a safe food for infants; (2) until this condition is remedied, it is safest and wisest to pasteurize the milk given to infants. This, I say, has been the unanimous verdict of the leaders of the radical school of milk reformers, and I see no reason why the cities should not frankly teach the mothers that and provide them with the means of getting pasteurized milk.

Concerning the third objection, that pasteurization tends to encourage slovenliness upon the part of the milk producer and the milk dealer, I am inclined to think that it is the most serious and weighty objection of all from a practical viewpoint. There can be no doubt of the force of the objection, I think, even though it may not rest upon a statistical study. It requires but an ordinary knowledge of human weakness. Teach people that impure and disease-infected milk can be rendered harmless by any process of germicide, and, unless special efforts are directed to counteract the tendency, there will be a drifting away from standards of care and cleanli- 
ness on the part of the milk producer and the milk dealer, as well as a slackening of energy and a lessening of zeal on the part of the consumers. The advocates of pasteurization vigorously deny that this would be the tendency, but I remain unconvinced by their optimism. There is always the factor of human weakness to be reckoned with. Boston's bacteriological standard lulls the Boston citizen into idle complacency, and I wonder if it would be otherwise with pasteurization. "Milk Sweet" and "Preservaline" and the host of other germicidal preservatives increased the sloth and the weakness of the farmer, and I wonder if pasteurization would do less. Frankly, I am very sceptical.

It is this factor which keeps me from being wholly one of the opportunists and drives me ever and anon to the radical camp - this and the radical ideal. But it must be said in justice to the opportunists that they do not propose to trust entirely to pasteurization. Their plan necessitates no lessening of the effort to obtain pure milk which will need no pasteurization. They do not propose that there shall be less inspection of dairies and stables than now, but more. And it is in this attitude that I see the hope of a unison of both forces. The radicals agree that until milk can be obtained by the average citizen which is absolutely safe and fit for use as a food for babies it is wise to pasteurize it. The opportunists on their side 
agree that pasteurization ought not to be necessary, that it ought not to be regarded as a solution of the problem. They, too, believe in trying to get a milk supply which it will not be necessary to pasteurize.

Here, then, it seems to me, is a basis upon which they can unite for many years to come - years of fruitful labor and progress toward a common goal. As I see it, the present situation may be likened to an outbreak of typhoid in a city, which has been traced to the water supply. While the disease is ravaging the community, the doctors come together and discuss the situation. There is no question as to the cause of the epidemic, it can be definitely traced. The only question is as to what shall be done. One set of doctors say: "Our duty is plain: we must begin an agitation and compel the city government to put an end to the pollution of the water supply. They must stop the sewage from running into the reservoirs." They are the radicals of the moment. "But that will take five years to accomplish," say the opportunists. "Five years, and meanwhile the disease will go on; people will needlessly die. We must give them more immediate relief. We must get the people to boil their water so that the disease germs will be killed." In such a situation, the obvious thing to do is to adopt both plans - to urge boiling the water 


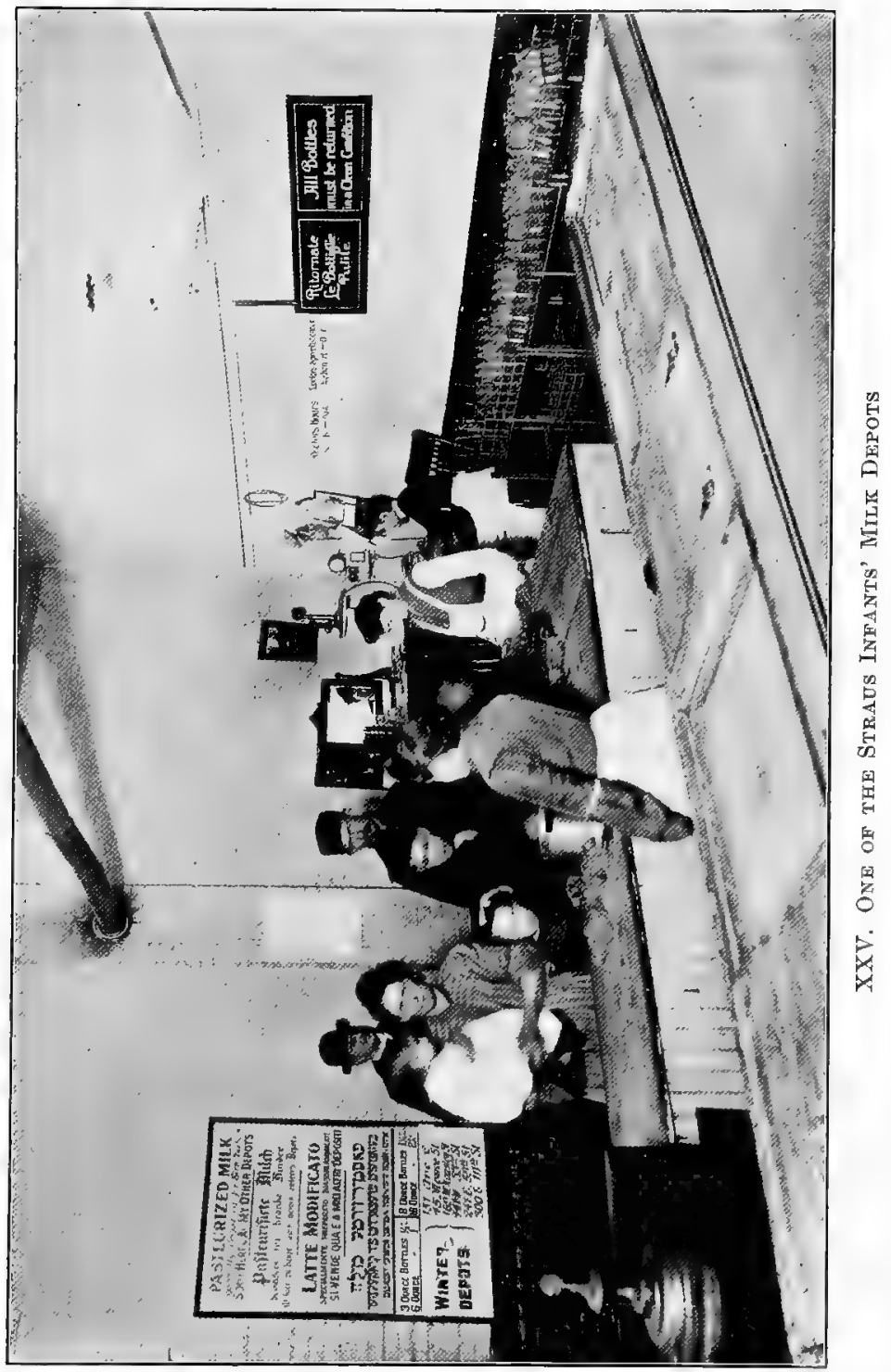



while the fundamental reform is being carried out. And, as I see it to-day, that is precisely the situation with the milk reform controversy.

Given the union of the two forces, of the spirit of the radical and the opportunist, and there would be no reason to fear the one really important objection to pasteurization. There would be no fear that pasteurization would be regarded as a solution; no fear that the movement for better inspection would be retarded. Time and again I have submitted this view of the situation to adherents of both schools, and I have never yet failed to get an answer that implied a readiness to unite in a common movement upon such a basis as I have outlined in these pages. I have submitted to leading workers on both sides a programme for united action which they have invariably expressed their willingness to accept. Unity of forces seems to me, therefore, easily attainable.

In the hope that something may be done to bring together the radicals and the opportunists, I venture to place here, as a fitting conclusion to this chapter in which the controversy is so hastily summarized, a practical programme upon which both sides may agree: -

(1) The establishment of a National Milk Reform Association, with branch organizations all over the country, and having for its object the promotion of legislation for the improvement of the milk supply 
of cities and towns; the education of the milk producers, the milk dealers, and the milk consumers upon the subject; the publication of literature upon the subject.

(2) The principal reforms urged by such an organization to be (a) more efficient inspection and the rigid enforcement of certain standards of cleanliness and purity, the ideal to be aimed at being a safe and germless supply; (b) the establishment of infants' milk depots for the supply of pasteurized milk, with the understanding that raw milk of a certain accepted standard of purity and cleanliness may be also sold; (c) the elimination of tuberculosis from dairy herds; (d) the promotion of breast-nursing and the education of mothers in the principles of milk hygiene. ${ }^{20}$

There are doubtless many other matters which could be very conveniently incorporated into such a platform as I have suggested, but my purpose is simply to demonstrate that it is possible for all who are working for the reform of our public milk supply to join hands in a great all-inclusive, effective movement. 


\section{CHAPTER IX}

\section{OUTLINES OF A POLICY OF REFORM}

I

THose who have read the preceding pages with reasonable attention will be able to anticipate most of the leading features of the policy of reform which I desire to outline in bringing this study to a close. The problem is many-sided; the evils are so numerous and varied in character that no single reform will suffice. The evils spring from so many sources from the animals themselves, their environment, their attendants, the utensils into which the milk is drawn, the mode of its conveyance from the farms to the cities, the places where it is sold, and the unhygienic conditions which abound in the homes where it is consumed. At every stage, from the time it is drawn from the cow's udder until it enters the infant's stomach, ignorance, carelessness, and greed - but ignorance above all! - add to the natural difficulties and perils of using cow's milk as a food for the human infant.

While the conditions described in the earlier pages of this volume obtain generally in all states and in most cities, whether large or small, the degree in which 
particular conditions exist differs very greatly. It would be quite futile and foolish, therefore, to attempt to formulate here an absolute programme for general adoption, to urge that such a programme should be adopted in its entirety, regardless of the density of population, climate, industrial conditions, and other factors of like importance. It would be quite absurd to advocate the adoption of the programme which New York needs in North Dakota; and just as absurd to urge the adoption of the programme suited to the requirements of Chicago by some little hamlet in Missouri.

In considering the suggestions herein made, it will therefore be necessary to bear in mind that they are not put forward as an absolute programme, that it is not claimed that they apply to all places. So far as the suggestions for state action are concerned, I believe that with very few and slight modifications they apply to practically all the states. The great fundamental conditions with which the states must deal are practically universal, and the needs of Wyoming or Idaho differ, not in kind, though greatly in degree, from those of Illinois or New York. It is particularly desirable that there should be practical uniformity of legislation and policies throughout the states with regard to these conditions. There is just as much need for a vigorous effort to eradicate bovine tuberculosis in one state as in another. On 
the other hand, the needs of cities vary greatly, so that a uniform policy is impossible.

The elimination of tuberculosis from dairy herds is by far the greatest task confronting the states. It is the first great need, before which everything else seems relatively unimportant. Not only is it important from the point of view of those reformers who are seeking to obtain a satisfactory milk supply for infant feeding, but there is a growing conviction that we can never halt the ravages of the plague among mankind until we can eliminate it from our cattle. There are many reasons why this should be regarded as a national problem, to be solved by federal action, only a few of which need be enumerated here.

First of all, the problem is so big, its economic aspects so serious, that it will be difficult to secure a uniform, thorough, aggressive policy on the part of all the states. In those states where the proportion of dairy farms to the population is greatest, where the largest part of the population depend on dairy farming, it will, naturally, be more difficult to get such a policy adopted than elsewhere, by reason of the vast economic interests at stake. In those states where dairying is of less importance economically, where the mass of people only consider the perils to which they are exposed through the sale of the milk of tuberculous cows, it will be more easy' to get such 
a policy adopted. Secondly, milk is largely a subject of interstate commerce. In the city of New York, for example, we have a great population drawing its milk supply from seven different states, and it is foolish to argue that New York has no interest at stake when Pennsylvania or Ohio legislates upon this question. It is also quite preposterous that the citizens of New York, in order to be sure of a decent milk supply, should be obliged to maintain a costly system of inspection in half a dozen states, as at present. Finally, the organization of such work under federal auspices would be, or could be made, much more economical than if carried on by the various states.

\section{II}

It seems to me, then, that this great work should be undertaken by the nation; that steps should be taken to stamp out the disease within a given period of time. That this is possible, and not a mere dream, no one who is familiar with the work done in Denmark, under the leadership of such men as Professor Bang, will very seriously doubt. They have not reached the ideal, but they have demonstrated that, given the necessary funds, bovine tuberculosis can be eradicated.

Denmark, as is generally known, has long suffered to an extraordinary degree from tuberculosis, both 
bovine and human. It was found by physicians and veterinarians who were alarmed by the excessive prevalence of the disease, both among cattle and human beings, that there was a very close connection between the two. As a result of the agitation by the veterinarians which resulted, Copenhagen secured from the imperial parliament an act giving it certain powers to attack the problem of eliminating the disease from the dairy herds, and preventing the infection of the people through the use of tuberculous milk and meat. The Copenhagen system, as it is called, is to-day universally regarded as the most significant experiment ever made in this direction. ${ }^{1}$

Under this system there is frequent and careful inspection of all herds. The tuberculin test is used, no charge being made to the farmer, either for the tuberculin or for the services of the veterinarian. The worst animals are slaughtered, including all those with badly diseased udders. Others, less seriously affected, are separated from the healthy stock, so as to prevent the spread of infection. Such segregated infected animals may be used for breeding purposes, or they may be fattened for the market, but their milk must not be sold or used for any purpose whatsoever. This is frankly regarded as a compromise, and the general opinion is that nothing short of the slaughter of all infected animals will prove finally effective. 
All cattle slaughtered in the city, and all carcasses brought into the city, intended for the market, must be thoroughly inspected for traces of tuberculosis. Where general tuberculosis is discovered the whole carcass is condemned and no part of it may be used as food. It is first rendered unsalable, after which it may be used for soap-making and similar purposes. Carcasses in which no trace of the disease can be found are marked "First Class" and, of course, bring the best prices. Where localized infection only is found, the infected parts are first cut away and destroyed, after which the remainder is permitted to be sold, but it must bear the label "Second Class." Great care is taken to protect healthy animals, as it is hoped from them to breed a new, healthy stock. While the law under which this system is operated applies only to Copenhagen, the system is being gradually adopted throughout Denmark.

Of course, Denmark is a little country, and its conditions differ from ours in every way. The Danish experience is of value to us only as showing that bovine tuberculosis can be very greatly reduced and that it is not idle to think of its entire eradication. To obtain that result it will be necessary to destroy an enormous number of valuable dairy cattle, for which their owners must be compensated, involving an enormous outlay of money, aggregating many millions of dollars. It will be necessary, also, to 
disinfect many thousands of cow barns and to destroy altogether many thousands more which cannot be disinfected. It will also be necessary to rehabilitate the breed of dairy cattle by breeding from sound stock. It may be necessary even to prohibit under severe penalties breeding from any animals except those certified to be perfectly healthy. I frankly confess that I do not see how these things can be done except by the federal government.

The problem is a national one, and its ramifications are so numerous and varied in character that to cope with it in any other way than by federal action seems almost impossible. That much can be done by means of state legislation and administrative genius I have no doubt whatever, but the problem will never be entirely solved until it is faced by the union of states. Failing such a policy being undertaken by the federal government, then our only hope lies in securing an agreement of all the states upon a uniform policy of aggressive warfare upon tuberculosis and all other diseases which mankind may acquire from his four-footed friends in his food and drink.

III

In most of the states there has been some provision made for the inspection of dairy cattle with a view to eliminating tuberculosis from our herds, and the 
tuberculin test is very generally used. It is a notorious fact, however, that the inspection is pitifully and hopelessly inadequate. There are not enough inspectors, and as a result too small a percentage of the total number of cattle comes under observation at any time. Nothing short of a periodical examination of every herd will suffice, and we are lamentably far from that requirement as yet.

There would seem, also, to be a great deal of incompetency in the use of the tuberculin test. On the one hand, we have such obviously inconclusive results as those noted in the South by Professor Doane, ${ }^{2}$ pointing, it would seem, either to incompetence or dishonesty - probably both. On the other hand, there are frequent complaints from farmers of serious bungling. Some of the stories told, and too well attested to be lightly passed over, are almost incredible on account of the stupidity of the inspectors. They err sometimes one way and sometimes another, but the percentage of error is too high. The result is ta discredit the tuberculin test in the mind of the farmer and the public. Yet, when it is properly applied, the tuberculin test is marvellously reliable. A number of years ago, some very searching investigations into this matter were made in Belgium. It was found that post mortem examination confirmed the diagnosis made upon the tuberculin test in more than 99 per cent 
of all such examinations. ${ }^{3}$ Since then the test has been greatly perfected, so that the percentage of error ought to be almost nil. Too much stress cannot be laid upon the fact that frequently the bestlooking animals in a herd are the ones most seriously affected. It is important, therefore, that every animal should be regularly tested, regardless of appearances.

Nothing less than a periodical test of every dairy herd, and of every animal in every such herd, will do. The infected animals should be destroyed, and not merely segregated. This is the verdict of practically every serious student of the Danish experiment. Segregation, breeding from diseased animals, or fattening them for sale as second-class food for the poor are compromises to be avoided. Not only do such compromises prolong the process of eradicating the disease, but lead to all kinds of corrupt and fraudulent practices. So I am assured, and certainly such results might be expected. However true this latter charge may be of Denmark, it can scarcely be doubted that it would be terribly true in this country. Every infected animal should be destroyed, and its carcass rendered unfit for use as food.

And this at once raises the question of compensation, which the British government has found so troublesome. It is plain that if we are ever to eliminate bovine tuberculosis, the active support 
and coöperation of the dairy farmers must be secured: They must realize that the eradication of the disease; however difficult and troublesome it may be, will ultimately benefit them. Judging from the attitude of the farmers in other countries upon this question, from the expressions of opinion of some hundreds of farmers in this country, and from the attitude of the farmers' journals, there is no doubt that the farmers would gladly join with the authorities in a heroic campaign for the elimination of the disease, provided that they are not unfairly burdened.

It cannot be expected that the farmers, among whom the percentage of altruists and saints is not appreciably higher than among other classes, will be very energetic and enthusiastic in securing the slaughter of their cattle if they are to lose 60 or 70 per cent of the value of all animals so slaughtered. That is the condition in the state of New York at present. The state pays only 40 per cent of the value of any animal killed by order of the state veterinarian. It is freely admitted that in a majority of cases the farmer is personally not responsible. He cannot tell whether his animals are healthy or not. Even a clinical examination by competent and experienced veterinarians will fail very often to detect the presence of the disease. It seems to me, therefore, extremely unjust to punish the farmer for what is not his fault, to impose upon him: 
the bulk of the cost of our common, social protection.

As a result of this policy, many farmers, men upon whom we must largely depend if we are to eradicate the disease, are in a conspiracy to prevent the detection of infected cattle. They are human and their conduct is human. It is our public policy in the matter that is at fault; it is unjust in the extreme. Said one old farmer to me: "We farmers, working with the state, could wipe out the plague in ten years or so. But instead of the state treating us as equal parties in a great effort for the common good, it penalizes us. Instead of breeding healthy cattle from sound stock and giving the farmer healthy animals in the place of those it condemns and slaughters, which would be just and wise, the state takes 60 per cent or more of the value of our cattle away and drives us toward bankruptcy and ruin."

That old farmer spoke bitterly, but with a certain justice. I do not know whether his suggestion of breeding cattle upon state or national farms and replacing the condemned animals with healthy ones would be practicable or not. If so, it would meet one very great objection, the fear of a meat and milk famine as a result of the lessening of the number of dairy cattle. If diseased animals were replaced with healthy ones, there would be no such fanine. It is not for me to express an opinion as to the practi- 
cability of such a plan, but I do say without hesitation that the present policy of paying the farmer less than half of the value of the cattle condemned is neither just nor wise.

There should be uniform rules in all parts of the United States providing for proper inspection and the efficient use of the tuberculin test; for the slaughter of all diseased animals and the encouragement of breeding from healthy stock only; for just and adequate compensation for animals destroyed, so that the farmer would have to bear only his fair share of the burden of loss. A large annual appropriation in each state for a period of ten years, augmented perhaps by federal aid, would go far toward suppressing bovine tuberculosis altogether. Except the organization of the entire work by the federal government, no other plan than one of uniform state action seems adequate to the solution of the problem.

\section{IV}

Tuberculosis is not, however, the only evil which must be remedied. It is just as important to see that the cow barns, dairies, and creameries are kept up to the highest possible standards of cleanliness and hygiene, as to see that the cows are free from tuberculosis. This is, of course, only another way of saying that it is quite as important to prevent the disease as to cure it. It is just as necessary to 
see that every possible safeguard is provided against the dissemination of typhoid, scarlet fever, and other milk-borne diseases as against tuberculosis. Here, in this general inspection, is a task big enough to tax the energies of the states. To do it thoroughly requires, everywhere, a large extension of the system of inspection, more money and more men.

One very great defect in the present methods of inspection prevailing throughout the states is the lack of uniformity, the same anarchical spirit which permeates so much of our national life. There is. no common standard to which the farmers must keep, nor any common method of judging the merits of a farmer's conditions. Many different "score cards" have been devised for the purpose of establishing as nearly as possible ideal standards of requirements which the milk producers and the milk dealers should be compelled to fulfil. Of late there has been a bewildering increase in the number of these score cards, and a careful examination of a large number of them is at once interesting and instructive.

Some of the cards which I have examined seem to me to be fairly open to the charge of being "faddish." More of them are open to the grave objection that they are not explicit enough to the farmer, and leave room for friction between the farmer and the inspector. Too much is left to the personal judgment of the inspector. I know well enough that the per- 
sonal factor can never be wholly eliminated, but it can be reduced to a minimum. It is not enough to tell the farmer that his stable is badly constructed or that it is not clean. The score card ought to tell him just exactly where the faulty construction or the lack of cleanliness lies. It is not enough to have a card which allows ten points for a stable that is entirely satisfactory to the person drawing up the card, and then to have another person, with possibly another ideal of what a stable should be, go and arbitrarily allow the farmer only five points. The card should show upon its face exactly what defects caused the low award of the inspector. In the event of the farmer's feeling that his score is unfairly low, he ought to be able to check the award, point by point. And the reviewing officer ought to be able to tell by reading the card whether the award made by his subordinate is fair and just.

How important this aspect of the problem of inspection is the following personal experience may serve to illustrate: In company with a physician who has long been identified with the milk reform movement, a man of unusual knowledge and fine judgment, I went through a stable in Orange County, New York. We agreed that each should fill in a popular score card, with the result that my friend marked his "Very Good" and awarded the stable 95 per cent of the marks allowed, while I marked 
my card "Fair," allowing only 50 per cent of the marks allowed. Which of the judgments more correctly represented the actual conditions is not here and now a matter of moment. The important point is that two fairly competent and experienced observers, absolutely uninfluenced by any personal feelings toward the farmer, should come to such different conclusions. That there might easily be a similar difference in the reports of different inspectors is quite evident. In such a case either an injustice is done to the farmer or to the public. My objection is that there is too much guesswork, too much is left to the accidents of personal judgment. Some time afterward, my friend and I went through another stable, with score cards providing for more explicit information. The cards allowed 40 points for the stable out of a total of 100 points covering all the conditions of the farm. In this case we reached practically identical conclusions, one awarding 38 points and the other awarding 39 points.

It seems to me, therefore, a matter of considerable importance, though little attention has as yet been given to it, that there should be a uniform standard of inspection based upon the best score card that can be devised. The card used by the inspectors of the Health Department of New York City, devised by my friend Mr. Burton, is in many ways superior to any other with which I am familiar, and I note with 
satisfaction that it was chosen by Dr. Coit for submission to the International Congress of the Gouttes de Lait, which met in Brussels in September, 1907." The omission of any record of bacteriological examination is a weakness, however, in an otherwise almost ideal card. In this respect the very admirable card devised by Dr. Goler and used in Rochester is to be commended. An ideal card, suited to all parts of the country, could probably be devised by compounding the best features of the two.*

There has been somewhat of a tendency of late, among a section of the opportunists, to decry inspection and to question its value. That attitude cannot be adopted, however, by any one who has a practical knowledge of the subject. It may be very slow work, it may be impossible to show the results in figures that are convincing; but whoever will take the trouble to go through the dairy farming districts with an open mind upon the subject, interested only in ascertaining the truth, will be astonished at the immense amount of good accomplished by a few efficient inspectors. I have gone through the farming districts of New York, a stranger, entirely unknown to the farmers with whom I have talked, asking all sorts of questions and going through all sorts of farms. Invariably I have found that the inspectors leave a well-marked trail of improvement behind them -I speak of the inspectors * See Appendix II. 
sent out by the Health Department of the City of New York, for I rarely heard of the state inspectors.

Wherever I have gone, I have found the careless farmer and the ignorant farmer embittered because the inspectors - "Darlington's Devils" they are often called - had compelled them to be more careful in handling the milk or keeping their cows. On the other hand, I have found the careful and competent farmers, especially the younger men, appreciative of the importance of strict cleanliness, of ten grateful for advice given by the inspectors, and less inclined to complain of "red tape" and "fads" than the others. Above all, I have never heard any suggestion of graft, though I have pushed inquiries in that direction very far. Of the few places visited in Pennsylvania much the same might be said. Wherever I heard condemnation of Dr. Dixon's policy, or of his inspectors, it was from men who obviously belonged to the reactionary, slovenly school of farmers.

Personally, I look mainly to increased and more efficient inspection for the improvement of our public milk supply. Not the old-fashioned inspection which aimed mainly at catching culprits, but the more effcient inspection which seeks the intelligent coöperation of the farmer, the inspection which lays most stress upon education and least upon persecution. The most efficient worker for reform is not the sharpnosed inspector who catches the occasional culprit, 
but the man who can win the confidence of the farmer; the man who can successfully appeal to his good sense and show him the practical advantages which arise from the observance of certain elementary rules of hygiene. It must have been some such inspector a dairyman told me about in the neighborhood of Media, Penn. "I would rather see the inspector come to my place than almost anybody I know. He has taught me things worth hundreds of dollars to me," he said.

\section{$\mathbf{v}$}

How far the cities may depend wholly upon the state inspectors to properly safeguard the production of the milk they consume is a question which every city will have to decide for itself. Certainly not until the inspection by the officials of the state is so perfect that city inspectors would be a waste of time and money, will it be advisable for the cities to give up the present general practice of having a staff of inspectors divided into two divisions, one for the inspection of dairies in the city limits, receiving stations, and all places where milk is sold, the other for country inspection, of farms, creameries, and so on. I am inclined to think that it will always be well at least in the case of the larger cities - to have some city inspectors at work in the districts where the milk is produced, as a sort of check upon the inspectors working under direction of the state. I do not sug- 
gest that the cities should trust too implicitly the state inspectors.

At the same time, it is evident that the burden of inspection falls too heavily upon our cities at the present time. I take the case of New York City as an illustration, because I am more familiar with the details of its system of inspection, and because the situation in other large cities is different only in degree. A very brief summary of conditions will suffice to show how enormous the problem is in a great city. ${ }^{5}$

The daily milk supply of New York City averages about $1,600,000$ quarts. This great ocean of milk is drawn from more than 35,000 farms, shipped through some 700 creameries. These farms and creameries are located in Vermont, Massachusetts, Connecticut, Pennsylvania, New York, New Jersey, and Ohio. It will be seen at once that the health authorities of the city have no legal powers in other states. As a matter of fact their authority is confined to the geographical limits of the city. But the Sanitary Code of the city of New York provides that "No milk shall be received, held, kept, offered for sale, or delivered in the city of New York without a permit from the Board of Health."

Herein lies the power of the Board of Health in sending its inspectors outside of the city limits, even into other states. It can refuse a permit for the milk to enter the city until satisfied that it is produced 
under proper conditions, or it can rescind a permit once given. To safeguard the interests of the city there are some thirty-five inspectors of food detailed to milk inspection. Eighteen of these are engaged in the city, looking after the conditions in the railroad terminals where the milk arrives at night, seizing and destroying all that is above the legal temperature. They must also inspect all depots, trucks, retail wagons, stores where milk is sold, the condition of cans and bottles being returned to the country in short, all the conditions of the milk supply after it reaches the city are subject to their inspection.

If a householder complains of the quality of the milk supply, either by letter, by telephone, or in person, the complaint is promptly investigated. Samples are secured and such action as may be necessary is taken. Some of the inspectors are detailed to the work of taking samples for bacteriological examination and analysis. When there is an excessive bacterial count reported, the report is made the basis of an investigation of the conditions at the place where the sample was taken, or the dealer from whom the milk was obtained. Then the matter is turned over to the country inspectors, who pursue the investigation at the creamery from which the milk came and thence back to the farms from which the creamery is supplied. And whenever a case of typhoid occurs in 
the city, it is tabulated and the source of the milk supply ascertained. If several cases occur among the patrons of any retailer, this is regarded as a sufficient reason to suspect the milk supply, and a careful investigation of the retailer's methods and of his source of supply is made through the country force, going right back to the farms.

From this account it will be seen that the requirements of city inspection in any city - for these things are just as necessary in a city of seventy-five thousand inhabitants as in New York - are many and complex. That they might be considerably simplified is unquestionable. The retailing of "loose" milk, for example, might well be restricted, and certainly ought never to be permitted by pedlers. Further, the sale of milk ought to be prohibited in stores where other than dairy products are sold, except, of course, milk sold in restaurants and the like to be consumed on the premises. The sale of milk in grocery stores is an almost unmitigated evil. It is conceivable, then, that the number of milk retailers could be greatly reduced. There is no good reason why New York should have from twelve to thirteen thousand places where milk is sold. True, there would be some objection to any attempt in the direction of lessening the number, on the ground that it crushed out small dealers and tended to the centralization of the trade. But that is the law of progress, in distribution as well 
as in production. The small farmer and the small retailer must go !

The amount of work performed by these city inspectors in New York is enormous. Figures give a very inadequate idea of the work, though the fact that they make annually something like one hundred and sixteen thousand inspections is impressive. Still, it is recognized that work is inadequately done, and the constant cry is for more inspection - for more money and more men. Sometimes the cry is raised that men should be taken away from the country work and used in the city, but those who raise the cry have never taken the trouble to understand the situation. Nothing could be more foolish than to lessen the rigidity of the inspection at the farms and creameries. So long as our milk supply continues to be produced as at present there will always be the necessity of a very costly system of inspection.

To realize the great importance of the country inspection one has only need to consider the case with which the outside work of the New York Health Department practically began. It occurred toward the end of 1904. One of the inspectors went into a creamery and found the manager in the act of adulterating the milk. In the centre of the creamery there was a well which acted as a cesspool for the drainage from a badly broken and filth-saturated floor. Off from the main room of the creamery, in 
a smaller room, the inspectors found a small keg of formaldehyde and a cask of "Lactine," a coloring used in the adulteration of cream and milk. It developed that when the manager had notified the proprietors of the creamery that he was without an ice supply, they had answered him by sending the keg of formaldehyde with instructions how to use it, which he had done regularly. Skim-milk was regularly colored up with "Lactine" and shipped to the city as pure milk, while the bottles were all washed in water taken from that contaminated well which was practically a cesspool. The inspectors found a large shipment of milk from this creamery upon the platform ready for the New York train, whither they followed it, and, finding it adulterated, seized and destroyed more than sixty cans of the stuff. Of course, the permit of that company was revoked.

Now, it is doubtless true that this was an exceptionally bad case. It taught New York the value of country inspection as no amount of arguing could have done. It was a lesson that went home. I do not think that I am violating any confidence when I say that all kinds of influence were used to stop the Health Commissioner from pursuing the radical course thus begun, but to no purpose. Fifteen inspectors dividing their time between 35,000 farms and 700 creameries scattered through seven states is, naturally, an altogether inadequate staff. Making rather 
less than 25,000 inspections a year, they must leave some places uninspected and they have little opportunity for reinspections. When one thinks of it, there is something radically wrong in a system which compels the city of New York to send its inspectors to Vermont and Ohio to make sure that the milk is produced under decent conditions. Testing the herds for tuberculosis is a state function and sanitary inspection ought to be. As the states become-more and more conscious of their duty in the matter, and develop their systems of inspection, the cities will be relieved of a great deal of needless expense. How the neglect of the states burdens the great cities we see in the case of the part of its milk supply which New York draws from Pennsylvania. As the state improves its methods of inspection it becomes less important for New York inspectors to devote their time to that state. A similar improvement in the other states would make it possible for New. York to use most of the force at present employed in the country division upon the work of city inspection. In other words, New York City has to pay for the negligence of New York State and other states.

To sum up the whole matter: If the testing of herds so as to secure a milk supply drawn from perfectly healthy cattle is the first article in the creed of the milk reformer, the second is efficient inspection to insure perfect sanitary conditions at every point, from 


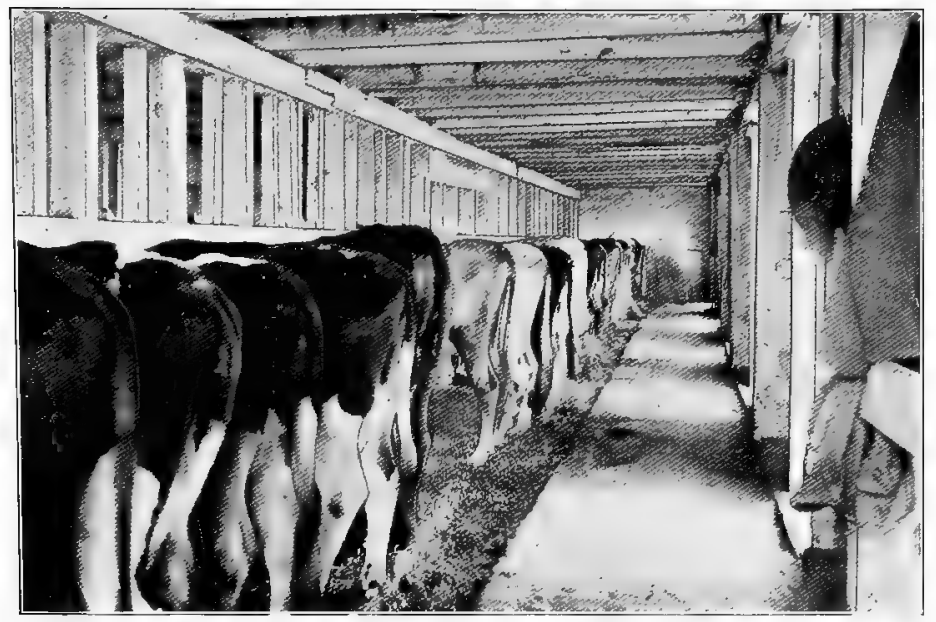

XXVI. (a) A Modest And Inexpenstve Cow Starle Where cleanliness is observed.

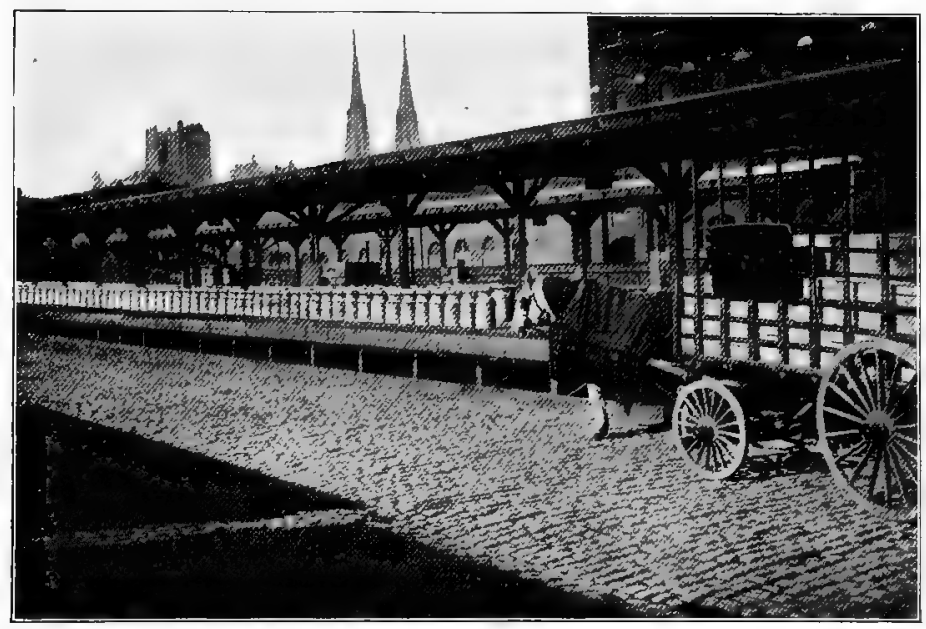

XXVI. (b) A RaIlroad Milk Station - New YoRk City 

the cow to the consumer. Filthy and impure milk cannot be made safe by any process of pasteurization or sterilization, and the logical thing is to aim at clean, wholesome milk. Without deprecating pasteurization in any way, it can be safely said that the protection of the general milk supply and its improvement can best be secured by proper state and federal legislation looking to the eradication of tuberculosis and other diseases from dairy cattle; the exclusion of all persons suffering from infectious or contagious diseases from any direct connection with the production or distribution of milk; the adoption of a uniform score card as a standard for inspectors; the thorough inspection of all the conditions under which milk is produced, shipped, and sold. And this creed can be reduced to two words, "health" and "cleanliness."

\section{VI}

I do not believe that any city should pasteurize, or compel to be pasteurized, all its milk supply, except under exceptional conditions, as a temporary measure. I can very well imagine a condition arising which would make it absolutely essential that all milk coming into a city should be pasteurized, but that condition does not normally exist in this country, where, in spite of everything, our milk supply is equal to that of any other country in the world. In this $\mathrm{I}$ have been compelled to differ from many of my 
friends in the movement for milk reform who demand compulsory pasteurization of the entire milk supply of our cities. That seems to me to be a retrogressive step and not a progressive one.

The municipalization of the entire milk supply of any large city is out of the question for many years to come. But I do believe in the establishment of municipal farms for producing, under the very best conditions and most scientific direction obtainable, the milk necessary for such municipal institutions as hospitals and asylums, and for such other institutions of a like nature which may not be actually under municipal management and control, but which are essentially public institutions. As I have tried to show, ${ }^{*}$ such a system of municipal production would not only make it possible for these institutions to secure a pure and wholesome milk supply, but would also set a standard for private enterprise to follow. That the proposal is a perfectly practical one the experience of English cities shows.

I believe as firmly as any of the advocates of pasteurization that, until we can get a better milk supply than any city now has, wise parents will pasteurize the milk fed to their infants. Even if I lived in Rochester, I think I should continue to pasteurize the milk given to my baby, unless I could get a supply of extraordinary purity and cleanliness. Therefore, 
I believe in the establishment of infants' milk depots as one of the most important means of lessening infant mortality. I imagine that there are very few cities having a population of more than twenty-five thousand in which there is not a need for such depots.

I am clearly of the opinion, moreover, that these should be in all cases established and maintained by municipal authorities rather than by private philanthropy, for reasons already stated in another chapter. Under present conditions, and probably for many years to come, pasteurization of the milk supplied at these infants' milk depots will be necessary in most cases. There are doubtless many cities which will need to adopt pasteurization only temporarily, if at all. Where there is a comparatively small city, having a high standard of citizenship and better housing conditions than those which exist in the larger cities, and where the milk supply is produced within a short distance from the city limits, making its control relatively easy, there ought to be no difficulty about getting a milk supply of a high average standard of excellence, and a special supply for the infants' milk depots so pure as to need no pasteurization.

I choose for illustration a typical Southern city, the city of Savannah, Ga. How far the conditions which Professor Doane described as existing there three or four years ago ${ }^{\circ}$ still exist I am unable to 
judge. From one correspondent of good judgment I learn that there has been "considerable improvement," while another assures me that "things remain in about the same bad way." This is immaterial, however, for my purpose. I desire simply to use the city as an illustration. Here we have a population of between fifty and sixty thousand, with many cows kept in the city limits by private families, the rest of the milk supply coming from herds kept within a few miles of the city. With no milk inspection, Professor Doane found that it was quite common for dairymen to water, skim, color, "preserve," and otherwise adulterate their milk. So poor was the milk supply that physicians almost invariably preferred condensed milk for infant feeding, and very few infants were fed upon cow's milk. These are, of course, the conditions of a small city at their worst. In such a city, it seems to me, the first need is a campaign of education and the organization of its public-spirited citizens for reform. The establishment of infants' milk depots would seem to be one of its most pressing needs, and I should say that, for some time, it would be necessary to pasteurize the milk supplied by such depots. But, with the sources of supply so near and so easily controllable, pasteurization ought not to be regarded as a permanent condition, but as a temporary expedient. It should be possible to obtain in a very little while a supply of milk for the depots 
so pure that pasteurization would be unnecessary and foolish.

Upon these general lines, it seems to me, our cities must proceed. Infants' milk depots are generally necessary, and in most of the large cities, as well as in many of the small ones, conditions are such that pasteurization of the milk supplied for infant feeding seems to be inevitable for a very long time to come. While this should be regarded as an evil to be overcome, and efforts to obtain a pure supply should be made, in my opinion it is necessary to recognize the condition - and to pasteurize. In our great cities, without exception, there is need for a chain of such depots at which parents can obtain satisfactory food for their infants. I protest against the taint of charity in connection with such depots, for they are as necessary to the fairly well-to-do citizen as to the poorest. In the homes of the wealthy, where expense is not considered, where trained nurses and other competent help are available, there is a chance to obtain milk of a high grade and to modify and pasteurize it skilfully and under aseptic conditions. But this is practically impossible for all except the wealthy few, for the great mass of ordinarily prosperous families not less than for the poorest. Such depots should, in my judgment, be under medical supervision, nurses and physicians being employed in connection with them to advise mothers concerning the care of their babies. 
Connected with the infants' milk depots in the larger cities I should like to see something like the French Consultations de Nourrissons, described in Chapter VII. It may not be necessary to follow the French method exactly, but the principle of having incorporated into the system of providing proper food for infants some plan for the encouragement of breastnursing seems to me a good one. It is my firm conviction, based upon long and careful study of the problem, that a great deal may be done to lessen infantile mortality by means of education. The mothers need educating, and it has been shown that breast-nursing, the natural way of feeding a child, can be promoted by education. At the risk of some rather tedious repetition, I would remind the reader that this question of breast-nursing goes to the roots of the evil. It is no accident that the infant death-rate in such a crowded ward of a great city as the Cheetham Division of Manchester, England, should be the lowest in the city. The Jewish mothers there, as a rule, suckle their infants. It is not an accident, either, that similar conditions are found in the crowded districts of the East Side of New York City, where the infant mortality is lower than for the whole city, or that the infant death-rate in Ireland is low. Breast-nursing is the explanation. ${ }^{7}$ Whatever can be done, therefore, to promote breast-nursing should be done. 


\section{VII}

It is rather fashionable to speak pessimistically of the great problem of maternal education. Everybody recognizes the need for such education of the mothers, but there is very little faith shown in any comprehensive programme aiming to provide the education. As an abstract proposition, every one agrees with the statement that mothers need education, but it is relatively difficult to get up any interest or enthusiasm when practical measures are proposed. Nevertheless, in outlining these suggestions for a programme of reform, I desire to lay special emphasis upon this aspect of our problem. Given the purest possible milk supply, and the most efficient system in the world, if the mothers do not know how to take care of the milk, a great deal of the social effort and care will be utterly wasted and lost.

It is not merely among the much patronized "poor" of our cities, who have come somehow to be regarded as rather less than human, that there is maternal ignorance. The evil is by no means confined to that class for whose benefit social settlements and similar institutions are established. In the course of an address to the members of a fashionable church not long ago, I remarked that in many of the essentials of motherhood they could learn from the poorest, and that it might not be a bad idea for some of the 
East Side mothers to establish a social settlement for the wealthy mothers of Central Park West. Maternal ignorance is fairly well distributed among the classes, but the wealthy few can, and do as a rule, engage trained and competent nurses. If we leave this class out of question, their children being provided for, it will be found that education is the great need for the mothers of the rest of the community.

Everywhere there is ignorance of the most elementary principles of infant care and feeding. Among the poorest of our immigrants, accentuated by poverty and squalor, ignorance shows itself more, but there is an appalling amount of ignorance among mothers higher in the social scale. Many of the underfed children in our schools come from homes where there is no poverty, except poverty of intelligence on the part of the mothers, and some of the worst instances of maternal ignorance I have ever heard of have been among the fairly well-to-do.

Can anything be done to educate the mothers? To that question I unhesitatingly give an affirmative reply. I think we begin too late when we begin with the mother, that we ought to have begun with the girl long before she became a mother; but it is possible to do a great deal in the way of educating mothers, a work in which public authorities and voluntary agencies can unite. In Australia, for example, as soon as a baby is born the health authorities are 
notified by telephone, and, as soon as possible, a lady "nurse inspector" visits the home and sees that everything is all right. Where the mother seems to need her assistance, the nurse inspector gives it; and if it develops that the mother needs instruction, as most do, friendly visits of the nurse inspector, which are robbed of all official appearance, are continued as long as necessary. The system works well and it is the universal testimony of those I have consulted concerning it that this education of mothers is most successful. ${ }^{8}$

In New York City, I have taken great pains to observe the work of the special corps of nurses employed by the Health Department during the summer months, and what has most impressed me has been the educational side of their work. Few citizens, I imagine, have any very clear idea of the work that is done by these nurses in educating mothers. I have seen a nurse teaching an Italian mother how to prepare her baby's bed, for example, so that the child could sleep restfully, and later seen the mother showing several other Italian mothers how to do it. I have seen mothers following every movement of the nurse, as she cut off the clothes little babies had been "sewed up for the winter" in and then properly dressed them, with an intense interest which could not be mistaken. The mothers want to learn and are, therefore, teachable. One who has followed 
the work of the corps of nurses and friendly visitors employed by the New York Association for Improving the Condition of the Poor cannot fail to believe in the practicability of educating mothers.

In this connection, the much-discussed "Huddersfield experiment" is of interest principally because it points to the union of municipal and voluntary forces in a most successful undertaking. The city is divided into nine districts. For each of these districts there is a voluntary ladies' committee, made up of "lady helpers" and a "lady superintendent." It is the business of these voluntary agencies to coopperate with the officials of the Board of Health in the following manner: There are two lady doctors appointed by the City Council, working under the immediate direction of the Medical Officer. All births in the city must be reported to the Medical Officer within twentyfour hours, and it is the business of the lady doctors to visit the newly born infants and their mothers at the earliest possible moment. They make it as much as possible a friendly and informal call, giving advice only where it seems to be necessary. They leave with the mothers a few printed rules for the care of the little ones and, if it seems necessary, repeat the visits. Each Saturday the lady doctors place in the hands of each lady superintendent a list of the cases in her district where friendly visits are likely to be helpful and appreciated. These cases are then 
divided among the assistants, each lady helper undertaking to make periodic visits for a certain period, usually a year, and to keep the case under observation. The greatest possible care is taken to avoid encroachment upon the domain of the family physician, and to keep the visits upon a friendly basis rather than an official one.

I regret that I am unable to speak of the Huddersfield experiment from personal observation. At first, upon reading an account of it in the Annual Report of the Medical Officer of the city, I was inclined to question its practicability. It seemed to me that there would inevitably be friction between the visiting physicians employed by the Board of Health and the family doctors, and also that the volunteer visitors would be likely to offend many mothers by their tactlessness. I submitted these matters to a medical man of standing in Huddersfield and he assured me that, in his experience, neither of the difficulties had arisen, and that the plan was working splendidly and accomplishing great good. Since it has been in operation only two years, it is too early to attempt a statistical measure of its value, but the Huddersfield authorities seem to believe in it and to expect great results from it. ${ }^{\circ}$

One thing is evident from these fragmentary experiences and experiments, namely, that the great majority of mothers are fully aware of their need of 
education and willing to receive it. That, I take it; is the most promising condition that could be desired. In every city in the land I should like to see some effort made to develop a comprehensive, practical plan for the education of mothers in the essentials of motherhood. Until we can accomplish this, babies will continue to die needlessly, victims of ignorance and social helplessness.

But why should we begin education after motherhood has been reached? Is it idle to hope that we shall yet develop our educational system so that our girls will not enter wifehood and motherhood - as most of them must - so utterly unprepared and unfitted for their life work? Is it too much to expect that some means will be devised to give them a practical education in these matters? No girl, it seems to me, ought to leave school until she has learned how to cook simple and wholesome food in a practical and economical manner; how to sew and mend; how to wash and dress, feed and manage, infants and young children. She should know, from actual practice, how to do these things, and how to clean a house properly. She should have a standard of cleanliness - for, alas! the house which many regard as being very clean is really very dirty. She should know something of the values of foods, and, especially, the dangers which may be incurred through contamination. She should know some- 
thing of sexual physiology, as, indeed, should our boys.

To put the whole matter in a few words, our girls should know enough before they enter upon wifehood to avoid the awful mistakes for which such a terrible price in baby lives is now paid. Among the greatest defects of our civilization to-day is our failure to fit for parental responsibilities the boys and girls who go through our schools.

VIII

In this chapter I have tried to indicate, very briefly and simply, the most important features which a practical programme of reform should embrace. I do not expect that it will be adopted in its entirety by any city; nor do I expect that it will escape criticism. But, in the main, it represents, I believe, the consensus of practical and expert opinion upon a most important problem. I believe, too, that upon the lines indicated a programme can be framed to suit the needs of each individual city upon which all sincere friends of milk reform can unite. Such unity of forces is above all things else desirable, and if this study, inadequate as I know it to be, helps to create that unity, I shall feel abundantly repaid.

Healthy herds - efficient inspection - insistence upon cleanliness and careful handling of the milk - 
municipal farms for providing public institutions infants' milk depots for the sale of properly modified and pasteurized milk for babies - education of the mothers and of the girls before they reach wifehood and motherhood, - such are the principal features which must be included in our campaign for the reform of our public milk supply and saving the babies.

I have been asked many times whether the ordinary farmer will be able to meet the conditions which it will be necessary to impose upon the production of milk, and I frankly reply that I cannot believe he will. The small farmer, in my judgment, will be unable to do all that will be demanded. Like the small retail stores, the small dairy farms will, in all probability, be forced out of existence. Not this year or next, perhaps, but sooner or later. It is inevitable. With our present unorganized production and distribution of milk, it will be impossible to carry reform very far without raising the price of milk to a very injurious and deplorable standard. And to greatly increase the price of milk means that the babies will perish for want of milk - if, indeed, there is not a revolt which will sweep aside the reformers and their schemes of reform.

But I differ from many careful students of the problem in believing that, given proper organization, a satisfactory milk can be produced even more cheaply than the poor and contaminated stuff now 
sold in our cities. I believe with Sir Richard Douglas Powell that "scientifically conducted dairy farms on a large scale, with urban depots for the reception and distribution of pure milk in clean bottles," could be made to pay without any excessive prices. $^{10}$ I should like to see the experiment tried by a sort of "model milk trust," organized upon much the same lines as the various model tenements associations. Given the necessary capital, it would be perfectly possible, I believe, to have large, scientifically conducted farms within a reasonable distance of the cities, and a system of retail establishments of the very highest type scattered through the cities, supplying milk of a much higher standard of purity and excellence than is now supplied anywhere in the worldexcept in a few cases where small quantities are sup- plied to a few rich people at fancy prices. I believe that it could be done, even in competition with the ordinary milk of commerce, at a fair profit. When one considers the wastefulness of present methods, this does not seem an unreasonable hope, for the economies which could easily be effected would more than compensate for the additional expense incurred in protecting the supply.

In the campaign for a better milk supply, especially for the protection of our babies from unnecessary disease and premature death, we need the earnest coopperation of all the constructive forces in society. 
306 THE COMMON SENSE OF THE MILK QUESTION

Civic loyalty, paternal and maternal love, and enlightened minds are needed to solve the great problem which, unsolved, demands so many innocent little lives as tribute for our failure to solve it. Shall we have a clean milk supply? Shall we have a safe supply for our little ones?

It is for America to answer! 


\section{APPENDIX I}

Mitik as a Carrier of Inhectious Diseastes

MrLK may acquire infective properties after it leaves the udder of the animal. Numerous instances have been observed in which outbreaks of typhoid fever, scarlet fever, and diphtheria, by their sudden and explosive character, affecting families living in streets and localities supplied by the same milkman, naturally pointed to the milk supply as a common cause. Dr. Michael Taylor, however, was the first physician (in 1857) to point out definitely that cow's milk might serve as a medium of spreading typhoid fever from a dairy where the disease prevailed. In 1867 he also showed that scarlet fever might be distributed in the same way. In 1877 Jacob traced a diphtheria epidemic at Sutton, England, to the milk supply; and in 1872 Macnamera traced an outbreak of cholera at Calcutta, India, to an infected dairy. These facts could not fail to sharpen the powers of observation in others, and in consequence similar outbreaks were more frequently reported, so that $\mathrm{Dr}$. Kober was enabled to present to the International Medical Congress, held in Paris in 1900, the history of 195 outbreaks of typhoid fever, 99 of scarlet fever, and 36 of diphtheria, all traceable to the milk supply.

It has been demonstrated that disease germs may not only survive, but in many instances actually proliferate, in the milk, and it is not a difficult matter to point out the many ways by which these germs gain access, especially when some of the employees are also engaged in 
nursing the sick, or are suffering themselves from some mild infection while continuing their duties, or are convalescent from disease, and thus infect the milk in handling it.

It is quite conceivable how animals, in wading in filth and sewage-polluted water, may infect the udder, and through it the milk, with the germs of typhoid fever. We can also appreciate how infected water may convey the germs when used for washing the utensils or in deliberate adulterations. Infection may also take place through the agency of scrubbing brushes, dishcloths, flies, and exposure to infected air.

\section{MILK-BORNE TYPHOID FEVER EPIDEMICS}

Of the 195 epidemics of typhoid fever tabulated by Dr. Kober, there is evidence in 148 of the disease having prevailed at the farm or dairy. In 67 instances the infection probably reached the milk by percolation of the germs into the well water with which the utensils were washed; in 16 of these the intentional dilution with water is a matter of evidence. In 3 instances the Bacillus coli communis and the typhoid germs were demonstrated in the suspected water. In 7 instances infection is attributed to the cows wading in sewagepolluted water and pastures; in 24 instances the dairy employees also acted as nurses; in 10 instances the patients while suffering from a mild attack, or during the onset of the disease, continued their work; and those who are familiar with the personal habits of the average dairy hands will have no difficulty in surmising the manner of direct digital infection. In one instance the milk tins were washed with the same dishcloth used among the fever patients. In 2 instances dairy employees 
were connected with the night-soil service, and in another instance the milk had been kept in a closet in the sick room.

In the recent exhaustive investigation conducted by the Public Health and Marine-Hospital Service the commission definitely traced 85 of the 866 cases of typhoid fever in the District to the use of infected milk.

\section{MILK-BORNE BCARLET FEVER EPIDEMICS}

Of the 99 epidemics of scarlet fever the disease prevailed in 68 instances at the dairy or milk farm. In 6 instances persons connected with the dairy either lodged in or had visited infected houses. In 2 instances the infection was conveyed by means of infected bottles or milk cans left in scarlet fever houses. In 17 instances the infection was conveyed by persons connected with the milk business while suffering or recovering from the disease, and in at least 10 instances by persons who acted as nurses while handling the milk. In 3 instances the milk had been stored in or close to the sick room. In 1 instance the cans had been wiped with an infected cloth. (In 19 instances the infection was attributed to disease of the milk cows, such as puerperal fever and inflammation of the udder and teats; but these outbreaks were probably not genuine scarlet fever, but a so-called streptococcus or staphylococcus infection, the symptoms of which closely resemble those of scarlet fever.)

\section{MILK-BORNE DIPHTHERIA EPIDEMICS}

Of the 36 outbreaks of diphtheria, there is evidence that the disease prevailed at the dairy or farm in 13 instances. In 3 instances the employees continued to 
handle the milk while suffering themselves from the disease. In 12 instances the disease is attributed directly to the cows having inflammatory conditions of the teats and udders. (These instances, however, may be regarded as typical examples of streptococcus and staphylococcus infection, giving rise to a form of follicular tonsilitis or pseudo-diphtheria, often difficult to distinguish clinically from true diphtheria or scarlet fever.)

In addition to the foregoing diseases there are recorded a limited number of outbreaks of cholera which have been traced to milk infection through various channels already referred to, chiefly in handling with infected fingers, by contaminated water, and the agency of flies. There is also reason to assume that the organism of cholera infantum and the infectious agent of smallpox may find in milk a suitable medium for growth and transmission.

It is interesting to note that of the 330 epidemics analyzed by Dr. Kober, 243 have been recorded by English authors, 52 by American, 14 by German, 11 by Scandinavian, and 5 each by French and Australian writers. This is probably due to the fact that the English and Americans usually consume raw milk, while on the Continent the milk is rarely used without being boiled.

-From Sanitary Milk Production. Report of a Conference appointed by the Commissioners of the District of Columbia, with accompanying papers. - Circular 114, Bureau of Animal Industry, August 20, 1907.

At the time of going to press with this volume, the "Report on Milk in its Relation to Public Health," by Surgeon General Walter Wyman, of the United States 
Public Health Service, has not been published. To-day, March 5th, 1908, as the last proofs are being read, the New York Times contains the following statement, plainly indicating that the position taken in this volume is, in the main, supported by this federal investigation: -

\section{EPIDEMICS FROM MILK}

\section{Surgeon Grneral Wyman Reporta Restlts of FEDERAL Investigation}

WAshington, D.C., March 4.-Surgeon General Walter Wyman of the Public Health Service to-day submitted to Secretary of the Treasury Cortelyou a "Report on Milk in its Relation to Public Health." The report is the result of an investigation ordered by President Roosevelt and conducted by Federal experts.

In his introduction to the twenty-two treatises of the experts, Dr. Wyman says: "The steady decrease in general mortality does not apply to the infants. It is recognized that gastrointestinal disease is the largest single factor determining infant mortality. This enormous loss of potential wealth is of grave concern to the state and worthy of most careful consideration. It has been the object of this work to include all available data showing the influence of milk as a carrier of infection and the measures necessary in consequence."

The Surgeon General writes:-

"Dr. Mohler points out that probably the most important disease of cows from the standpoint of public health is tuberculosis, and that it is the most prevalent. He insists that all milk should come from either tuberculosis tested cattle or be subjected to pasteurization.

"References will be observed to the achievements of Mr. Nathan Straus in promoting the use of clean pasteurized milk for infants and the establishment of infants' milk depots both in the United States and abroad, and it is proper here to give recognition to his philanthropic and successful efforts." 
The report contains an amazing array of evidence of the responsibility of infected milk for epidemics of typhoid fever, scarlet fever, and diphtheria. Past Assistant Surgeon General John W. Trask has tabulated the data of 500 epidemics that were definitely traced to the milk supplies, including $\mathbf{3 1 7}$ typhoid epidemics, 125 scarlet fever, 51 diphtheria, and 7 of pseudo-diphtheria, or epidemic sore throat. 


\section{APPENDIX II \\ Score Cards - I. Rochester}

\section{Rochester Bureau of Health. Division of Milk Inspection}

Inspector

Date..................

Name.

Town

P. O. Address

Marketed .Containing Fresh Cows...Dry Cows...

$\frac{1}{2}$ Separate Place for Calving ...............

I. $\quad 3$ Health and Comfort of Cows (Deduct not to

4 Tuberculosis Test (each cow not Tested takes off 20 divided by number of cows)..20

1 (Location on Hill or Slope.............. 5

2 Window Space for Each Cow, 4 square feet

b $\left\{\begin{array}{l}\text { counts } 10 ; 3 \text { square feet } 7.5 ; 2 \text { square } \\ \text { feet } 5 ; 1 \text { square foot } 2.5 \ldots \ldots \ldots \ldots \ldots .10\end{array}\right.$

8 Efficient System of Ventilation.............10

4 Cubic feet of Air for each Cow, 450 counts 10 ; for each 25 feet less, take off $1 . . . \ldots \ldots . .10$

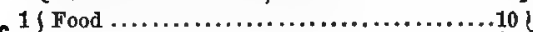

\begin{tabular}{c|c|c} 
& Prratet & Boore \\
\hline & 45 &
\end{tabular}

II. a 1 -Cleanliness of Cows....................... ...

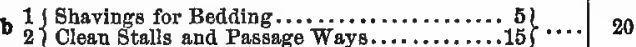

c 1-Barnyard and Pasture Clean................... 20

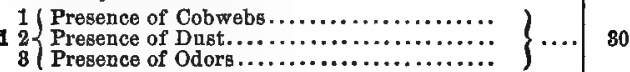

TотаL................... $\overline{\mathbf{1 0 0}}$

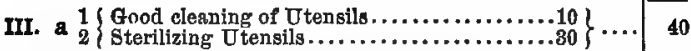

1 Plentiful Supply of water................10 \}

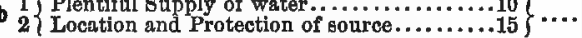

c 1-Inside of Utensils kept free from Dust after

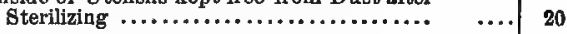

d 1-Small Top Pail........................... 15

TotaL...................

IV. a 1-Health of Employees....................

b 1 W $\left\{\begin{array}{l}\text { Wearing Clean Washable Suit............10 } \\ \text { Washing and }\end{array}\right.$

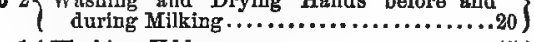

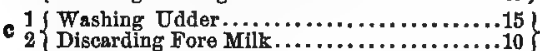

TOTaI

V. a 1-Prompt and Efficient

b 2-Holding Milk at Low Tem. in Transporta-

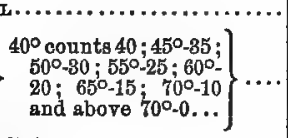




\section{Scori Cards - II. New York}

Fule No

Perfect Score $100 \%$

Bcore Allowed.........\%

\section{DEPARTMENT OF HEALTH}

\section{CITT OF IEW TORK}

Dairy Inspection

Division of Inspections

1 Inspection No......Time......A. P. M. Date.........180

2 Tenant................... O. Address.................

3 Township............ County ........... State..........

4 Owner...............Party Interviewed..............

5 Milk delivered at................ Since..............

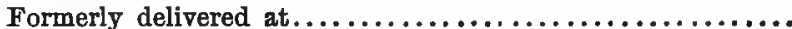

6 Creamery on......R. R.......Branch.......Miles to N. Y.....

7 Creamery operated by ...............Address

8 Distance of farm from creamery...... Occupied farm since.....

9 No. of Cows..........Breed........... No. Milking......... Quarts milk produced.

10 All persons in the households of those engaged in producing or handling milk are........ free from all infectious disease.....

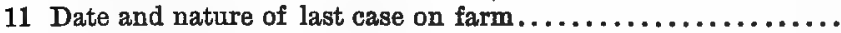

12 A sample of the water supply on this farm taken for analysis

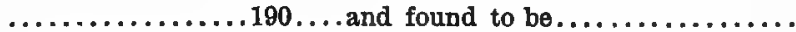

13 Size of cow barn, length...... feet. Width...... feet. Height

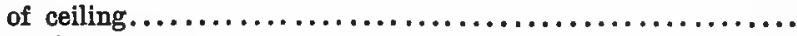

\begin{tabular}{|c|c|c|}
\hline & Prrfiot & ALLOW \\
\hline STABLE & & \\
\hline $\begin{array}{l}14 \text { Cow stable is........ located on elevated pround with no } \\
\text { stagnant water, hog pen, or privy within } 100 \text { fest......... } \\
15 \text { Floors are........ constructed of concrete or some non- }\end{array}$ & 1 & \\
\hline 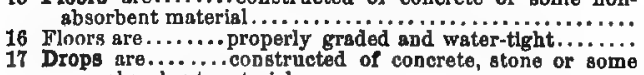 & $\begin{array}{l}1 \\
2\end{array}$ & \\
\hline 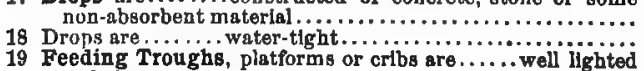 & $\frac{2}{2}$ & \\
\hline 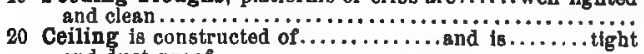 & 1 & \\
\hline 21 Ceiling is......... fres from hanging straw, dirt or cobwobs & $\begin{array}{l}2 \\
1\end{array}$ & \\
\hline
\end{tabular}




\section{STABLE - Continued}

22 Number of Windows........totel square feet....... which is $\ldots \ldots \ldots$ sufficient. ............................

23 Window panes are........ washed and kept clean........

24 Ventilation consists of. 25 Air Space is................................ sufficient $(600$ and over -3$)(500$ to $600-2)(400$ to $500-1)$

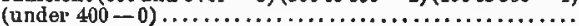

26 Interior of stable painted or whitewashed on ........ which

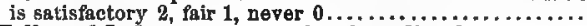

27 Walls and Ledges are........ free from dirt, dust, manure or cobwebs.................................

28 Floors and Premises are.........free from dirt, rubbish or decayed animal or vegetable matter..................

29 Cow Beds are........ clean .........................

80 Live Stock, other than cows, are............................. rooms in which milch cows are kept.................

81 There is.......direct opening from barn into sllo or grain

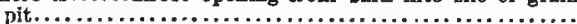

82 Bedding used is........elean, dry and absorbent.........

gs Separate Building is..........provided for cows when sick..................................

84 Separste quarters are............ provided for cows when

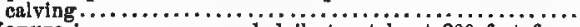

35 Manure is......... removed dally to at lesst 200 feet from

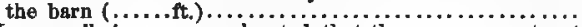

86 Manuro pile is........so located that the cows cannot get

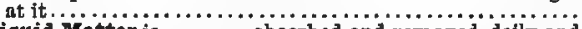

a7 Liquid Matter is..........absorbed and removed daily and ........allowed to overflow and saturate ground under

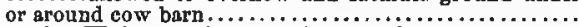

38 Running Water supply for washing stables is....... located

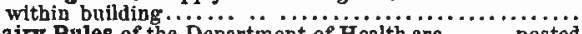

89 Dairy Rules of the Department of Heaith are....... posted

\section{COW YARD}

L0 Cow Fard is........properly graded and drained........

41 Cow $Y$ ard is ......... elean, dry and free from manure.....

\begin{tabular}{|c|c|}
\hline Peefect & ALLOW \\
\hline 2 & …....... \\
\hline 8 & $\ldots \ldots$ \\
\hline 8 & ......... \\
\hline 2 & $\ldots$. \\
\hline 2 & $\ldots \ldots$ \\
\hline $\begin{array}{l}1 \\
1\end{array}$ & …....... \\
\hline 2 & $\ldots \ldots$ \\
\hline $\begin{array}{l}1 \\
1\end{array}$ & $\ldots \ldots$ \\
\hline 1 & \\
\hline 1 & $\ldots \ldots$ \\
\hline 2 & $\ldots \ldots$ \\
\hline 1 & $\ldots \ldots$ \\
\hline 2 & $\ldots \ldots$ \\
\hline $\begin{array}{l}1 \\
1\end{array}$ & $\ldots \ldots \ldots$ \\
\hline $\begin{array}{l}1 \\
2\end{array}$ & $\ldots \ldots$ \\
\hline 8 & $\ldots \ldots$ \\
\hline 5 & $\ldots \ldots$ \\
\hline 2 & $\cdots \ldots$ \\
\hline 4 & $\ldots \ldots$ \\
\hline 1 & $\ldots \ldots$ \\
\hline 2 & $\ldots \ldots$ \\
\hline 1 & $\ldots \ldots$ \\
\hline$\frac{1}{2}$ & ……... \\
\hline
\end{tabular}

42 Cows have........ been examined by Veterinarian........ Date............................... Report was ......

43 Cows have........ been tested by tuberculin, and all tuber-

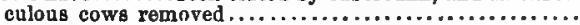

44 Cows are.........all in good flesh and condition at time of

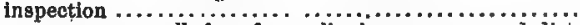

45 Cows are........sil free from clinging manure and dirt.

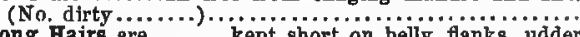

46 Long Hairs are...................... short on belly, flanks, udder

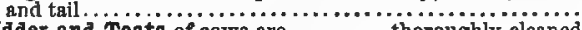

47 Jdder and Teats of cows are..............................

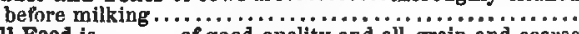

48 All Feed is ......... of good quality and all grain snd cosis $\theta$ fodders are........ free from dirt and mould ...........

49 Distillery waste or any substance in a state of fermentation or putrefaction is ......... fed.......................

50 Water Supply for cows is....................................... 


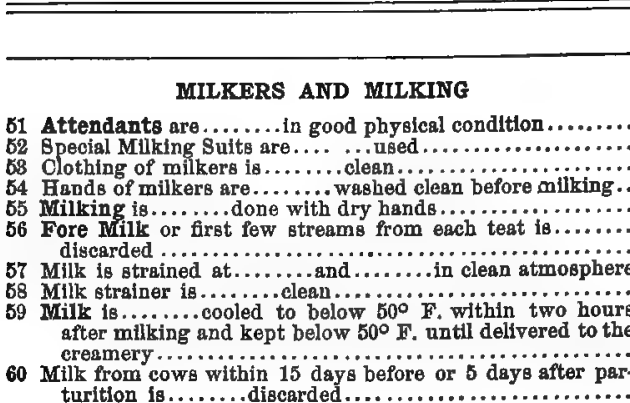

\section{DTENSILS}

61 Milk Pails have........ all seams soldered flush.........

62 Milk pails are............ of the small-mouthed design, top opening not exceeding 8 inches in diameter. Diameter...

68 Milk pails are........ rinsed with cold water immediately after using and washed clean with hot water and washing

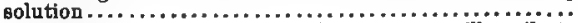

64 Drying racks are......... provided to expose milk palls to

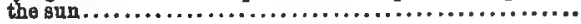

\section{MILK HOUSE}

65 Milk House is......... located on elevated ground with no hog pen, manure pile or privy within 100 feet...........

66 Milk house has........ direct communication with...........

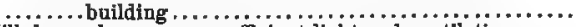

67 Milk house has......... sufficient light and ventilation......

68 Floor is ........ properly graded and water-tight............

69 Milk house is........ free from dirt, rubbish and all materlal not used in the handling and storage of milk............

to Mdlk house has......... running or still supply of pure clean

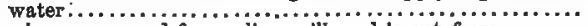

71 Ice is.......... used for cooling milk and is cut from........

\section{WATER}

72 Water Supply for utensils is from a............. located ................. feet deep and apparently is............. pure, wholesome and uncontaminated...................

78 Ів......... protected against flood or surface drainage.......

74 There is.........privy or cesspool within 250 feet (.........

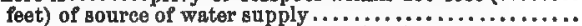

75 There is....... stable, barnyard, or plle of manure or otber source of contamination within 200 feet (........... feet)

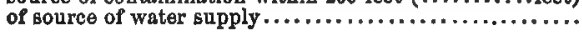

\begin{tabular}{|c|c|}
\hline Prafreot & ALLOW \\
\hline $\begin{array}{l}1 \\
1 \\
1 \\
1 \\
2\end{array}$ & 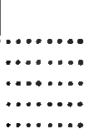 \\
\hline $\begin{array}{l}2 \\
1 \\
1\end{array}$ & $\ldots \ldots \ldots$ \\
\hline 2 & .......... \\
\hline 1 & $\ldots \ldots$ \\
\hline 1 & $\ldots \ldots$ \\
\hline 2 & $\ldots \ldots$ \\
\hline 2 & $\ldots \ldots$ \\
\hline 1 & \#..... \\
\hline 1 & $\ldots \ldots$ \\
\hline $\begin{array}{l}1 \\
1 \\
1\end{array}$ & $\ldots \ldots \ldots$ \\
\hline 1 & $\ldots \ldots$ \\
\hline $\begin{array}{l}1 \\
1\end{array}$ & $\ldots \ldots$ \\
\hline $\begin{array}{l}\mathbf{5} \\
\mathbf{2}\end{array}$ & $\ldots \ldots \ldots$ \\
\hline 8 & $\ldots \ldots$ \\
\hline 1 & :........ \\
\hline 100 & \\
\hline
\end{tabular}


Score Cards - III. U.S. Department of Agriculture UNITED STATES DEPARTMENT OF AGRICULTURE BUREAU OF ATIMAL INDUSTRY. DAIRY DIVISION

\section{SANITARY INSPECTION OF DAIRIES}

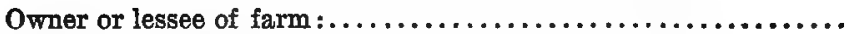

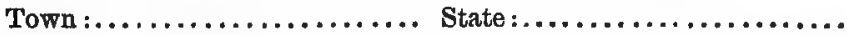

Total No. of cows :........... No. milking:............

Quarts of milk produced daily:.

Is product sold at wholesale or retail ?.

If shipped to dealer give name and address :................

...................................................

Permit No..... Date of inspection :.............. 190

\begin{tabular}{|c|c|c|c|}
\hline & \multicolumn{2}{|c|}{ SOORE } & \multirow{2}{*}{ ReMarks } \\
\hline & Perfect & Allowed & \\
\hline \multicolumn{4}{|l|}{ cows } \\
\hline Condition (2) $\ldots \ldots \ldots \ldots \ldots \ldots \ldots$ & 10 & *......... & n................... \\
\hline Health (8) $\ldots \ldots \ldots \ldots \ldots \ldots \ldots \ldots$ & & $\cdots \cdots \cdots$ & $\ldots \ldots \ldots \ldots \ldots \ldots \ldots \ldots \ldots$ \\
\hline Cleanliness......................... & $5-20$ & $\cdots \cdots \cdots$ & 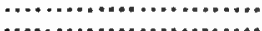 \\
\hline 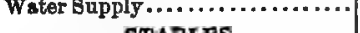 & & $\cdots \cdots+\cdots$ & • \\
\hline \multicolumn{4}{|l|}{ STABLES } \\
\hline Construction ....................... & b & $\ldots \ldots . . .$. & - \\
\hline $\begin{array}{l}\text { Oleanliness } \\
\text { Light. } \ldots \ldots \ldots \\
\end{array}$ & $\frac{5}{5}$ & $\cdots \cdots \cdots \cdots$ & 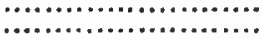 \\
\hline 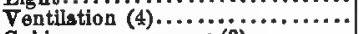 & $\tau$ & (.......... & ...................... \\
\hline Cubic space per cow (8) $\ldots \ldots \ldots \ldots$ & & $\cdots \cdots \cdots$ & 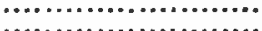 \\
\hline 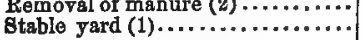 & $8-25$ & $\cdots \ldots \ldots$ & \\
\hline \multicolumn{4}{|l|}{ MILK HOOSE } \\
\hline Construction (2) $\ldots \ldots \ldots \ldots \ldots \ldots$ & Б & $\cdots \ldots \ldots$ & n......................... \\
\hline Equipment (8) .................. & 5 & & $\cdots$ \\
\hline Clestiliness............................... & & $\cdots \cdots$ & (n...................... \\
\hline 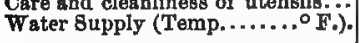 & $5-20$ & $\cdots \ldots \ldots$ & (1) \\
\hline \multicolumn{4}{|l|}{ MULKERS AND MILKING } \\
\hline Health of attendants.............. & & $\ldots \ldots \ldots$ & a........................ \\
\hline Cleanliness of milking ............. & $10-15$ & & \\
\hline \multirow{4}{*}{$\begin{array}{l}\text { HANDLING THE MILK } \\
\text { Prompt and efficient cooling } . \ldots \ldots . . . \\
\text { (Temperature of milk :........... } \\
\text { Storing at a low temperature..... } \\
\text { Protection during transportation.. }\end{array}$} & & & \\
\hline & 10 & …....... & 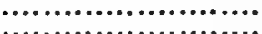 \\
\hline & & $\cdots \cdots \cdots$ & a........ \\
\hline & $5-20$ & $\ldots \ldots \ldots$ & …................... \\
\hline TotaL SoORE............... & 100 & $\ldots \ldots \ldots \ldots$ & . $\ldots \ldots \ldots \ldots \ldots \ldots \ldots \ldots \ldots$ \\
\hline
\end{tabular}

Sanitary conditions are -Excellent .... Good :... Fair .... Poor :... Suggestions by inspector $: \ldots \ldots \ldots \ldots \ldots \ldots \ldots \ldots \ldots \ldots \ldots \ldots \ldots$ 


\section{DIRECTIONS FOR SCORING}

\section{cows

Condition and Healthfalness. - Deduct 2 points if in poor flesh, and 8 points

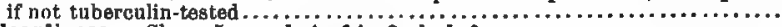

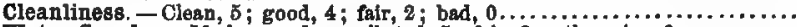
Water Supply. - If clean and unpolhted, 5 ; fair, 8 ; otherwlse, $0 . . . . . . .$.

\section{STABLES}

Construction. - F'or cement floor $(a) * 1$ in good condition allow 2 polnts ; fair, 1 pnor, 0 ; wood floor $(b)$ or other material in good condition, 1 ; fair, $1 / 2$; poor, 0 ; good tie $(c), 1$; good manger $(d), 1$; box stall $(e), 1 \ldots \ldots \ldots \ldots \ldots$.

cleanliness. - If thoroughly clesn, including floor $(a)$, windows $(b)$, and ceilings $(c), 5$; good, 4 ; medium, 3 ; fair, 2 ; poor, 1 ; bad, $0 . \ldots \ldots \ldots \ldots \ldots \ldots$

Light. - Four square feet of glass per cow, $5 ; 1$ point off for each 20 per cent

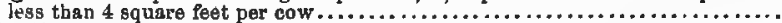

Ventilation. - Good ventilating system, 4 ; fair, $3 ;$ poor, $2 ;$ bad, $0 \ldots \ldots \ldots \ldots$.

Cubic Space per Cow. - If 500 cubic feet or over per cow, 8; less than 500 and over 4011,2 ; less than 400 and over 800,1 ; less than $800,0 \ldots \ldots \ldots \ldots$

Removal of Manure. - Hauled to fleld dally, 2 ; removed at least 80 feet from

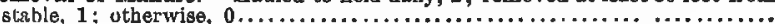

Stable Yard. - In good condition $(a), 1 / 2 ;$ well drained $(b), 1 / 2 ;$ otherwise, $0 .$.

\section{MILK HOUSE}

Construction. - Tight, sound floor, and not connected with sny other building (a), well lighted $(b)$, well ventilated $(c), 2 ;(d)$ if connected with another building under good conditions, 1 : otherwise, $0 ;(e)$ if no milk bouse, $0 \ldots . .$.

Equipment. - Hot water for cleaning utensils $(a), 1$; cooler $(b)$, 1 ; proper pails $(c)$ and strainers $(d)$ used for no other purposes, $1 \ldots \ldots \ldots \ldots \ldots \ldots \ldots$

cleanliness. - Interior clean, 5 ; good condition, 4 ; medium, 8 ; $18 i \mathbf{r}, \mathbf{2}$;

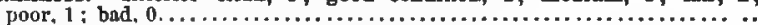

Care and cleanliness of Utensils. - Clean $(a), 8$; kept in milk house or suitable outgide rack $(b), 2$; otherwise, $0 . \ldots \ldots \ldots \ldots \ldots \ldots \ldots \ldots \ldots \ldots \ldots \ldots$

Water Supply. - If pure and clean running water, $\overline{5}$; pure and clean still water, 8 ; otherwise, $0 \ldots \ldots \ldots \ldots \ldots \ldots \ldots \ldots \ldots \ldots \ldots \ldots \ldots \ldots \ldots \ldots \ldots \ldots \ldots \ldots \ldots$

\section{MLEING}

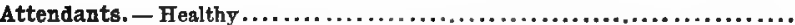

Cleanliness of Milking. - Clean milking snits, milking with clean dry hands, and attention to cleanliness of udder and teats while milking, 10 ; no special suits, but otherwise clean $(a), \gamma$; deduct 4 points for uncleanly teats $(b)$ and

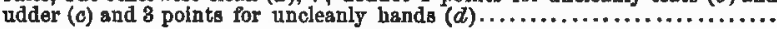

\section{HANDLING THE MLK}

Prompt and Efficient Cooling. - If prompt $(a), 5$; efficient $(b)$; if $50^{\circ} \mathrm{F}$. or under, 5 ; over $50^{\circ}$ and not over $55^{\circ}, 4$; over $55^{\circ}$ and not over $60^{\circ}, 8$; over

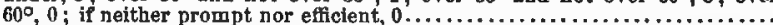

Storing at Low Temperature. - If $50^{\circ} \mathrm{F}$. or under, 5 ; over $50^{\circ}$ and not over

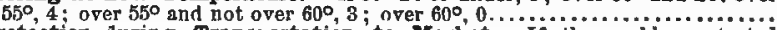

Protection during Transportation to Market. - If thoronghiy protected (iced), 5 ; good protection, 4 ; partly protected, 2 ; otherwise, $0 . . . \ldots . . . .$.

\section{SCORE}

If total score is 90 or above and each division $85 \%$ perfeot or over, the dairy is Bxcellent (entitled to reglstry).

If total score is 80 or above and each division $75 \%$ perfect or over, the dairy is Good.

If total score ls 70 or above and each divlsion $65 \%$ perfect or over, the dairy is Fair.

If total score is below 70 and any division is below $63 \%$ perfect, the dairy is Poor.

* The letter $a, b, c$, etc., should bo entered on score card to ehow condition of dairy, and when so ontered hould alwayl indicate sefolency. 


\section{NOTES AND AUTHORITIES}

\section{The Rise in the Value of Babies}

1. The Family, an Ethnographical and Historical Outline, by Elsie Clews Parsons, Ph.D., 1906. Das Kind in Brauch und Sitte der Volker, by Professor Ploss, ch. vii.

Principles of Sociology, by Herbert Spencer, vol. i.

2. The Children of the Nation, by Sir John E. Gorst, 1907, p. 16.

3. See speech of Dr. Northrup, Report of Milk Conference, New York, 1906, p. 38.

4. Infantile Mortality and Infants' Milk Depots, by G. F. MeCleary.

Infant Mortality, by G. Newman, M.D., D.P.H., F.R.S.E.

Gorst, op. cit.

Reports of the Royal Commission on Physical Training (Scotland) and the Interdepartmental Committee on Physical Deterioration; Memorandum by Sir William Taylor, Director-General (British) Army Medical Service, in Parliamentary Paper, Cd. 1501. See also The Bitter Cry of the Children, by John Spargo.

5. McCleary, op. cit., p. 2.

6. Idem, p. 11. 
7. Annual Report of the Medical Officer of Health, city of Montreal, 1902.

8. Gorst, op. cit., p. 16.

Poverty, by Robert Hunter, pp. 309-313.

9. Hunter, op. cit., pp. 304-313.

Discussions in Economics and Statistics, by Francis A. Walker, vol. ii, pp. 417-426.

10. McCleary, op. cit., p. 12.

See also the Report of the Royal Commission on the Decline of the Birth-rate and on the Mortality of Infants in New South Wales, 1904.

11. Mankind in the Making, by H. G. Wells, pp. 8090.

12. Census of 1900 , vol. iii, pp. li and lii.

13. The Wealth of Nations, by Adam Smith, vol. i, ch. viii.

14. Quoted by Thirlwall, History of Greece.

15. Roman Imperialism, Lectures and Essays, by J. R. Seeley.

16. The History of Rome, by Th. Mommsen, Book $\mathrm{v}$, ch. xi.

17. Adam Smith, op. cit., vol. i, ch. viii.

18. Parsons, op. cit., Lecture iii.

Other works used more or less freely include: Vital Statistics, by William Farr; The Elements of Vital Statistics, by A. Newsholme; The Infant, The Parent, and The State, by H. Llewllyn Heath, D.P.H. 
Also the following journals: Journal of the Royal Statistical Society, 1890; The Pedagogical Seminary, 1903 to date; and the files of the Popular Science Monthly.

\section{When the Mothers FaIL}

1. For a fuller discussion of this subject, see The Bitter Cry of the Children, ch. i.

2. Parsons, op. cit., pp. 44-59.

3. The Jewish Encyclopædia, article Milk (vol. viii), by Rabbi J. H. Greenstone.

4. Gorst, op. cit., p. 21.

Report of the Interdepartmental CommitteeEvidence.

5. Jewish Encyclopædia, article, cited.

6. Parsons, op. cit., pp. 26-27, 45-46.

Gorst, op. cit., pp. 21-22.

See also McCleary, op. cit., for the opinions of Dr. Marfan and others.

7. Parsons, op. cit., p. 27.

Gorst, op. cit., pp. 20-24, 40-45.

See also Spargo, op. cit., pp. 37-44.

8. Report Interdepartmental Committee, pp. 50-51.

9. Die Zunehmende Unfähigkeit der Frauen hire Kinder zu Stillen, by G. von Bunge, Munich, 1903.

See also the same writer's pamphlet, Alkoholvergiftung und Degeneration, Leipzig, 1904. 
10. American Medicine, July, 1906, p. 233.

11. Diseases of Infancy and Childhood, by L. Emmet Holt.

12. Parsons, op. cit., p. 27.

13. See The Slav Invasion, by Warne; On the Trail of the Immigrant, by Steiner; the Studies of Slavic Immigration (in Charities and the Commons) by Emily Greene Balch, etc.

14. Vide the opinion of Sir William Jenner, quoted in Transactions of the National Association for the Promotion of Social Science, 1882, p. 387. See also Spargo, op. cit., p. 16.

It should be noted that bottle-fed babies are less "rickety" than breast nurslings of the poorer classes. See Archives of Pediatrics, June, 1906, p. 452.

15. The Feeding of Animals, W. H. Jordan, NewYork, 1903.

16. Facts About Milk, by R. A. Pearson, M.S., p. 11 (United States Department of Agriculture, Farmers' Bulletin No. 42).

17. Pediatrics: the Hygiene and Medical Treatment of Children, by Thomas Morgan Rotch, Third Edition, 1901.

18. See article by Dr. St. George T. Grinnan, in $A r-$ chives of Pediatrics, April, 1905, p. 272.

19. The Variations in the Fat Percentage of Mother's Milk, by Louise Tayler-Jones, M.S., M.D., in Archives of Pediatrics, July, 1906. 
A Clinical Report on the Chemical Examination of Two Hundred Cases of Human Breast Milk, by V. and J. S. Adriance.

See also Rotch, op. cit.

20. The Composition and Methods of Analysis of Human Milk, by Professor Albert R. Leeds, Ph.D.

21. G. von Bunge, op. cit.

22. Heredity and Human Progress, by W. Duncan McKim, M.D., Ph.D., pp. 147-158.

The Criminal, by Havelock Ellis, p. 109.

23. The Theory and Practice of Infant Feeding, by Henry Dwight Chapin, M.D., p. 196.

24. British Medical Journal, May 21, 1904.

25. Report Interdepartmental Committee, pp. 50-51. 26. Chapin, op. cit., p. 214.

27. Idem.

28. Chapin, Breast Feeding and the Infant's Development, in Archives of Pediatrics, August, 1904.

29. It was at one time seriously proposed to substitute some artificial food for human infants in place of breast milk, on the ground that it would be better for the infants ! See report of a lecture by Professor Leeds before the New York Academy of Sciences, the Sanitarium, May 24, 1883, p. 325.

30. Ambulatory and Hospital Management of the 
Gastro-intestinal Derangements of Infancy, Archives of Pediatrics, May, 1900.

31. Dr. St. George Grinnan, op. cit.

32. Idem.

33. Gorst, op. cit., p. 24.

34. How to save the Babies of the Tenements, by

Virginia M. Walker, Charities [and the Commons], August 5, 1905.

Spargo, op. cit., p. 245.

See also Dr. Newman's valuable work, Infant Mortality, 1907.

35. British Medical Journal, June 4, 1904, p. 1339.

36. Gorst, op. cit., p. 22.

See also Infant Mortality and Factory Labour, by Dr. George Reid, in Dangerous Trades, edited by Professor Thomas Oliver, p. 89.

37. Idem.

Spargo, op. cit., p. 231.

38. Chapin, op. cit., p. 179.

39. Idem.

40. Idem.

41. See article by Saunderson-Wells in the British Medical Journal, July 8, 1905.

42. Idem.

43. McCleary, op. cit., p. 38.

The following works have been more or less freely used: The Nutrition of the Infant, by Ralph M. Vincent, M.D.; The Diseases of 
Children, by Henry Ashby, M.D., Lond., and G. A. Wright, B.A., Oxon.; Foods and the Principles of Dietetics, by Robert Hutchinson, M.D.; Milk, by E. F. Brush, M.D.; and Milk and Its Products, by H. H. Wing.

Also the following journals, other than those noted above: International Clinics; Medical Record; American Medicine; and The Lancet.

\section{Why Cow's Milk?}

1. Ancient Society, by Lewis H. Morgan, ch. ii.

2. See Deuteronomy xxxii, 14. The Iliad, iv, 433.

3. Pearson, op. cit.

4. Idem.

5. Human and Bovine Tuberculosis, by E. F. Brush, M.D.

6. Chapin, op. cit., p. 280.

7. Idem, pp. 25-27.

8. Idem.

9. New International Encyclopædia, vol. xiv, article Reindeer.

10. Idem.

11. Idem.

Also Annual Reports United States Department of the Interior, 1890 and on.

12. See McCleary, op. cit., p. 31.

13. Jewish Encyclopædia, vol. v, article Sheep, by

I. C. Casonowicz, Ph.D. 
14. New International Encyclopædia, article cit.

15. See, for example, the Encyclopædia Britannica, art. Goat; and the London Quarterly Review.

16. Idem.

17. As noted in the foot-note to which this reference belongs, there are cases on record of the inoculation of the goat with tubercle bacilli, bovine and human. It is very evident, however, from the few cases on record of the disease developing naturally, and the extreme difficulty with which the animal can be experimentally inoculated, that its immunity is practically. complete.

18. Some Fat Problems and Goats' Milk, J. Finley Bell, Archives of Pediatrics, March, 1906.

19. Idem.

20. British Medical Journal, quoted in Current Literature, 1907.

21. Idem.

22. See testimony of Dr. Winters and Dr. Matthias Nicoll, Jr., at the New York Academy of Medicine, January 11, 1906, reported in the Archives of Pediatrics, March, 1906, pp. 225226.

23. Casanowicz, op. cit. (Jewish Encyclopædia).

24. The Talmud (Temurah $15 \mathrm{~b}$ ).

25. The Talmud (Shebbat 109 b).

26. Pearson, op. cit. 
27. New International Encyclopædia, art. Milk, vol. xiv, by L. Emmet Holt, M.D.

28. Idem.

29. Idem.

30. Idem.

31. Chapin, op. cit., p. 8.

32. Idem, pp. 22-23.

33. Idem., ch. iii.

34. Idem., p. 51.

35. McCleary, op. cit., pp. 33-37.

36. Étude clinique sur quelques maladies infectieuses, par Professor Roger, Revue de Medicin, April, 1900.

McCleary, op. cit., pp. 35-36.

37. Idem.

38. Very useful formulas will be found in Dr. Chapin's Theory and Practice of Infant Feeding and Dr. Holt's The Care and Feeding of Children.

39. McCleary, op. cit., p. 49.

40. Chapin, op. cit., p. 221.

41. Idem.

42. See Feeds and Feeding, by W. A. Henry (Madison, Wis., 1902).

The Feeding of Animals, by W. H. Jordan (New York, 1903).

The Feeding of Farm Animals, by E. W. Allen (Washington, 1897).

43. Archives of Pediatrics, November, 1906, p. 830. 
The following works have also been frequently consulted with great advantage: Food and Principles of Dietetics, by R. Hutchinson, 1903; Bibliographia Lactaria, by Dr. H. de Rothschild (contains over eight thousand titles); Milk and Its Products, by H. H. Wing, 1897; Milk: Its Nature and Composition, by C. M. Aikman, 1899; The Problem of the Milk Supply, by F. Lawson Dodd; Bacteriology of Milk, by Swithinbank and Newman, 1903; many of the publications of the United States Department of Agriculture, and of the agricultural experiment stations in New York, Wisconsin, Illinois, Maine, California, etc.

Also the following journals: Hoard's Dairyman; The American Farmer; British Medical Journal; Journal of Hygiene; Public Health.

\section{Filth as Infants' Food}

1. Pearson, op. cit., p. 10.

The Problem of the Milk Supply, by F. Lawson Dodd, p. 13.

2. Information received in a personal letter from Dr. Park.

3. See Archives of Pediatrics, December, 1906, p. 943.

4. See the descriptive scores of exhibits at the National Dairy Show, 1906, published in Bulletin 87 of the Bureau of Animal Industry. 
The Milk and Cream Exhibit at the National Dairy Show, 1906, by Clarence B. Lane, B.S.

5. Dairy Products at the Paris Exposition of 1900 , by $H$. E. Alvord, United States Department of Agriculture Year Book, 1900.

Dairy Development in the United States, by H. E. Alvord, Sixteenth Annual Report Bureau of Animal Industry.

6. Idem.

7. Pearson, op. cit.

Chapin, op. cit., pp. 93-99.

The Bacteriological Examination of Milk, by Professor H. W. Conn, in Chapin's book above cited, p. 154.

8. Idem.

9. Tuberculosis as a Disease of the Masses and How to Combat It, by S. A. Knopf, M.D., p. 11.

10. Idem.

11. Idem.

12. Consumption and Civilization, by John B. Huber, M.D., p. 47.

13. Report of the Royal Commission (England) on the Effect of Food derived from Tuberculous Animals on Human Health, Part ii.

14. Idem.

15. Care of Milk on the Farm, by R. A. Pearson, United States Department of Agriculture, Farmers' Bulletin No. 63, p. 12. 
16. Chapin, op. cit., pp. 88-99, 148-169.

17. Idem.

18. Market Milk: A Plan for Its Improvement, by R. A. Pearson, M.S., Seventeenth Annual Report Bureau of Animal Industry.

19. The Hygiene of Milk, by Leslie Mackenzie, M.D., Edinburgh Medical Journal, 1898.

McCleary, op. cit., pp. 50-51.

Dodd, op. cit., pp. 13-14.

20. The Milk Supply of Large Towns, published by the British Medical Journal, 1903, pp. 11-12. Dodd, op. cit., pp. 14-15.

21. Parliamentary Paper, Cd. 833, Appendix IV Report on a Visit to Ireland, by Dr. Bulstrode and Professor Tunnicliffe.

22. Municipal Milk and Public Health, by F. Lawson Dodd, Fabian Tract No. 122.

23. Chapin, op. cit., pp. 88-89.

24. Conn, op. cit., pp. 148-169.

25. Idem.

26. The Suppression of Tuberculosis, by Professor E. von Behring, p. 67.

27. The Economic Production and Distribution of Clean Milk, by Joseph Robey, M.D., 1906.

28. Vide London press reports of the Congress. 29. Pearson, Facts About Milk (Farmers' Bulletin No. 42).

30. Jewish Encyclopædia, art. Milk. 


\section{MilK-Borne Diseases}

1. Efficient Democracy, by W. H. Allen, ch. viii.

2. Idem.

3. Knopf, op. cit., p. 13.

4. The Statistical Laws of Tuberculosis, by Frederick L. Hoffman, Maryland Medical Journal, February, 1904.

5. Tuberculosis and Children, by A. Jacobi, M.D., in A Handbook on the Prevention of Tuberculosis, Appendix VIII.

6. E. von Behring, op. cit.

7. Report of Royal Committee on The Effects of Food derived from Tuberculous Animals, Part i, p. 20.

8. Report of the Royal Commission on Administrative Procedures for controlling the Danger to Man through the Use as Food of the Meat and Milk of Tuberculous Animals, Part i, p. 2.

9. Report of the Royal Commission on the Relations of Human and Animal Tuberculosis, Interim Report (1904); Final Report, 1906, Part i.

10. Jacobi, op. cit.

11. Idem.

12. Quoted by Ravenel, Maryland Medical Journal, February, 1904.

13. Report of Tuberculosis Commission of Maryland, p. xxxii et seq. 
14. Report of Royal Commission on the Relations of Human and Animal Tuberculosis.

15. Maryland Committee Report, pp. xxxii, lx. Huber, op. cit., p. 63.

16. Maryland Report, p. xxxii.

17. Idem., p. xxxiii.

18. Idem., pp. xxxii, xli.

19. Report of Royal Commission on Effect of Food derived from Tuberculous Animals, Part iii.

20. Maryland Commission Report, pp. xxxviii, lviii.

21. Knopf, op. cit., pp. 24-25.

22. Huber, op. cit., p. 63.

23. Report of Royal Commission on Effect of Food derived from Tuberculous Animals.

24. Maryland Commission Report, pp. xxxiii-xli. 25. Idem.

26. Report of Royal Commission on Effect of Food derived from Tuberculous Animals, Part iii.

27. Quoted by Ravenel, Maryland Report, p. xxxiv. 28. See Sanitary Milk Production - Circular 114, Bureau of Animal Industry, United States Department of Agriculture.

29. The Milk Supply of Twenty-Nine Southern Cities by C. F. Doane, M.S., Bureau of Animal Industry, Bulletin No. 70.

30. Maryland Report, p. 6.

31. Idem. 
32. See Reports of the British Royal Commissions cited.

33. Idem.

34. Idem.

35. Idem.

36. Idem.

37. Report of Royal Commission on the Effect of Food derived from Tuberculous Animals.

38. February 10, 1907.

39. Report of Royal Commission on Effect of Food derived from Tuberculous Animals.

40. Idem.

41. Idem.

42. British Medical Journal.

43. Report of the Milk Conference, New York, November, 1906.

44. Dodd, op. cit.

45. Idem.

46. Vide press reports.

47. Idem.

48. Dodd, op. cit.

Note: The reader is specially referred to the Report of a Conference Appointed by the Commissioners of the District of Columbia published as Circular 114 by the Bureau of Animal Industry for an interesting and vauable account of the spread of infectious diseases by milk. 


\section{A Brief Summary of the Problem}

1. How to Reduce Infant Mortality, by Nathan Straus. Letter to the New York Board of Health, March 22, 1897.

2. See Gorst, op. citt., pp. 108, 247 ; Spargo, op. cit., pp. 8, 9, 291-296.

Also, Report of the (British) Interdepartmental Committee on Physical Deterioration.

3. Idem.

4. The Lancet, February 2, 1901.

5. Newman, op. cit., ch. i.

6. Idem.

7. Idem.

8 and 9. Spargo, op. cit., pp. 43, 44, 51

Gorst, op. cit., p. 42.

Newman, op. cit., p. 227.

10. Rotch, op. cit.

11. See Newman, op. cit., p. 145 et seq.

12. Chapin, op. cit., p. 286.

13. Doane, op. cit.

14. Pearson, Facts About Milk.

15. Idem.

Also, The Use and Abuse of Food Preservatives, by W. D. Bigelow, in United States Department of Agriculture Year Book, 1900.

16. Idem.

17. Idem.

18. Idem.

19. Idem. 


\section{Remedial Theories and Experiments}

1. Municipal Monopolies, edited by E. W. Bemis: I, Water Works, by M. N. Baker, Ph.B.

2. Idem.

See also The Problem of the Milk Supply, by Dodd; and Germ Diseases, by Kenelm Winslow, B.A.S., M.D., in vol. i, The Home Medical Library.

3. Typhoid: an Unnecessary Evil, by Samuel Hopkins Adams, in McClure's Magazine.

4. Dodd, The Problem of the Milk Supply and Municipal Milk and Public Health.

5. See the issues of January, February, March, 1907.

6. Fabian Leaflet No. 90.

7. The Milk Supply of Boston, New York, and Philadelphia, Bulletin 81, Bureau of Animal Industry.

8. Dodd, op. cit.

9. Idem.

10. Idem.

11. McCleary, op. cit., p. 85.

12. Idem.

13. This sketch is based largely upon McCleary's book, supplemented by Budin's Le Nourrisson and Manuel Pratique d'Allaitment.

14. For this sketch, also, I have drawn freely from. 
Dr. McCleary's work, as well as from the works of Dufour and others.

15. British Medical Journal, August 18, 1900. Annual Report of the Health of St. Helens, 1900. 16. Vide reports from Liverpool, Battersea, St. Helens, and Finsbury medical authorities.

17. McCleary, op. cit., p. 85.

18. Vide annual reports.

19. Idem.

20. McCleary, op. cit., pp. 130-131.

21. Idem.

22. La Goutte de Lait a Fécamp, by Dr. Leon Dufour (1900), and Comment on Crée une Goutte de Lait Fécamp (1902), by the same writer.

23. Information received from Mr. Straus.

24. McCleary, op. cit.

25. A large part of this section is reproduced from my article in the Craftsman, on The Political Economy of Saving Babies' Lives.

26. Figures supplied by Dr. Goler.

27. How to produce Milk for Infant Feeding, by E. F. Brush, M.D.

28. Idem.

29. Robey, op. cit.

30. Gorst, op. cit., pp. 10-14.

31. Consultations de Nourrissons et Gouttes de Lait, article by Dr. Peyroux in La Semaine Médicale, Paris, December 24, 1902. 
32. L'Avenir des Gouttes de Lait, in the Archives de Médicine des Enfants, April, 1903.

33. Peyroux, op. cit.

34. British Medical Journal, February 20, 1904.

35. Report of the Medical Officer of Health for Liverpool.

36. Report of the Medical Officer of Health for Battersea.

37. Newman, op. cit., pp. 301-304.

38. Idem.

39. Annual Report on the Health of Liverpool, 1903.

40. Vide Mr. Straus's paper read at the Congrès International des Gouttes de Lait, 1905.

41. Report upon the Results with Different Kinds of Pure and Impure Milk in Infant Feeding, etc., by W.H. Park, M.D., and L. Emmet Holt, M.D.

42. Idem.

43. See, for instance, Peyroux, op. cit.

44. The Efficient Life, by Luther S. Gulick.

45. Journal of the Statistical Society of London, vol. xxix, 1866. Quoted by Newman, op. cit., pp. 228-233.

46. Idem.

47. Idem.

VIII. Pure versus Purified Milk

1. Among the best statements of the position of the radical school are the works of F. Lawson Dodd, 
Chapin, and the pamphlets by Dr. Goler, frequently quoted in these pages.

2. I do not wish this statement to be taken too literally. It would be hard to say, without a good deal of calculation, whether the advocates of pasteurization or the radical opponents have done a greater amount of research. But I do not think the most radical will deny the pasteurizers the credit of being the pioneers of popular agitation on the subject of milk reform.

3. See, for instance, Mr. Straus's paper, Pure Milk or Poison? read at the Milk Conference, New York, November 20, 1906.

4. See page 111.

Also New York Times, January 11, 1908.

5. Vide letter of Dr. Park, to Milk Conference, New York, November 20, 1906.

\section{Idem.}

7. Some Experiments on the Temperature Necessary for killing Tubercle Bacilli in Milk, by Gustav Bang, Transactions of the British Congress on Tuberculosis, London, 1901, vol. iii.

8. The Thermal Death Point of Tubercle Bacilli in Milk and Some Other Fluids, by Theobald Smith, Journal of Experimental Medicine, March, 1899, pp. 217-233.

9. See Straus, Pure Milk or Poison?

10. Idem. 


\section{Idem.}

12. Idem.

Upon this subject see also: (1) New York Agricultural Experiment Station Bulletin No. 172 for the experiments of Harding and Rogers; and the 17th and 21st annual reports of the Wisconsin Agricultural Experiment Station (1900-1904) for the experiments of Russell and Hastings.

13. Report of Royal Commission on Effect of Food derived from Tuberculous Animals, Part ii, pp. 54-56.

14. The Prolongation of Life, by Elie Metchnikoff. 15. Idem.

See also the 16th annual report of Storrs Agricultural Experiment Station, Connecticut, 1904, pp. 27-88, for the views of Conn and Esten.

16. Park and Holt, op. cit.

17. Jacobi, op. cit.

18. Report of Royal Commission on Effect of Food derived from Tuberculous Animals, Part ii, p. 59.

19. Valeur nutritive du lait de vache stérilisé a $180^{\circ}$ pour l'allaitment artificiel, par G. Variot, Compts Rendus Académie des Sciences, t. 139, No. 23, pp. 1002-1003. Paris, 1904.

20. See the report of the Conference appointed by the 
Commissioners of the District of Columbia, Circular 114 of the Bureau of Animal Industry.

IX. Outlines of a Policy of Reform

1. Report of Royal Commission on Effect of Food derived from Tuberculous Animals, Parts ii and iii.

2. Doane, op. cit.

3. Report of Royal Commission on Administrative Procedures for controlling Danger to Man through the Use as Food of the Meat and Milk of Tuberculous Animals, Part ii, p. 266.

4. Du Development pris Aux États Unis par le Mouvement Pour la Consommation du Lai Pur, Dr. Henry L. Coit.

5. I am indebted to Dr. Darlington, and to Mr. Burton of the country division of the department of food inspection, for kindly placing at my disposal many facilities for the observation and investigation of this work of the Department of Health.

6. Doane, op. cit.

7. Newman, op. cit., p. 226.

8. Spargo, op. cit., pp. 244-247.

9. Newman, op. cit., pp. 264-265.

Gorst, op. cit., p. 23.

10. Journal Sanitary Institute, August, 1904, p. 350. 


\section{INDEX}

$\mathbf{A}$

Adulteration of milk, 168-172, 180.

Alaska, reindeer's milk used in, 54.

Allentown, epidemic of typhoid in, traced to milk supply, 146.

Alvord, Major, 89.

America :

Attitude toward milk modification in, 75-78.

Bacteriological standards of some cities in, 113-115.

Certified milk movement in, 113, 206, 207, 219.

Decline of native stock in, 6, $9,10$.

Infant death-rate in, 154-158.

Infants' milk depots in, 192, $194,195,205-217,228$, 235.

Infants' milk depots needed in, $185,186$.

Not ready for municipalization of entire milk supply, 177, 178, 181, 292.

Pasteurization in, 76, 202-203, $205,209-217,231-235,245$ et seq.

Pasteurization controversy in, 241-266.

Possibility of saving infants' lives in, 157-158, 240.

Science of milk question advanced in, 77 .

Tuberculosis in, 122-123.

Tuberculous cattle in, 134-136, 137.
Amsterdam, condition of milk supply, 116.

Analysis of milk of various animals, 49, 53 .

Analysis of human breast milk, $28-29,49,53,54-56,59$.

Animals, milk of various, used as food, 46, 49, 53.

Anti-bodies, 72-73.

Antiquity of the use of animals' milk as food, 46.

Archives of Pediatrics, 80.

Argentina, infants' milk depots in, 192.

Arloing, goats inoculated by, $58 \mathrm{n}$.

Artificial feeding becoming general, 16, 17, 35, 37, 38 .

Ashton-under-Lyne, infants' milk depot in, 197.

Ashton-under-Lyne, milk for older children and adults sold, 201.

Asiatic cholera, 154.

Ass, digestive system of, 66 .

Ass, milk of, 49, 51, 53.

Australia :

Decline of birth-rate in, 3, 6, 7,8 .

Infanticide in Central, 2.

.Visiting nurses for infants in, 298.

AUSTRIA :

Death-rate of infants in, 158.

Decline of birth-rate in, 8.

Mothers of, unable to nurse offspring, 21.

Peasant women of, neglecting their own babies to become "wet-nurses," 238. 
B

Bacillus tuberculosis, discovery of, 91.

Bacillus tuberculosis, bovine and human varieties of, 126-129.

Bacillus tuberculosis found in cow's milk, 92.

Bacteria :

Behring, Professor E. von, on dangers to infants from, 124.

Cause decomposition of milk, 89, 93, 171.

Cause gastro-intestinal troubles, 112, 164, 165, 166.

Description of, 90.

Found in intestines of infants, 134, 164.

How examined, 163-164.

How they get into milk, 93-98, 99-100.

Lactic acid, 253-259.

Milk in udder free from, 87.

Millions of, in the air, 97.

More in milk than in sewage, $107,111,247$.

Not indigenous to milk, 89.

Number of, in certified milk, 113.

Number of, in Rochester milk, 113.

Number of, permitted under bacteriological standards, 113-115.

Pasteurization and, 250-253.

Pathogenic varieties of, 93.

Poisonous, resisted by antibodies, 72-73.

Rate of increase of, 98, 104-106.

Small proportion of, dangerous, 110-112, 117.

Some kinds of, harmless, 93.

Temperature in which they thrive, 98, 108.

Useful kinds of, 93.

Vast numbers of, in milk, 105, 107, 109, 111, 116.

Ballard, Dr., 39.
Bang, Professor Gustav, 92, 136, $252,270$.

Battersea :

Establishment of infants' milk depot, 197.

Modified milk formula used in, 198.

Mothers induced to weigh babies, 200.

Statistics of infant mortality in, 226.

Sterilized milk sold, 203-204, 205.

Beauvais, Goutte de Lait, 194.

Beef, nutritional value of, 63-64. Behring, Professor E. von, 112, $113,124,136 \mathrm{n}$.

Belgium, decline of birth-rate in, 8 . Belgium, Laiterie Maternelles in, 192.

Bell, Dr. J. Finley, 60-61.

Belleville Dispensary, Paris, 191.

Bhir and Bhir, Messrs., 40.

Birmingham, England, 39, 184.

Birth-Rate, Decline of:

Among Americans, 9, 10.

Among Australians, 3, 6, 7, 8.

Among leisured classes, 6, 10 . 11-13.

Among people of British stock in Canada, 5, 6.

Causes of, 12-13.

In eighteen different countries (table), 8.

In France, 4, 7, 8.

In Greece, 10-11.

In Rome, 11-12.

(See also Race suicide.)

Bollinger, Dr., 130.

Booker, Dr., 164.

Boston, Mass., has bacteriological standard, 113-115.

Bottles, milk in, foul, 149.

BradFoRd :

Infants' milk depots in, 197, 201.

Partial municipalization of millk supply, 201-202. 
Bread, nutritional value of, 6364.

Breast-Nursing :

Accompanied by low deathrate of infants, $33,38,39$, 159, 296.

Among Hebrews, 16, 31, 32, 296 ; immigrants, 24 ; Irish, 296.

Among mothers attending the Consultations de Nourrissons, 187-190, 296.

British Interdepartmental Committee on, 20.

British National Health Society, the, 116 .

Decline of: ascribed to alcoholism, 30; to atrophy, 17, 21 ; dress and, 22-24; food, 24-30 ; greatest among wellto-do and leisured classes, 18, 22, 31 ; Dr. Holt on, 21-22, 31; Dr. Morgan on, 23 ; industrial conditions and, 1719; necessitates system of artificial feeding, 35 et seq.; not necessarily sign of degeneracy, 30, 35 ; rare among savages and primitive peoples, 16,31 ; result of physiological changes, 17 , 19 et seq.; voluntary causes, $17,18$.

General in Norway and Sweden, $33,38$.

Infants' milk depots and, 191, 235-237.

Law to punish neglect of, 237.

Schemes to promote, 39-41, $160,187-190$.

Substitute (wet-nurse), limitations of, 44.

The Consultations de Nourrissons and, 187-190, 296.

British well-to-do classes infertile, 6.

British Medical Journal, 61, 100, 140.
British Royal Commissions and Parliamentary Committees, $20,124,125,128,129,138$, $140,143$.

Brockton, Mass., has bacteriological standard, 115.

Brush, Dr. E. F., 124 n., 218, $254 \mathrm{n}$.

Budin, Professor, 40, 188, 190.

Buffalo, N.Y., condition of milk supply of, 141-142.

Buffalo's milk, 49.

Bulgaria, infants' milk depots in, 192.

Bunge, Professor von, 20, 30.

Bureau of Animal Industry, United States Department of Agriculture, 99, 127, $147 \mathrm{n}$.

Burnley, England, infants' milk depot in, 197.

Burton, Mr. E. W., 149 n., 281.

Butter made from tuberculous milk dangerous, 140.

Cambridge, Mass., has bacteriological standard, 115.

Camel, milk of, $49,51,53,54$.

Camel, unsuited to American needs, 55.

Canada, decline of birth-rate in, $5,6$.

Canada, infants' milk depots in, 192.

Carbohydrates, 52, 54.

Casein, 50.

Cat, milk of, 49 .

Cato, 10.

Cattle, tuberculosis among, 134139.

Certified milk, 113, 219.

Chapin, Dr., 36, 65, 76, 113. quoted, 36, 42, 66, 71.

Charité Hospital, Paris, 188.

Chaterinkoff, Dr., 38.

Chaveau, Dr., 129. 
Cheese, bacteria used in making, $93,111$.

Cheese, tubercle bacilli active in, 140.

Chicago, epidemic in, 147-148, 152.

Chicago, infants' milk depot in, 194.

Chicimecs, infanticide among, 2.

Children, see Infants.

Cholera infantum, 164.

Christian Science, 261.

Clinique d'Accouchement Tarnier, $188,189$.

Coit, Dr., 113, 219, 282.

Cologne, mothers paid by city for nursing babies, 40, 238.

Compensation for tubercular cattle destroyed, 135.

Concentration in distribution of milk, 181-182.

Conn, Professor, 247.

Connecticut, native birth-rate declining, 9.

Connentifut supplies New York iy with milk, 285.

Consultations de Nourrissons, 187191.

Copenhagen, see Denmark.

Cornell University, $137 \mathrm{n}$.

Cows :

Analysis of milk of, 49, 50, 53 .

Causes of tuberculosis among, 137-139.

Comparison of milk of, with milk of other animals, 49, $53-54,58$.

Dangers to infants from milk of, 65-69, 124, 125, 133.

Diarrhcal diseases caused by impure milk of, 38, 39, 108 n., 112, 120.

Digestive system of, 66-69.

Diseases spread by means of milk of, 58, 85, 92, 93, 108 n., $110,112,120$ et seq.

Milk of, compared with human milk, 49, 53, 54, 59.
Cows:

Milk, food values of, 63-65.

Milk, inferior to goat's milk, 58-61.

Number of, in United States, 63.

\section{D}

Darlington, Dr. Thomas, 131, $257,283$.

Death-Rates :

In Austria, 158; England, 39 ; France, 8, 157-158; New Zealand, 158; Norway and Sweden, 33, 38; Russia, 158; the United States, 154-158.

Influenced by breast-nursing, $33,38,39,159,296$.

Of native whites exceeds birthrate in New England, 9-10.

Reduced by infants' milk depots, 223-234.

Reduced when mothers can care for their babies, 159160.

De Jong, $58 \mathrm{n}$.

DeNMarK :

Infants' milk depots in, 192.

Statistics of tuberculous cattle in, 134-139.

Systematic efforts to eradicate tuberculosis, 270-273, 275.

Tuberculosis, bovine and human, in, 270-271.

Diagram showing components of cow's milk, 50.

Digestive systems of man and various animals compared, 66-69.

Diphtheria, 72, 109, 110, 144, 147.

Dirt in cow's milk, 84 et seq.

Dixon, Dr., 283.

Doane, Professor, on adulteration of milk, 169, 294.

Doane, Professor, on tuberculin test, $135,274$.

Dodd, Dr. F. Lawson, 101.

quoted, 150, 176. 
Dog, milk of, 49.

Dolphin, milk of, 49 .

Dufour, Dr. Leon, 76, 192.

Dundee, infants' milk depot in, 197.

Dunkinfield, infants' milk depot in, 197.

E

Edinburgh, tuberculous cattle in, 92.

Effects of industrialism upon maternal functions, $17,19 \mathrm{n}$.

Elbeuf, France; 40.

Elephant, milk of, 49 .

Engel, Dr., 21.

ENGLAND:

Decline of birth-rate in, 3,6 , 8.

Excessive mortality of artificially fed infants, 39 .

Experiments in partial municipalization of the milk supply, 183-184, 201-202.

Infants' milk depots in, 192.

Municipal infants' milk depots, 193, 196, 197-202.

Report of Local Government Board of, 101.

EPIDemics:

Allentown, Penn., 146.

Chicago, 147-148.

Diarrhceal diseases, 108 n., 149, 154.

Diphtheria, 144-145.

Infant paralysis, 153.

St. John's Wood, England, epidemic of diphtheria in, 144145.

Scarlet fever, 72, 120, 147, 148.

Sore throat, 140.

Typhoid, 145-146.

Woking, England, epidemic in, caused by milk, 140 .

Erysipelas, 72.

Eskimos, infanticide among, 2.

Eskimos, use of reindeer's milk by, 54 .
Evanston, III., epidemic in, 147.

Ewe, milk of the, 49, 51, 53.

\section{$\mathrm{F}$}

Fabian Society, the, 177-178.

Fécamp, Goutte de Lait, 193, 202, 227.

Fijians, infanticide among, 2.

Finland, refusal to nurse infants at breast punished, 237.

Finland, women of, compelled to neglect babies, 238.

Finsbury, infants' milk depot reduces mortality, 227.

Foticide, 13.

Foster, Sir M., 128.

France:

Breast-nursing encouraged in government factories, 44.

Consultations de Nourrissons in, 187-191.

Decline of birth-rate in, 8 .

Decrease of scorbutic diseases in, 258.

Gouttes de Lait in, 191-1.

Influence of Gouttes de La on infant death-rate, 225-226.

Modified milk not commonly used, 76.

Use of goats' milk in, 61 .

French Canadians, superior fertility of, 5-6.

French cities, breast-nursing subsidized by, 40-41.

Fry, Dr. F. M., 80.

\section{G}

\section{Germany :}

Decline of birth-rate in, 8.

Infants' milk depots in, 192.

Tubercular cattle in, 136, 137.

Glasgow, infants' milk depot in, 197.

Goats :

Advantages of milk of, for infant feeding, 56-62.

As milch animals, 56-57. 
Gonts:

Curative properties of milk of, believed in by Hebrews, 6162.

Immunity of, from tuberculosis, 58.

Milk of, compared with cows' milk, 59.

Milk of, compared with woman's milk, 59.

Milk of, used by Italians, 61 .

Milk of, used in France and Switzerland, 61.

Goler, Dr. G. W., 186, 205, 207, $209,213,282$.

Gorst, Sir John E., quoted, 3, 221.

Gosse, Swiss physician, 133.

GouTters DE LAIT:

French system used as pattern by other countries, 192-193.

Influence of, on infant deathrate, 225.

Medical supervision and, 191.

Methods of the, 193-194.

Modified milk in a few, 194.

Origin of, 191-192.

Small number of children served by, 225.

Spread to other lands, 192.

Sterilized, unmodified milk generally used in, 193-194.

(See also Infants' Milk Depots.) Greece, depopulation of, 10.

Greene, Dr., quoted, 141-142.

Grenoble, Goutte de Lait, 225.

\section{H}

Harris, Dr. F. Drew, 197.

Hartley, Robert M., 120-122.

Havre, sterilization practised in infants' milk depot, 194.

HeBrow :

Mothers and breast-nursing, 16, 31.

Scriptures and milk, 46.

Talmud and milk hygiene, 118119.
Herrgott, Professor, 187, 188, 190.

Hippocrates, 30, 91.

Hoffman, Frederick L., 122.

Holland, infant milk depots in, 192.

Holmes, Oliver W., quoted, 138.

Holt, Dr. L. Emmet, 21, 22, 31, $75,233,257$.

quoted, 22.

Homer's Iliad, 46.

Hope, Dr., 39.

Horace, quoted, 56.

Horse, digestive system of, 6669.

Huddersfield system, the, 300301.

Human Breast Mtrk :

Analysis of, 28, 49, 53.

Compared with other milks, 49, $53,54$.

Influenced by diet, 24-29.

Variations of fat percentages in, 28.

Humphrey Clinker, 85.

Hungary, decline of birth-rate in, 8.

\section{I}

Ibsen, 160.

Illinois, milk sent to Paris from, 88.

Imperial Sanitary Office of Germany, 130.

INFANTS:

Breast-nursing best for, 72,73 , 237.

Breast-nursing lowers mortality of, 33, 38-39, 159.

Class inequality in death-rates of, 155-157.

Mortality among artificially fed, 38-39, 65.

Mortality of, lessened by infants' milk depots, 223-235.

Needless sacrifice of, 157-159.

Proprietary foods dangerous for, 41-44, 82, 161-162.

Rich and poor born on equal physical terms, 156. 
INFANTS :

Statistics of mortality of, 38, 39, 154-155, 165.

Infants' Mith Depots :

American, mostly of French type, 193, 194.

American inferior to French in management, 194-196.

Beyond mere theoretical stage, 186.

Consultations de Nourrissons only incidentally milk depots, 187-191.

Countries in which established, 192.

Duty of municipalities to provide, 185, 220, 293.

Formulas used in American, British, and French, 202-205.

Gouttes de Lait, the French type, 191-192.

Influence of, in lessening mortality, 185-186, 223-235.

Municipal, American, 205-217.

Municipal, British, 197-202.

Needed in most cities, $186 \mathrm{n}$.

Objections to, 235.

Pasteurized and modified milk used in America, 202-203.

Rochester system, the, 186, 205-217.

Sterilized and unmodified milk commonly used in French, 202.

Sterilized and modified ("humanized") milk in British, 198.

Straus system, 186, 193, 194, 195, 229-235.

Infanticide, 2.

Inspection of dairies important, 282-291.

Ireland, decline of birth-rate in, 8.

Isocrates, 91.

Italy, decline of birth-rate in, 8.

Italy, infants' milk depots in, 192.

Ithaca, water supply of, 175-176. Macfadyean, Professor, 92, 130.
Jacobi, Dr. A., 124, 125, 258.

Johne, 126.

Jordan, Professor, 25, 26, 27.

Jupiter's intemperance, 30 .

\section{K}

Knopf, Dr. S. A., 130.

Kober, Dr. George M., 133.

Koch, Professor R. :

Announces discovery of tubercle bacillus, 91 , 126-127.

Declares bovine and human tuberculosis essentially different diseases and not transmissible, 126-127, 129.

Early experiments pointing to another conclusion, 129.

$\mathrm{He}$ admits validity of case of transmission, 132.

His conclusions not supported by investigation, 130-133.

Koplik, Dr. H. M., 38.

L

Lactation, influence of food upon, 24-29.

Lactation, problems of, should be studied, 20, 29, 35.

(See also Breast-nursing.)

Laplanders and reindeer's milk, 54-55.

Lecithin, 70-71.

Lederle, Dr., $150 \mathrm{n}$.

Leipzig, tuberculous cattle in, 137 .

Leith, infants' milk depot in, 197.

Lister, 87.

Liverpool, infants' milk depot, 197.

Llama, milk of, 49.

London, milk supply in, 116.

M

McCleary, Dr., 187, 200. quoted, 45 . 
MacKenzie, Dr. Leslie, quoted, MrLK: 99-100.

Maine, decline of native birthrate in, 9.

Malthus, 10, 124.

Martin, Dr., 139. quoted, 140.

Maryland, tubercular cattle in, 136.

Maryland Medical Journal, $58 \mathrm{n}$.

Massachusetts supplies milk to New York, 285.

Maternity hospitals, 187, 188, 190.

Maygrier, Dr., 189.

Media, Pennsylvania, 284.

Meinert, Dr., 39.

Melanesians, infanticide among, 2.

Metchnikoff, Professor E., 254.

MILK :

Adulteration of, 168-172, 182.

Analysis of various kinds of, $28,29,49-53,54,56,59$.

Anti-bodies in, 72-73.

Ash in, 50-52.

Ass's, 49, 51, 53.

Bacteria in, see Bacteria.

Behring, Professor E. von, on tuberculous infection through, 124.

Behring, Professor E. von, on standard of bacterial content, 112.

Biblical references to, 16 . -

Buffalo's, 49.

Camel, 49, 53.

Casein in, 50, 52.

Cat's, 49.

Certified, 113.

Compared with bread and meat, 63.

Cow's, see Cows.

Dangerous "preservatives" used in, 168-173.

Depots, see Gouttes de Lait and Infants' Milk Depots.

Diagram showing components of cow's milk, 50 .

Digestibility of, 64 .

Diseases conveyed through, 120 et seq.

Dog's, 49.

Elephant's, 49.

English Royal Commissions on dangers from, 124-125.

Ewe's, 49, 53.

Food constituents of various kinds of, 53.

Formulas for modified, 202205.

Goat's, $16,49,51,53,55,56-$ 62.

Human, 26-29, 37, 47, 49, 51, $53-55,59,60$.

Inspection, 282-291.

Llama's, 49.

Lecithin in, 70-71.

Mare's, 49, 53.

Modification of, for infants, 7578.

Municipalization of, 177-185.

Pasteurization of, 241-266.

Porpoise, 49.

Rabbinical regulations concerning, 16, 118-119.

Reindeer's, 51, 53-55.

Science of, in United States, 77.

Sent to Paris from United States, 88-89.

Sow's, 49.

"Trusts," 181.

Tubercle bacilli found in, 92 .

Tuberculosis spread by, 123134.

Milking machines, 179-180.

Mommsen, Professor, quoted, 11.

Montreal, decline of birth-rate in, 5-6.

Moore, Dr. V., 137 n.

Morgan, Dr. J. M., 23.

Morocco, infants' milk depots in, 192.

Mothers, education of, 297-303.

Mothers, ignorance of, 14, 297298. 
Munich, foul supply of milk in, 116.

Municipalization of the milk supply, 177-185.

\section{N}

Nancy, France, 187-188, 190.

National Dairy Show, 88.

Negro women, decline of nursing ability, 23.

Newark, N.J., 219.

New Hampshire, decline of native birth-rate in, 9.

New Jersey supplies milk to New York, 285.

New Jersey, tuberculous cattle in, 135.

New Jersey Tuberculosis Commission, 134.

Newman, Dr. Alfred, 227.

New York, tubercular cattle in, $137 \mathrm{n}$.

New York City, milk supply of, 116, 285.

New York City, system of inspection employed, 283, 285290.

New Zealand, decline of birthrate in, 9.

New Zealand, infantile death-rate in, 158.

Nocard, Professor, 58.

Norfolk, Va., 135, 136.

Norway, breast-nursing responsible for low death-rate, $33,38$.

Norway, decline of birth-rate in, 8.

Norway, infants' milk depots in, 192.

Nottingham, England, Municipal milk, 183-184.

\section{o}

Ohio and adulteration of milk, 169.

Ohio supplies milk to New York, 285.
Olivier, Dr., 125.

Ontario, decline of birth-rate in, 5.

\section{$P$}

Paris Exposition of 1900, 88.

Park, Dr., 233, 257.

Pasteur, 257.

Pasteurization :

Abandoned in Rochester, N.Y., $205,214$.

Arguments for and against, 241-266.

At Pol-sur-Mer infants' milk depot, 194.

Commercial, 251-252.

Defined by Straus, 251.

Destroys disease germs, 250253.

Employed in America, 194.

Statistics showing reduction of infantile mortality by, 210$213,225,229-234$.

Sterilization and, 202.

Patent foods, 41-44, 161-162.

Pearson, Professor, 136.

Pevroux, Dr., 225.

Philadelphia, infants' milk depot in, 194.

Pol-sur-Mer, milk pasteurized in, 194.

Polybius, 10, 11, 12.

Portugal, decline of birth-rate in, 8.

Portugal, infants' milk depots in, 192.

"Preservatives" in milk, 168$173,180$.

Q

Quebec, decline of birth-rate in Province of, 5 .

Queensland, decline of birth-rate in, 8.

R

Rabbinical regulations concerning milk, 16, 118-119.

Race suicide, 4, 12, 13. 
Race suicide, among bacteria, 104.

Rachitis, 25.

Ravenel, Dr. M. P., 130, 136.

Reading, England, municipal milk experiment, 184.

Reindeer, milk of, 51, 53-54.

Rhode Island, decline of native birth-rate in, 9.

Roby, Dr., 219.

Rochester, N.Y., municipal milk depots, 205-217.

Roger, Professor, 72.

Rome, decline of population in, 11-12.

Roosevelt, Theodore, 4, 8, 10, 12.

Rotch, Dr. T. Morgan, 27, 75, 76, 162.

Rowntree, Seebohm, $198 \mathrm{n}$.

Russia, death-rate of infants in, 158.

Russia, infants' milk depots in, 192.

\section{$\mathbf{s}$}

St. Helens, England, infants' milk depot in, 197.

Salmon, Dr., quoted, $58 \mathrm{n}$.

Saxony, tuberculous cattle in, 136.

Scarlet fever, 72, 109, 110, 120, $147,148$.

Scorbutus, 42, 258.

Score cards, 279-282.

Scotland, decline of birth-rate in, 8.

Seeley, Professor, quoted, 1112.

Seltzer, Dr., 88.

Shroeder, Dr., 167 n.

Smith, Adam, 10.

Smith, Dr. Theobald, 127, 128, 129.

Smollett, quoted, 85-86.

Sophocles, quoted, 12, 156.

Sore throat, epidemic of, 140.
South Australia, decline of birthrate in, 8.

Sow, milk of, 49.

Spain, infants' milk depots in, 192.

Statistical tables, $5,7,8,28,29$, $49,53,135,165$.

Sterilization, 189, 190, 194, 198, 201, 202, 204, 259.

Strads Milk Depots:

Closely follow French depots, 194.

Formulas used in, 202-203.

Reduction of death-rate through, 229-234.

Sick children served by, 199.

Straus, Nathan, 186, 194, 195, $221,229,230,231$. quoted, 154.

SWEDEN :

Breast-nursing in, 33, 38.

Decline of birth-rate in, 8 .

Infants' milk depots in, 192.

Low mortality in, 33, 38.

Switzerland, use of goat's milk in, 61.

\section{$\mathbf{T}$}

Tasmania, decline of birth-rate in, 8.

Tayler-Jones, Dr. Louise, 28.

Troje, Dr., 132.

Tubercle bacilli, see Bacillus tuberculosis.

Tuberculin, 131, 135, 136, 273275.

Tuberculosis :

A house disease, 137.

Cattle and, 134-139.

Conveyed through milk, 123, $124,125,126$.

Extent of ravages of, 122-123.

Fowls and, 131.

Goats and, 58-59.

Human and bovine, 126-134.

In Denmark, 136 n., 270-273, 275.

In United States, 122-123. 
Typhoid, 72, 92, 109, 110, 145146, 147 n., 152, 166-167.

U

Udder, tuberculosis of, dangerous, 126, 133, 139-143.

United States, see America.

\section{V}

Variot, Dr., 76, 191.

Vermont, decline of native birthrate, 9.

Vietoria, decline of birth-rate in, 8.

Villemin, 127.
WATER :

Municipalization of, 174-176.

Tuberculosis germs not found in, 176.

Typhoid germs in, 109, 145, 146, 175.

West Australia, decline of birthrate in, 8.

Wet-nurse, 44.

Woodhead, Dr. G. Sims, 92, 130, 140.

$\mathbf{Y}$

Yonkers, N.Y., 194, 195.

York, England, infants' milk depot in, 198. 



\section{BY THE SAME AUTHOR}

\section{The Bitter Cry \\ of the Children}

\section{By JOHN SPARGO}

With an Introduction by ROBERT HUNTER

"It is well that the subject should be put before the reading public in its fulness, that the public should be spared no detail, that it should be forced to realize how through sheer ignorance there is consummated an appalling sacrifice of child life." - Charities.

"The book will live and will set hundreds of teachers and social workers and philanthropists to work in villages and cities throughout the country. . . . Whatever our feeling as to the remedy for starved and half-starved children, we are grateful for the vivid, scholarly way in which this book marshals the experience of two continents in awaking to the physical needs of the children who are compelled to be in school though unfit for schooling. ... School teachers need this book, social workers, librarians, pastors, editors, all who want to understand the problem of poverty or education." - William H. ALLEN in The Annals of the American Academy.

\section{Socialism}

A Summary and Interpretation of Socialist Principles

I2mo, cloth, \$T.25 net.

"The 'man in the street' will find this little volume an up-to-date exposition of the Socialism that is alive in the world to-day."

- Review of Revieres.

"Anything of Mr. Spargo's is well worth reading, for it is written with conviction and with a sense of concrete life far removed from mere doctrinairism. . . A Anybody who wants to know exactly what the American Marxian of the saner sort is aiming at will find it here. In view of the present situation it is a book that every thoughtful person will want to read and read carefully." - World To-day.

\section{THE MACMILLAN COMPANY}

PUBLISHERS, 64-66 FIFTH AVENUE, NEW YORK 


\section{POVERTY}

\section{AN ATTEMPT TO DEFINE IT AND TO ES- \\ TIMATE ITS EXTENT IN THIS COUNT'RY}

\section{BY ROBERT HUNTER}

I2mo, cloth, $\$ 1.50$ net.

(Postage 12c.)

"Despite the abundance of sociological literature in this field, really good books dealing with poverty are conspicuously rare. To this exceptional class belongs, however, a volume on ' Poverty,' by Mr. Robert Hunter, formerly head of the New York University Settlement. . . : Mr. Hunter's baok is at once sympathetic and scientific. He brought to this task a store of practical experience in settlement and relief work gathered in many parts of the country. His analysis of the problem is marked by keen insight and sound judgment. There is no sentimental foolishness, no hysterical extravagance in this book ; nor, on the other hand, is it the smug treatise of a cold-blooded statistician. It is the work of a man who has observed the evils of poverty at first hand, who feels strongly the injustice of what he has seen, and yet who thinks straight - a man with a heart and a brain. ... Whether we agree or disagree with the particular measures of prevention proposed by Mr. Hunter, one can hardly dispute, on general principles, the correctness of his diagnosis and the wisdom of his advice."

- The Social Settler in The Boston Transcript.

\section{THE MACMILLAN COMPANY}

POBLISHERS, 64-66 FIFTH AVENUE, NEW YORK 


\section{New Worlds for Old AN ACCOUNT OF SOCIAIISM}

I2mo, cloth, \$I.50 net.

In this book Mr. Wells's pleasant, always interesting, style and the clearness of his logic lay solid foundations for the spread of a broadly human, enlightened type of socialism. Very simply, yet with undeniably strong arguments and a fascinating lucidity, he sets forth the two great ideas upon which he builds his faith. You cannot agree with him wholly, perhaps, certainly you cannot quarrel with his frank discussion; and it is equally sure that you will read on, captivated by his evident open-mindedness, his recognition of the difficulties in the way of bettering social conditions, and the force of his enthusiasm without impatience.

Socialism is much in the air, but there is no book which states so clearly and so interestingly as this does what it really amounts to.

One competent critic writes in a personal letter: "It is the wisest and sanest championship of extensive social reconstruction that I have ever seen." Another speaks of the book as, "written with a directness of language and a purity of spirit which makes the reading of it a continuous delight."

\section{THE MACMILLAN COMPANY}

PUBLISHERS, 64-66 FIFTH AVENUE, NEW YORK 
Other books of special interest to those who realize

that the welfare of the next generation depends upon the care or the neglect of the children of this

Some Ethical Gains through Legislation

By Florence Kelley, Secretary of the National Consumers' League

The author is not only a lawyer of large experience in Chicago, but has served that city, the State of Illinois, and the Federal Government in many investigations of conditions among various trades, and in reference to the circumstances of the poorer classes.

Among the topics here treated are:

The Right to Childhood.

Interpretations of the Right to Leisure.

The Right of Women to the Ballot.

The Rights of Purchasers and the Courts.

The Care of Destitute, Neglected, and Delinquent Children

By Homer Folks, Ex-Commissioner of Public Charities of the City of New York

The Development of Thrift

remo, cloth, \$r.00 net.

By Mary Wilcox Brown, Secretary of the Henry Watson Children's Aid Society, Baitimore

r6mo, cloth, $\$ r .00$.

Friendly Visiting among the Poor: A Handbook for Charity Workers

By MARY E. RIChmond, General Secretary of the Charity Organization Society of Baltimore

Constructive and Preventive Philanthropy

s6mo, cloth, \$r.oo.

By Joseph LEE, Vice-President of the Massachusetts Civic League $12 \mathrm{mo}$, cloth, $\$ 1.00$ net.

Among the contents of this book are chapters on Model Tenements; The Setting of the Home; Vacation Schools; Playgrounds for Small Children; Baths and Gymnasiums; Playgrounds for Big Boys; Model Playgrounds ; Outings ; Boys' Clubs ; and Industrial Training.

\section{THE MACMILLAN COMPANY}

POBLISHERS, 64-66 FIFTH AVENOE, NEW YOBK 



